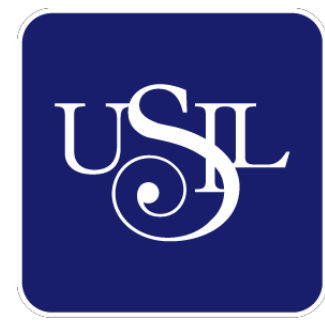

UNIVERSIDAD

SAN IGNACIO

DE LOYOLA

ESCUELA DE POSTGRADO

Maestría en Ciencias Empresariales

\title{
PLAN ESTRATÉGICO 2018 - 2021 PARA NARANJA PRODUCCIONES S.A.C.
}

Trabajo de Investigación para optar el grado de Maestro en Ciencias Empresariales

\section{JESSICA VERÓNICA FERNÁNDEZ ESPINOZA RUBÉN DARÍO MOSCOSO CARBONEL CARLOS JOSÉ SIGNORI BEZADA}

Asesor:

Horacio Javier Barrios Cruz

$$
\text { Lima - Perú }
$$

2018 

"PLAN ESTRATÉGICO 2018 - 2021 PARA NARANJAS PRODUCCIONES S.A.C." 
Este trabajo, lo dedicamos a nuestros familiares por su apoyo incondicional y a la empresa Naranja Producciones S.A.C., por asistirnos en todo momento en la recolección de información. 


\section{Resumen Ejecutivo}

En el presente Proyecto Gerencial Aplicado (PGA) se desarrolla el plan estratégico para la empresa Naranja Producciones S.A.C. en el período del 2018 al 2021, con el fin de que la empresa pueda incrementar su rentabilidad y mejorar el servicio a su clientela. Naranja Producciones S.A.C. es una empresa fundada hace cuatro años con la finalidad de publicitar a las organizaciones, desde las más pequeñas hasta las más grandes, con el objetivo de comunicar su razón de ser en el mercado peruano, generando así un mejor posicionamiento de la marca y fidelización del cliente final.

Naranja Producciones S.A.C. comenzó vendiendo el servicio de shows infantiles bajo la marca de Castillo Mágico. Es mediante este servicio que los propietarios César Hugo Jaén Seminario y Sherylin Román, empezaron a ofrecer otros servicios como BTL y la elaboración de eventos a sus clientes.

El mayor problema de Naranja Producciones S.A.C., es que ha crecido tan rápido en estos últimos cuatro años, que internamente se han desorganizado y no pueden atender de manera rápida y efectiva a sus clientes. Sin embargo, una oportunidad es que las empresas realizan campañas interactivas que les permite fidelizar a sus clientes, de modo que personalizan sus anuncios y sus productos con el propósito de crear una experiencia nueva y única.

Las estrategias a utilizar son de Penetración de Mercado, Desarrollo de Mercado y Desarrollo de Producto, las cuales, nos permitirán lograr los objetivos planeados.

La inversión para llevar a cabo las iniciativas que nos permitirán lograr las metas de Naranja Producciones S.A.C. es asciende a S/ 295,734.00. El financiamiento se conseguirá de manera interna y externa; por lo tanto, la empresa Naranja Producciones S.A.C. destinará de sus recursos propios $S / 208,234.00$ y la diferencia de $S / 87,500.00$ se obtendrá de un crédito financiero.

Empleando las estrategias ya mencionadas, el VAN de nuestro flujo financiero sería S/472,868.62 y el TIR de 42\%. Esto significa que el VAN al ser mayor a cero, ha cumplido con la tasa y ha generado una ganancia. Además, el TIR es mayor a la tasa exigida por los inversionistas, por tal motivo, el proyecto debería ser aprobado. 
Finalmente, recomendamos la implementación de este Plan Estratégico 2018 - 2021 porque la empresa Naranja Producciones S.A.C. puede lograr incrementar su participación de mercado, la rentabilidad, la eficiencia y eficacia, por ende, su público objetivo estaría satisfecho con su desarrollo. 


\section{ÍNDICE}

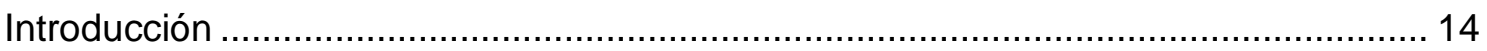

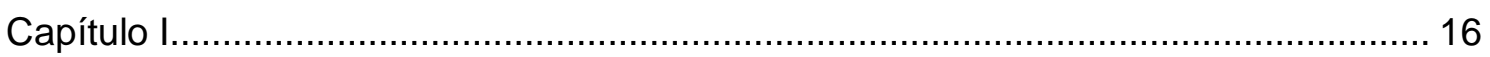

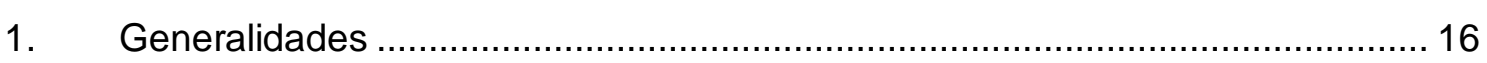

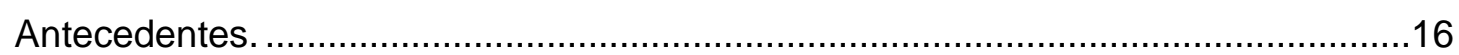

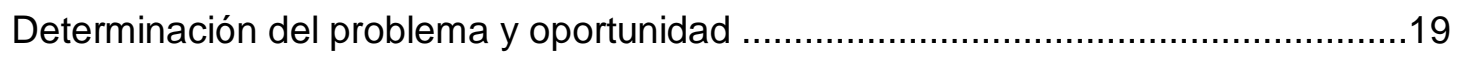

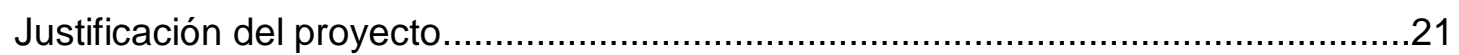

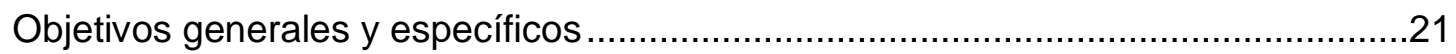

Alcance y limitaciones de la investigación ..............................................................22

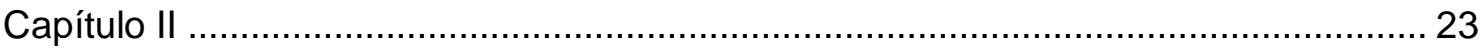

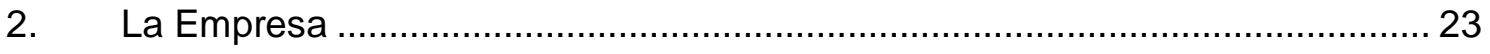

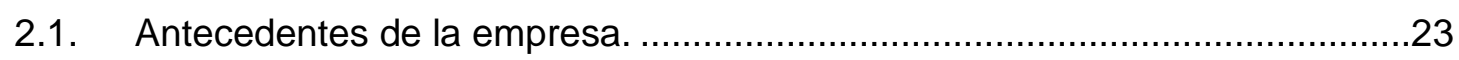

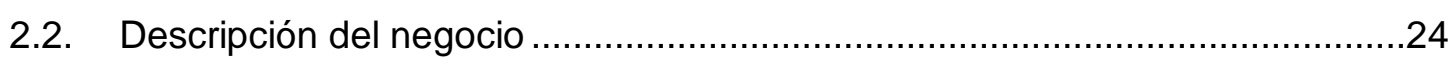

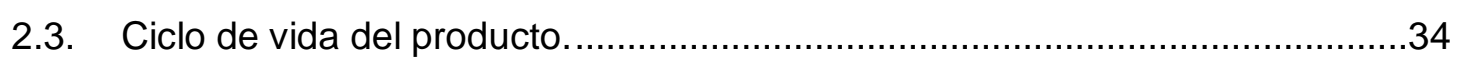

2.4. Estructura organizacional actual de la empresa...........................................39

2.5. Situación de Mercado y Financiera actual de la Industria...............................43

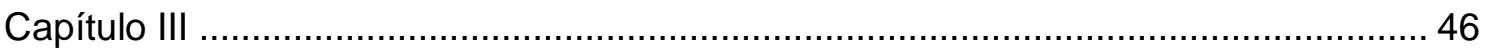

3. Formulación de la Visión, Misión y Valores de la Empresa ................................46

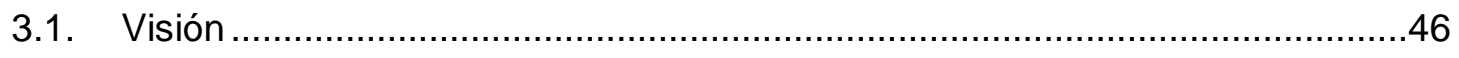

3.1.1. Visión actual de la empresa............................................................46

3.1.2. Análisis de la visión actual .................................................................46

3.1.3. Matriz de la visión propuesta para la empresa.....................................47

3.1.4. Visión propuesta. ................................................................................48

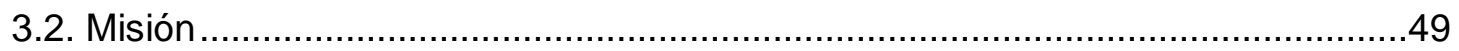

3.2.1. Misión actual de la empresa ................................................................49

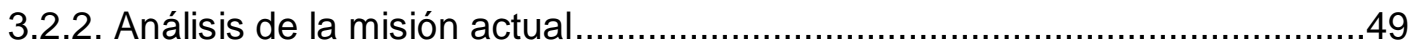

3.2.3. Elementos de la misión propuesta para la empresa ..................................50

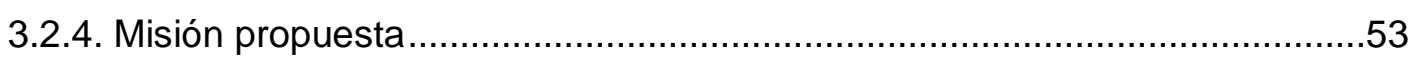

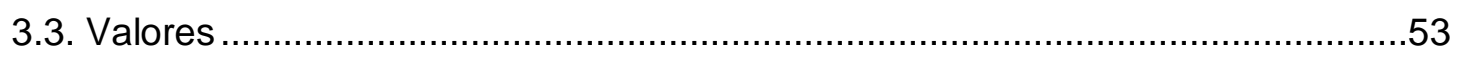

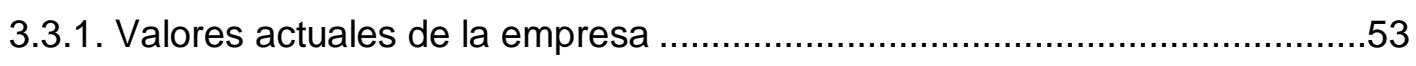

3.3.2. Análisis de los valores actuales..............................................................54

3.3.3. Elementos de los valores propuestos para la empresa ..............................54

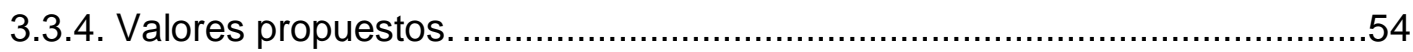

3.4. Alineamiento estratégico de la Visión, Misión y Valores de la empresa...........55

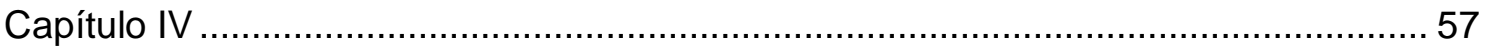




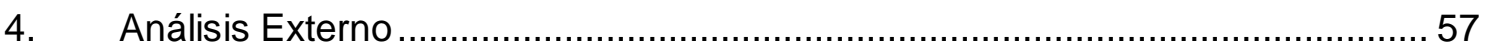

4.1. Tendencias de las variables del entorno.......................................................57

4.1.1. Análisis Político-Gubernamental ......................................................57

4.1.2. Análisis Económico.- ..................................................................61

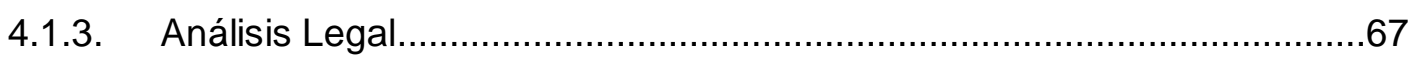

4.1.4. Análisis Cultural ...........................................................................69

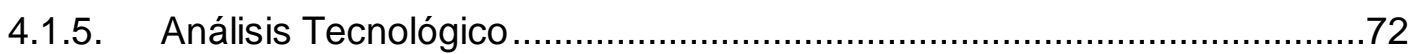

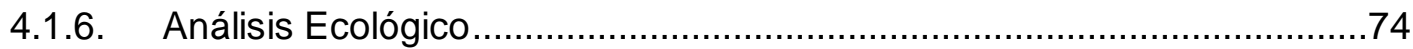

4.2. Impacto en clientes/proveedores de cada una de las variables del entorno...76

4.3. Efecto en la empresa de cada una de las variables del entorno ......................77

4.4. Oportunidades y Amenazas ..................................................................

4.5. Matriz de Evaluación de los Factores Externos EFE …................................79

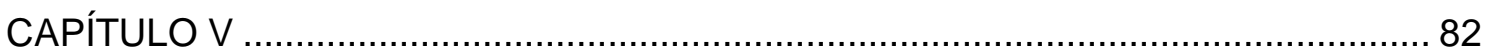

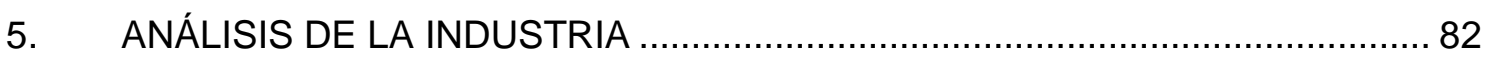

5.1. Descripción del Mercado (demanda) e Industria (oferta) ...................................82

5.2. Descripción de las cinco fuerzas competitivas de la industria.............................82

5.2.1. Amenaza de productos o servicios sustitutivos .....................................83

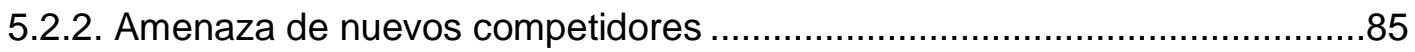

5.2.3. El poder de negociación de los compradores o clientes.............................88

5.2.4. El poder de negociación de los proveedores o vendedores .........................90

5.2.5. Competencia en el mismo sector ..............................................................92

5.3. Matriz de atractividad de cada una de las cinco fuerzas..................................96

5.3.1. Poder de negociación de los clientes y consumidores .............................97

5.3.2. Poder de negociación de los clientes y consumidores .................................98

5.3.3. Amenaza del ingreso de nuevos competidores .........................................98

5.3.4. Amenaza de productos sustitutos ............................................................... 100

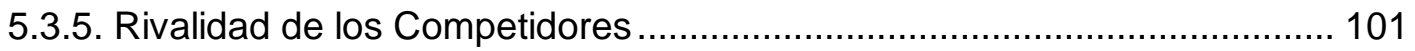

5.4. Análisis del Grado de atractividad de la industria ......................................... 102

5.5. Matriz de Perfil Competitivo MPC …............................................................. 102

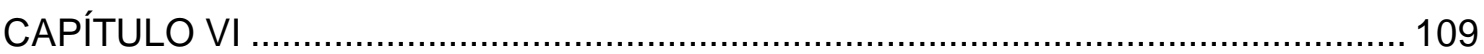

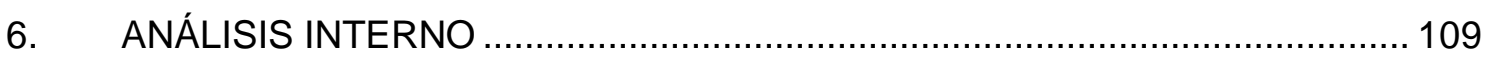

6.1. Descripción de las actividades de la cadena de valor de la empresa.............. 109

6.1.1. Marketing y Ventas........................................................................ 110

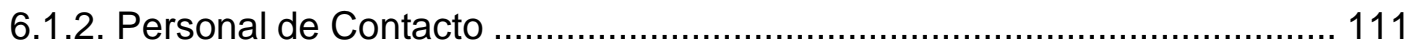

6.1.3. Soporte físico y habilidades ............................................................... 112

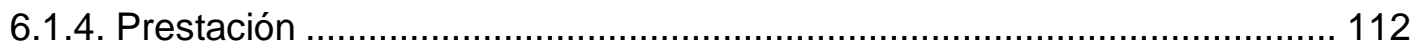




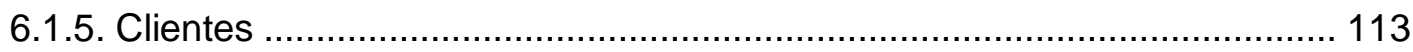

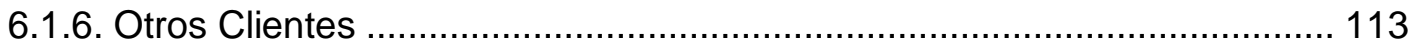

6.1.7. Dirección General y de Recursos Humanos ........................................... 114

6.1.8. Organización interna y de Tecnología................................................. 114

6.1.9. Infraestructura y Ambiente................................................................ 114

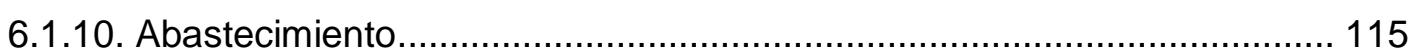

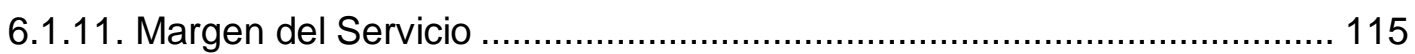

6.2. Indicadores de cada una de las actividades de la cadena de valor.............. 116

6.3. Benchmarking y comparación con los líderes de la industria de cada una de las actividades de la cadena de valor .......................................................................... 118

6.4. Determinar las competencias de la empresa. .......................................... 120

6.5. Identificación y determinación de las ventajas competitivas de la empresa. 121

1.6. Matriz de Evaluación de los Factores Internos EFI .................................... 124

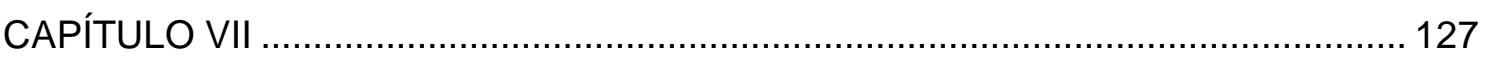

7. FORMULACIÓN DE LOS OBJETIVOS Y DISEÑO DE LAS ESTRATEGIAS. 127

7.1. Alcance y planeamiento de los objetivos estratégicos ............................... 127

7.1.1. Objetivos Estratégicos ..................................................................... 127

7.1.2. Análisis de los objetivos estratégicos ................................................. 127

7.2. Diseño y formulación de estrategias .......................................................... 129

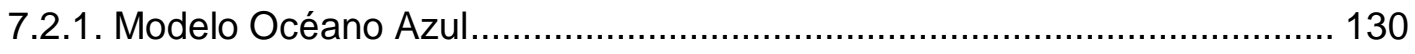

7.2.1.1. Lienzo de la estrategia actual de la empresa..................................... 130

7.2.1.2. Lienzo de la estrategia de la industria ................................................. 132

7.2.1.3. Matriz (eliminar, reducir, incrementar, crear). ....................................... 134

7.2.1.4. Lienzo de la nueva estrategia considerada.......................................... 135

7.2.2. Matrices de formulación de estrategias.................................................. 136

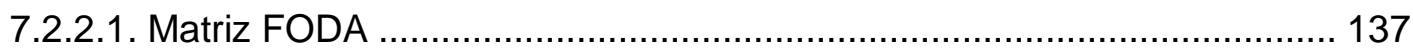

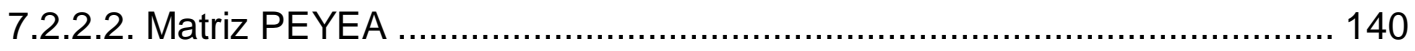

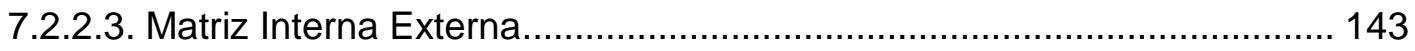

7.2.2.4. Matriz Boston Consulting Group....................................................... 145

7.2.2.5. Matriz de la Gran Estrategia ........................................................ 148

7.3. Resumen de las Estrategias Formuladas............................................... 149

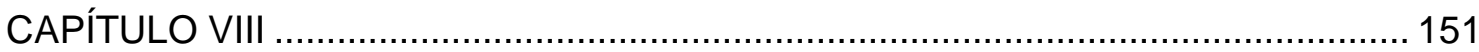

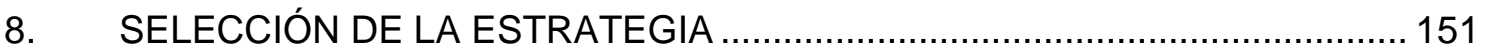

8.1. Métodos Factores Estratégicos Claves .................................................. 151

8.1.1. Criterios de selección............................................................................... 152

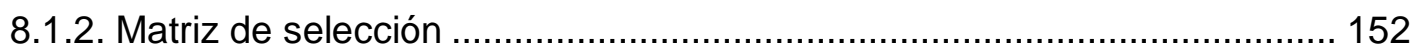




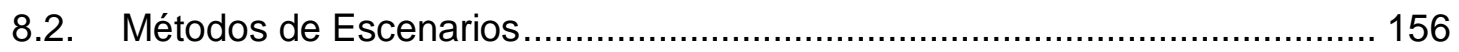

8.2.1. Descripción de escenarios considerados ................................................ 156

8.2.2. Comparación de Estrategias con escenarios ...................................... 158

8.3. Matriz de Planeación Estratégica Cuantitativa MPEC ............................... 159

8.4. Descripción de estrategia seleccionada .................................................... 163

8.5. Descripción de estrategia contingente...................................................... 163

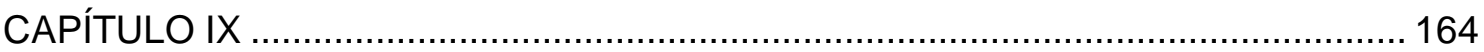

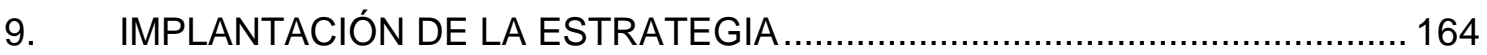

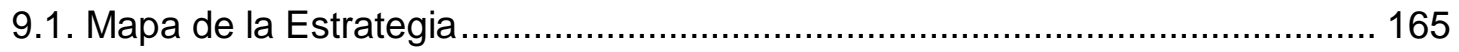

9.2. Objetivos específicos según el mapa de la estrategia ................................ 166

9.3. Indicadores para cada uno de los objetivos específicos .............................. 166

9.4. Metas para cada uno de los objetivos específicos ...................................... 168

9.5. Iniciativas (acciones a llevar a cabo para cada uno de los objetivos específicos) 168

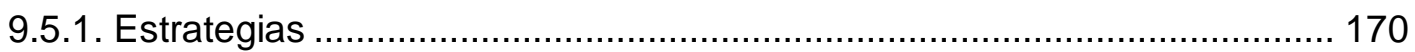

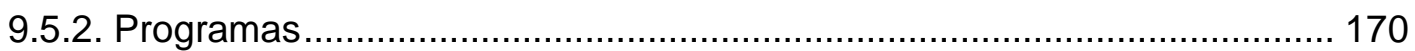

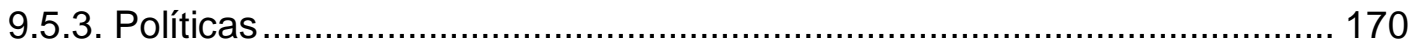

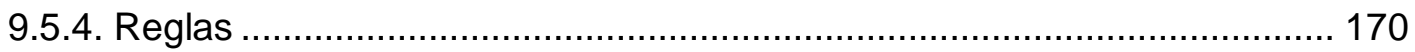

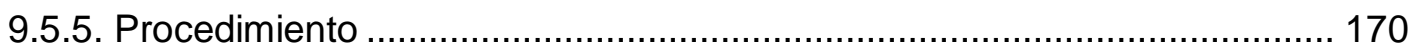

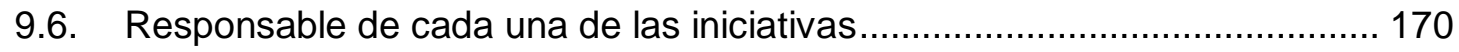

9.7. Presupuesto de cada una de las iniciativas ............................................ 171

9.8. Cronograma de cada una de las iniciativas ............................................... 173

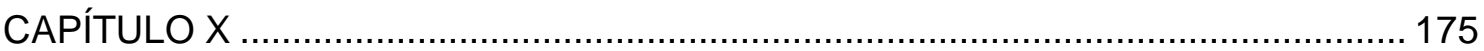

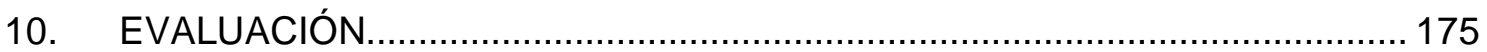

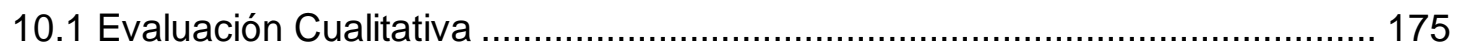

10.1.1. Criterios de Evaluación ................................................................ 175

10.1.2. Comparación de la estrategia con los criterios ..................................... 176

10.2. Evaluación Financiera de la Estrategia ..................................................... 177

10.2.1. Proyección de Estados Financieros (situación actual y con la nueva

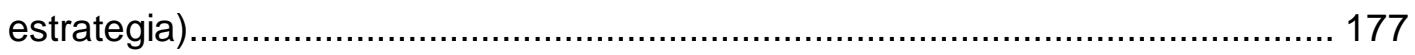

10.2.2. Estado de resultados (situación actual y con la nueva estrategia) ....... 178

10.2.3. Balance General (situación actual y con la nueva estrategia) .............. 180

10.2.4. Flujo de efectivo (situación actual y con la nueva estrategia) ............... 185

10.2.5. Proyección de flujos (situación actual y con la nueva estrategia) ......... 187

10.2.6. Evaluación Financiera (VAN, TIR y ratios financieros).......................... 188

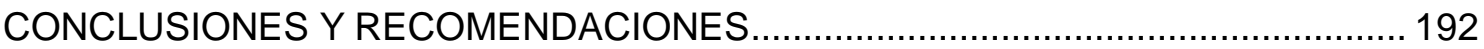




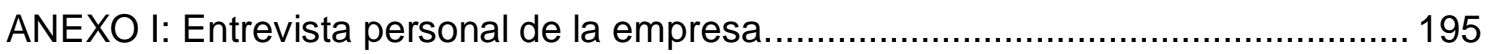

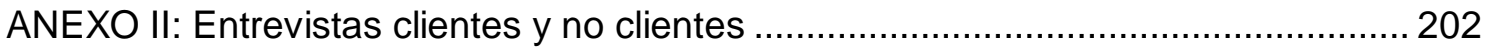

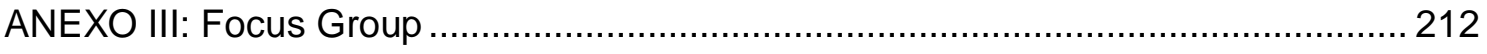

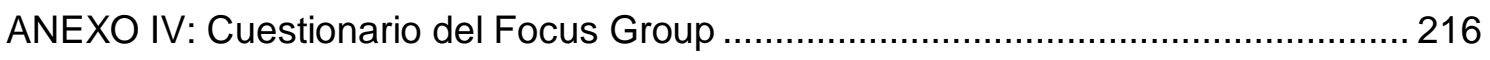

ANEXO V: CUESTIONARIO: Entrevista a Profundidad............................................ 219

ANEXO VI: CUESTIONARIO: Entrevista a Profundidad para futuros clientes........... 221

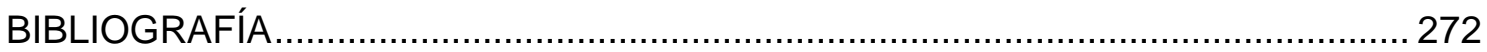

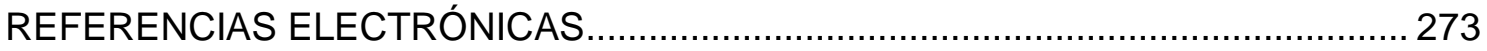

\section{ÍNDICE DE CUADROS}

Cuadro 3.1: Preguntas para analizar la visión actual ..............................................46

Cuadro 3.2: Análisis para formular la visión propuesta ............................................47

Cuadro 3.3: Declaración de la visión ...................................................................48

Cuadro 3.4: Análisis de la misión actual .............................................................49

Cuadro 3.5: Análisis para formular la misión propuesta..........................................52

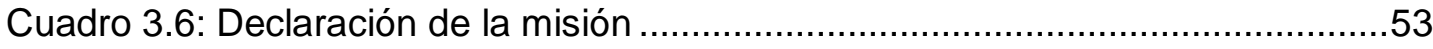

Cuadro 3.7: Alineación estratégica de la visión, misión y valores .............................55

Cuadro 4.1: Desarrollo del PBI del Perú durante el 2017 .......................................62

Cuadro 4.2: Factores Externos claves de Naranja Producciones S.A.C. ..................81

Cuadro 5.1: Matriz de atractividad para el poder de negocio de los clientes y consumidores

Cuadro 5.2: Matriz de atractividad para el poder de negociación de los proveedores98

Cuadro 5.3: Matriz de atractividad para la amenaza de nuevos competidores ........99

Cuadro 5.4: Matriz de atractividad para la amenaza de productos sustitutos ........100

Cuadro 5.5: Matriz de atractividad para la rivalidad de los competidores ..............101

Cuadro 5.6: Matriz de atractividad de la Industria ...............................................102

Cuadro 6.1: Indicadores de cada actividad de la Cadena de Valor .......................117

Cuadro 6.2: Benchmarking competitivo Naranja Producciones S.A.C. ..................118

Cuadro 6.3: Matriz EFI ................................................................................126

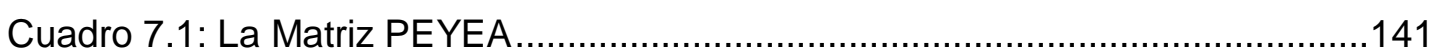

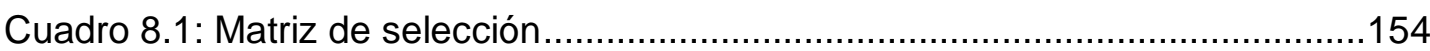

Cuadro 8.2: Comparación de Estrategias con escenarios ....................................158

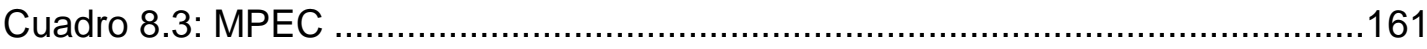

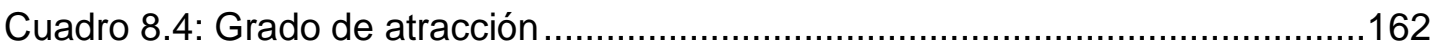


Cuadro 9.1: Objetivos, indicadores, metas, iniciativas y responsables para las

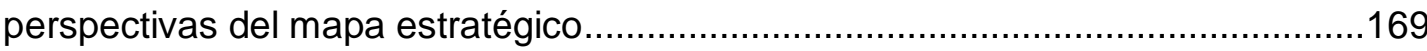

Cuadro 9.2: Presupuesto para las iniciativas del mapa estratégico ......................172

Cuadro 9.3: Cronograma de implementación de las iniciativas del mapa estratégico para

Naranja Producciones S.A.C. 174

Cuadro 10.1: Estado de Resultados (situación actual) 179

Cuadro 10.2: Estado de Resultados (con estrategia).... 180

Cuadro 10.3: Flujo de caja (escenario actual) 181

Cuadro 10.4: Balance General (escenario actual) 181

Cuadro 10.5: Flujo de caja (con estrategia) 185

Cuadro 10.6: Balance General (escenario con la nueva estrategia) .185

Cuadro 10.7: Flujo de Efectivo (escenario actual) .............................................186

Cuadro 10.8: Flujo de Efectivo (escenario con la nueva estrategia) ......................187

Cuadro 10.9: Flujo de Efectivo (escenario actual) ................................................187

Cuadro 10.10: Flujo de Efectivo (escenario con la nueva estrategia).....................188

Cuadro 10.11: VAN sin estrategia para el período 2018-2021 .............................190

Cuadro 10.12: VAN con estrategia para el período 2018-2021 ............................190

Cuadro 10.13: TIR con estrategia para el período 2018-2021 191

\section{ÍNDICE DE GRÁFICOS}

Gráfico 1.1: Presupuesto asignado por las empresas peruanas al márketing BTL..16

Gráfico 1.2: Criterios para decidir si invierten en márketing BTL 17

Gráfico 1.3: Número de eventos realizados por la empresa Naranja Producciones S.A.C. desde su creación

Gráfico 2.1: Campañas BTL realizadas por Naranja Producciones de manera directa e indirecta 32

Gráfico 2.2: Ciclo de vida del Producto. .35

Gráfico 2.3: Ciclo de vida del Producto. 37

Gráfico 4.1: El nivel de percepción en la economía nacional 64

Gráfico 6.1: Cadena de Valor para servicios 109

Gráfico 7.1: Lienzo de Naranja Producciones y principales empresas del sector..131

Gráfico 7.2: Lienzo de Naranja Producciones S.A.C. y Promedio de la industria ..133

Gráfico 7.3: Lienzo propuesto .136

Gráfico 7.4: Matriz Interna y Externa (IE) .144

Gráfico 7.5: Matriz IE de Naranja Producciones S.A.C 144

Gráfico 7.6: Matriz de la Gran Estrategia (GE) 149 
Gráfico 9.1: Indicadores del Balanced Scorecard 164

Gráfico 9.2: Mapa estratégico de Naranja Producciones S.A.C

\section{ÍNDICE DE TABLAS}

Tabla 5.1: Agencias del Año por país y su puntaje 102

Tabla 5.2: Agencias peruanas 102

Tabla 5.7: Matriz del perfil competitivo (MPC) 111

Tabla 10.1:Ratios Financieros 2016 193

\section{ÍNDICE DE FIGURAS}

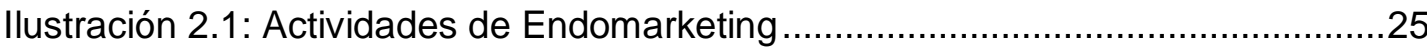

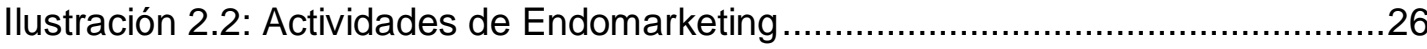

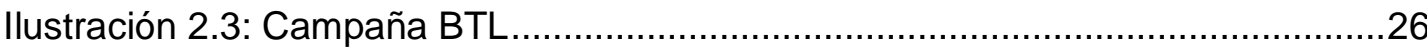

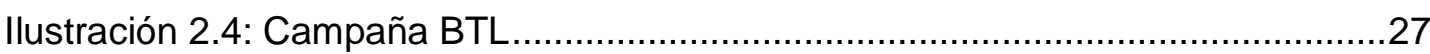

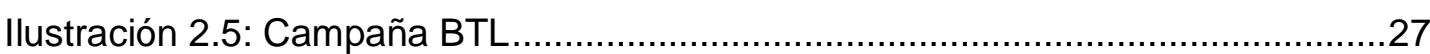

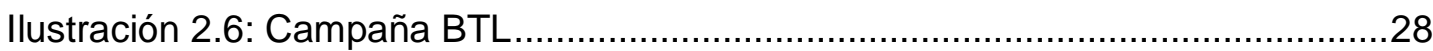

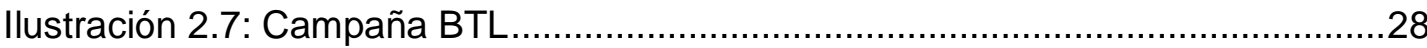

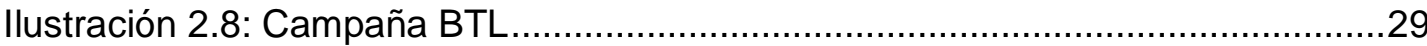

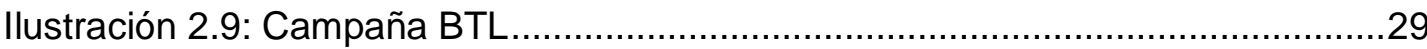

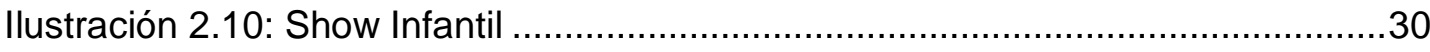

Ilustración 2.11: Web Naranja Producciones .............................................................

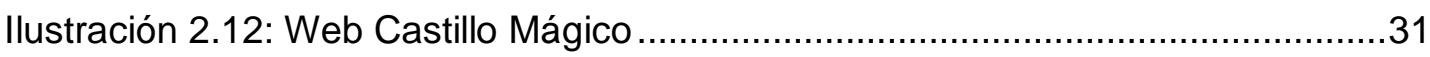

Ilustración 5.1: Fuerzas que impulsan la competencia en la industria .......................83

Ilustración 7.1: Esquema analítico para la formulación de la estrategia .................137

Ilustración 7.2: Matriz BCG .................................................................................146 


\section{Introducción}

En la actualidad, el marketing y la publicidad trabajan juntas para lograr un objetivo en común: llegar al cliente a través de diferentes estrategias, de tal manera que se pueda percibir lo que una empresa desea ofertar. Una de estas estrategias de publicidad es el "Below The Line", más conocida por sus siglas BTL, consiste en un medio de publicidad no tradicional dirigida a segmentos específicos del mercado, teniendo en cuenta que para ser efectiva debe generar una experiencia, identificación y relación con el consumidor, transmitiéndole la certeza de que, al adquirir el bien o servicio, éste contendrá los beneficios que necesita, obteniendo así una solución a su necesidad.

Es así que, Naranja Producciones S.A.C. se funda el 05 de abril de 2013 con la finalidad de ayudar a las organizaciones, desde las más pequeñas hasta las más grandes, con el objetivo de comunicar su razón de ser en el mercado peruano, generando así un mejor posicionamiento de la marca y fidelización del cliente final.

El presente documento contiene diez capítulos cuyos contenidos se describirán a continuación de una manera sintetizada.

El Capítulo I expone las generalidades del documento, es decir, se abordarán temas como los antecedentes de la empresa, determinación del problema y oportunidades, justificación, objetivos, alcances y limitaciones de la investigación.

El Capítulo II presenta a la empresa, sus antecedentes, la descripción del negocio, el ciclo de vida del producto, estructura organizacional, situación de mercado y situación financiera de la industria en la actualidad.

El Capítulo III contiene la formulación de visión, misión, valores de la empresa y su alineamiento estratégico.

El Capítulo IV expone el análisis externo, las tendencias de las variables del entorno, el impacto en los clientes y proveedores, el efecto en la empresa, las oportunidades y la matriz de evaluación de los factores externos EFE.

El Capítulo V contiene el análisis de la industria, la descripción del mercado, las cinco fuerzas competitivas de la industria, la matriz de atractividad de cada una de las cinco 
fuerzas, el análisis del grado de competitividad de la industria y matriz de perfil competitivo MPC.

El Capítulo VI formula el análisis interno, la descripción e indicadores de las actividades de la cadena de valor de la empresa, benchmarking, sus principales competidores, identificación y determinación de las ventajas competitivas de la empresa y la matriz de evaluación de los factores internos EFI.

El Capítulo VII expone la formulación de los objetivos y diseño de las estrategias, el alcance y planeamiento de los mismos.

El Capítulo VIII comprende la selección de la estrategia, la matriz de planeación estratégica cuantitativa MPEC, la descripción de la estrategia seleccionada y de la estrategia contingente.

El Capítulo IX desarrolla la implementación de la estrategia, para lo cual se hará uso del mapa estratégico y de sus objetivos específicos, los indicadores y metas para cada uno esos objetivos, iniciativas, presupuesto, estrategias, programas, políticas, reglas, procedimientos y cronograma de cada una de las iniciativas.

El Capítulo X contiene la evaluación cualitativa y financiera de la estrategia.

Finalmente, se presentan las conclusiones y recomendaciones, índices de cuadros, gráficos, figuras, tablas, anexos y bibliografía. 


\section{Capítulo I}

\section{Generalidades}

\section{Antecedentes.}

Below The Line significa en castellano "por debajo de la línea", pero es más conocido por sus siglas en inglés BTL. Es una técnica de marketing que consiste en la formación de comunicación no masiva dirigida a segmentos específicos del mercado.

Según una investigación realizada por la empresa de marketing MD Group ${ }^{1}$ a empresas peruanas, con respecto al presupuesto que asignan anualmente para campañas de marketing BTL (Below the Line), el 53\% de las empresas invierten entre $\mathrm{S} / 30,000$ y $\mathrm{S} / 50,000$, y el presupuesto asignado, en promedio, es de $\mathrm{S} / 45,000$.

Adicionalmente, esta misma investigación reveló que las principales razones para decidir en invertir en marketing BTL son: la originalidad o creatividad (67\%), la efectividad o alcance del público objetivo (69\%), entre otros, con la finalidad de poder desarrollar una relación personalizada y directa con los clientes.

\section{Gráfico 1.1: Presupuesto asignado por las empresas peruanas al marketing BTL}

(En porcentajes)

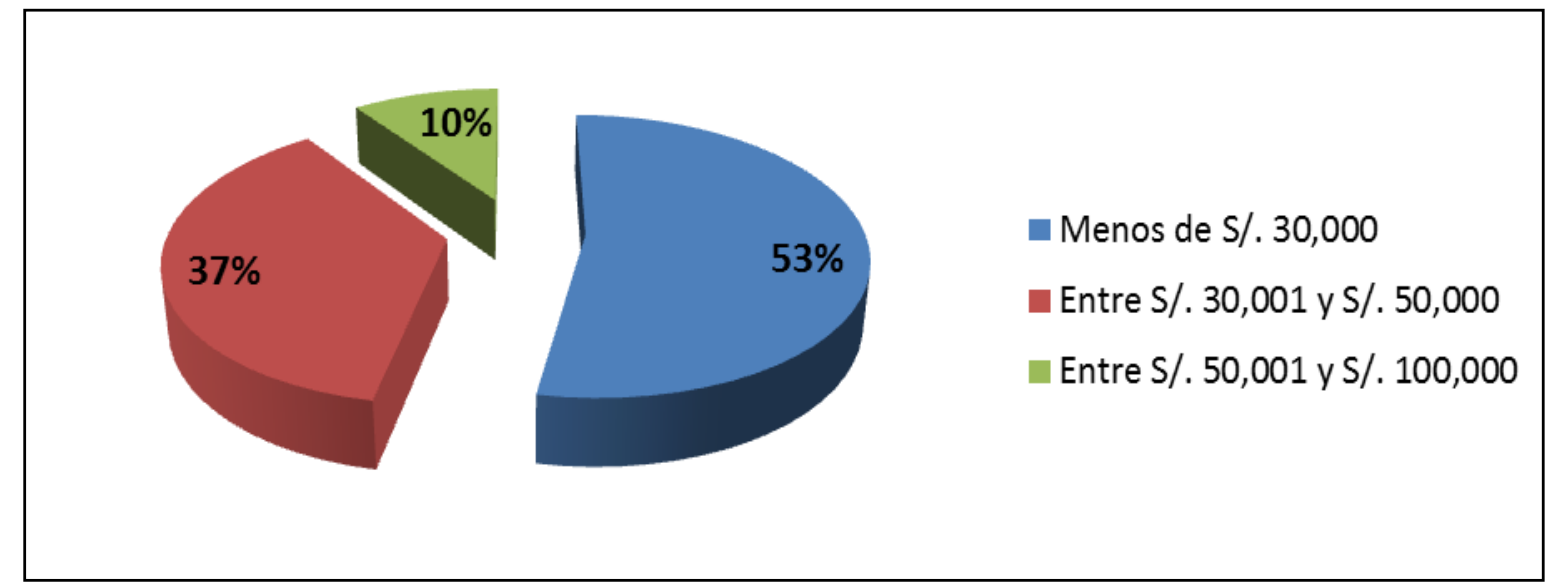

Fuente: MD Group. “Empresas peruanas destinan S/ 45,000 en promedio a campañas BTL”.En: Diario Gestión. [en línea], PE, mayo, 2014. [citado 22 septiembre 2014]. Disponible: http://gestion.pe/empresas/empresas-peruanas-destinan-s-45000-promedio-campanas-btl-2098810 Elaboración propia.

\footnotetext{
1 MD Group, articulo en Diario Gestión. (en línea), Jueves, 29 de mayo del 2014. Disponible: http://gestion.pe/empresas/empresas-peruanas-destinan-s-45000-promedio-campanas-btl-2098810
} 


\section{Gráfico 1.2: Criterios para decidir si invierten en marketing BTL}

(En porcentajes)

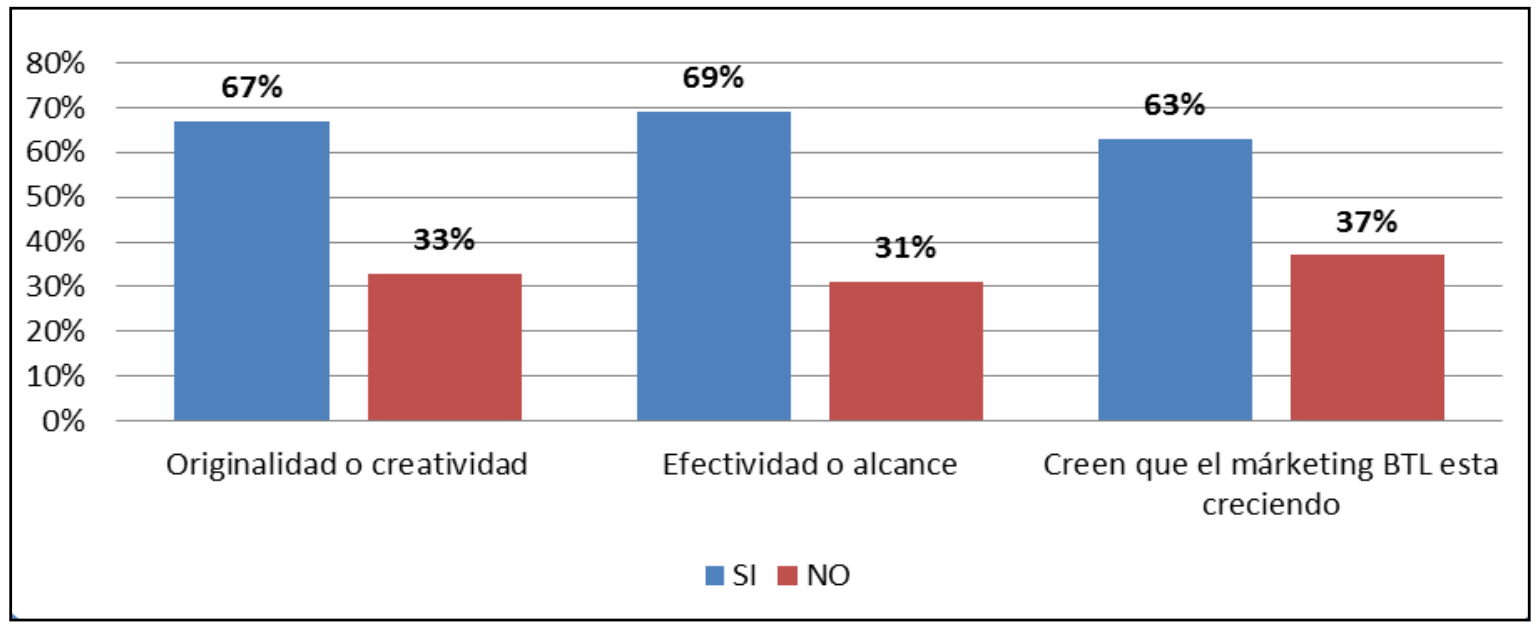

Fuente: MD Group. “Empresas peruanas destinan S/ 45,000 en promedio a campañas BTL”. En: Diario Gestión. [en línea], PE, mayo, 2014. [citado 22 septiembre 2014]. Disponible: http://gestion.pe/empresas/empresas-peruanas-destinan-s-45000-promedio-campanas-btl-2098810 Elaboración propia.

En la actualidad, existen en el mercado peruano las siguientes empresas de Marketing BTL: FCB MAYO Perú, Yellow BTL, Chirimoya BTL, Rocoto Producciones, Mangosta Producciones, Moving Pack, AKM Warketing, Publicis Perú - Perú, SIVAL, Glenda Yaker Eventos Especiales, Garwich BBDO, Marketing Alterno, 360 BTL, OB 460, Mercadotecnia, Chok y Transit Media, y otras más, siendo las más importantes Yellow BTL y AKM Warketing debido a que estas empresas cuentan con una capacidad instalada, recursos económicos para solventar campañas de gran envergadura, además de un área creativa y con una capacidad logística para la atención de grandes eventos. Por tal motivo, tienen a su cargo cuentas de clientes importantes en el mercado nacional y la capacidad de realizar eventos BTL de gran envergadura, así como también grandes lanzamientos de productos y servicios, eventos y ceremonias corporativas, entre otros. A pesar que sus precios son elevados, los clientes confían en los servicios de estas empresas debido a su prestigio, tiempo en el mercado y capacidad de atención.

Los jóvenes empresarios, César Hugo Jaén Seminario y Sherylin Román Orosco, se iniciaron trabajando como anfitriones y modelos de diferentes marcas, durante más de 10 años. De esta manera, pudieron observar que los clientes de las empresas para las cuales trabajaban buscaban campañas más personalizadas, en lugar de campañas masivas que tenían poca llegada con el cliente final. 
Con la finalidad de poder contar con capital para crear una empresa de BTL, los socios César Hugo Jaén Seminario y Sherylin Román Orosco, primero crearon durante el año 2010 una marca de shows infantiles llamada Castillo Mágico, la cual implementaron con $S / 5,000$. Esta marca operó informalmente durante 3 años, sin contar con un RUC. Esta marca ofrece shows infantiles, baby showers y hora loca para fiestas y eventos. Además, los socios hacían la función de animadores, de técnicos de sonido, de coreógrafos, de vendedores de los shows infantiles, todo esto con la finalidad de poder ahorrar en personal.

Después, en el año 2013, los socios Hugo y Sherylin, crearon la empresa Naranja Producciones S.A.C., con la finalidad de ser una empresa dedicada a la elaboración de campañas publicitarias, activaciones BTL, campañas de fidelización, lanzamientos de nuevos productos, modelos, anfitriones y promotores, endomarketing, eventos corporativos, deportivos, aniversarios e integración, exposición y congresos, elaboración de merchandising, estructuras, vallas y paneles publicitarios, alquiler de carritos snacks, juegos de clowns, risoterapias y animaciones temáticas.

Con el transcurrir de los años Naranja Producciones S.A.C., logró tener a una diversa clientela, como son el Ministerio de Salud, Petroperú, Seguro Integral de Salud, Línea 1 del Metro de Lima, entre otros. La empresa Naranja Producciones S.A.C. cuenta con un mayor número de clientes provenientes del Estado. Tal como lo afirmaron en una entrevista los dueños de la empresa, las instituciones públicas, en su mayoría, buscan un precio bajo a la hora de llevar a cabo alguna actividad y, como Naranja Producciones S.A.C., cuenta con precio relativamente menor que la competencia, las instituciones del Estado prefieren trabajar con ellos. Además, poseen una red de contactos más desarrollada en el sector público.

Naranja Producciones S.A.C. cuenta con cinco colaboradores fijos incluyendo a los socios y veinte personas adicionales, bajo la modalidad de trabajadores independientes.

La empresa se encuentra en pleno crecimiento. Desde su apertura en el 2013, no ha dejado de crecer. Según lo expresado por el directivo, el señor César Hugo Jaén Seminario, durante el 2012 la empresa realizó 36 eventos, en el 2013 logró 75 eventos, en el 2014 tuvo, aproximadamente, 170 eventos, durante el 2015, llegó a 477 eventos, en el 2016 realizo 670 evento y finalmente durante el 2017 realizo 695 eventos. Se debe aclarar que la empresa fue informal desde el año 2010 hasta el 2013 cuando la empresa 
fue formalmente constituida. El nivel de ventas durante el 2012, fue cuando la empresa Naranja Producciones S.A.C., no estaba constituida.

\section{Gráfico 1.3: Número de eventos realizados por la empresa Naranja Producciones}

\section{S.A.C. desde su creación}

(En unidades)

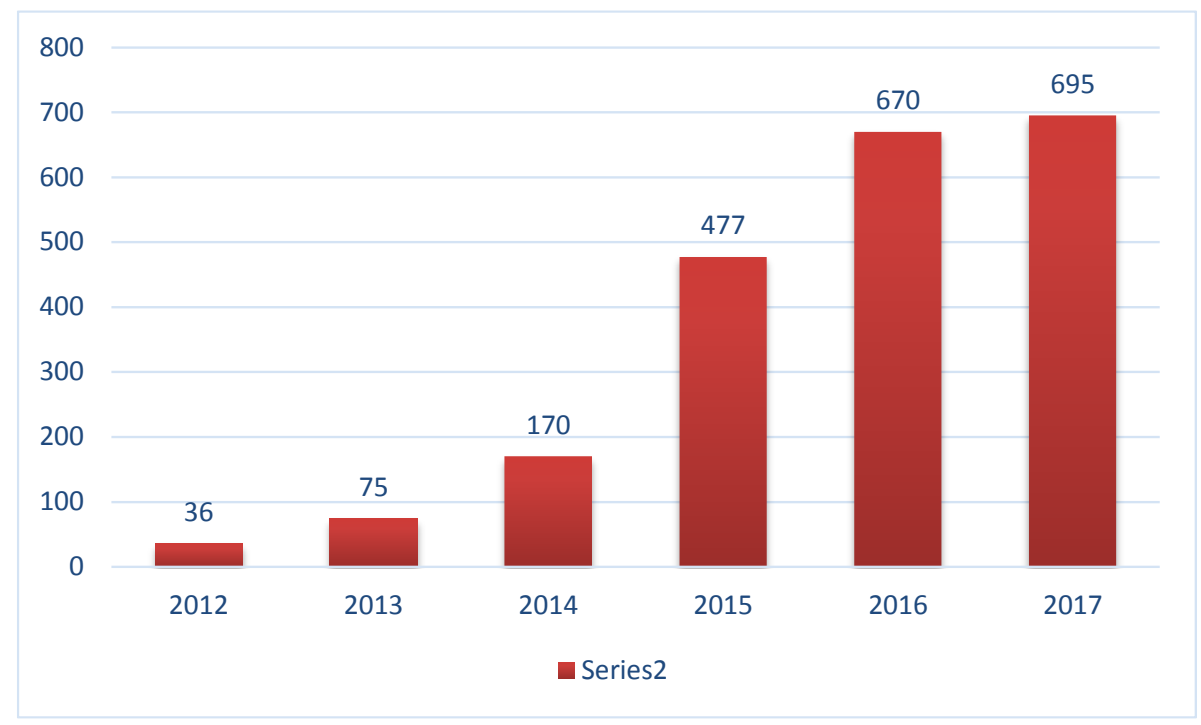

Elaboración Propia.

\section{Determinación del problema y oportunidad}

A continuación, explicaremos el problema y oportunidad que se encontró para la empresa Naranja Producciones S.A.C..

\section{a. Problemas}

El mayor problema de Naranja Producciones S.A.C. mencionado durante la entrevista que se llevó a cabo con los dueños, es que ha crecido de manera sustancial y rápida desde el 2013, pero en ese proceso, se han desorganizado internamente y, por tal motivo, no están trabajando de manera óptima para poder atender los requerimientos de sus clientes reales o potenciales. Su desafío es reorganizarse para atender rápida, efectiva y creativamente las necesidades de su público objetivo, mejorando sus procesos y, de ser necesario, reformulando la estrategia empresarial.

Otro problema es que cada año ingresan nuevos competidores a dicho mercado, y a pesar que ofrecen precios muy competitivos al contar con una estructura de costos 
bajos, uno de sus desafíos es lograr una diferenciación más relevante, dinámica y que se renueve constantemente en comparación a sus competidores.

La competencia cuenta con áreas creativas para ofrecer conceptos totalmente innovadores a los clientes. Por tal motivo, si un cliente importante desea lanzar una campaña BTL que logre posicionarlo en el mercado nacional, estará dispuesto a pagar un precio mayor por una idea creativa, innovadora e impactante. Es por ello que consideramos que la diferenciación de precios bajos con la que cuenta Naranja Producciones S.A.C. no es muy relevante cuando se presentan clientes de consumo masivo y que cuenta con la capacidad financiera para invertir en grandes campañas BTL.

A pesar de contar con una cuenta en Facebook y con una página Web, y siendo sus principales recursos de publicidad la comunicación verbal y su red de contactos, aún no son lo suficientemente conocidos en el sector.

\section{b. Oportunidades}

En la actualidad, las empresas buscan llegar de manera más directa a su público objetivo mediante el Marketing BTL, minimizando los esfuerzos a la hora de lanzar campañas masivas, a sabiendas que la información puede llegar a personas que no están dentro del segmento seleccionado, permitiéndole así una demanda creciente. Según MD Group $^{2}, 7$ de cada 10 empresas en el Perú realizan acciones de marketing BTL por lo tanto, se evidencia que son más las empresas que optan por esta herramienta de marketing.

En el sector privado, las empresas realizan campañas interactivas que les permite fidelizar a los clientes, ya que éstos buscan una mayor interacción con las marcas. Del mismo modo, personalizan sus anuncios y sus productos con el propósito de crear una experiencia nueva y única. Desde esta óptica, la empresa Naranja Producciones S.A.C. tiene una gran oportunidad para seguir creciendo en los próximos años.

\footnotetext{
${ }^{2}$ MD Group. “Empresas peruanas destinan S/ 45,000 en promedio a campañas BTL”. En: Diario Gestión. [en línea], PE, mayo, 2014. [citado 28 septiembre 2014]. Disponible: http://gestion.pe/empresas/empresas-peruanas-destinan-s-45000promedio-campanas-btl-2098810
} 


\section{Justificación del proyecto}

Ahora explicaremos la justificación del proyecto desde los siguientes puntos de vista:

\section{a. Empresarial}

Nos permitirá delinear los lineamientos estratégicos que contribuyen a la mejora de los procesos, la reorganización interna de la empresa, un mejor manejo de los costos y de las finanzas, así como un análisis interno de la empresa y del mercado actual de competencias. De modo tal que el objetivo principal será la sostenibilidad y crecimiento de la empresa.

\section{b. Académico}

Para desarrollar el plan estratégico se deben aplicar los conocimientos adquiridos durante la Maestría de Ciencias Empresariales en los cursos de Investigación de Mercado, Costos y Presupuestos, Marketing Comercial, Coaching, Planeamiento Estratégico y Finanzas principalmente.

\section{Objetivos generales y específicos}

En este momento, indicaremos los objetivos generales y específicos del plan estratégico para la empresa Naranja Producciones S.A.C.

\section{a. Objetivo general}

Desarrollar un Plan Estratégico para Naranja Producciones S.A.C. para el periodo $2018-2021$.

\section{b. Objetivos específicos}

- Revisión y formulación de la visión, misión y valores de la empresa.

- Hacer un diagnóstico del análisis interno y externo.

- Formulación de los objetivos y diseño de estratégicas.

- Realizar la evaluación financiera del impacto de las estrategias propuestas en la empresa. 


\section{Alcance y limitaciones de la investigación}

En este punto, indicaremos el alcance y limitaciones del plan estratégico para la empresa Naranja Producciones S.A.C.

\section{a. Alcance}

La investigación se realizará en la ciudad de Lima Metropolitana y en la Provincia Constitucional del Callao. El Plan Estratégico tiene como horizonte de planeación el periodo 2018-2021.

\section{b. Limitaciones}

Existen pocas fuentes secundarias a nivel nacional, asimismo, es escasa la información sobre los competidores locales y su participación en este rubro del BTL. Además, en el Perú casi no existe información secundaria como tesis, investigaciones de mercado o revistas especializadas en BTL 


\section{Capítulo II}

\section{La Empresa}

En este capítulo, describiremos a la empresa Naranja Producciones S.A.C., al igual que los servicios que brinda.

\subsection{Antecedentes de la empresa.}

La empresa Naranja Producciones S.A.C. con RUC Nro. 20551826717 fue constituida en el año 2013 y se ubica en la Av. La Molina 849, oficina 301 en el distrito de La Molina (esta oficina es alquilada). Asimismo, cuenta con un almacén en el mismo edificio, para los equipos y vestuarios utilizados en los eventos.

La empresa se inició con la marca Castillo Mágico, la cual continúa brindando servicios de shows infantiles, baby showers y hora loca para fiestas y eventos. Es mediante este servicio que empezaron a ganar experiencia y a formar un capital, que sirvió de base para formalizar una empresa de mayor envergadura. Es así como, posteriormente, la empresa Naranja Producciones S.A.C. empezó a incursionar en el marketing BTL.

La empresa fue constituida por los socios: el Licenciado en Economía César Hugo Jaen Seminario y la Bachiller en Comunicación Sherylin Román Orosco, ambos con experiencia en el rubro, gracias a que anteriormente fueron modelos y anfitriones en diferentes empresas que realizaban eventos y campañas BTL. El capital social para constituir la empresa fue de $S / 5,000$.

El personal inicial de la empresa sólo estaba constituido por los socios durante los primeros 6 meses, pero posteriormente vieron la necesidad de incrementar el personal, llegando a tener seis personas. Al incrementarse el número de shows, eventos y campañas BTL de la empresa Naranja Producciones S.A.C., se contrata a personal que los apoyaran durante la realización de los eventos. Actualmente, pueden realizar dos shows, dos eventos o dos campañas BTL en simultáneo.

Su actual propuesta de valor es emplear en sus campañas BTL elementos como clowns, la risoterapia, juegos y animaciones temáticas, entre otros. Con estos elementos 
mencionados, Naranja Producciones S.A.C. busca una mayor interacción y comunicación entre la empresa que contratan sus servicios y sus clientes.

\subsection{Descripción del negocio}

La empresa Naranja Producciones S.A.C. es una empresa que fue creada para satisfacer las necesidades de sus clientes en las áreas de publicidad, marketing, comunicaciones y prensa, pero, por lo general, la empresa actualmente se dedica a la elaboración de campañas BTL y Shows Infantiles. Eventualmente, realiza campañas de Endomarketing y eventos corporativos. A continuación, se puede apreciar las actividades que la empresa Naranja Producciones S.A.C. realiza:

1. Campañas BTL en donde se realizan varias actividades como:

- Activaciones BTL, consisten en el empleo de creatividad en medios no masivos para realizar el mercadeo de un producto dirigido a un público objetivo. Para poder llevar a cabo las campañas de BTL, la empresa Naranja Producciones S.A.C., emplea personal especializado como modelos, anfitriones y promotores, de acuerdo a las características que desea el cliente para los eventos. Además, si el cliente lo requiere, Naranja Producciones S.A.C. puede tercerizar el merchandising, las estructuras, las vallas y los paneles publicitarios; asumiendo la responsabilidad de la calidad del servicio.

- Campañas de fidelización, consisten en mantener a sus clientes a lo largo del tiempo, teniendo en cuenta que perder un cliente puede ser fácil, pero ganar otro cliente es muy difícil. Para llevar a cabo las campañas de fidelización, la empresa Naranja Producciones S.A.C. emplea el BTL como herramienta para poder fidelizar a los clientes.

- Lanzamientos de nuevos productos, consiste en realizar campañas o actividades para productos o servicios nuevos que ofrece la empresa. El lanzamiento de nuevos productos se realiza en el punto de venta (centros comerciales, instituciones públicas, establecimientos comerciales), mediante la implementación de campañas de BTL para poder captar a los futuros clientes.

- El alquiler de carritos snack a las empresas se ofrece bajo la marca de Dulcemanía. El cual consiste en el alquiler de carritos de pop corn, de algodón, de hot dog, panchos, de helados, de raspadillas, chorizos, manzanas acarameladas, entre otros. Estos carritos se decoran con la marca propia del cliente. Es otra forma de realizar BTL, pero por medio de carritos snacks. 
2. Endomarketing, es una estrategia de venta interna de la empresa que contrata los servicios de Naranja Producciones S.A.C., hacia sus empleados y profesionales. La empresa Naranja Producciones S.A.C., busca mediante el endomarketing, el desarrollo de la comunicación interna de sus clientes, para poder fidelizar y mejorar el compromiso de sus colaboradores.

3. Eventos corporativos, deportivos, aniversarios e integración, exposición y congresos.

4. La elaboración de shows infantiles se realiza bajo la marca de Castillo Mágico de Naranja Producciones S.A.C.

En las siguientes imágenes, se podrá observar los servicios brindados por la empresa Naranja Producciones S.A.C.:

\section{llustración 2.1: Actividades de Endomarketing}

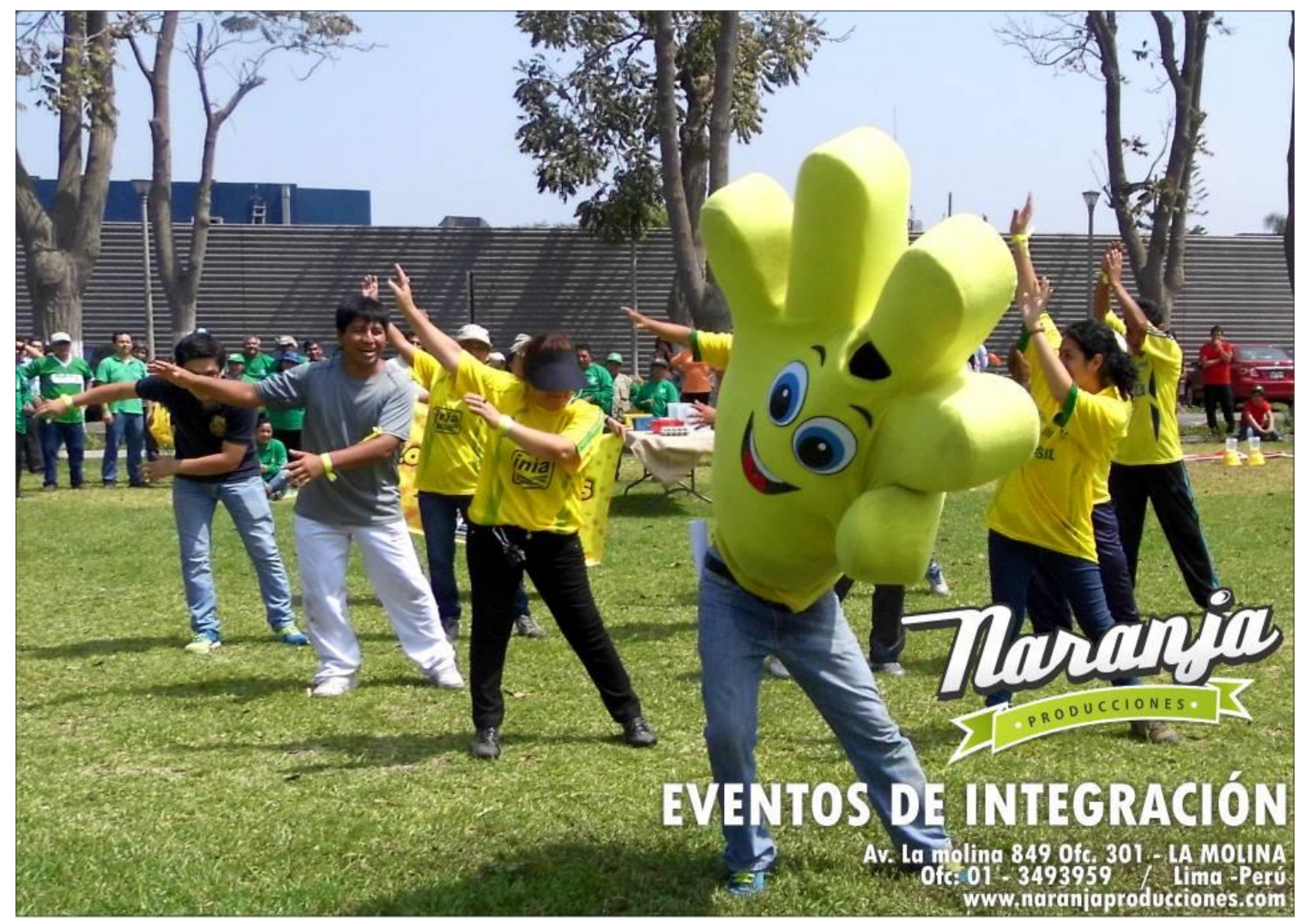

Fuente: Facebook Naranja Producciones [en línea]. Lima. 2014. [citado 26 enero 2017]. Disponible en: https://www.facebook.com/Naranjaproduccionesperu/photos/ 
llustración 2.2: Actividades de Endomarketing

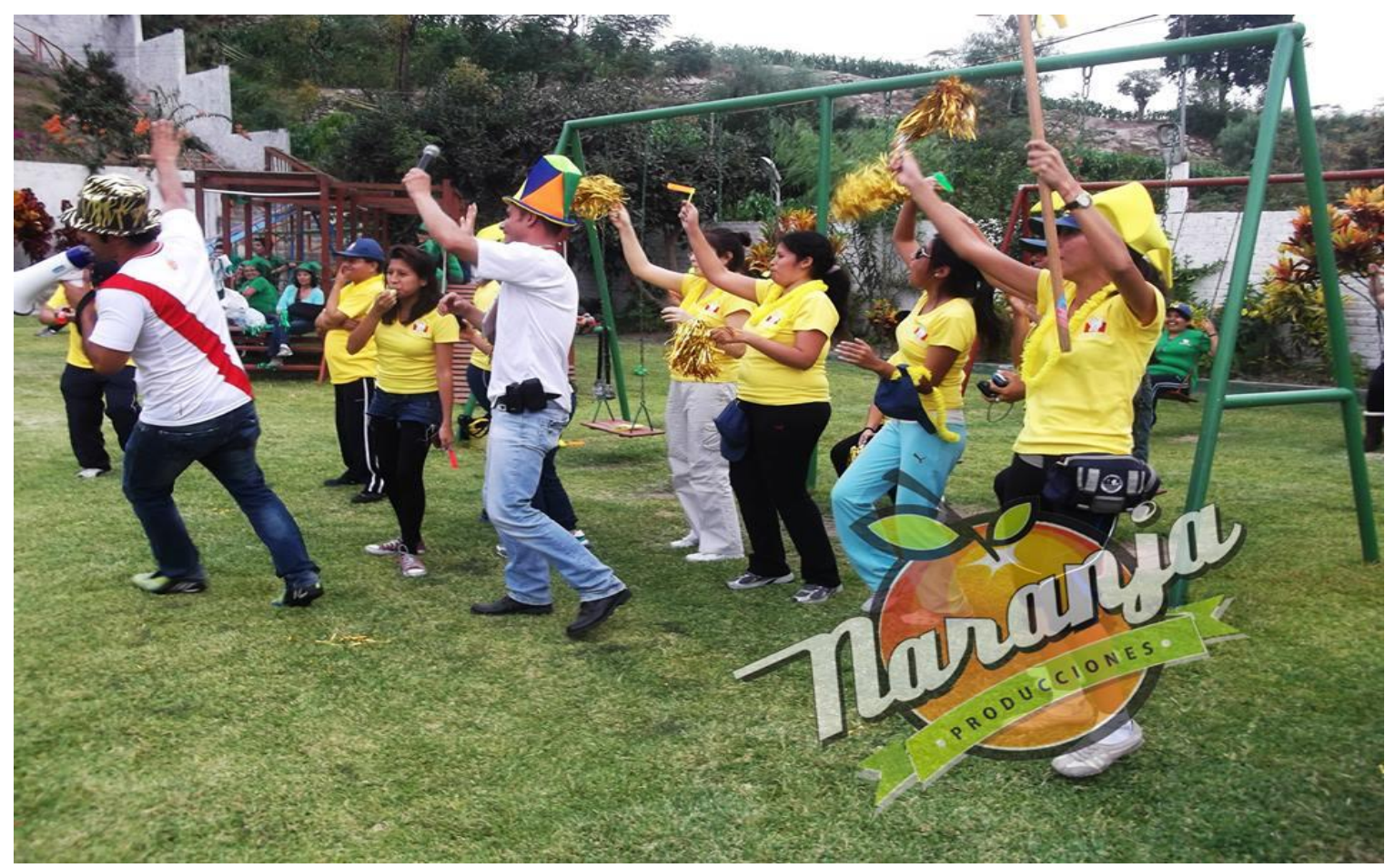

Fuente: Facebook Naranja Producciones [en línea]. Lima. 2017. [citado 26 enero 207]. Disponible en: https://www.facebook.com/Naranjaproduccionesperu/photos/

llustración 2.3: Campaña BTL

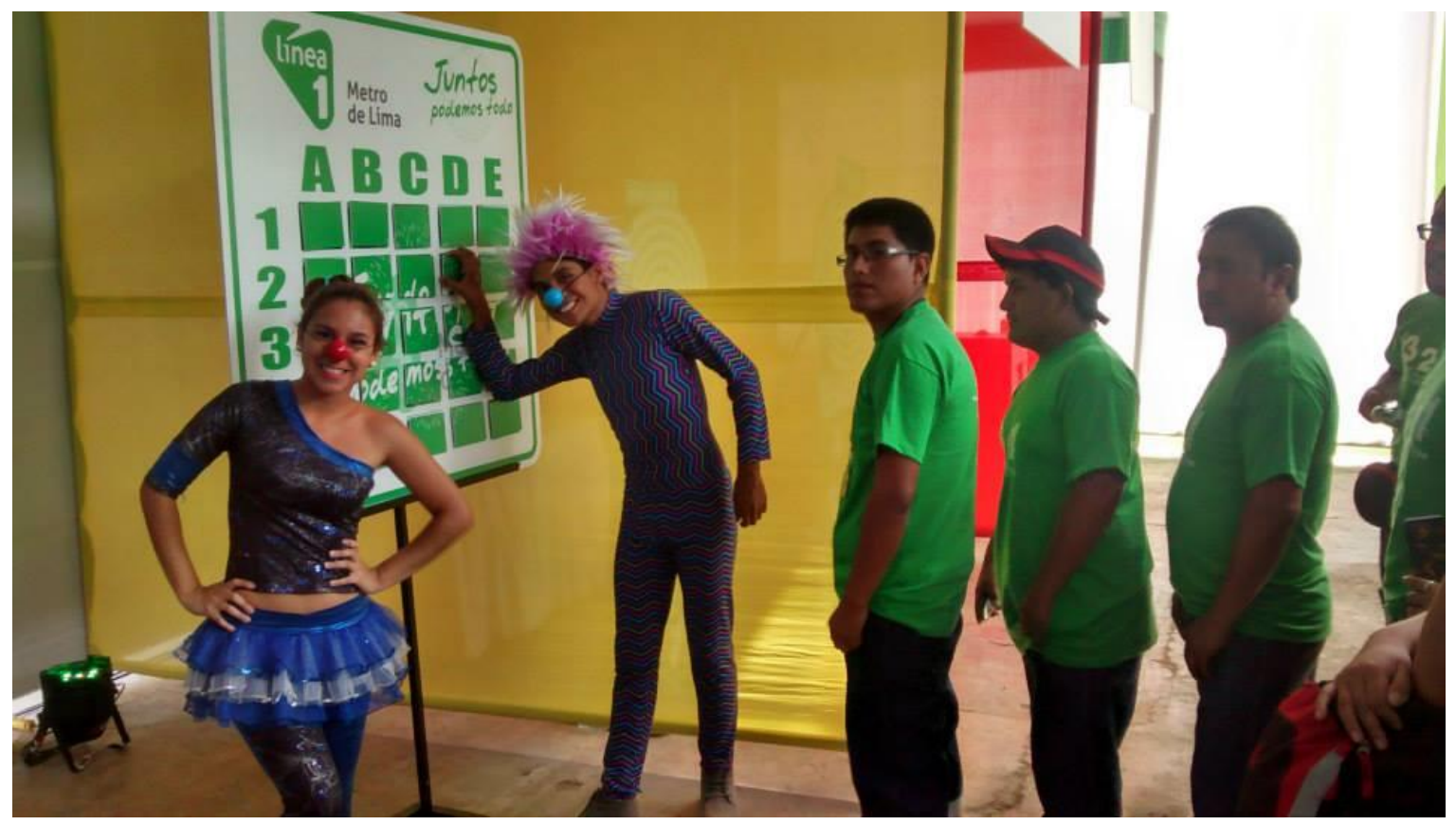

Fuente: Facebook Naranja Producciones [en línea]. Lima. 2017. [citado 26 enero 2017]. Disponible en: https://www.facebook.com/Naranjaproduccionesperu/photos/ 
Ilustración 2.4: Campaña BTL

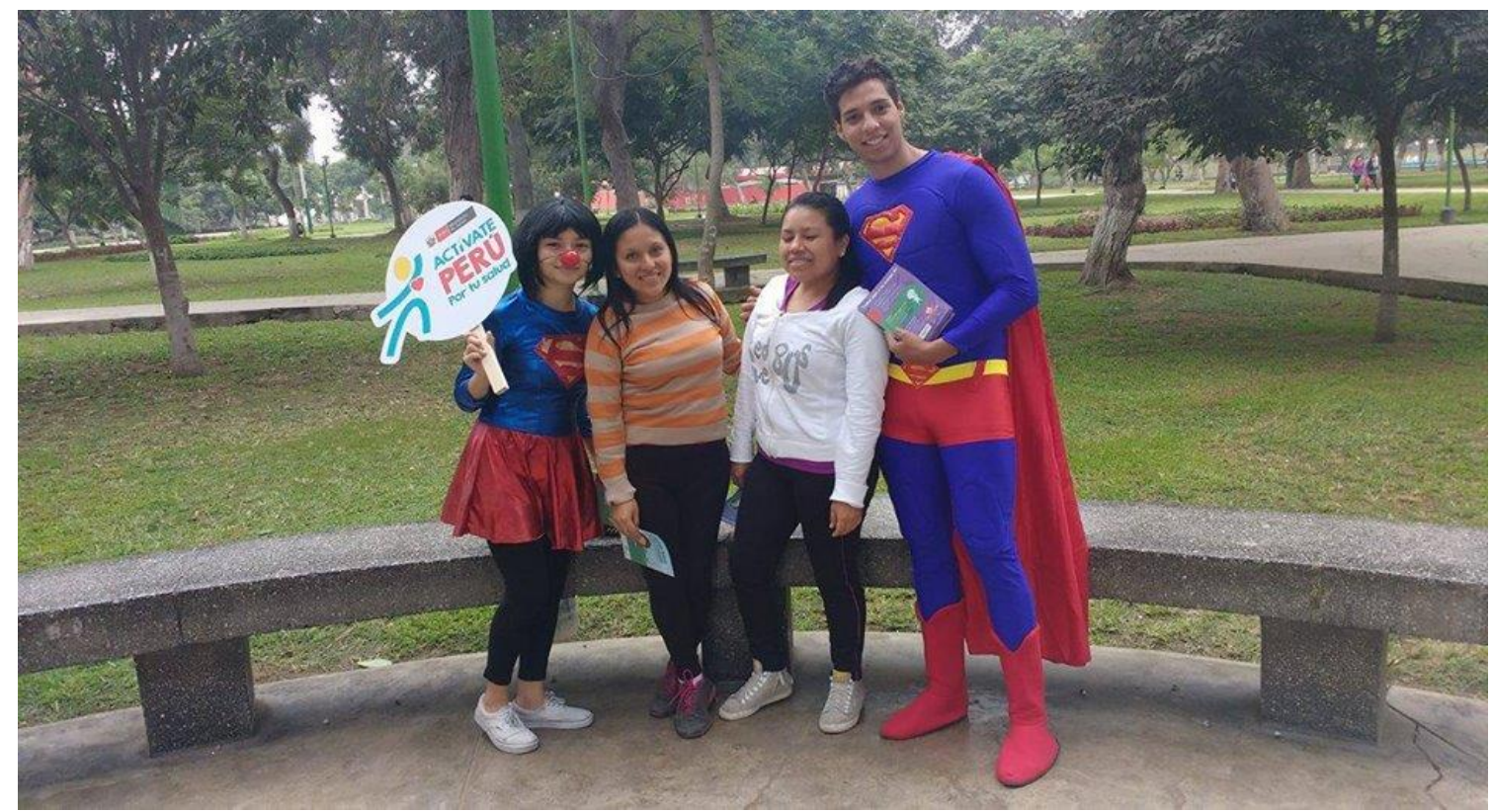

Fuente: Facebook Naranja Producciones [en línea]. Lima. 2017. [citado 26 enero 2017]. Disponible en: https://www.facebook.com/Naranjaproduccionesperu/photos/

Ilustración 2.5: Campaña BTL

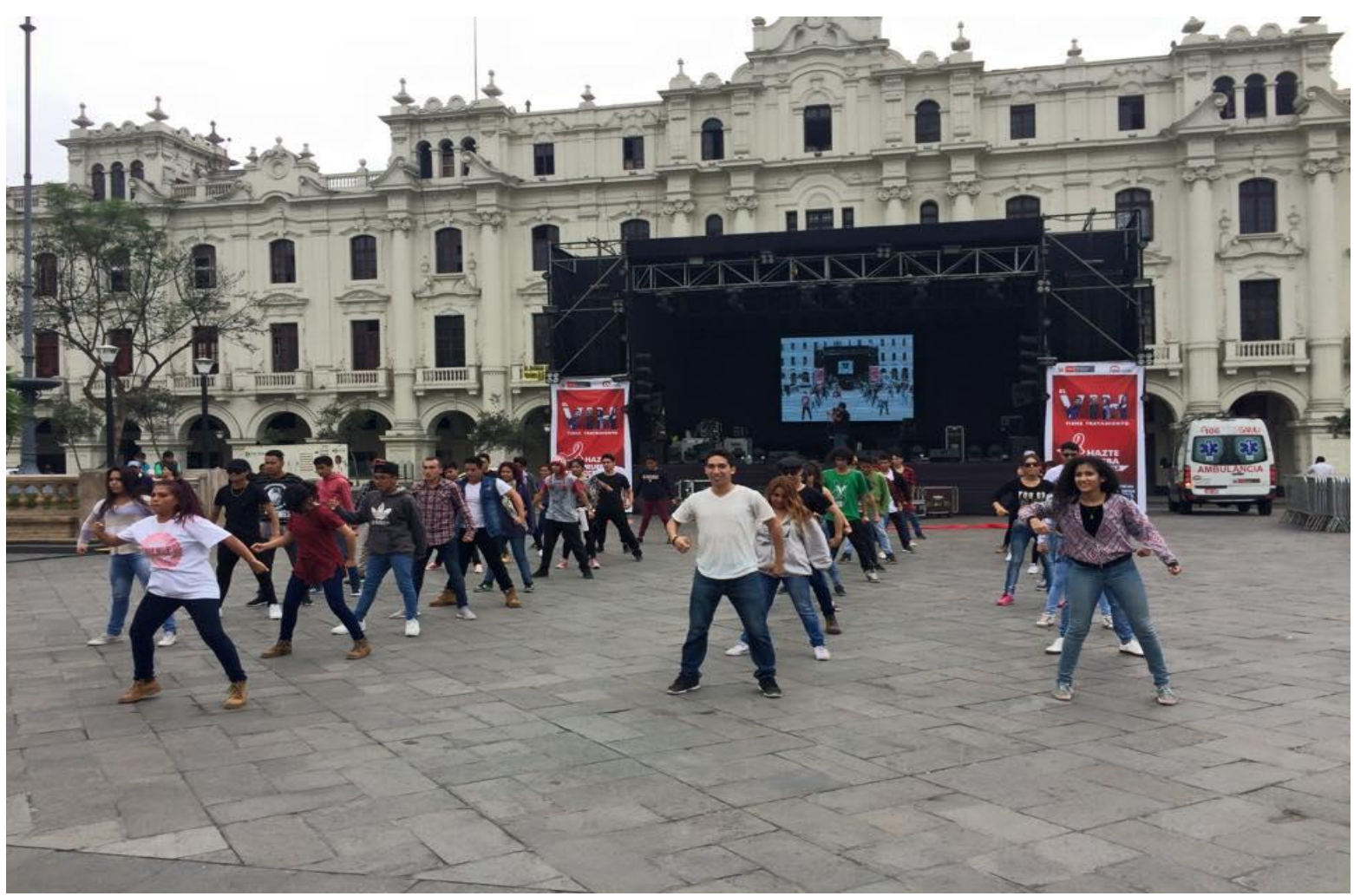

Fuente: Facebook Naranja Producciones [en línea]. Lima. 2017. [citado 26 enero 2017]. Disponible en: https://www.facebook.com/Naranjaproduccionesperu/photos/ 
Ilustración 2.6: Campaña BTL

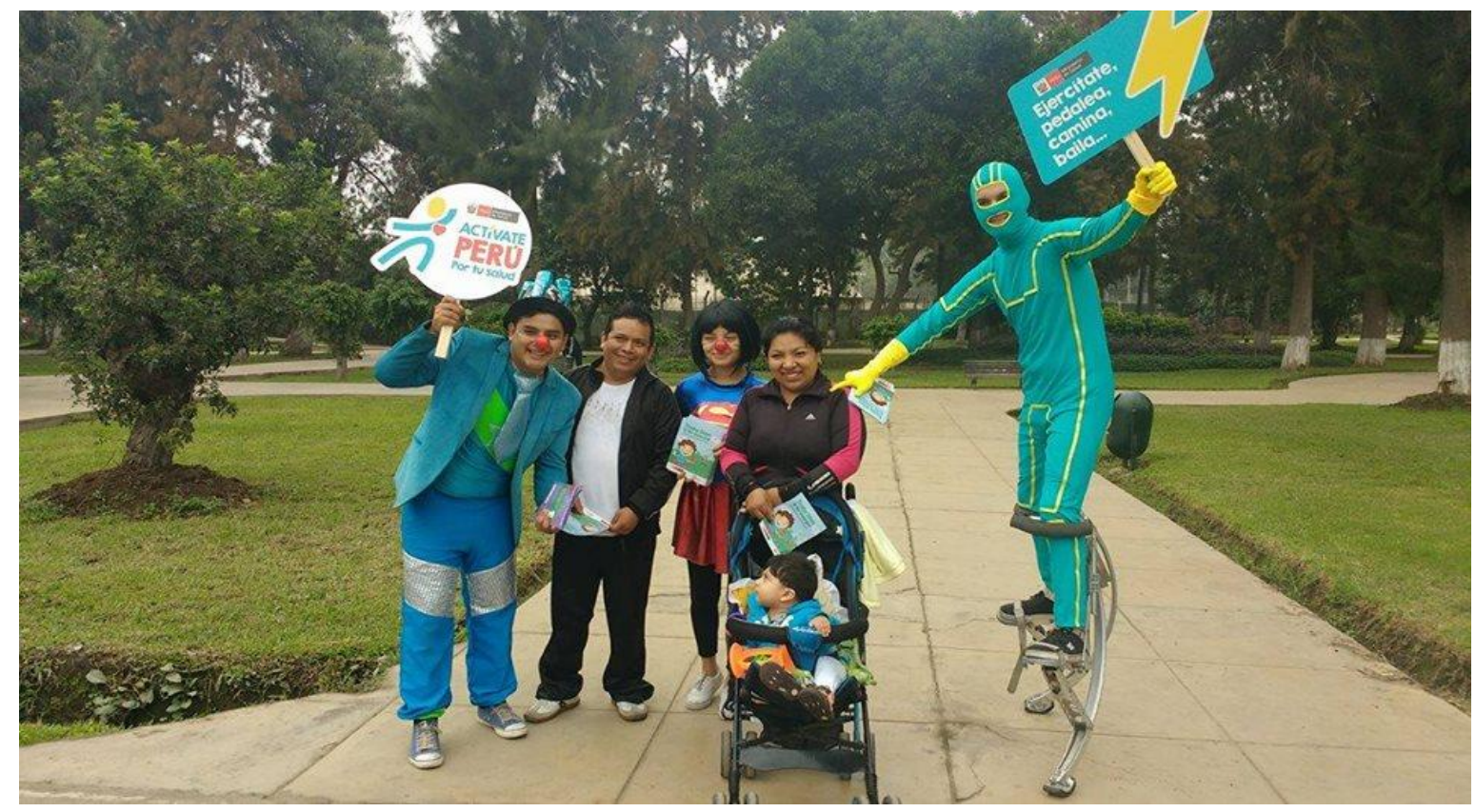

Fuente: Facebook Naranja Producciones [en línea]. Lima. 2017. [citado 26 enero 2017]. Disponible en: https://www.facebook.com/Naranjaproduccionesperu/photos/

Ilustración 2.7: Campaña BTL

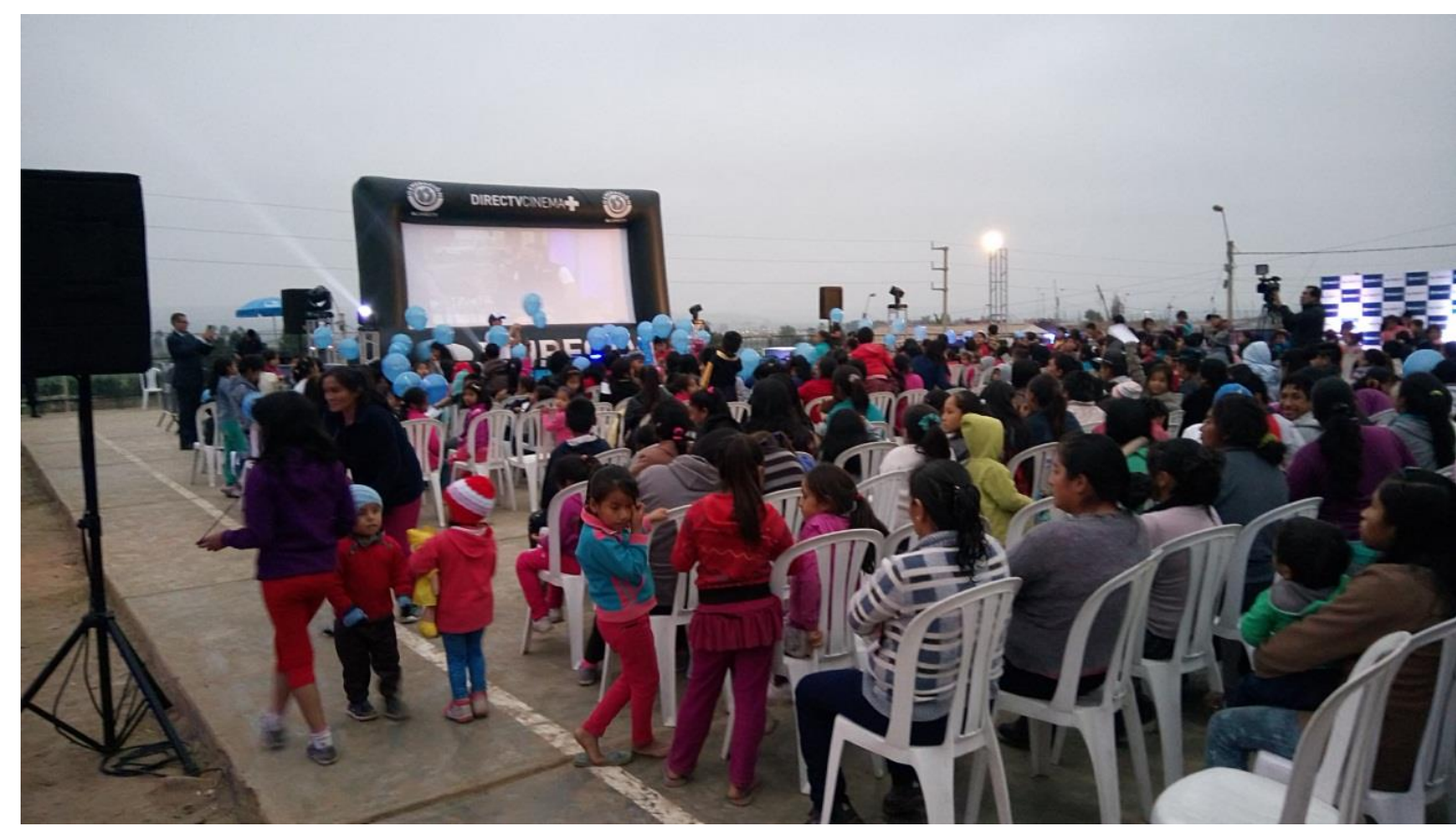

Fuente: Facebook Naranja Producciones [en línea]. Lima. 2017. [citado 26 enero 2017]. Disponible en: https://www.facebook.com/Naranjaproduccionesperu/photos/ 
Ilustración 2.8: Campaña BTL

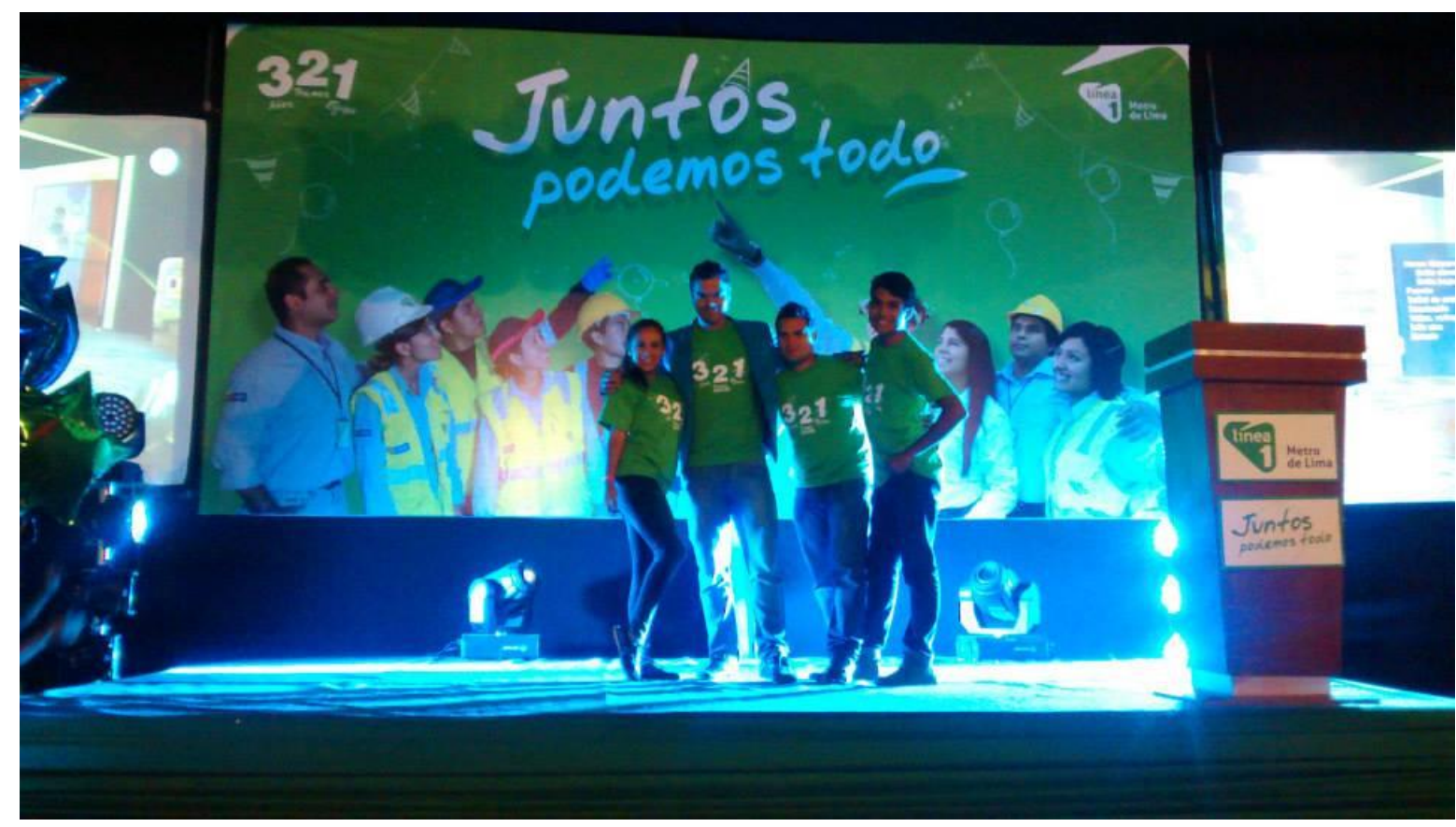

Fuente: Facebook Naranja Producciones [en línea]. Lima. 2017. [citado 26 enero 2017]. Disponible en: https://www.facebook.com/Naranjaproduccionesperu/photos/

llustración 2.9: Campaña BTL

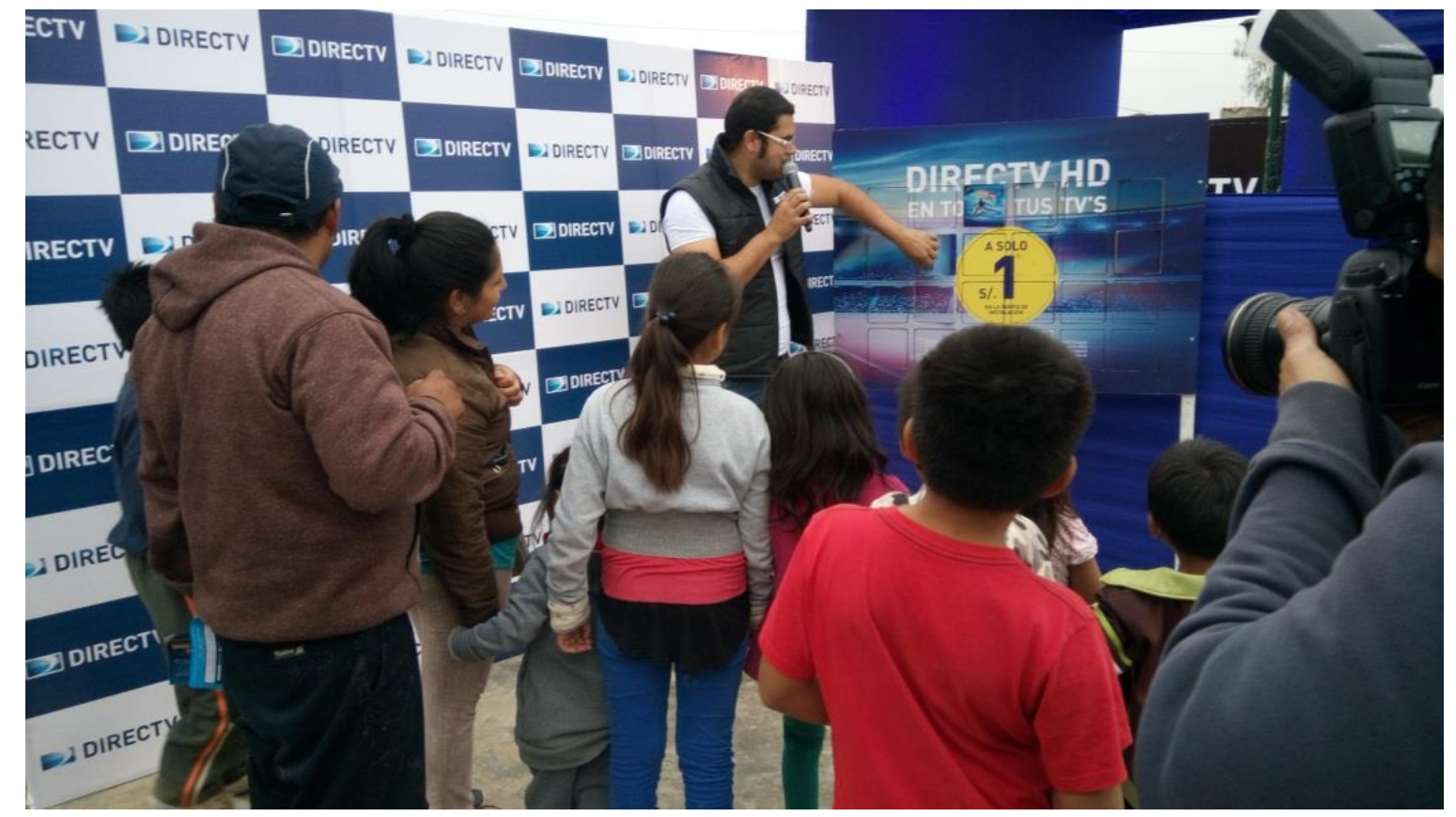

Fuente: Facebook Naranja Producciones [en línea]. Lima. 2017. [citado 26 enero 2017]. Disponible en: https://www.facebook.com/Naranjaproduccionesperu/photos/ 
llustración 2.10: Show Infantil

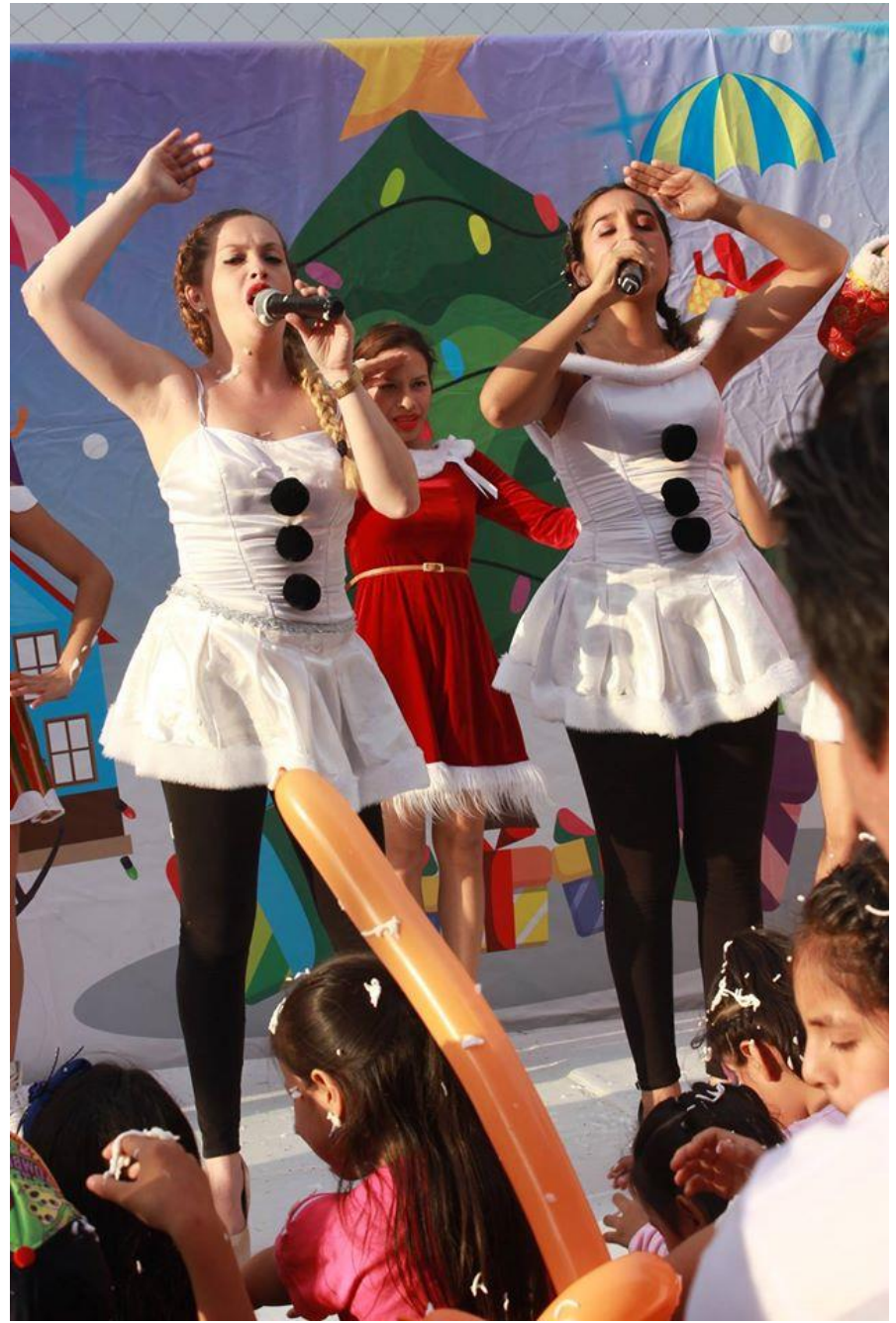

Fuente: Castillo Mágico [en línea]. Lima. 2017. [citado 26 septiembre 2017]. Disponible en: https://www.facebook.com/castillomagicoperu/photos/

Todos estos servicios los ofrecen en su página web:

Naranja Producciones:

www.naranjaproducciones.com

Castillo Mágico:

http://www.castillomagicoperu.com 


\section{Ilustración 2.11: Web Naranja Producciones}

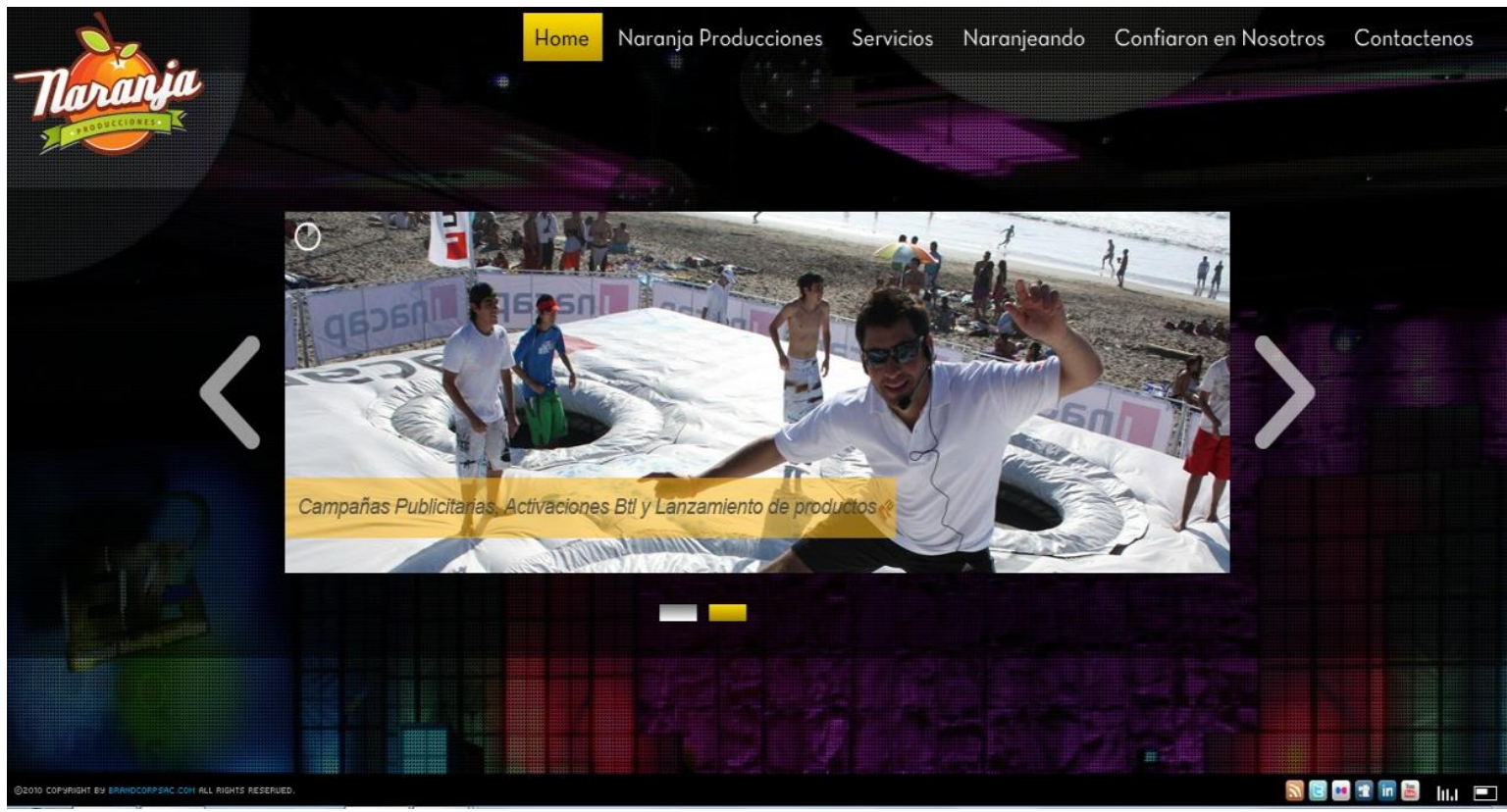

Fuente: Naranja Producciones [en línea]. Lima. 2014. [citado 28 septiembre 2014]. Disponible en: www.naranjaproducciones.com

\section{Ilustración 2.12: Web Castillo Mágico}

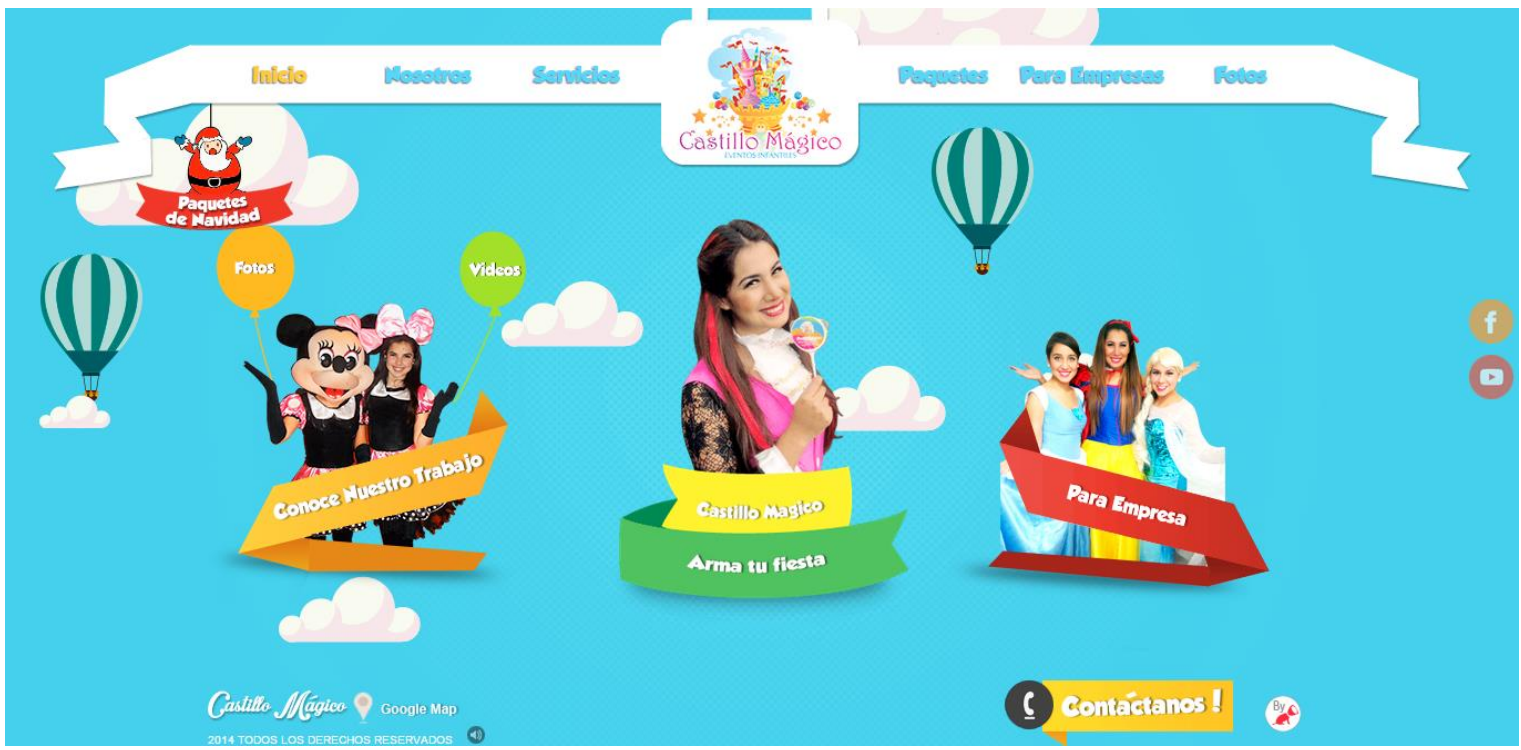

Fuente: Castillo Mágico [en línea]. Lima. 2014. [citado 28 septiembre 2014]. Disponible en: http://www.castillomagicoperu.com./

La empresa Naranja Producciones S.A.C., también ofrece su capacidad logística y de producción a otras empresas BTL que sólo cuentan con área creativa y no poseen equipos ni proveedores para llevar a cabo los eventos. Es de esta manera que los dueños han ido aprendiendo más de este sector. La empresa se encuentra en crecimiento constante y durante el año 2017 tuvo ventas anuales aproximadas de S/464,373. 
Como se puede apreciar en el siguiente gráfico, los contratos firmados por la empresa Naranja Producciones S.A.C. con los clientes representan un 75\%. En estos casos Naranja Producciones S.A.C. se encarga de la elaboración de la parte creativa de la campaña y del desarrollo de la producción de la misma. Por otra parte, el $25 \%$ de los contratos que tiene Naranja Producciones S.A.C. son realizado con otras empresas BTL de mayor envergadura, quienes subcontratan a Naranja Producciones S.A.C. para que sólo realicen la parte de producción, es decir, que la empresa contratante es la que se encarga de la parte creativa de la campaña y es quien contacta al cliente.

\section{Gráfico 2.1: Campañas BTL realizadas por Naranja Producciones de manera directa} e indirecta

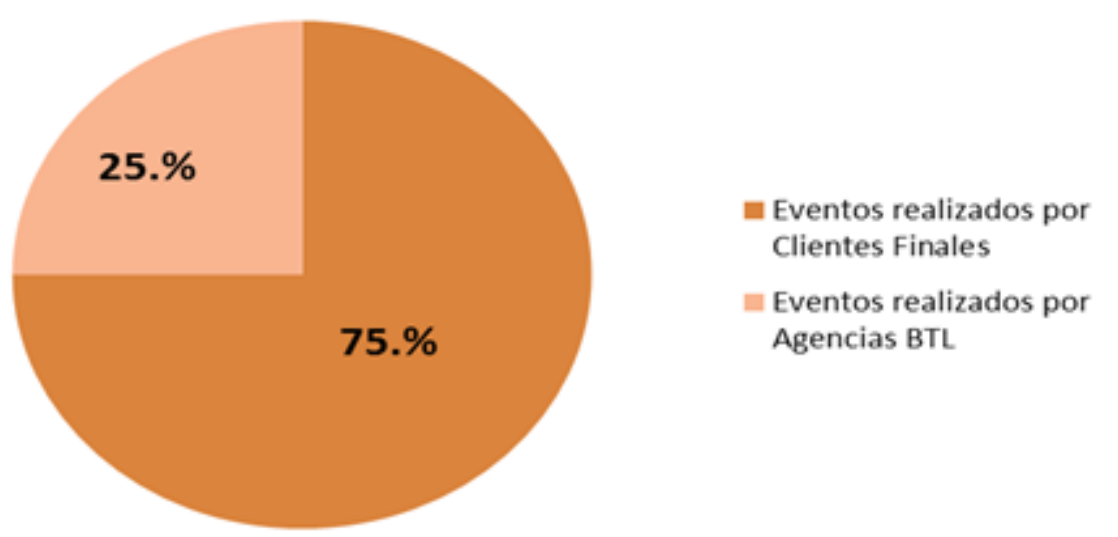

Fuente: Entrevista realizada a los directivos de la empresa Naranja Producciones S.A.C.. Anexo 1. Elaboración Propia.

Actualmente la empresa cuenta con los siguientes activos:

- Sistemas: 4 Laptop, 2 computadoras - Aprox. S/ 7,500

- Equipo de Sonido: 5 Consolas profesionales, 10 Parlantes, todo con su cableado respectivo, trípodes y demás. - Valor Aprox. S/ 6,000

- Camioneta pick up modelo 2016- S/ 47,125

- 1 Carrito Snack de Pop Corn - S/ 1,500

- 1 Carrito Snack de Algodón - S/ 1,200

- 1 carritos de hot dog - S/1,500

- 1 Carrito de panchos - S/1,200

- 1 carritos de helados - S/1,200

- 1 carritos de raspadillas - S/ 1,500 
- 1 carrito de chorizos - S/1,500

- 1 carrito de manzanas acarameladas - S/ 1,200

- Vestuários: 40 - S/ 5,500

- Muñecos: 40 - Aprox. S/ 7,000

- Stock en Decoración: Aprox. S/ 5,000

- 5 Camarás fotográficas - Aprox. S/1,500

- 1 Filmadora - Aprox. S/ 700

- Otros - Aprox. S/ 5,000

Por otra parte, cuenta con un amplio número de proveedores que los apoyan a la hora de llevar a cabo un evento. Entre estos proveedores tenemos:

- Toldos El Árabe.

- Belvedere Eventos.

- Cut \& Vector (gráfico).

- Feel Impresiones (Merchandasing).

- Perú Audiovisual de Dante Córdova (luces, cámaras, filmaciones, etc).

- Polka Producciones (audiovisual, trailers).

- Dulce Bocado (catering).

- Santa Creaciones (muñecos).

- Las Gemelas (trajes).

En el tema de los proveedores de locales, Naranja Producciones S.A.C., no ha ingresado a ese giro por el momento. Según lo conversado con el Directivo César Hugo Jaén Seminario, por lo general las empresas ya cuentan con el local o establecimiento para llevar a cabo la producción y realización de los shows y campañas BTL. Solo en una ocasión contrataron el local llamado Hacienda Monterrico.

Según lo conversado con los dueños de la empresa Naranja Producciones S.A.C., la mayor demanda de shows infantiles, eventos y campañas BTL es durante los meses de octubre, noviembre y diciembre, debido a que las empresas del sector público tratan de gastar el presupuesto asignado para este rubro para el año. La demanda baja durante los meses de enero, febrero y marzo, en comparación a los tres últimos meses del año, pero durante el verano, las campañas BTL que realizan las empresas privadas se trasladan a 
las playas del sur de la capital. Siendo el balneario de Asia, el lugar en donde se llevan a cabo el mayor número de campañas BTL, durante los tres meses de verano.

De los shows, eventos y campañas BTL realizados, el 95\% son contratos firmados en Lima y solamente el $5 \%$ de los contratos firmados son de clientes con sede en las provincias. Por otra parte, las provincias en donde Naranja Producciones S.A.C. tiene mayor demanda son las siguientes: Trujillo, Chiclayo, Piura, Arequipa y Cusco.

Cuando se realizan los shows y campañas BTL en provincia, el $90 \%$ del staff y de proveedores son de la localidad a realizar el evento, siendo sólo el $10 \%$ del staff y proveedores de Lima (básicamente supervisores y algunas animaciones puntuales). Se ha tomado esta decisión por motivos económicos, para no elevar los costos y por consiguiente, los precios a los clientes.

\subsection{Ciclo de vida del producto.}

En el libro Dirección de Marketing de Philips Kotler "La estrategia de diferenciación y posicionamiento debe cambiar conforme se modifican el producto, el mercado y los competidores a lo largo del ciclo de vida del producto..."3. Al decir que un producto o servicio tiene un ciclo de vida, es afirmar que los productos y servicios tienen una vida limitada, que el nivel de ventas de las empresas pasa por distintas etapas, que las utilidades pueden aumentar o disminuir en las diferentes etapas del ciclo de vida del producto o servicio de la empresa y que los productos y servicios necesitan diferentes estrategias de marketing, financieras, de productos y de personal en cada una de sus fases.

El ciclo de vida del producto o servicio tiene forma de campana. Esta curva se divide en cuatro fases o etapas, las cuales son: introducción, crecimiento, madurez y declinación, las cuales de explican a continuación:

- Introducción.- Se inicia durante el lanzamiento del producto o servicio al mercado. En esta fase el crecimiento de las ventas es lento y por tal motivo, las ganancias son pocas y la inversión es alta por el lanzamiento del producto o servicios.

\footnotetext{
${ }^{3}$ KOTLER, Philip. LANE KELLER, Kevin. Dirección de Marketing. 12ma ed. México DF.: Pearson Educación de México, 2006. P. 321-322.
} 
- Crecimiento.- En esta fase, el producto ya se hizo conocido y está en un proceso de aceptación por parte del público objetivo. Las ganancias aumentan, al incrementase las ventas.

- Madurez.- En esta fase, la mayoría del público objetivo ya ha aceptado el producto o servicios. Por tal motivo, las utilidades de la empresa se estabilizan o llegan a disminuir debido al aumento de la competencia.

- Declinación.- En esta última fase, las ventas tienen una tendencia a la baja y las utilidades son afectadas de manera contundente.

\section{Gráfico 2.2: Ciclo de vida del Producto}

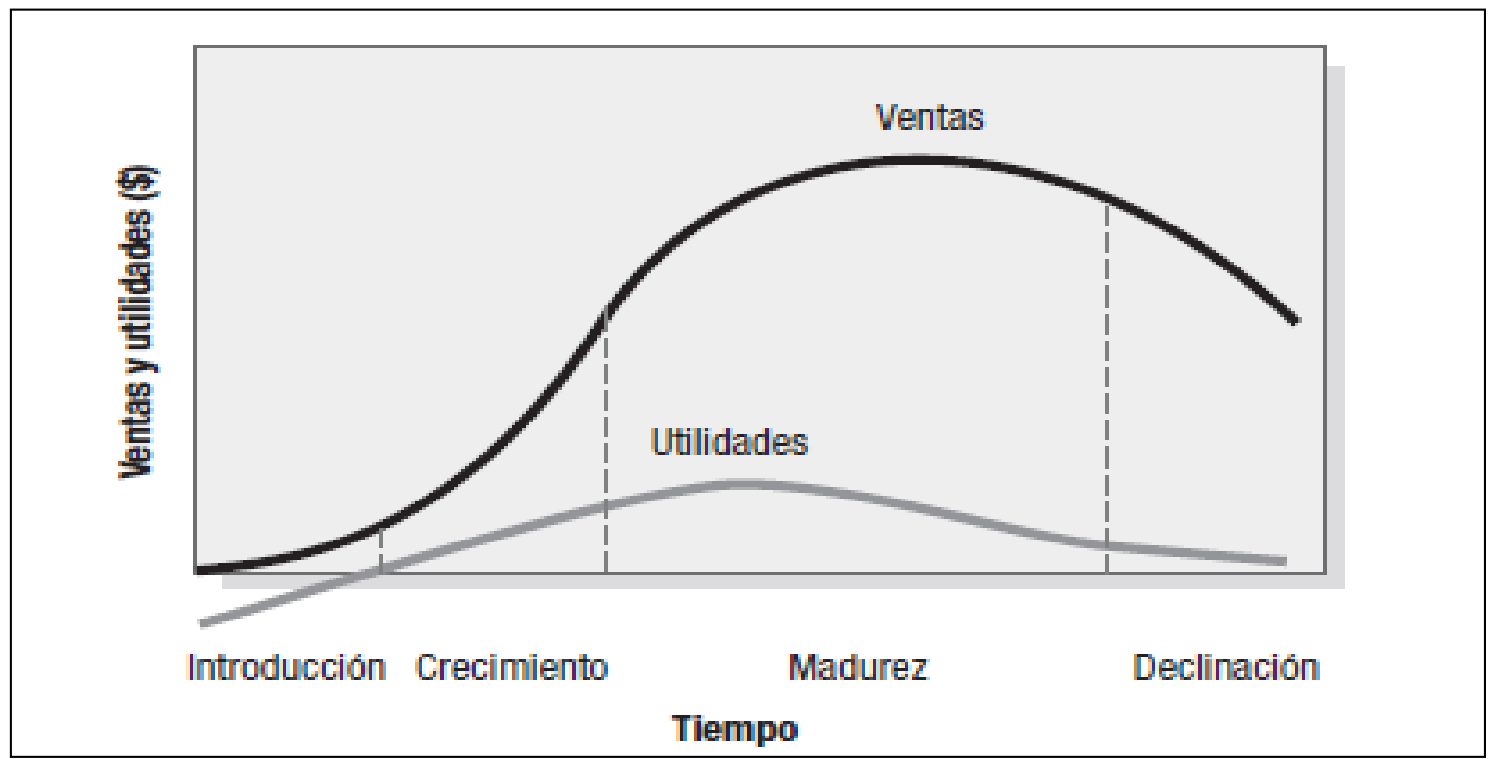

Fuente: KOTLER, Philip. LANE KELLER, Kevin. Dirección de Marketing. 12ma ed. México DF.: Pearson Educación de México, 2006. p. 321-322.

Al respecto, Rolando Arellano en su libro Marketing, Enfoque para América Latina, nos dice: "La marca sufre variaciones según la etapa del ciclo de vida del producto en que se encuentre..." 4 .

La interpretación de las cuatro fases del ciclo de vida, según lo mencionado por el autor Rolando Arellanos, es que durante la introducción del producto, las empresas buscan comunicar la descripción del producto y en posicionar la marca en la mente de los consumidores.

\footnotetext{
${ }^{4}$ ARELLANO, Rolando. Marketing, Enfoque para América Latina. 1er ed. México: Pearson autorización de México, 2010. p. 163.
} 
Durante la etapa de crecimiento, la marca se hace más conocida, lo cual colabora a que sea más aceptada por el público objetivo. Rolando Arellano afirma: “...la marca sirve como un importante elemento de diferenciación del producto en el mercado" 5 .

Respecto a la etapa de la madurez sostiene: "Los mayores esfuerzos de la empresa aquí son desplegados para evitar la copia o falsificación de la marca, así como para evitar su distorsión o utilización indebida dentro o fuera de la empresa"6.

Por último, respecto a la etapa de declinación, expresa: “...la empresa no insiste más en la utilización de su marca, puesto que ella no es más que una variable tomada en cuenta para la compra"7.

Analizando el ciclo de vida del producto, la empresa Naranja Producciones estuvo en la fase de introducción cuando lanzó al mercado su marca Castillo Mágico. Con este servicio, la empresa empezó a ser conocida en el mercado local. Posteriormente, ofreció los servicios de eventos y BTL bajo la empresa de Naranja Producciones S.A.C.., logrando conseguir una cartera de clientes tanto de empresas privadas como de instituciones públicas. Actualmente, la empresa se encuentra en la fase de crecimiento, debido a que según lo conversado con los dueños de la empresa, las ventas de los paquetes de servicios y el número de clientes se han incrementado constantemente. Al ser un segmento del mercado que poco a poco ha ido creciendo en el país, las empresas de BTL son requeridas para poder desarrollar conceptos y, de esta manera, incrementar las ventas de las empresas que contratan este servicio.

\footnotetext{
${ }^{5}$ ARELLANO, Rolando. Marketing, Enfoque para America latina. 1er ed. México: Pearson autorización de México, 2010. p. 164.

${ }^{6}$ ARELLANO, Rolando. Marketing, Enfoque para Americalatina. 1er ed. México: Pearson autorización de México, 2010. p.164.

${ }^{7}$ ARELLANO, Rolando. Marketing, Enfoque para Americalatina. 1er ed. México: Pearson autorización de México, 2010. p.164.
} 


\section{Gráfico 2.3: Ciclo de vida del Producto}

\section{Campañas BTL}

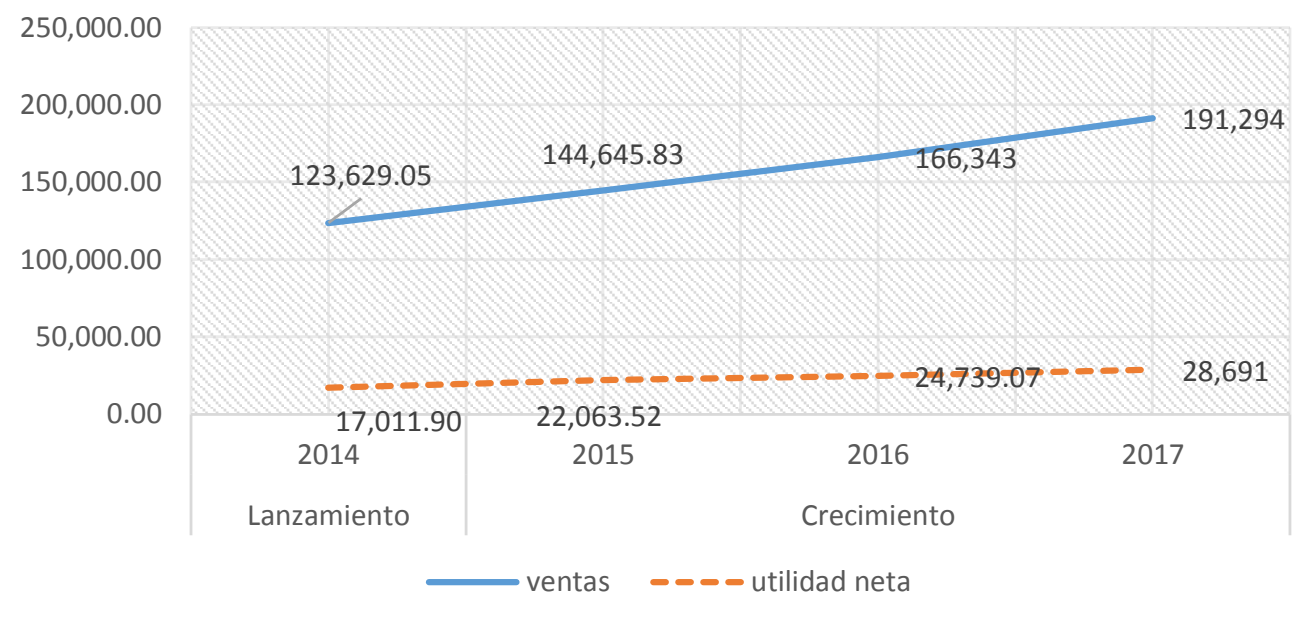

Elaboración propia.

Gráfico 2.4: Ciclo de vida del Producto

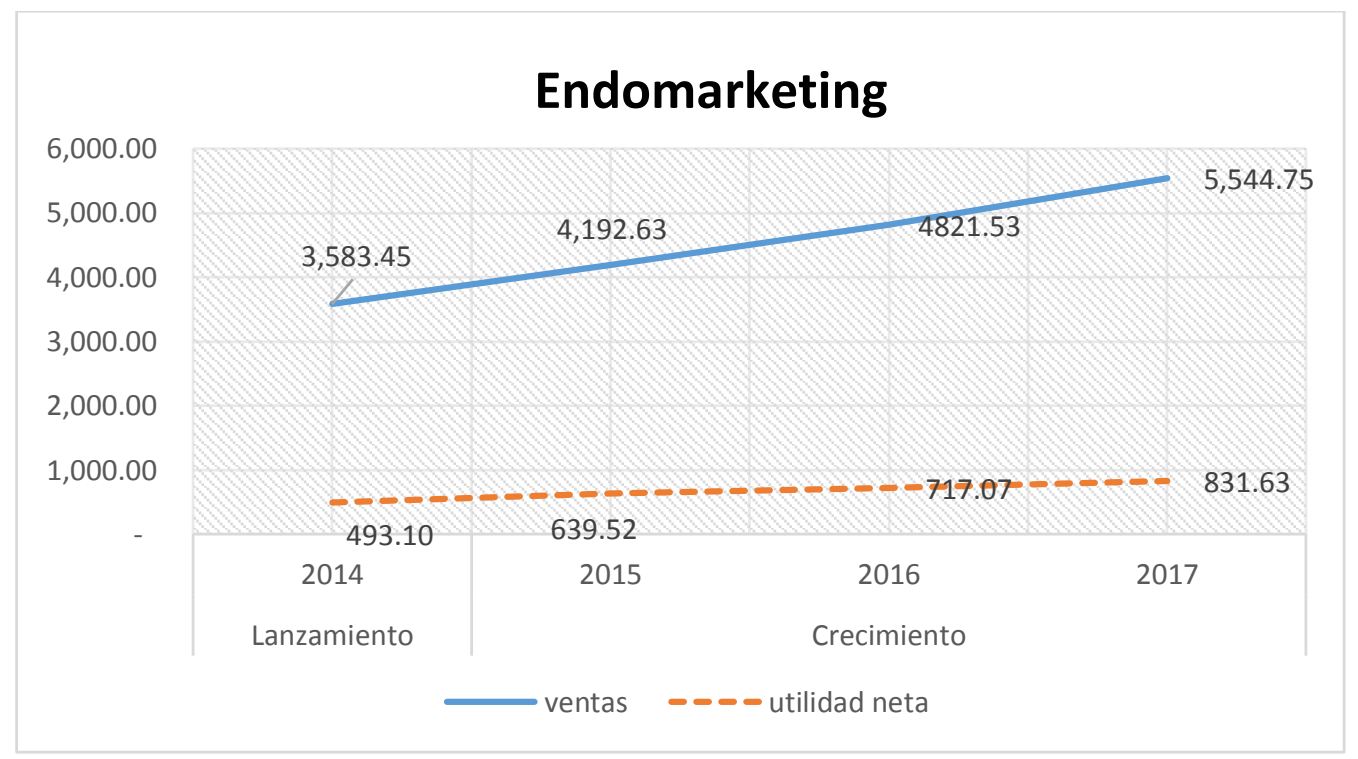

Elaboración propia. 
Gráfico 2.5: Ciclo de vida del Producto

\section{Eventos Corporativos}

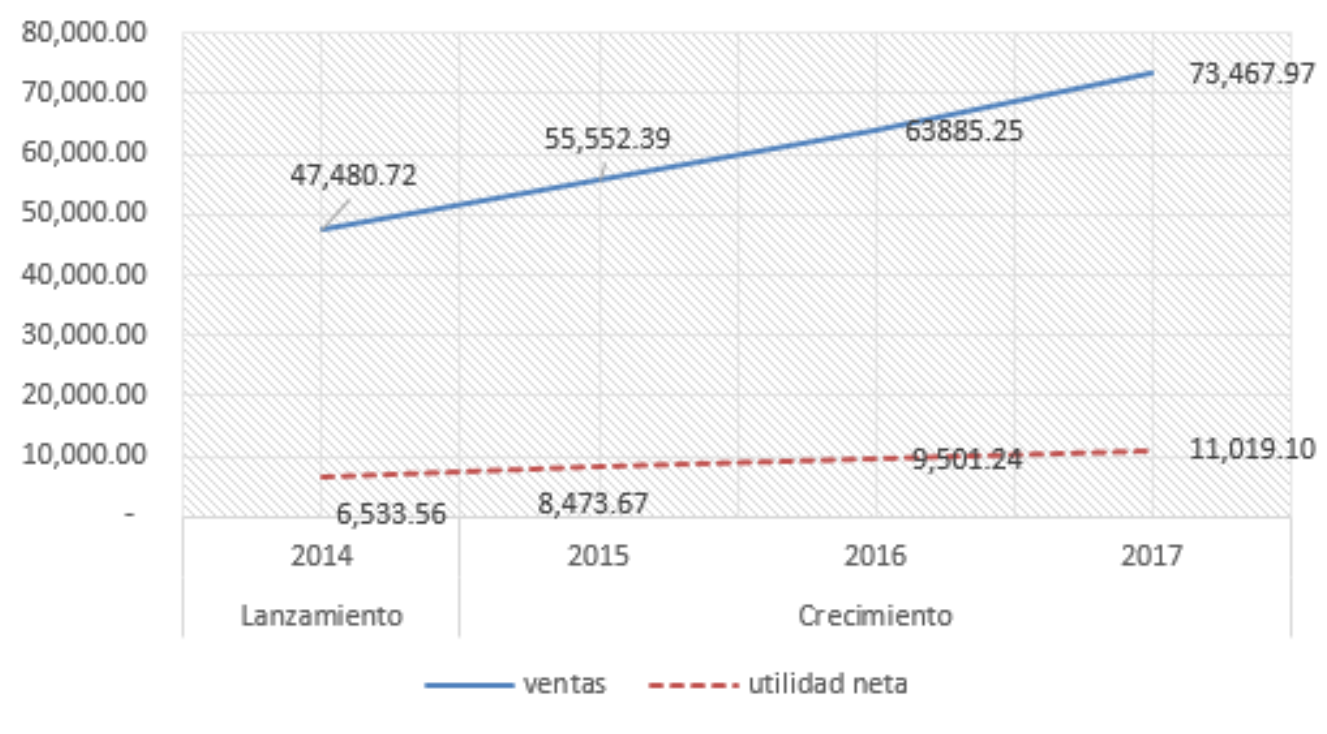

Elaboración propia.

Gráfico 2.6: Ciclo de vida de la marca

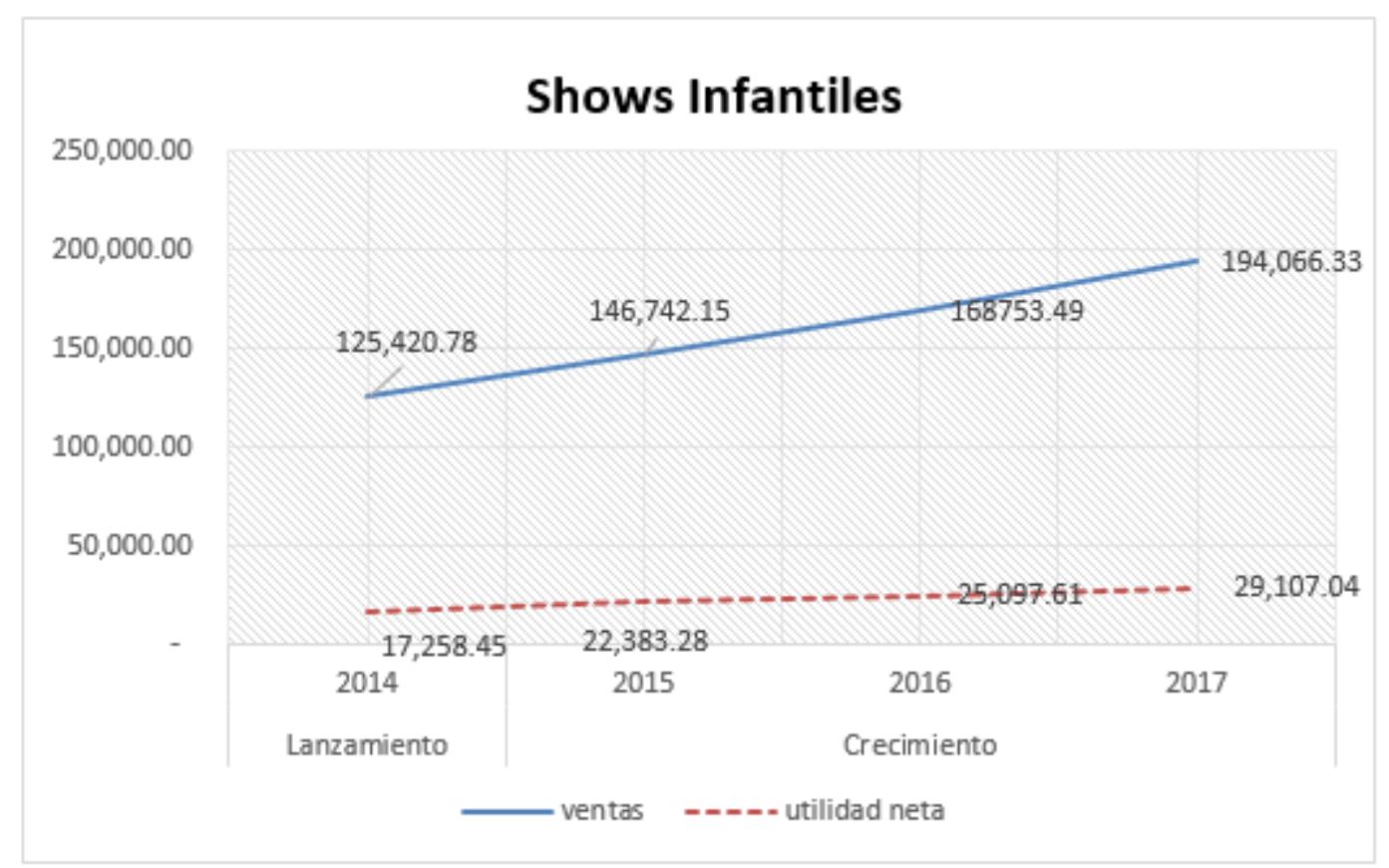

Elaboración propia. 


\subsection{Estructura organizacional actual de la empresa.}

La empresa Naranja Producciones S.A.C. cuenta con el siguiente organigrama:

Gráfico 2.7: Organigrama de la empresa Naranja Producciones S.A.C.

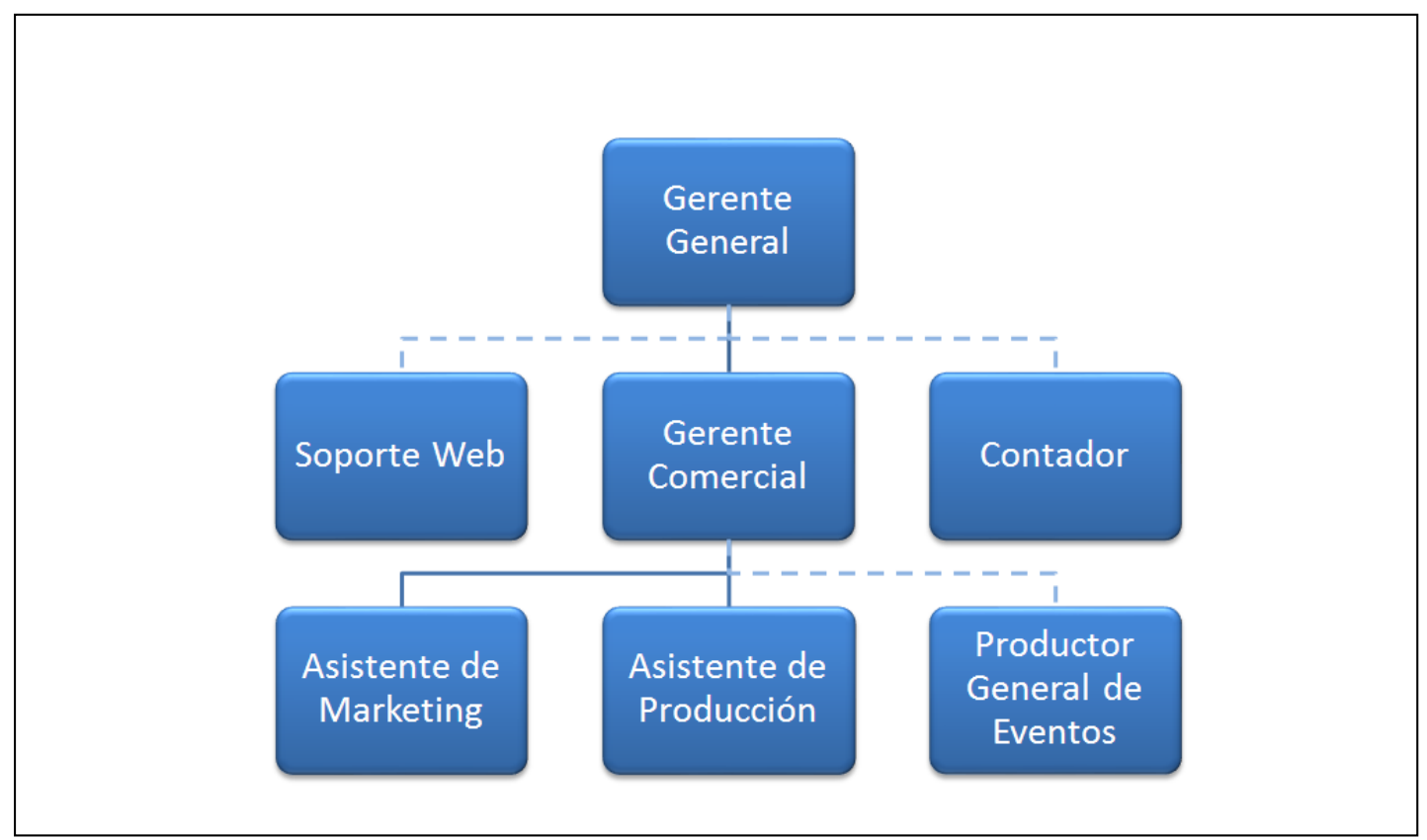

Fuente: Entrevista realizada a los directivos de Naranja Producciones Anexo 1.

Elaboracion propia.

- Gerente General: El cargo de Gerente General lo ejerce la señorita Sherylin Roman Orosco. Sus principales funciones son:

- Revisar semanalmente cómo se llevan las campañas y/o eventos a realizarse, para ello observa las grabaciones y las fotos de cada uno de los eventos. De esta manera, se busca que los servicios de la empresa cumplan con los requerimientos de los clientes.

- Revisar los contratos de las empresas, ya sean grandes o pequeñas, antes de firmar. Esto se debe porque los pagos se realizan a 45 días después de realizado el evento, por tal motivo, se busca que las fechas de pagos se cumplan.

- La contratación del personal nuevo para los eventos, lo ve la Gerente General junto al Gerente Comercial. Sin embargo, la Gerente General se encarga netamente de la vestimenta, la enseñanza de tres veces por semana de las coreografías y escoger a las chicas para los bailes.

- Es la responsable de la decisión de inversión de un nuevo activo en la empresa. 
- Se encarga de revisar los costos de cada uno de los proveedores, para saber si hay que aumentar los precios de los paquetes a ofrecer.

- Es responsable de las finanzas de la empresa, como también de la administración.

- Gerente Comercial: El cargo de Gerente Comercial, lo tiene el señor César Jaén Seminario. Sus principales funciones son:

- Responsable de cuentas corporativas y cuentas varias.

- Contactar a los proveedores y cerrar los contratos.

- Contactar a los clientes potenciales, visitarlos y cerrar el contrato ya supervisado por la Gerente General.

- Visitar la feria de publicidad anual.

- Agendar en su base de datos, los eventos corporativos; mientras que los eventos menores en la agenda del Asistente de Marketing.

- Actualizar las redes sociales de los últimos eventos realizados entre la semana.

- Llevar a los colaboradores y recogerlos de los distintos eventos junto con las vestimentas.

- Junto con el Gerente General, realizar compras conjuntas de la nueva vestimenta de los colaboradores, este dinero sale de la caja chica y solo lo ven los dos Gerentes.

- Productor General de eventos asociado: El cargo lo desempeña el señor Leonardo de la Cruz. Sus principales funciones son:

- Mano derecha del Gerente Comercial. Se asocia con Naranja Producciones S.A.C. para eventos más grandes y van $50 \%$ cada uno en las ganancias. Asimismo, se prestan los servicios de los proveedores, colaboradores, equipos de sonidos y decoración.

- Asistente de Marketing: El cargo lo desempeña el señor Jorge Seminario Nuñez. Sus principales funciones son:

- Realizar las cotizaciones para eventos menores y shows infantiles ya que también es la mano derecha del Gerente Comercial.

- Realizar visitas a los clientes de los shows menores, darles a conocer sus servicios y firmar con ellos los contratos.

- Agendar en la base de datos del Gerente Comercial los eventos por realizar.

- Supervisar los shows infantiles que tiene a cargo. 
- Si en un día, tienen 3 shows, el Asistente de Marketing tiene que también apoyar junto con el personal.

- Actualizar las redes sociales por las tardes, cuando el Gerente Comercial se encuentre fuera de oficina.

- Asistente de Producción: El cargo lo desempeña el señor José Luis Alvarado. Es estudiante de medicina, pero labora a medio tiempo en la empresa Naranja Producciones S.A.C. Sus principales funciones son:

- Llevar en la camioneta los equipos y las vestimentas.

- Llevar a los diferentes eventos a los colaboradores que ese día actúan.

- Contador: Es un trabajador independiente bajo la modalidad de recibos por honorarios. El cargo lo desempeña el señor Alex Otárola y sus principales funciones son:

- Llevar la parte contable de la empresa.

- Asesorar a los Gerentes en la parte contable.

- Gestionar las liquidaciones tributarias.

Durante las entrevistas realizadas ${ }^{8}$ a los directivos de la empresa Naranja Producciones S.A.C., se observa que no tienen un manual de funciones que reglamente las actividades de cada uno de los miembros del equipo. Tampoco un manual de funciones para el personal eventual que trabaja con ellos solamente durante la realizacion de los shows, eventos y campañas BTL, como son los modelos, anfitriones, bailarines, etc. Por otra parte, no cuentan con contratos de confidencialidad de su Know How o de sus estructura de costos, ya que anteriormente han sufrido un robo por parte de una de sus bailarinas, al no contar con el manejo adecuado de su informacion y por no contar con un contrato que estipule la confidencialidad de los elementos y conocimientos de la empresa.

Asimismo, la empresa no cuenta con personal especializado, por ejemplo, en el área de operaciones se tiene un estudiante de medicina, que no tiene nada que ver con las operaciones o logística de la empresa en los eventos.

De igual manera, no se cuenta con un área propia de creatividad, como sí lo tiene la competencia; en este punto todos los integrantes de la empresa dan su opinión para el

\footnotetext{
${ }^{8}$ Anexo I, Entrevista realizada a los Directivos de Naranja Producciones S.A.C..
} 
desarrollo de un nuevo programa o un gran evento. La opinión más creativa y rentable es la que se ejecuta.

Sobre los equipos, los gerentes han comprado una máquina de coser, con el fin de economizar la compra de nuevas vestimentas y corregir las imperfecciones de los vestuarios. Pero esta compra del activo es innecesario para la empresa, ya que no va acorde con el objetivo de la empresa; fue más bien, una pérdida de tiempo para los colaboradores porque no cuentan con una persona dedicada a coser todo el día, sino con un colaborador que en ese momento no está realizando otras tareas.

Sobre el ambiente de la oficina, comparten la mitad del departamento para atender a los clientes y la otra mitad para laborar. También se debe mencionar que la oficina no se encuentra ordenada, es decir, que muchas veces los equipos de audio y video que se utilizaron en un show intantil, evento o campaña de BTL del día anterior, se encuentra en el recibidor de la empresa, ocacionando que los clientes que llegen a la oficina, se percaten del desorden de la oficina.

Si hablamos del cuidado de las indumentarias, no cuentan con un personal único para el arreglo, limpieza u organización de los mismos ya que todos, al momento de finalizar los shows infantiles, eventos y campañs BTL, guardan en el almacén las indumentarias sin una correcta separación, pues al próximo evento a realizarse, los colaboradores que están libres se ponen a planchar, limpiar, lavar y ubicar donde se ha guardado el disfraz. Esta desorganización es muy perjudicial porque se pierde mucho tiempo en buscar y ver si se prestan equipos o vestimenta a su porductor de eventos asociados o, en todo caso, de realizar una nueva compra.

Una anécdota que comentaron los gerentes es que sufrieron un robo de información de la empresa de los últimos 2 años por parte de una de sus bailarinas, pues no contaban con el manejo adecuado de la informacion correspondiente y tampoco con un contrato que estipule la confidencialidad de los elementos y conocimientos de la empresa. Este hecho hace pensar que en un futuro podría suceder lo mismo con otros colaboradores.

Para finalizar, lo que se busca es que todos los colaboradores de la empresa se organicen y separen las tareas por área para no duplicar trabajos y evitar pérdidas en futuros eventos. 


\subsection{Situación de Mercado y Financiera actual de la Industria.}

En el mercado actual existen dos formas para realizar publicidad, estas son: ATL y BTL. El ATL son los medios masivos de comunicación como son la radio y la televisión, mientras que el BTL son todas las actividades que se realizan en el mismo punto de contacto, para poder comunicar la propuesta de valor a los clientes.

Para poder saber si el BTL ha crecido en los últimos años, debemos analizar que porcentaje del total del presupuesto de publicidad se le ha estado asignando al BTL.

En la entrevista realizada a Jorge Jara, Director de Operaciones BTL Trade de la agencia FCB Mayo por la InfoMarketing indicó que: “...en una reunión de la ANDA, se mencionó que los principales anunciantes destinaban casi un $50 \%$ de su presupuesto a acciones de BTL"9.

Por su parte, la señorita Desirée Taboada, Directora Comercial del Grupo Lucky dice que: “...señala que la inversión en BTL en el Perú ocupa un $40 \%$ del total de los presupuestos de marketing de las empresas, mientras el ATL alcanza un 60\%"10.

Por otro lado, Julio Centurión, Directivo de Shock MKT sostiene que “...según fuentes que estudian la inversión publicitaria, las empresas destinan al BTL solamente un $20 \%$ del presupuesto de marketing" ${ }^{11}$. A pesar que él no brinda un porcentaje muy alto a la inversión realizada por las empresas en BTL, lo que si afirma es que: "No se ha dado un crecimiento exponencial ni hubo un salto gigante. Se ha dado de a pocos, de menos a más"12.

El Jefe de Trade Marketing de Telefónica Móviles, Elmer Saavedra nos expresa que: “...la compañía asigna al BTL entre $40 \%$ y $45 \%$ de su presupuesto total en marketing"13. Lo mencionado nos demuestra que, las grandes compañías están invirtiendo parte importante de su presupuesto en campañas BTL. Además, el señor Elmer Saavedra

\footnotetext{
9 “EI BTL en Perú es un adolescente por S.A.C.ar su DNI". En: InfoMarketing. [en línea], PE, noviembre, 2014. [citado 10 noviembre 2014]. Disponible: http://www.infomarketing.pe/btl-int.php?id=4

10“Especial BTL: Haciendo Camino al andar". En: InfoMarketing. [en línea], PE, noviembre 2014. [citado 15 noviembre] Disponible: $h t t p: / / w w w . i n f o m a r k e t i n g . p e / b t l-i n t . p h p ? i d=8$

11 "Especial BTL: Haciendo Camino al andar". En: InfoMarketing. [en línea], PE, noviembre 2014. [citado 15 noviembre] Disponible: http://www.infomarketing.pe/btl-int.php?id=8

12 "Especial BTL: Haciendo Camino al andar". En: InfoMarketing. [en línea], PE, noviembre 2014. [citado 15 noviembre] Disponible: http://www.infomarketing.pe/btl-int.php?id=8

13 "Especial BTL: Haciendo Camino al andar". En: InfoMarketing. [en línea], PE, noviembre 2014. [citado 15 noviembre] Disponible: http://www.infomarketing.pe/btl-int.php?id=8
} 
nos comenta que hace tres años, el porcentaje invertido en BTL era sólo del $20 \%$ anual, lo cual nos indica que el crecimiento ha sido paulatino durante esos tres años.

Una opinión diferente tiene el señor Abraham Bravo, de Goma BTL pues expresa que: "Me atrevería a decir que están por encima del $75 \%$ de la torta de la publicidad" Según lo que explica, es que muchas empresas no invierten en ATL, porque estas empresas solo buscan un target especifico, como el caso de las mineras.

Aunque existen muchas diferencias entre los expertos sobre el porcentaje asignado al BTL dentro de las empresas, lo que sí se puede precisar es que este segmento de la publicidad está creciendo y teniendo una mayor participación dentro de los presupuesto de las empresas, a la hora de llevar a cabo estrategias de posicionamiento o de fidelización.

El crecimiento del sector publicitario en el Perú se ha incrementado en un $8 \%$ durante el 2013 en comparación al año anterior. La investigación de CPI concluye en que: "Las inversiones publicitarias durante el 2013 tuvieron un crecimiento similar al año 2012, de un $8 \%$ versus $11 \%$ respecto al $2012 \ldots . " 14$. Por otra, parte, durante el 2014 , el crecimiento de este sector fue menor, como lo indica Market Report de CPI 2014: "Es importante destacar que mientras el PBI crece 2,6\%, la inversión publicitaria se incrementa en 5,8\% respecto al 2013; es decir, el crecimiento publicitario ha sido el doble del crecimiento del PBI" ${ }^{15}$. A pesar que el crecimiento ha sido el doble, este ha sido menor que el 2013, el cual fue del 8\%. Además, en el Market Report de CPI 2015 nos indica que: "El 2015 no ha sido un buen año para la inversión publicitaria en nuestro país, puesto que la inversión bajó de 746 millones en el 2014 a 711 millones, es decir tuvo una merma de casi 5\%"16. En el tema de publicidad ha sido afectada por el bajo desempeño de nuestra economía de los últimos años. CPI nos dice que: "Vía pública, a pesar de algunos esfuerzos por renovar sus elementos, tales como mejores pantallas digitales y vallas con iluminación, también presenta una baja del $6 \%$ en sus inversiones" ${ }^{17}$.

\footnotetext{
${ }^{14}$ Boletín mensual Marketreport. [en línea]. Lima: Compañía Peruana de Estudios de Mercado y Opinión Pública (CPI). Enero 2014. [citado 12 octubre 2014]. Adobe Acrobat. Disponible en: http://www.cpi.pe/images/upload/paginaweb/archivo/26/MR_201401_01.pdf

${ }^{15}$ Boletín mensual Marketreport. [en línea]. Lima: Compañía Peruana de Estudios de Mercado y Opinión Pública (CPI). Enero 2015. [citado 27 junio 2016]. Adobe Acrobat. Disponible en: cpi.pe/banco/market-report.html

${ }^{16}$ Boletín mensual Marketreport. [en línea]. Lima: Compañía Peruana de Estudios de Mercado y Opinión Pública (CPI). Enero 2016. [citado 23 junio 2016]. Adobe Acrobat. Disponible en: cpi.pe/banco/market-report.html

${ }^{17}$ Boletín mensual Marketreport. [en línea]. Lima: Compañía Peruana de Estudios de Mercado y Opinión Pública (CPI). Enero 2016. [citado 23 junio 2016]. Adobe Acrobat. Disponible en: cpi.pe/banco/market-report.html
} 
Esta desaceleración económica ha llevado a que las empresas reduzcan su presupuesto en el sector publicitario. En la revista Mercado Negro se menciona que: "Esto ha generado la necesidad de reducir costos, y una de las áreas que se verá afectada dentro de las empresas será la de marketing y publicidad. Un reporte de CPI de enero de este año determinó que las inversiones publicitarias durante el 2014 cayeron en comparación al $2013(5.8 \% \text { versus } 8 \%)^{\prime \prime 18}$.

Por su parte, el señor José Domenack, nos dice en relación al crecimiento que el: “...Marketing BTL y Marketing en el punto de venta, en los que la variación podría ir de $15 \%$ a $20 \%$, en función del sector" 19 .

\footnotetext{
${ }^{18}$ Inversión publicitaria en el Perú cayó en un 8\%. [en línea]. Lima: Mercado Negro. Julio 2015. [citado 27 junio 2016]. Disponible en: cpi.pe/banco/market-report.htmlhttp://www.mercadonegro.pe/noticia/5638/inversin-publicitaria-en-el-per-cayen-un-8

19 ASENCIOS, Maritza. “Jorge Jara, gerente general de Periscopio: "Internet no es un medio alternativo, es el medio"”. En: Serperuano. [en línea] PE, noviembre 2014. [citado 05 diciembre 2014]. Disponible: http://www.serperuano.com/2013/06/empresas-peruanas-invertiran-mas-de-us-900-millones-en-servicios-de-marketing-ypublicidad-durante-2013/
} 


\section{Capítulo III}

\section{Formulación de la Visión, Misión y Valores de la Empresa}

En el presente capítulo daremos a conocer a detalle la visión, misión y valores de la empresa Naranja Producciones S.A.C.

\subsection{Visión}

\subsubsection{Visión actual de la empresa.}

Naranja Producciones S.A.C. expresa que tiene como visión: "Ser la mejor alternativa de comunicación y ejecución de eventos BTL para nuestros clientes”.

\subsubsection{Análisis de la visión actual}

La visión actual de la empresa no es clara y los colaboradores de la empresa no saben cuál es la visión actual que ha estado manejando Naranja Producciones S.A.C..

\section{Cuadro 3.1: Preguntas para analizar la visión actual}

\begin{tabular}{|l|l|}
\hline \multicolumn{2}{|c|}{ VISION ACTUAL } \\
\hline $\begin{array}{l}\text { "Ser la mejor alternativa de comunicación y ejecución de eventos BTL para } \\
\text { nuestros clientes". }\end{array}$ \\
\hline \multicolumn{2}{|c|}{ PREGUNTAS PARA FORMULAR LA VISION } \\
\hline $\begin{array}{l}\text { ¿Qué queremos llegar a ser en el } \\
\text { futuro? }\end{array}$ & $\begin{array}{l}\text { Ser la mejor alternativa de } \\
\text { comunicación y ejecución de BTL }\end{array}$ \\
\hline $\begin{array}{l}\text { ¿Qué resultado queremos alcanzar } \\
\text { en el futuro? }\end{array}$ & No se especifica \\
\hline $\begin{array}{l}\text { ¿Qué necesidad o beneficio } \\
\text { satisfago? }\end{array}$ & Desarrollar eventos BTL \\
\hline
\end{tabular}

Elaboración propia. 
Como se puede apreciar la empresa Naranja Producciones S.A.C. cumple con el primer punto, el cual es "que queremos llegar a ser en el futuro", pero en la siguiente pregunta la visión de la empresa no explica cuál es el resultado que desean satisfacer.

Por ello, se debería realizar una nueva visión integrando las tres preguntas sustanciales para que la empresa se vea reflejada en un futuro próximo. Una visión estable es la razón de la empresa, por ello a mayor participación de los integrantes, innovaciones y rentabilidad lograrán elevados niveles de compromiso y el éxito de Naranja Producciones S.A.C.

\subsubsection{Matriz de la visión propuesta para la empresa.}

La visión debe guiar a toda empresa en un cambio organizacional y mejoras para el buen funcionamiento tanto empresarial como social. En el Cuadro 3.2 se podrá apreciar la base para la formulación de la visión de la empresa.

\section{Cuadro 3.2: Análisis para formular la visión propuesta}

\section{PREGUNTAS PARA FORMULAR LA VISION}

\begin{tabular}{|l|l|l|}
\hline $\begin{array}{l}\text { ¿Qué queremos llegar a ser en el } \\
\text { futuro? }\end{array}$ & $\begin{array}{l}\text { Ser la mejor alternativa de comunicación y } \\
\text { ejecución de BTL }\end{array}$ \\
\hline $\begin{array}{l}\text { ¿Qué resultado queremos alcanzar } \\
\text { en el futuro? }\end{array}$ & $\begin{array}{l}\text { Posicionamiento, rentabilidad y } \\
\text { reconocimiento en el mercado nacional. }\end{array}$ \\
\hline $\begin{array}{l}\text { ¿Qué necesidad o beneficio } \\
\text { satisfago? }\end{array}$ & $\begin{array}{l}\text { La realización y producción de shows } \\
\text { infantiles y campañas BTL. }\end{array}$ \\
\hline
\end{tabular}

Elaboración propia.

El señor Fred R. David en su libro Administración Estratégica expresa: "Una declaración de la visión debe responder a la pregunta básica "¿qué queremos llegar a ser?...20".

${ }^{20}$ DAVID, Fred R. . (2003) Concepto de Administración Estratégica. 9na ed. México D.F.: Pearson Educación de México. P. 56. 
Por otra parte, el señor Fred R. David en su libro Administración Estratégica no dice: "La declaración de la visión debe ser corta, formada de preferencia por una oración y desarrollada por tantos gerentes como sea posible"21.

Asimismo, se debe tener una visión a largo plazo que busque identificar las actividades claves de todas las áreas de la empresa. Para lograr que todos los miembros de la empresa adopten una visión real y acorde a sus ideales, el señor Peter Senge dice que: "La visión es una imagen futura que deseamos, la visión es compartida, la visión compartida no es una idea y que la visión es infinita" ${ }^{22}$.

Se puede concluir que la visión describirá cómo será la realidad cuando se llegue ahí, teniendo el presente como puente para construir el futuro deseado, que todos son participantes en la creación de la visión, que la visión impone poder, sentimiento de identificación y compromiso de todos los colaboradores y que, cuando la visión haya logrado la primera meta, ya se está preparando el futuro para lograr más metas. Este punto es un proceso largo y de constante cambio, en el que se busca que todas las personas que lo integran vayan adoptando la visión como parte del trabajo diario.

\subsubsection{Visión propuesta.}

La visión propuesta para Naranja Producciones S.A.C. después de expresar varios puntos para el mejoramiento de la empresa, es la siguiente:

\section{Cuadro 3.3: Declaración de la visión}

\section{DECLARACIÓN DE LA VISIÓN}

"Ser reconocidos a nivel nacional como una empresa líder en la realización y producción de campañas BTL, brindando una solución creativa a los clientes".

\section{Elaboración propia.}

${ }^{21}$ DAVID, Fred R. . (2003) Concepto de Administración Estratégica. 9na ed. México D.F.: Pearson Educación de MéxicoP. 56.

${ }^{22}$ KAITEN, Juan Carlos. Importancia de la Visión y Misión dentro de las organizaciones. En: revista mensual de Contaduría Pública, Instituto Mexicano de Contadores Públicos. [en línea]. México D.F.: abr., 2007. [citado 12 octubre 2014]. p.20. Adobe Acorbat. Disponible en: http://spip.imcp.org.mx/spip.php?article1587 


\subsection{Misión}

A continuación, detallaremos la misión de la empresa Naranja Producciones S.A.C.

\subsubsection{Misión actual de la empresa}

"Ser líderes en el desarrollo de soluciones integrales de comunicaciones publicitarias, transformando las necesidades de nuestros clientes en ideas exitosas y conceptos creativos, efectivos e impactantes para colaborar, superar con éxito sus metas y objetivos trazados"

\subsubsection{Análisis de la misión actual}

A continuación se analizará la misión de la empresa Naranja Producciones S.A.C. para saber si cumple con los criterios sugeridos por Fred R. David en su libro Administración Estratégica.

Cuadro 3.4: Análisis de la misión actual

\begin{tabular}{|c|c|}
\hline \multicolumn{2}{|c|}{ PREGUNTAS PARA FORMULAR UNA MISIÓN } \\
\hline ¿Cuál es mi producto? & Comunicaciones publicitarias. \\
\hline ¿Quién es mi cliente? & $\begin{array}{l}\text { Todas las empresas privadas y públicas que } \\
\text { necesiten realizar shows o campañas BTL. }\end{array}$ \\
\hline $\begin{array}{l}\text { ¿Qué necesidad o beneficio } \\
\text { satisfago? }\end{array}$ & No especifica \\
\hline ¿Qué beneficio satisfago? & Producción de shows y campañas BTL \\
\hline $\begin{array}{l}\text { ¿Cómo satisfago la necesidad } \\
\text { o beneficio? }\end{array}$ & $\begin{array}{l}\text { Realizando de manera creativa shows infantiles y } \\
\text { campañas BTL }\end{array}$ \\
\hline ¿Con qué tecnología & No se especifica \\
\hline ¿Cuál es el insumo principal? & $\begin{array}{l}\text { La creación de la campaña BTL y shows, banners, } \\
\text { brochures, contratación de modelos, anfitriones, } \\
\text { bailarines, actores, catering }\end{array}$ \\
\hline $\begin{array}{l}\text { ¿Qué valores son } \\
\text { importantes? }\end{array}$ & $\begin{array}{l}\text { Servicio, Responsabilidad, Trabajo en equipo, } \\
\text { Transparencia, Innovación y motivación. }\end{array}$ \\
\hline ¿Por qué lo hacemos? & Rentabilidad \\
\hline
\end{tabular}




\section{DECLARACIÓN DE LA MISIÓN}

"Ser líderes en el desarrollo de soluciones integrales de comunicaciones publicitarias, transformando las necesidades de nuestros clientes en ideas exitosas y conceptos creativos, efectivos e impactantes para colaborar, superar con éxito sus metas y objetivos trazados".

\section{Elaboración propia.}

La Misión actual de la empresa se asemeja más a una visión que a una misión. La actual Misión no cumple la visión de ser la razón de la empresa ni lo que desea llegar a ser en el futuro.

La misión de Naranja Producciones S.A.C. está omitiendo algunos temas importantes. El servicio que se ofrece en la misión no está claro porque, al decir "comunicaciones publicitarias" la empresa no específica el servicio o servicios que realmente ofrece, siendo muy genérico. Haciendo que los clientes tengan una percepción errada de los servicios que realmente ofrece la empresa. Por otra parte, la necesidad o el beneficio que satisface tampoco se especifica con claridad. Por último, tampoco la tecnología a emplear es mencionada en la misión de la empresa, lo cual no deja claro que elementos se van a emplear durante la realización y producciones de los shows y campañas BTL.

\subsubsection{Elementos de la misión propuesta para la empresa}

El señor Fred R. David no dice que: “...la misión, denominada en ocasiones una declaración del credo"23, ya que es la declaración de creencias, filosofías y principios de negocios.

Por otra parte, en el libro Concepto de Administración Estratégica el señor Fred R. David dice: "La misión de una empresa es el fundamento de prioridades, estrategias, planes y tareas; es el punto de partida para el diseño de trabajos de gerencia y, sobre todo, para el diseño de estructuras de dirección."24.

\footnotetext{
${ }^{23}$ DAVID, Fred R. (2003) Concepto de Administración Estratégica. 9na ed. México D.F.: Pearson Educación de México. p. 59

${ }^{24}$ DAVID, Fred R. . (2003) Concepto de Administración Estratégica. 9na ed. México D.F.: Pearson Educación de México. p. 59
} 
El libro Concepto de Administración Estratégica del señor Fred R. David dice que: “... recomiendan que las empresas elaboren con esmero una declaración de la misión por escrito para: Garantizar la unanimidad del propósito dentro de la empresa, proporcionar una base para distribuir los recursos de la empresa, Establecer un carácter general o ambiente corporativo, servir como punto central para que los colaboradores se identifiquen con el propósito y la dirección de la empresa, facilitar la traducción de objetivos en una estructura laboral que incluya la asignación de tareas por área, especificar los propósitos de la empresa y traducirlos en objetivos" 25 .

Por otro lado, los componentes de una declaración de misión que nos según Fred R. David en su libro Concepto de Administración Estratégica son: "clientes, producto o servicio, mercados, tecnología, Interés en la supervivencia, el crecimiento y la rentabilidad, filosofía, concepto propio, Preocupación por la imagen pública e interés en los empleados" 26. Utilizando estos componentes, podemos desarrollar la misión de la empresa Naranja Producciones S.A.C.:

\section{Formulación de la Misión}

En el Cuadro 3.5 se contestarán cada una de las preguntas sugeridas por Fred R. David en su libro Administración Estratégica para elaborar una Misión.

\footnotetext{
${ }^{25}$ DAVID, Fred R. . (2003) Concepto de Administración Estratégica. 9na ed. México D.F.: Pearson Educación de México. p. 61-62.

${ }^{26}$ DAVID, Fred R. . (2003) Concepto de Administración Estratégica. 9na ed. México D.F.: Pearson Educación de México. p. 99
} 
Cuadro 3.5: Análisis para formular la misión propuesta

\begin{tabular}{|c|c|}
\hline \multicolumn{2}{|c|}{ PREGUNTAS PARA FORMULAR UNA MISIÓN } \\
\hline ¿Cuál es mi producto? & Realización y producción de Shows y campañas BTL \\
\hline ¿Quién es mi cliente? & $\begin{array}{l}\text { Todas las empresas privadas y públicas que } \\
\text { necesiten realizar shows o campañas BTL. }\end{array}$ \\
\hline $\begin{array}{l}\text { ¿Qué necesidad o beneficio } \\
\text { satisfago? }\end{array}$ & $\begin{array}{l}\text { Entretenimiento, lanzamiento, fidelización de } \\
\text { productos y servicios al mercado. }\end{array}$ \\
\hline ¿Qué beneficio satisfago? & Producción de shows y campañas BTL \\
\hline $\begin{array}{ll}\text { ¿Cómo satisfago la } \\
\text { necesidad o beneficio? }\end{array}$ & $\begin{array}{l}\text { Realizando de manera creativa shows y campañas } \\
\text { BTL }\end{array}$ \\
\hline ¿Con qué tecnología & $\begin{array}{l}\text { Equipos audio-visuales y de comunicación } \\
\text { tecnológica, impresiones digitales de materiales } \\
\text { publicitarios. }\end{array}$ \\
\hline ¿Cuál es el insumo principal? & $\begin{array}{l}\text { La creación de la campaña BTL y shows, banners, } \\
\text { brochures, contratación de modelos, anfitriones, } \\
\text { bailarines, actores, catering, trajes, disfraces y juegos } \\
\text { dinámicos. }\end{array}$ \\
\hline $\begin{array}{l}\text { ¿Qué valores son } \\
\text { importantes? }\end{array}$ & $\begin{array}{l}\text { Servicio, Responsabilidad, Trabajo en equipo, } \\
\text { Transparencia, Innovación y motivación. }\end{array}$ \\
\hline ¿Por qué lo hacemos? & Rentabilidad \\
\hline
\end{tabular}

Se refuerza el servicio que la empresa ofrece a los clientes, haciendo que éste sea más claro y especifico. Resaltando que, la empresa se dedica a la realización y producción de shows y campañas BTL. Por otra parte, se considera el entretenimiento, lanzamientos y fidelización de productos y servicios al mercado como el beneficio que la empresa brinda a los clientes. Además, se refuerza el tema de la tecnología como soporte de la empresa, a la hora de llevar a cabo los shows y campañas BTL. Estos elementos tecnológicos son de alta gama, de fácil manejo y de menor tamaño para poder trasladarlo a diferentes puntos del país.

Por último, se resaltan los valores que rigen a la empresa, debido a que estos son los que orientan el comportamiento de cada uno de los colaboradores de Naranja Producciones S.A.C. cuando realizan y producen los shows y campañas BTL. 


\subsubsection{Misión propuesta}

Después de analizar cada una de las preguntas para formular una Misión se ha desarrollado la siguiente propuesta:

Cuadro 3.6: Declaración de la misión

\section{DECLARACIÓN DE LA MISIÓN}

Brindar un servicio de campañas BTL de manera creativa y personalizada, logrando el éxito de los productos y servicios a lanzar para satisfacer las necesidades de nuestros clientes, con el soporte de un equipo de profesionales de alto nivel creativo.

\section{Elaboración propia.}

\subsection{Valores}

A continuación explicaremos los valores de la empresa Naranja Producciones S.A.C..

\subsubsection{Valores actuales de la empresa}

Los valores actuales de Naranja Producciones S.A.C. son:

a. Compromiso: Mantener una postura responsable y ética que contribuyan a una mejor sociedad, con nuestro trabajo de calidad, acciones concretas y claras.

b. Creatividad: Buscar la innovación continua y resolución de problemas en forma no convencionales de todas las áreas y actividades de nuestro trabajo otorgado.

c. Eficiencia: Cumplir con todos los objetivos planteados en cada proyecto con calidad y tiempos establecidos.

d. Motivación: Escuchamos sus necesidades, ofrecemos nuestro esfuerzo y experiencia y aportamos las mejores soluciones.

e. Respeto: Valoramos a las marcas y sus productos a tal grado que nos consideramos parte de los equipos de las empresas con las que trabajamos. Tratamos a las personas involucradas en nuestro negocio con dignidad y consideración. 


\subsubsection{Análisis de los valores actuales}

Los valores actuales propuestos por Naranja Producciones S.A.C. fueron realizados en sus actividades diarias, ya que requieren lineamientos para una convivencia armoniosa entre todas las áreas. Sin embargo, hay que tener en cuenta que existen más valores que engloban tanto a la misión como a la visión.

\subsubsection{Elementos de los valores propuestos para la empresa}

Los valores empresariales son elementos de gran importancia para la cultura organizacional de la empresa. Ellos determinan los principios fundamentes de las labores diarias de los colaboradores, ya que estos últimos transmiten a los clientes las futuras creencias empresariales.

Los valores son los principios básicos para accionar dentro de una organización, ya que así se logran los objetivos de la misión. Para establecer los valores se deben desarrollar dos puntos importantes:

a. Competitividad: analizar los valores que reflejan la competitividad de la empresa, ya que este valor tiene que ser transmitido a los colaboradores para que se vea reflejado en el servicio brindado.

b. Convivencia: analizar los valores que rigen en la organización para asegurar la sana convivencia entre los miembros de la organización.

\subsubsection{Valores propuestos.}

Para Naranja Producciones S.A.C. Ios nuevos valores propuestos serían:

a. Servicio: Tener la mejor predisposición a la hora de apoyar a los demás.

b. Responsabilidad: Ser la empresa que da los servicios con lo concordado en el contrato.

c. Trabajo en equipo: Garantizar que los colaboradores multiplican logros.

d. Transparencia: Es el valor por el cual se actúa bajo solidos principios. Es ser honesto y transparente en cada una de sus acciones.

e. Innovación: buscar nuevas alternativas para las necesidades de los clientes.

f. Motivación: Deseo de buscar nuevos retos y desafíos para crecer en todos los aspectos de la vida. 


\subsection{Alineamiento estratégico de la Visión, Misión y Valores de la empresa.}

Para ser un resumen de este capítulo, se tendrá presente los 3 datos importantes para la formación exitosa de la empresa Naranja Producciones S.A.C. a lo largo de su futura trayectoria.

\section{Cuadro 3.7: Alineación estratégica de la visión, misión y valores}

\begin{tabular}{|c|c|c|}
\hline Visión & Misión & Valores \\
\hline $\begin{array}{l}\text { Ser reconocidos a } \\
\text { nivel nacional como } \\
\text { una nueva alternativa } \\
\text { de publicidad, } \\
\text { brindando una } \\
\text { solución creativa a los } \\
\text { clientes. }\end{array}$ & $\begin{array}{l}\text { La empresa brinda soluciones } \\
\text { integrales de comunicación } \\
\text { publicitaria, transformado las } \\
\text { necesidades de sus clientes en } \\
\text { conceptos reales, creativos y } \\
\text { efectivos, facilitando el desarrollo } \\
\text { profesional e innovador de sus } \\
\text { colaboradores y el desarrollo } \\
\text { sostenido del país. }\end{array}$ & $\begin{array}{l}\text { Responsabilidad } \\
\text { Trabajo en equipo } \\
\text { Transparencia } \\
\text { Innovación } \\
\text { Motivación }\end{array}$ \\
\hline
\end{tabular}

Elaboración propia.

Consideramos que, cada uno de los seis valores que se propone a la empresa Naranja Producciones S.A.C. la ayudará a conseguir su misión. De esta manera, el valor del servicio es estar predispuesto a colaborar con todo el equipo para brindar un servicio óptimo; la responsabilidad es cumplir con la promesa que la empresa brinda; el trabajo en equipo busca que cada uno de sus miembros se apoye y colabore para lograr la promesa al cliente; la transparencia se refiere a la honestidad en todo sentido; la innovación es ser siempre creativos para buscar soluciones a las necesidades de los clientes; la motivación es el impulso que cada miembro necesita para lograr los objetivos. De esta manera, lograrán la misión de la empresa.

Por otra parte, la misión que se propone a la empresa cuenta con los aspectos que creemos colaborará para conseguir la visión. Debido a que la misión significa lo que es la empresa en el presente y como su accionar les permitirá conseguir lo que ellos desean ser en el futuro, es decir, su visión.

La visión de la empresa se conseguirá al transformar las necesidades de los clientes en conceptos reales, creativos y efectivos en campañas de comunicación integral para 
poder satisfacer a sus consumidores. Por tal motivo, consideramos que la empresa al brindar soluciones integrales y creativas, con el apoyo de un equipo innovador y motivado, logrará su visión. 


\section{Capítulo IV}

\section{Análisis Externo}

En el presente capítulo explicaremos el análisis externo que se realizó a la empresa Naranja Producciones S.A.C.

\subsection{Tendencias de las variables del entorno}

A continuación detallaremos las tendencias de las variables del entorno que afectan a la empresa Naranja Producciones S.A.C., muchas de ellas influenciadas por el cambio en la política de gobierno de nuestro nuevo presidente de la República Martín Alberto Vizcarra Cornejo quien sucediera en el cargo el 23 de marzo de 2018 al ex presidente Pedro Pablo Kuczynski Godard, luego de casi 20 meses de gobierno.

El presidente Martín Vizcarra señaló en su discurso de juramentación al cargo las siguientes prioridades en su gobierno: Lucha contra la corrupción, la educación, la estabilidad institucional y la recuperación de la gobernabilidad.

\subsubsection{Análisis Político-Gubernamental}

Con la finalidad de tomar la información de primera mano con respecto a los acontecimientos nacionales, se ha tomado como referencia la información obtenida de la Sala de Prensa e Imagen Institucional de la Presidencia del Consejo de Ministros (PCM) en la cual se han realizado varios anuncios, principalmente, a través del presidente de la PCM, César Villanueva.

Entre todos los anuncios informados por el gobierno en los últimos meses, vamos a poner mayor énfasis a las que están orientadas a reactivar la economía nacional, a brindarnos mayor seguridad a la ciudadanía, y a la inestabilidad política que se vive entre el poder Ejecutivo y Legislativo. 


\section{a) Medidas para reactivar la economía nacional}

En lo que respecta a las políticas tomadas por el gobierno en los últimos meses con la finalidad de fomentar la reactivación económica nacional, podemos hacer mención a las siguientes noticias:

"El presidente del Consejo de Ministros, César Villanueva Arévalo, junto con el titular del Ministerio de Economía y Finanzas, David Tuesta, recibió hoy a la misión para Perú del Fondo Monetario Internacional (FMI), la cual expresó su respaldo a las recientes medidas fiscales adoptadas por el Gobierno, como la modificación de las tasas del Impuesto Selectivo al Consumo (ISC) y la mejora en la administración del gasto."27

El presidente de la República, Martín Vizcarra, informó que el Consejo de Ministros aprobó el decreto de urgencia Nro. 006-2018 con medidas para reactivar la economía peruana, donde se incluye la transferencia de aproximadamente $S / 6,200$ millones para financiar proyectos de gobiernos regionales y locales, asimismo señaló: “...En estos dos meses ya he recorrido más de la mitad de las regiones del país; de costa, de sierra y de selva; del norte, del centro y del sur del país. He constatado, una vez más, las grandes necesidades que tiene nuestra población......Se están transfiriendo más de $S /$ 1,300 millones para proyectos de educación, S/ 230 millones para proyectos de agricultura y S/ 1,094 millones para proyectos de salud. Para proyectos de vivienda y saneamiento se han transferido cerca de $\mathrm{S} / 1,400$ millones principalmente a municipios; mientras que otros $\mathrm{S} /$ 1,800 millones serán para la construcción y mantenimiento de carreteras.". ${ }^{28}$

El presidente del Consejo de Ministros, César Villanueva indico en el Muni Ejecutivo que se realizó en Arequipa junto a ministros de Estado y alcaldes provinciales y distritales de esta región: “...Un total de 919 millones de soles transfirió el Gobierno para Arequipa este año, lo cual incluye recursos para los municipios, el gobierno regional y lo asignado a los ministerios, que se están invirtiendo en sectores estratégicos, como transportes, salud, agricultura...." “...Hablamos de cosas concretas, en particular de recursos transferidos para invertirlos en la región. En este 2018, del presupuesto regular, el Gobierno nacional transfirió a los gobiernos locales 297 millones de soles para 81 proyectos y al gobierno

\footnotetext{
${ }^{27}$ Presidencia del Consejo de Ministros, artículo de la Sala de Prensa e Imagen Institucional de la PCM (2018, 21 de mayo) Misión del FMI respalda medidas fiscales del Gobierno [www.pcm.gob.pe]. Recuperado de: http://www.pcm.gob.pe/2018/05/mision-del-fmi-respalda-medidas-fiscales-del-gobierno/

${ }_{28}$ Redacción, (2018, 23 de mayo). Gobierno aprueba decreto de urgencia para reactivar la economía peruana [Gestion.pe] Recuperado de: https://gestion.pe/economia/gobierno-aprueba-decreto-urgencia-reactivar-economia-peruana-234270
} 
regional 289 millones de soles para 68 proyectos....." “...Además, se tiene lo que se ha asignado a los ministerios, 333 millones de soles, para 35 proyectos, todo lo cual suma 919 millones de soles..."29

\section{b) Medidas en materia de seguridad nacional}

En relación al punto de vista de seguridad, indicamos que ante el incremento de los actos delictivos debido a la escasa presencia policial, aumentando en consecuencia la sensación de inseguridad en la población, el gobierno a dictado las siguientes medidas:

El titular del Ministerio del Interior, Mauro Guimaraes, durante una reunión de con autoridades regionales y locales de Lima señaló que se pondría en marcha el plan Cuadrante Seguro, indicando: "Necesitamos el compromiso de todas las autoridades para hacer eficaz este plan. De esta manera, no solo será más efectivo el patrullaje integrado, sino también se hará más visible la presencia policial, se ofrecerá una pronta respuesta a los vecinos y mejorará la relación de confianza con la ciudadanía... Abordaron el funcionamiento y puesta en marcha de la estrategia multisectorial Barrio Seguro implementada en Barranca- y se informó sobre los próximos lanzamientos en Paramonga, Pativilca y Huaral....También coordinaron acciones inmediatas como el envío de más policías para reforzar las acciones contra la delincuencia común por medio del patrullaje a pie y motorizado, y la delincuencia organizada, a través de un equipo especial que verá los casos de extorsiones, falsos sindicatos y tráfico de tierras.". 30

El presidente de la República, Martín Vizcarra, en su primer discurso presidencial por 28 de julio, anunció que su Gobierno aprobará una serie de medidas en materias de seguridad y defensa nacional: “...Pondremos todo nuestro esfuerzo para perseguir, capturar y poner en disposición de la justicia a quienes actúen al margen de la ley... Asimismo, se fortalecerá la estrategia multisectorial para la prevención social del crimen y la violencia, denominada "Barrio Seguro" (del Ministerio del Interior), en territorios con altos índices de criminalidad. Este plan aprobado en marzo del 2017, se concibió para ejecutarse en coordinación con la Policía Nacional del Perú, los gobiernos regionales y locales.... En

\footnotetext{
${ }^{29}$ Presidencia del Consejo de Ministros, artículo de la Sala de Prensa e Imagen Institucional de la PCM, (2018, 22 de mayo). César Villanueva: Transferimos 919 millones de soles para Arequipa en el 2018 [www.pcm.gob.pe] Recuperado de: http://www.pcm.gob.pe/2018/06/cesar-villanueva-transferimos-919-millones-de-soles-para-arequipa-en-el-2018/

30 El Peruano, diario oficial. (2018, 21 de mayo). Fortalecerán la seguridad ciudadana en región Lima [www.elperuano.pe]. Recuperado de: https://elperuano.pe/noticia-fortaleceran-seguridad-ciudadana-region-lima-66500.aspx
} 
solo estos 120 días hemos puesto en funcionamiento 17 Barrios Seguros y, en los próximos dos meses, estaremos inaugurando 11 Barrios Seguros adicionales. Nuestra meta es contar con 120 barrios seguros para el 2021 ... También indicó la estrategia en la lucha contra los remanentes del terrorismo en la zona del Vraem... Con respecto a la prevención de desastres anunció que en el 2021 estará implementado el Sistema de Alerta Temprana (SAT) para prevenir posibles tsunamis, así como el nuevo Centro de Operaciones de Emergencia Nacional (COEN), que realizará un monitoreo de emergencias y oportuna protección y atención de las personas afectadas por emergencias o desastres." ${ }^{31}$

El ministro del Interior, Mauro Medina Guimaraes, presentó el concurso Mi Comisaría, mi Orgullo, el cual busca reconocer y premiar las iniciativas policiales más innovadoras para brindar una atención de calidad a la ciudadanía, el mismo que es organizado por el Ministerio del Interior, el Banco Interbank y la Policía Nacional del Perú (PNP). El concurso constituye una de las medidas impulsadas por el Ministerio del Interior para orientar la política de atención en las dependencias de todo el país, hacia una gestión de calidad enfocada en la satisfacción de la ciudadanía. "Este concurso es importante porque trata de estimular una buena capacidad de gestión y la atención en las comisarías". ${ }^{32}$

\section{c) Inestabilidad política interna}

La inestabilidad política interna ha sido generada por la fricción existente entre los poderes Ejecutivo, Legislativo y Judicial del Estado Peruano, fruto de ello, la economía interna no ha despegado como se tenía planificado y no hemos llegado a los indicadores proyectados, tal como se puede apreciar en los siguientes artículos:

Tal como lo indica Roque Benavides Ganoza en su artículo Conexiones ESAN "Los peruanos hemos visto con preocupación una pugna entre los poderes Ejecutivo y Legislativo. Se pudo alcanzar un punto intermedio sin llegar al extremo del juego fuerte. Ambos lados han cometido errores que llevaron a una situación de inestabilidad política que no favorece el desarrollo económico. El nuevo gabinete tiene el reto de concertar con la oposición. En el sector empresarial hay preocupación por la situación de inestabilidad

\footnotetext{
${ }^{31}$ El Comercio, Redacción. (2018, 29 de julio). Estas son las claves en materia de seguridad ciudadana y defensa nacional [www.elcomercio.pe]. Recuperado de: https://elcomercio.pe/peru/martin-vizcarra-son-propuestas-seguridad-defensa-noticia540983

${ }_{32}$ Ministerio del Interior, Oficina General de Comunicación Social e Imagen Institucional (2017, 17 de agosto). Mi Comisaría, Mi Orgullo. [www.conasec.mininter.gob.pe]. Recuperado de: http://conasec.mininter.gob.pe/notas.php?id=595
} 
que se ha presentado recientemente. Hay que entender que la estabilidad política y la estabilidad económica son los dos pilares que permiten a los países crecer y generar bienestar para su población. El Perú ha construido columnas en las cuales se basa su desarrollo económico. Ellas son los tratados de libre comercio, el grado de inversión, la Alianza del Pacífico y un Banco Central de Reserva (BCR) absolutamente independiente. Creo que el futuro económico del Perú está relativamente seguro. No obstante, con dichas columnas podemos crecer entre $3 \%$ y $4 \%$; pero necesitamos crecer a un ritmo mucho mayor. Si los poderes Ejecutivo y Legislativo van a seguir cometiendo estos errores, el resultado será mayor inestabilidad política, lo cual retrasará el crecimiento económico" ${ }^{33}$

\subsubsection{Análisis Económico}

Naranja Producciones S.A.C., se ve influencia por los factores económicos de nuestro país. En el artículo periodístico publicado en el Diario El Comercio ${ }^{34}$, el analista para el Perú de la Unidad de Inteligencia de The Economist, Abhijit Surya, redujo la proyección del crecimiento del PBI para el 2018 a un rango entre 3\% y 3.5\%. Este menor crecimiento económico es percibido por el consumidor, haciendo que gaste menos dinero durante la compra, para resguardarse de los acontecimientos menos favorables que se puedan presentar en el futuro.

El analista Abhijit Surya indicó que: "Estaremos revisando nuestra proyección de crecimiento del PBI del Perú para el 2018 a un rango de entre $3 \%$ y $3.5 \%$, desde un nivel actual de 4\%, por el ruido político (pedido de renuncia y vacancia presidencial)..."35. El analista para el Perú explicó: “...que este recorte en la proyección de la actividad económica peruana para el próximo año se debe a que esperan que los enfrentamientos entre el Ejecutivo y el Congreso empeoren, lo cual no dejará avanzar la aprobación de la legislación necesaria para el crecimiento de la economía ${ }^{36}$.

\footnotetext{
${ }^{33}$ Artículo en la p'gina web de Conexiones ESAN (en línea), 18 de setiembre de 2017. Disponible: https://www.esan.edu.pe/conexion/bloggers/el-blog-de-roque/2017/09/la-inestabilidad-politica-no-favorece-el-crecimientodel-peru/

${ }^{34}$ The Economist, artículo en el Diario El Comercio, articulo en Semana Económica. (en línea), 19 de diciembre de 2017. Disponible: https://elcomercio.pe/economia/peru/the-economist-baja-proyeccion-pbi-2018-ruido-politico-noticia-482587

${ }^{35}$ The Economist, artículo en el Diario El Comercio, articulo en Semana Económica. (en línea), 19 de diciembre de 2017. Disponible: https://elcomercio.pe/economia/peru/the-economist-baja-proyeccion-pbi-2018-ruido-politico-noticia-482587

36 INEI, artículo en el Diario El Comercio. (en línea), lunes 15 de febrero 2016 . Disponible: http://elcomercio.pe/economia/peru/increible-diciembre-hace-crecer-pbi-326-2015-noticia-1879017
} 
Por otra parte, el Banco Mundial: “...mantuvo su previsión de crecimiento económico del PBI del Perú en 3.8\% para el 2018, cifra más baja que los estimados del Banco Central de Reserva (BCR) y el Ministerio de Economía y Finanzas (MEF), en 4.2\% y $4 \%$, respectivamente. No obstante, el estimado del Banco Mundial está en línea con el del Fondo Monetario Internacional (FMI). El organismo multilateral también elevó ligeramente su proyección para el 2019 de 3.6\% a 3.8\%."37. Además, el Banco Mundial prevé: “...pronostica un crecimiento económico de 2.0\% para América Latina y el Caribe en el 2018, menor en 0.1 unidades al proyectado en junio pasado. El resultado se explica principalmente por el estimado de PBI de Venezuela, que este año caería $4.2 \%$, tres puntos porcentuales menos que lo proyectado previamente por el organismo. De manera adversa, la economía que más crecería este año sería la de Panamá (5.6\%), seguida de República Dominicana (4.9\%) y Nicaragua (4.4\%)" ${ }^{38}$.

En el siguiente cuadro se puede observar que el BCRP ha realizado un comparativo de las expectativas del crecimiento del PBI. Se puede apreciar que el sistema financiero estima un PBI al 28 de febrero del 2018 del 3.7\%, mientras los analistas económicos y empresas no financieras, estiman un $\mathrm{PBI}$ del $3.8 \%$ y $3.5 \%$ respectivamente.

\section{Cuadro 4.1: Desarrollo del PBI del Perú durante el 2018 BCRP}

\begin{tabular}{|c|c|c|c|}
\hline \multicolumn{4}{|c|}{ Encuesta de Expectativas Macroeconómicas del PBI 1/ } \\
\hline $\begin{array}{l}\text { Fecha } \\
\text { de encuesta }\end{array}$ & $\begin{array}{c}\text { Analistas } \\
\text { Económicos }\end{array}$ & $\begin{array}{c}\text { Sistema } \\
\text { Financiero }\end{array}$ & $\begin{array}{c}\text { Empresas } \\
\text { No Financieras }\end{array}$ \\
\hline 31 de enero de 2018 & $4.0 \%$ & $3.8 \%$ & $4.0 \%$ \\
\hline 28 de febrero de 2018 & $3.8 \%$ & $3.7 \%$ & $3.5 \%$ \\
\hline \multirow{2}{*}{$\begin{array}{l}\text { Expectativas anuales de } 2019 \\
28 \text { de febrero de } 2018\end{array}$} & & & \\
\hline & $4.0 \%$ & $4.0 \%$ & $4.0 \%$ \\
\hline \multicolumn{4}{|l|}{ Expectativas anuales de 2020} \\
\hline \multirow{2}{*}{$\begin{array}{l}28 \text { de febrero de } 2018 \\
28 \text { de marzo de } 2018\end{array}$} & $4.0 \%$ & $4.0 \%$ & $4.0 \%$ \\
\hline & $4.0 \%$ & $3.7 \%$ & $4.0 \%$ \\
\hline
\end{tabular}

Fuente: Encuesta de expectativas macroeconómicas BCRP.

Elaboración: Departamento de Indicadores de Actividad Económica.

37 Banco Mundial, artículo en Semana Económica. (en línea), martes 09 de enero 2018. Disponible: http://semanaeconomica.com/article/economia/macroeconomia/261938-banco-mundial-mantuvo-estimado-en-el-2018-pbidel-peru-creceria-3-8-este-ano/

38 Banco Mundial, artículo en Semana Económica. (en línea), martes 09 de enero 2018. Disponible: http://semanaeconomica.com/article/economia/macroeconomia/261938-banco-mundial-mantuvo-estimado-en-el-2018-pbidel-peru-creceria-3-8-este-ano/ 
Cuadro 4.2Desarrollo del PBI del Perú del 2018 al 2021 MEF

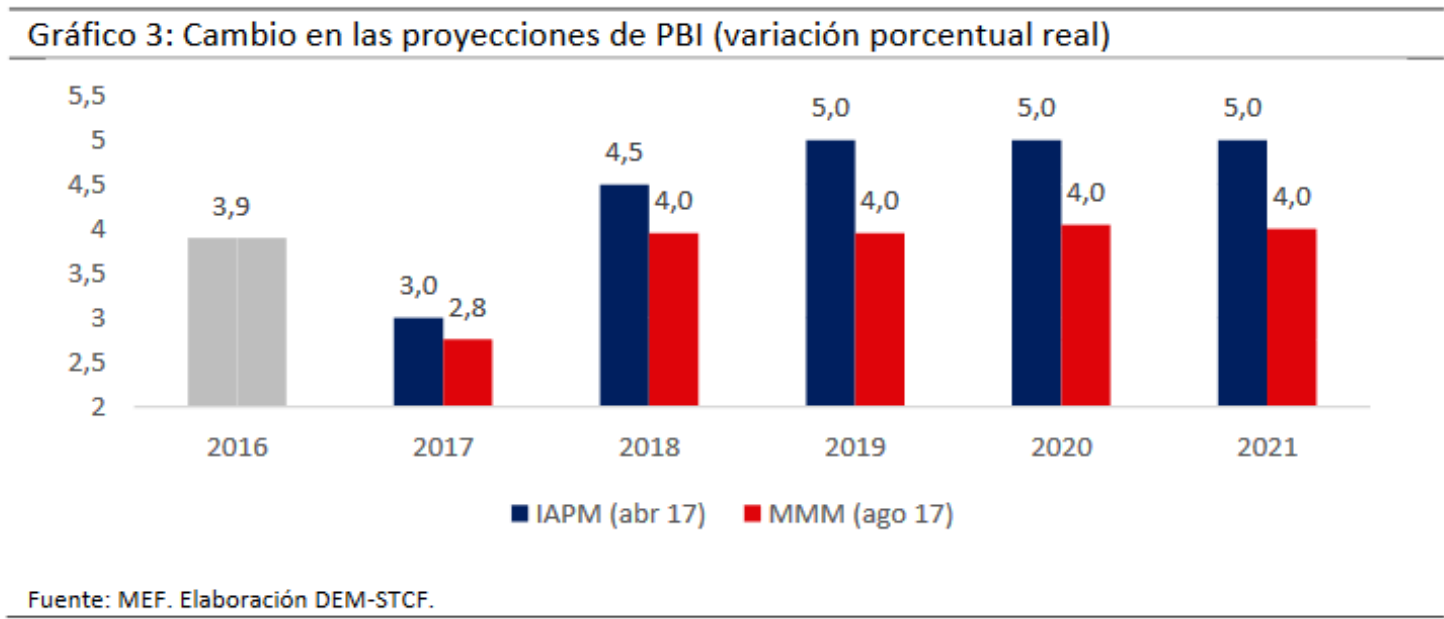

Fuente: Encuesta de expectativas macroeconómicas BCRP.

Elaboración: Departamento de Indicadores de Actividad Económica.

Cuadro 4.3Desarrollo de la Inflación del Perú durante el 2018

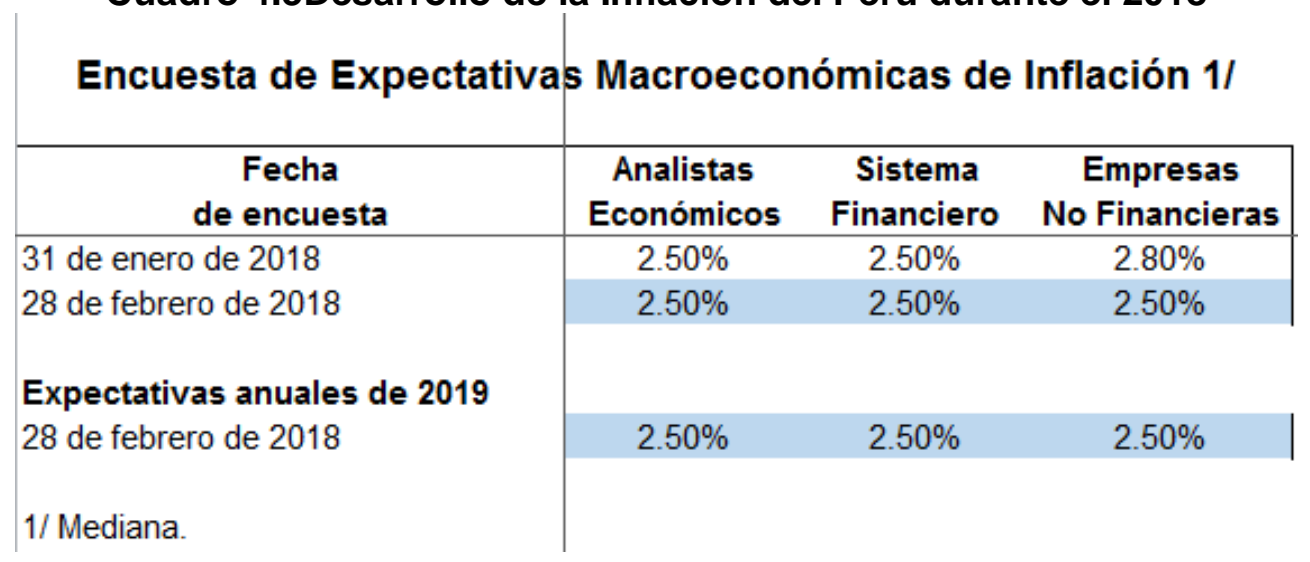

Fuente: Encuesta de expectativas macroeconómicas BCRP.

Elaboración: Departamento de Indicadores de Actividad Económica.

Por otra parte, Pulso Perú ha realizado un estudio en donde se puede apreciar que la percepción de que la economía del Perú no está mejorando, se ha incrementado en 5\%, mientras que si está mejorando ha disminuido en $1 \%$ y que no sabe, no opina a disminuido en $4 \%$. La percepción de que la economía no estará mejor en el Perú, ha tenido un crecimiento del $45 \%$ al $50 \%$ en los últimos 12 meses. 


\section{Gráfico 4.1: El nivel de percepción en la economía nacional}

\section{Cambios en la economia del pais}

En su opinión, ¿la economía del pais se está recuperando o no se está recuperando?

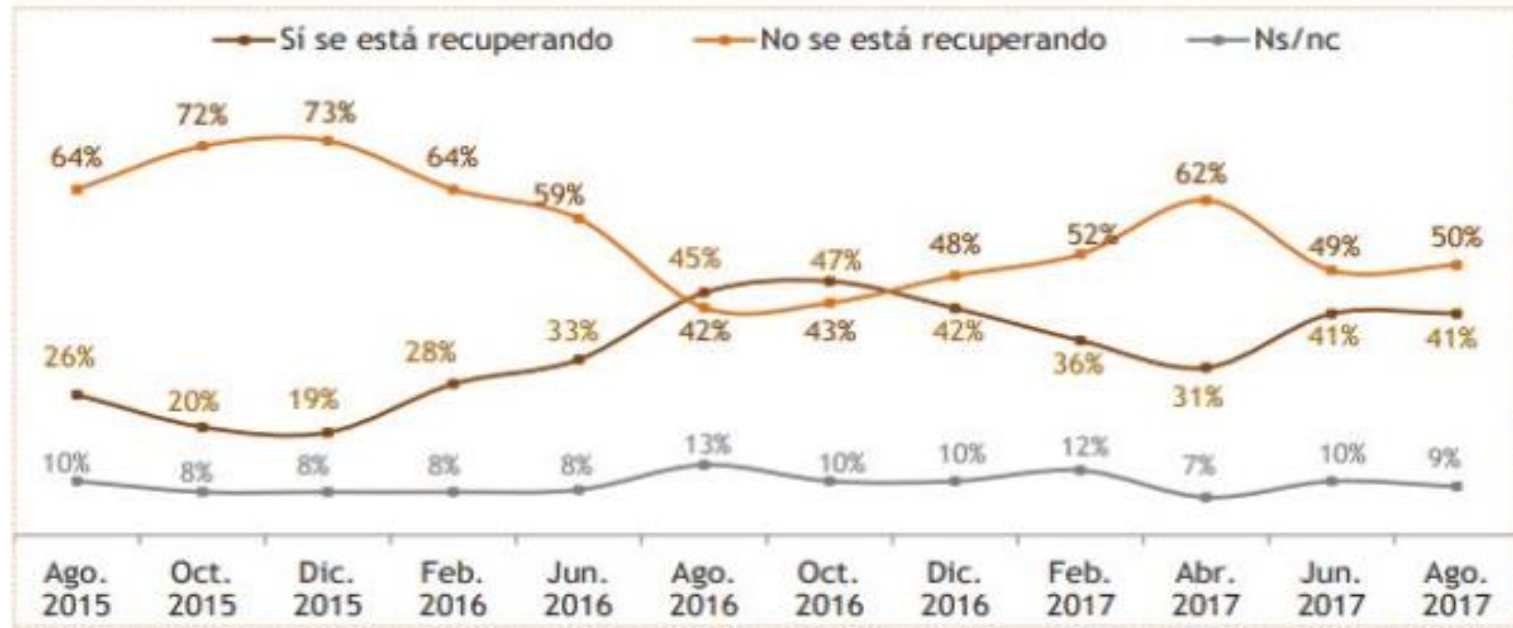

Fuente: "El $58 \%$ de los peruanos cree que será más difícil encontrar trabajo en los próximos 12 meses". En: Perú 21. [En línea] PE, martes, 20 de febrero del 2018. (Citado 20 de febrero del 2018) Disponible: https://peru21.pe/economia/pulso-peru-58-peruanos-cree-sera-dificil-encontrar-proximos-12-meses-1-239074

Por otra parte, Pulso Perú sostiene: "Asimismo, el 71\% de peruanos sostiene que sus ingresos no le alcanzan para satisfacer sus necesidades..."39. Esta percepción está ligada a que la población no cree que la economía del país mejore. Por tal motivo, consideran que sus ingresos no les van a permitir satisfacer sus necesidades. Esto puede afectar el consumo nacional y por ende contraer la oferta por parte de las empresas, lo cual podría afectar la inversión en las campañas de publicidad en general.

El índice de confianza del consumidor para Lima Metropolitana durante el mes de enero del 2018 se ha recuperado como lo indica Apoyo Consultoría: "El indicador que mide la expectativa de las familias sobre el futuro de su situación económica se ubicó en terreno optimista al cerrar en 52 puntos en enero, tres puntos por encima del resultado de diciembre" 40 . Además, el estudio de Apoyo indica que: “...son las perspectivas de empleo en los niveles socioeconómicos (NSE) C y D, que se desempeñan principalmente en la construcción. Este sector engloba "un gran puñado de esperanza este año" por el desarrollo de infraestructura, como obras públicas en general y los avances en proyectos

\footnotetext{
${ }^{39}$ Pulso Perú, artículo en el Diario Perú 21. (en línea), lunes 20 de febrero 2018. Disponiblehttps://peru21.pe/economia/pulsoperu-58-peruanos-cree-sera-dificil-encontrar-proximos-12-meses-1-239074

40 Apoyo Consultoría, articulo en Diario El Comercio (en línea), sábado, 27 de enero del 2018. Disponible: https://elcomercio.pe/economia/recupera-confianza-consumidor-enero-noticia-492496
} 
relacionados con los Juegos Panamericanos 2019"41. Por otra parte, este incremento de la confianza del consumidor se extiende al NSE como lo indica la consultora: "De hecho, casi el $60 \%$ de los hogares espera que su situación económica mejore en los próximos 12 meses, el mayor porcentaje registrado desde enero del año pasado..."42.

Por otra parte, en el último índice internacional realizado por YPO Global Pulse indicó que: “...El Perú encabeza el ránking de confianza económica en Latinoamérica...”33. Este crecimiento se debe porque: “...los directores entrevistados percibieron un escenario más favorable en relación a la encuesta anterior. Con ello, se dio un incremento de 2.5 puntos en la confianza económica del país, la cual ascendió a 69.3 puntos y lo convirtió en el líder de la región” ${ }^{44}$. Además, a pesar de la situación política actual de los EEUU: “...el $55 \%$ de los encuestados pronosticaron que el clima económico y comercial mejorará en la región en los próximos seis meses. Mientras tanto, el $21 \%$ espera que el panorama económico se deteriore durante la primera mitad de este año" 45.

El crecimiento de la inversión privada en el mercado nacional afecta directamente a las empresas dedicadas al BTL. No es de extrañarse que las campañas realizadas por las empresas de BTL se lleven a cabo cerca de los puntos de mayor dinamismo comercial en el Perú. Según la Cámara de Comercio de Lima. ${ }^{46}$ Sostiene que las ventas en los centros comerciales crecerán entre el $6 \%$ y el $9 \%$ el 2018. Además, entre los años 2017 y 2018, el país contará con 9 centros comerciales nuevos. Según lo informado por el señor José Cabanillas, presidente del Gremio de Retail y Distribución, el: "crecimiento del sector también se debe a que las personas están haciendo mayor turismo en país, visitando restaurantes, comprando souvenirs y ropa en retailers peruanos, a esto se suma las aperturas de nuevos centros comerciales. Los restaurantes y farmacias son negocios que más está creciendo actualmente, por otro lado, los negocios de ropa están detenidos por la coyuntura política y económica que vive el país, ya que al no haber inversión la compra

\footnotetext{
41 Apoyo Consultoría, articulo en Diario El Comercio (en línea), sábado, 27 de octubre del 2016. Disponible https://elcomercio.pe/economia/recupera-confianza-consumidor-enero-noticia-492496

42 Apoyo Consultoría, articulo en Diario El Comercio (en línea), sábado, 27 de octubre del 2016. Disponible: https://elcomercio.pe/economia/recupera-confianza-consumidor-enero-noticia-492496

43 YPO Global Pulse, articulo en Diario Perú 21 (en línea), miércoles, 08 de febrero de 2017. Disponible: http://peru21.pe/economia/peru-encabeza-ranking-confianza-region-2270179

44 YPO Global Pulse, articulo en Diario Perú 21 (en línea), miércoles, 08 de febrero de 2017. Disponible: http://peru21.pe/economia/peru-encabeza-ranking-confianza-region-2270179

45 YPO Global Pulse, articulo en Diario Perú 21 (en línea), miércoles, 08 de febrero de 2017. Disponible: http://peru21.pe/economia/peru-encabeza-ranking-confianza-region-2270179

${ }^{46}$ Mercado Negro, (en línea), 28 de marzo 2018. Disponible: http://www.mercadonegro.pe/crecimiento-del-retail-en-el-peru/
} 
de indumentaria ha disminuido ente 10\% a 15\%"47. Además el señor José Cabanillas, indico que: "el país experimenta nuevas tendencias de retail, por ejemplo la incursión y crecimiento de las tiendas de conveniencia con marcas que vienen posicionándose a nivel nacional, también ya vemos estrategias de crecimiento inorgánico con compras de cadenas de farmacias que incluso traen también con ellas tiendas de conveniencia, de la misma manera compra de cadenas de grifos, creciendo de manera inorgánica consolidándose con más tiendas en estaciones de servicio"48.

El Departamento de Estudios Económicos (DEE) de Scotiabank nos dice que: "estima que el tipo de cambio seguirá la tendencia descendente mostrada desde mediados de noviembre. Así, el precio del dólar cerrará en S/3,18 a fines del 2018"49. Por otra parte, Hugo Perea, Gerente de Estudios Economicos del BBVA Research nos indica que: "El tipo de cambio tendrá una tendencia al alza y fluctuaría entre los $\mathrm{S} / 3.25$ y los $\mathrm{S} / 3.30 \ldots$... Como se puede apreciar, hay opiniones divididas en relacion al futuro del tipo de cambio. En el caso de Naranja Producciones S.A.C. la empresa cobra en soles y no adquiere deudas en dólares.

Otro factor determinante en la economia peruana ha sido el caso por corrupción de la empresa Odebrecht, el cual esta afectando el crecimiento de la economia nacional, debido a que el Estado peruano ha paralizado varias obras de gran importancia para el país, por este caso de corrupción que ha envuelto a la politica de America Latina y del Mundo. Julio Velarde, presidente del Banco Central de la Reserva (BCR), indico que: “...el impacto que tendrá el escándalo de corrupción que envuelve a la constructora brasileña Odebrecht restaría entre 0,5\% a 0,6\% al Producto Bruto Interno (PBI) del país" ${ }^{51}$.

Por último, el Ministerio de Economía y Finanzas (MEF) indico que: "La inversión pública comenzó el 2018 dando señales de dinamismo capaz de sostener el crecimiento económico del año. En enero creció cerca de 14\% y en febrero superó el 50\% de

\footnotetext{
${ }^{47}$ Mercado Negro, (en línea), 28 de marzo 2018. Disponible: http://www.mercadonegro.pe/crecimiento-del-retail-en-el-peru/

${ }^{48}$ Mercado Negro, (en línea), 28 de marzo 2018. Disponible: http://www.mercadonegro.pe/crecimiento-del-retail-en-el-peru/ 49 Artículo en Diario El comercio. (en línea), lunes 11 de diciembre de 2017.2 Disponible: https://elcomercio.pe/economia/mercados/tipo-cambio-dolar-caera-s-3-18-fines-2018-noticia-480760

50 Artículo en El Economista América. (en línea), martes 12 de diciembre de 2017. Disponible: http://www.eleconomistaamerica.pe/economia-eAm-peru/noticias/8806193/12/17/Proyecciones-divididas-sobre-el-tipo-decambio-el-2018.html

51 Artículo en el diario El Comercio. (en línea), martes 13 de septiembre de 2017. Disponible: https://elcomercio.pe/economia/peru/julio-velarde-odebrecht-tendria-impacto-negativo-0-6-pbi-noticia-457769
} 
expansión" 52. Lo cual era una buena señal para la recuperación de la economía peruana, pero a finales del mes de marzo la cifra cambio de manera negativa como lo indica el MEF: "El retroceso, con datos actualizados el 31 de marzo, habría sido de 12,27\%, y con este resultado la ejecución de la inversión pública anotaría un crecimiento de 10,68\% en el primer trimestre del año" ${ }^{53}$. Este freno en la inversión pública coincide con la vacancia presidencial del ex presidente Pedro Pablo Kuczynski.

\subsubsection{Análisis Legal}

El desarrollo de la actividad empresarial comprende diversas acciones las cuales se inician con la constitución de la persona jurídica que se encargará de brindar el producto o servicio a sus clientes.

De acuerdo a la Ley № 26887, Ley General de Sociedades, se establece el marco legal regulatorio para realizar la actividad empresarial, la cual define las diversas formas societarias que se pueden escoger. En el caso específico de Naranja Producciones SAC, eligió la forma societaria Sociedad Anónima Cerrada. Esta forma societaria confiere a sus socios la limitación de su responsabilidad hasta la cantidad de su aporte y tiene como principal característica tener necesariamente las siglas de S.A. después de la denominación de la sociedad. Asimismo, el directorio o la junta general de accionistas (20 accionistas como máximo), según el estatuto, nombran a un gerente por un plazo determinado, quien está facultado para la ejecución de los actos y contratos ordinarios correspondientes al objeto social.

Después de la constitución de la empresa para el inicio de sus actividades, las empresas deben obtener su Registro Único de Contribuyentes ante la Superintendencia de Administración Tributaria - SUNAT, el cual es un padrón en el que deben registrarse los contribuyentes respecto de los tributos que administra la SUNAT y constituye una base de datos cuya información es actualizada permanentemente por los contribuyentes y por la misma SUNAT. Este registro permite otorgar a cada persona, entidad o empresa un RUC que consta de 11 dígitos que es de carácter permanente y de uso obligatorio en todo trámite ante la SUNAT. Con fecha 01 de marzo de 2013, Naranja Producciones SAC, gestionó la

\footnotetext{
52 Artículo en el diario El Comercio. (en línea), domingo 01 de abril de 2018. https://elcomercio.pe/economia/crecimiento-inversion-publica-ralentiza-marzo-noticia-508643

53 Artículo en el diario El Comercio. (en línea), domingo 01 de abril de 2018. https://elcomercio.pe/economia/crecimiento-inversion-publica-ralentiza-marzo-noticia-508643
} 
obtención de su RUC No: 20551826717 - NARANJA PRODUCCIONES S.A.C, teniendo como actividad económica principal "Principal - CIIU 93098 - OTRAS ACTIVID.DE TIPO SERVICIO NCP", pudiendo emitir factura, boleta de venta, nota de crédito guía de remisiónremitente.

En el ámbito laboral peruano, el régimen laboral de la actividad privada se rige por el Decreto Legislativo $N^{\circ} 728$, cuyo Texto Único Ordenado fue aprobado por Decreto Supremo $N^{\circ}$ 002-2007-TR y demás normas conexas que regulan todo lo concerniente a la actividad laboral en el ámbito privado tales como: Compensación por Tiempo de ServiciosCTS, vacaciones, utilidades, gratificaciones, tercerización etc. En el caso de Naranja Producciones SAC, tiene 6 personas en planilla.

En el ámbito Civil, el Código Civil Peruano regula la locación de servicios, y se encuentra definido en el artículo 1764 del Código Civil, el mismo que establece: "Por la locación de servicios el locador se obliga, sin estar subordinado al comitente, a prestarle sus servicios por cierto tiempo o para un trabajo determinado, a cambio de una retribución". En el caso de Naranja Producciones SAC, el número de personas contratadas por locación de servicios es a demanda de acuerdo a la cantidad y tipo de eventos que tengan que atender.

En el ámbito de la Ley $N^{\circ}$ 28015, Ley de Promoción y Formalización de la Micro y Pequeña Empresa, la misma que tiene por objeto la promoción de la competitividad, formalización y desarrollo de las micro y pequeñas empresas para incrementar el empleo sostenible, su productividad y rentabilidad, su contribución al Producto Bruto Interno, la ampliación del mercado interno y las exportaciones y su contribución a la recaudación tributaria, Naranja Producciones S.A.C. trabaja bajo la modalidad MYPE, ya que su principal característica es tener ventas menores a 150 UIT y máximo 10 trabajadores en la empresa.

En el ámbito tributario, el cual está regido por las disposiciones emitidas por el Código Tributario cuyo Texto Único Ordenado fue aprobado por Decreto Supremo $N^{\circ} 133$ 2013-EF, la Ley del Impuesto a la Renta cuyo Texto Único Ordenado fue aprobado por Decreto Supremo No 179-2004-EF y sus actualizaciones, y la Ley del Impuesto a la Ventas e Impuesto Selectivo al Consumo cuyo Texto Único Ordenado fue aprobado por Decreto Supremo $\mathrm{N}^{\circ} 055-99-\mathrm{EF}$. Por lo tanto, en base a estas normas legales, Naranja 
Producciones SAC debe pagar los impuestos que les corresponda producto de su actividad empresarial.

Finalmente, cabe señalar que Naranja Producciones S.A.C. también acata otras normas y disposiciones legales en el ámbito municipal para el tema de licencia y autorizaciones de funcionamiento, el Instituto Nacional de Defensa de la competencia y de la Protección de la Propiedad Intelectual - INDECOPI, por diversos temas como por ejemplo el libro de reclamaciones; entre otros.

\subsubsection{Análisis Cultural}

El señor Jorge Jara, quien es el director de operaciones BTL Trade de la agencia FCB Mayo, señala que: “...el crecimiento de las inversiones en BTL por parte de las empresas hace que esta herramienta consolide e incremente su relevancia en el campo publicitario, y prevé que dicha expansión continuará" ${ }^{54}$. Esto se debe a que en los últimos 30 años la cultura empresarial en relación al uso del BTL ha cambiado.

El señor Jorge Jara nos comenta que: "En los años 80 era muy común ver Risas y Salsa en familia. Hasta los 90, como los Simpson que se sientan todos a ver televisión. En aquel entonces los ratings de los programas superaban el 50\%. Ahora los mejores ratings televisivos llegan a $20 \%$ de la teleaudiencia. Las familias cuentan con un televisor en cada habitación y sus integrantes se dispersan en distintos canales, incluyendo el cable. El zapping no es el problema, sino el celular. La gente deja de ver la publicidad televisiva y revisa sus redes sociales o sus mensajes de texto. $Y$ la penetración de los smartphones no se detiene" 55 . Esto demuestra que el alcance del ATL está disminuyendo y que los medios de comunicación tradicionales que años atrás llegaban a varias familias, en la actualidad no lo está logrando. Además, el surgimiento de Netflix ha permitido otra forma de entretenimiento en casa. Por otra parte, el señor Jorge Jara nos dice que: "Todo eso hace que los directores de marketing de las empresas replanteen sus estrategias y sus pautas de publicidad". Debido a estos factores los directores de marketing se ven en la necesidad de cambiar sus perspectivas y apuntar en otra dirección para poder llegar a los consumidores. Es así que el BTL ha logrado posicionarse en las empresas para poder desarrollar campañas dirigidas a los consumidores y conseguir la comunicación deseada

\footnotetext{
54 “EI BTL en Perú es un adolescente por S.A.C.ar su DNI". En: InfoMarketing. (en línea) PE, domingo, 09 de noviembre del 2014. Disponible: http://www.infomarketing.pe/btl-int.php?id=4

55 "EI BTL en Perú es un adolescente por S.A.C.ar su DNI". En: InfoMarketing. (en línea) PE, domingo, 09 de noviembre del 2014. Disponible: http://www.infomarketing. pe/btl-int.php?id=4
} 
de los productos y servicios de las empresas. Si una marca se hace conocer es valorada por los consumidores, es por eso la preocupación de los directivos de marketing en buscar nuevas formas de comunicación efectiva. Este cambio cultural por parte de los clientes, también lleva a que la cultura de las empresas cambie poco a poco.

El señor Jorge Jara sostiene que: “...en una reunión de la ANDA, se mencionó que los principales anunciantes destinaban casi un $50 \%$ de su presupuesto a acciones de BTL. Esta es una señal de que la herramienta está muy vigente y presente con fuerza en el mercado" 56 . Este incremento en la participación del presupuesto de publicidad por parte del BTL no era inimaginable en los años 80 s e inicios de los 90 s en donde los medios masivos tenían el dominio total de las campañas publicitarias.

El BTL busca generar experiencia de marca, pues permite crear al consumidor un mensaje de manera inteligente, versátil y flexible, logrando así que esta nueva estrategia de marketing llegue en forma no muy limitada a los múltiples clientes. Para ello, el análisis cultural tiene un fuerte impacto en las empresas, ya que esta tendencia se va formando según la manera en que vivimos, trabajamos, producimos y consumimos.

Según un estudio realizado por MD Group ${ }^{57}$ las empresas son motivadas en invertir en BTL porque un $67 \%$ se centra en originalidad y creatividad; mientras que un $69 \%$ busca la efectividad y alcance al público objetivo y finalmente un $32 \%$ indica que los costos son más bajos que los tradicionales.

Por otra parte, Luciana Olivares, Gerente General de Publicidad del BBVA Continental no dice que: “...en los últimos 5 o 6 años sin embargo. Más anunciantes están apostando hoy por integrar las acciones BTL al brief inicial, por darle un rol más estratégico que táctico; y obviamente están destinando más recursos a la comunicación directa, presencial, al contacto inmediato con sus públicos objetivos" ${ }^{58}$. También nos dice que: "El BTL y el digital se necesitan mutuamente" ${ }^{59}$. Todo esto nos dice que el BTL está tomando

\footnotetext{
56 “El BTL en Perú es un adolescente por S.A.C.ar su DNI”. En: InfoMarketing. (en línea) PE, domingo, 09 de noviembre del 2014. Disponible: http://www.infomarketing.pe/btl-int.php?id=4

57 MD Group, articulo en Diario Gestión. (en línea), Jueves, 29 de mayo del 2014. Disponible: http://gestion.pe/empresas/empresas-peruanas-destinan-s-45000-promedio-campanas-btl-2098810

58 "Desafíos del BTL: Made in Perú". En: AndaPerú. (en línea) PE, domingo, 08 de marzo del 2015. Disponible: http://www.andaperu.pe/desafios-del-btl-made-in-peru/

59 "Desafíos del BTL: Made in Perú". En: AndaPerú. (en línea) PE, domingo, 08 de marzo del 2015. Disponible: http://www.andaperu.pe/desafios-del-btl-made-in-peru/
} 
mayor importancia en el mundo de la publicidad y que cada vez tiene mayor participación en el presupuesto anual que las empresas brindan en temas de comunicación. Cabe resaltar que con el desarrollo de las redes sociales, el BTL se puede comunicar de manera más rápida. Las campañas BTL se pueden viralizar por medio de las redes sociales, logrando un mayor impacto que antes.

EI BTL hoy por hoy es una de las herramientas más utilizadas en la publicidad, como lo indica Alejandro Gutiérrez Pineda, director general de Player Group quien afirma que: “...la evolución del BTL ha sido impresionante. "Hace 10 años casi nadie sabía lo que era el BTL, otros pensaban que era poner a un edecán y hoy por hoy, el BTL es parte de una estrategia completa y global 360. Las marcas sí o sí tienen que poner gran parte de su presupuesto y de su Budget al below the line", aseguró" ${ }^{60}$. No cabe duda que es una de las herramientas con mayor proyección dentro del mundo de la publicidad.

Un aspecto cultural importante es el vínculo que existe entre el empresario peruano y el BTL. Muchas veces las microempresas y las pequeñas empresas no cuentan con el presupuesto necesario para implementar el ATL, por ser un medio de promoción y comunicación de alto costo. Por tal motivo, la utilización del BTL es una alternativa de promoción muy útil y de bajo costo en comparación al ATL. Pero por diferentes factores como la falta de conocimiento por parte de muchos empresarios peruanos no utilizan esta herramienta.

En el artículo publicado en la Web de "Somos empresa" sostiene que: "Lamentablemente, en el sector de la micro y pequeña empresa, estas herramientas todavía no han alcanzado la madurez que debieran. Sobre todo cuando se trata de rentabilizar el negocio y darle liquidez"61. Las micro y pequeñas empresas cuentan con la posibilidad de utilizar una herramienta de bajo costo y de mayor impacto en comparación al ATL que no se debería desestimar.

También las empresas públicas realizan actualmente el BTL, un ejemplo claro es el caso del MINSA y del SEGURO INTEGRAL DE SALUD. Nos comentó los directivos de

\footnotetext{
60 “¿Cómo ha evolucionado el BTL?”. En: Infomarketing. (en línea) PE, domingo, 04 de marzo del 2016. Disponible: http://www.informabtl.com/como-ha-evolucionado-el-btl/

61 SOMOSEMPRESA, "Aprovecha las técnicas que te ofrece el BTL para tu promoción". (en línea) PE. Citado el 15 de noviembre del 2014. Disponible en: http://somosempresa.pe/soy-empresario/marketing-y-ventas/aprovecha-las-tecnicasque-te-ofrece-el-btl-para-tu-promocion
} 
Naranja Producciones S.A.C., que actualmente los diferentes departamentos de dichas instituciones públicas cuenta con su propio presupuesto anual para poder comunicar alguna campaña de prevención, utilizan el servicio de BTL.

\subsubsection{Análisis Tecnológico}

Gracias a los avances tecnológicos alcanzados tanto en la música, luces, escenografía y diversos factores alineados a la publicidad, han permitido que las estrategias de marketing sean más efectivas.

Un avance tecnológico para las campañas BTL, son las experiencias interactivas entre la marca y el consumidor en espacios específicos; por ejemplo, en centros comerciales, tiendas por departamento, ferias, eventos de integración, entre otros lugares ${ }^{62}$. Esta interacción hace que los clientes informen más de sus productos o servicios a su público objetivo; y por ende, existe mayor captación de los consumidores. Por ejemplo, experiencias en 3D al patear una pelota virtual en época mundialista.

La música actualmente es muy importante en las campañas BTL la cual muchas veces está compuesta de ritmos muy alegres, dinámicos, mix de canciones, ya que debe de transmitir sensaciones agradables, entendibles y sobre todo que pueda ambientar en el evento a realizarse; siempre teniendo en cuenta los nuevos equipos musicales, consolas, mezcladoras de sonidos, etc. que han salido al mercado facilitando su composición musical. Las canciones son una fácil conexión con los productos y servicios, las melodías logran ubicarse en el consiente y subconsciente, es por ello que incide en la conducta del consumidor. Es por ello, que el gerente comercial, César Hugo Jaén Seminario antes de cerrar un contrato, tiene una reunión con el cliente para ver el tipo de música a utilizar o en todo caso el cliente entrega el CD de música que requieren y así saber si está en buenas condiciones y es apto para el equipo a utilizar. Asimismo, el cliente hace un requerimiento de los equipos que se pondrán en el local, por ejemplo: consola 12 canales, micrófonos inalámbricos, parlantes para micrófonos, laptop con lector DVD y entrada USB, técnico operador, extensiones y cableados, parlantes externos con trípode, entre otros requerimientos necesarios para su evento.

\footnotetext{
${ }^{62}$ La República (2017, 25 de julio). Importancia de la tecnología en los eventos de publicidad BTL. Recuperado: https://larepublica.pe/marketing/1065746-importancia-de-la-tecnologia-en-los-eventos-de-publicidad-btl
} 
Otro factor importante es la portabilidad de la música y la facilidad de implementarla a través de los diferentes formatos, pudiendo llevar fácilmente cientos de canciones en un dispositivo USB.

Las luces son otro factor muy importante ya que nos permite ambientar el espacio donde se desarrollará las campañas de publicidad BTL.

Por otra parte, el consumidor al tener mayor acceso al internet, tiene mayor facilidad para obtener una mejor información sobre los productos y servicios. Por tal motivo, las empresas no pueden estar ajenas a esta tendencia mundial.

Otro tema importante es el uso del internet por parte de los consumidores peruanos en los últimos años. En la entrevista realizada por el Diario El Comercio, el señor Rafael Hospina Ossio, de Country Manager de PayU Latam, dice "El principal obstáculo es que el consumidor peruano no está acostumbrado a comprar por Internet. Recién el año pasado hemos visto a un número importante de personas que han querido utilizar este método, sobre todo clientes que no lo hacían antes" ${ }^{63}$, afirma. Por otra parte, el señor Hospina indica “... las cifras alcanzadas por el comercio electrónico en el país en el 2013 fue de US\$1000 millones, lo que habría significado un incremento del 60\% frente a las cifras alcanzadas en el 2012, superando así las proyecciones realizadas para el año anterior" 64 .

En el estudio de mercado realizado por Arellanos Marketing, llamado Encuesta Nacional del Consumidor Peruano 2013 dice que se puede apreciar lo siguiente: "Los cibernautas peruanos acceden a las redes sociales entre 6 y 7 veces por semana en promedio..."65. El mismo estudio también dice que: “...el 33\% de peruanos visita las redes sociales una vez al día, el 27\% de 2 a 6 veces por semana, el 21\% más de una vez al día y el $12 \%$ una vez a la semana"66.

\footnotetext{
63 HERNÁNDEZ, ROGER. “¿Por qué no despegan las compras por Internet en el Perú?”. En: El Diario El Comercio. (en línea) PE, Jueves, 29 de mayo del 2014. (citado 18 octubre 2014) Disponible: http://elcomercio.pe/economia/negocios/queno-despegan-compras-internet-peru-noticia-1707759

${ }^{64}$ HERNÁNDEZ, ROGER. “¿Por qué no despegan las compras por Internet en el Perú?”. En: El Diario El Comercio. (en línea) PE, Jueves, 29 de mayo del 2014. (citado 18 octubre 2014) Disponible: http://elcomercio.pe/economia/negocios/queno-despegan-compras-internet-peru-noticia-1707759

${ }^{65}$ ARELLANO, RONALD. “¿Peruanos visitan redes sociales entre 6 y 7 veces por semana?”. En: RPP Noticias. (en línea) PE, Jueves, 03 de julio del 2014. (citado 18 octubre 2014) Disponible: http://www.rpp.com.pe/2014-07-03-arellano-peruanosvisitan-redes-sociales-entre-6-y-7-veces-por-semana-noticia_705033.html

${ }^{66}$ ARELLANO, RONALD. “¿Peruanos visitan redes sociales entre 6 y 7 veces por semana?”. En: RPP Noticias. (en línea) PE, Jueves, 03 de julio del 2014. (citado 18 octubre 2014) Disponible: http://www.rpp.com.pe/2014-07-03-arellano-peruanosvisitan-redes-sociales-entre-6-y-7-veces-por-semana-noticia_705033.html
} 
Por último, el estudio indica que: “... los jóvenes y personas de niveles socio económicos (NSE) altos tienen un consumo más orientado a la diversión y las relaciones sociales, mientras que los mayores y personas de NSE bajos se destacan por su uso utilitario. Asimismo, del total de usuarios de Internet, el $84 \%$ dijo tener una cuenta en alguna red social, mientras que el $16 \%$ restante no tiene" 67 .

El internet es importante para el BTL porque ambas pueden ser combinadas y lograr un mayor alcance juntas. El BTL busca desarrollar una experiencia satisfactoria al consumidor para lograr la fidelización al producto o servicio. Si se realiza una adecuada campaña de BTL en donde se ubica el público objetivo, esta experiencia se podría transmitir por las redes sociales y oficiales de las empresas, creando un mayor alance de la campaña BTL.

Por otra parte, las empresas de BTL pueden utilizar el internet para poder comunicar mejor sus servicios a las personas naturales y jurídicas.

\subsubsection{Análisis Ecológico}

En la actualidad existe una nueva tendencia llamada consumidor verde. Cada día en el mundo los consumidores desarrollan una conciencia ecológica y las empresas no pueden omitir esta nueva tendencia mundial, la cual está creciendo en el Perú poco a poco. Es bajo este marco, que en el mundo se está desarrollando el Marketing verde. La señorita Antonieta Hamann Pastorino de ESAN no dice que “...el consumidor verde parte de su actitud hacia la ecología, dada la conciencia que ha adquirido con respecto a la preservación del entorno natural..."68.

Por otra parte, Rolando Arellanos nos dice que "...marketing verde" -quizás uno de los aspectos de la "ecolomía"-ha sido una respuesta de las empresas a las necesidades ecológicas del mercado..." ${ }^{69}$. Por tal motivo, se puede decir que las empresas se están adaptando a las nuevas exigencias del mercado. Esta tendencia seguirá creciendo en el mundo como en el Perú. Además, una de las herramientas que utiliza el marketing verde, es el ecobalance, que según Rolando Arellano “...el análisis del impacto de un producto

\footnotetext{
${ }^{67}$ ARELLANO, RONALD. “¿Peruanos visitan redes sociales entre 6 y 7 veces por semana?”. En: RPP Noticias. (en línea) PE, Jueves, 03 de julio del 2014. (citado 18 octubre 2014) Disponible: http://www.rpp.com.pe/2014-07-03-arellano-peruanos-visitan-redes-socialesentre-6-y-7-veces-por-semana-noticia_705033.html

68 Boletín Tiempo de Opinión. [en línea]. Lima. ESAN, 2013, (citado 21 octubre 2014). Adobe Acrobat. Disponible en: http://www.esan.edu.pe/publicaciones/2013/06/11/tiempo_de_opinion_antonieta_hamann.pdf

${ }^{69}$ ARELLANO, Rolando. Marketing, Enfoque para América latina. 1ēed. México: Pearson autorización de México, 2010. P 408.
} 
sobre el entorno, desde su proceso de transformación, embalaje, promoción, distribución, condiciones de uso y eliminación o recuperación después de su uso..."70.

Se desprende que la ecología está ingresando con fuerza a la vida de los consumidores y de las empresas. Es un aspecto relevante a la hora de realizar el plan estratégico de ellas. 


\subsection{Impacto en clientes/proveedores de cada una de las variables del entorno.}

\section{Cuadro 4.4: Variables del entorno y su impacto en los clientes}

\begin{tabular}{|c|c|c|}
\hline POLITICO-GUBERNAMENTAL & & \\
\hline $\begin{array}{l}\text { Incremento de la inversión pública y privada en el } \\
\text { Perú. }\end{array}$ & Se crearan nuevos puestos de trabajo. & $\begin{array}{l}\text { Se incrementara el volumen de } \\
\text { ventas }\end{array}$ \\
\hline $\begin{array}{l}\text { Descentralizar Proinversión para ofrecer as istencia } \\
\text { tecnica y fortalecer las capacidades de los } \\
\text { Gobiernos Regionales. }\end{array}$ & $\begin{array}{l}\text { Se podra realizar negocios en } \\
\text { diferentes regiones del pais. }\end{array}$ & $\begin{array}{l}\text { Mayor numero de clientes en } \\
\text { provincia. }\end{array}$ \\
\hline $\begin{array}{l}\text { Se elimino el Sistema Nacional de Inversión Pública } \\
\text { (SNIP) y se creo del nuevo sistema Invierte.pe }\end{array}$ & Menos tramites para invertir & $\begin{array}{l}\text { Aumentara la demanda de } \\
\text { recursos por parte de las } \\
\text { empresas. }\end{array}$ \\
\hline $\begin{array}{l}\text { Desarrollo de proyectos relacionados con el agua, el } \\
\text { saneamiento y con la vivienda para crear nuevos } \\
\text { puestos de trabajo. }\end{array}$ & $\begin{array}{l}\text { Que la empresa cuenta con los } \\
\text { servicios básicos para el buen } \\
\text { funcionamiento }\end{array}$ & $\begin{array}{l}\text { Que la empresa cuenta con los } \\
\text { servicios básicos para el buen } \\
\text { funcionamiento }\end{array}$ \\
\hline $\begin{array}{l}\text { La modernización de la Policía Nacional, la } \\
\text { adecuada gestión de los recursos y las alianzas con } \\
\text { los municipio }\end{array}$ & $\begin{array}{l}\text { Mayor seguridad para los ciudadanos y } \\
\text { empresarios. }\end{array}$ & $\begin{array}{l}\text { Mayor seguridad para los } \\
\text { ciudadanos y empresarios. }\end{array}$ \\
\hline $\begin{array}{l}\text { En temas de seguridad, el Gobierno piensa seguir } \\
\text { con el plan de recompensas, los mega operativos, la } \\
\text { campaña Barrio seguro y con programas de }\end{array}$ & $\begin{array}{l}\text { Se creara un clima de seguridad para } \\
\text { cada uno de los sectores. }\end{array}$ & $\begin{array}{l}\text { Mayor seguridada a nivel } \\
\text { nacional. }\end{array}$ \\
\hline \multicolumn{3}{|l|}{ ECONÓMICO } \\
\hline $\begin{array}{l}\text { Se redujo la proyección del crecimiento del PBI } \\
\text { para el } 2017 \text { a } 3.8 \% \text {. }\end{array}$ & Posibilidad que baje el consumo & $\begin{array}{l}\text { Reducción de pedidos de los } \\
\text { clientes }\end{array}$ \\
\hline Efecto Odebrecht en la economia peruana. & Afecte el crecimiento de la economia & $\begin{array}{l}\text { Panorama negativo para los } \\
\text { inversionistas. }\end{array}$ \\
\hline $\begin{array}{l}\text { La confianza del consumidor para Lima } \\
\text { Metropolitana durante el mes de enero del } 2018 \text { ha } \\
\text { subido. }\end{array}$ & $\begin{array}{l}\text { Sube el consumo de las familias a nivel } \\
\text { nacional. }\end{array}$ & Subida del volumen de ventas. \\
\hline $\begin{array}{l}\text { El Perú encabeza el ránking de confianza económica } \\
\text { en Latinoamérica. }\end{array}$ & $\begin{array}{l}\text { Panorama positivo para el Incremento } \\
\text { de la inversion. }\end{array}$ & Aumento de la demanda. \\
\hline $\begin{array}{l}\text { Las ventas en los centros comerciales crecerán entre } \\
6 \% \text { y } 9 \% \text { el } 2018\end{array}$ & Incremento de las ventas. & Aumento de campañas BTL. \\
\hline $\begin{array}{l}\text { El tipo de cambio tiene una tendencia a la baja en los } \\
\text { próximos meses }\end{array}$ & $\begin{array}{l}\text { Beneficio en la paga de las deudas en } \\
\text { dolares. }\end{array}$ & $\begin{array}{l}\text { No hay impacto para la } \\
\text { empresa. Debido a que compra } \\
\text { en soles y vende en soles. }\end{array}$ \\
\hline \multicolumn{3}{|l|}{ LEGAL } \\
\hline Jóvenes en el mercado laboral & $\begin{array}{l}\text { Más personal que apoya en los } \\
\text { servicios }\end{array}$ & $\begin{array}{l}\text { Más fácil la contratación de } \\
\text { personal }\end{array}$ \\
\hline \multicolumn{3}{|l|}{ CULTURAL } \\
\hline $\begin{array}{l}\text { Los cambios que se han producido en la cultura de } \\
\text { las personas en relación al uso de los medios } \\
\text { masivos de comunicación ha llevado a las empresas } \\
\text { adoptar el BTL }\end{array}$ & Disminucion de la publicidad ATL & Aumento de la demanda \\
\hline $\begin{array}{l}\text { Crecimiento de las inversiones en BTL por parte de } \\
\text { las empresas. }\end{array}$ & Incremento de las campañas BTL. & $\begin{array}{l}\text { Aumento de la oferta de las } \\
\text { empresas BTL }\end{array}$ \\
\hline $\begin{array}{l}\text { La gente deja de ver la publicidad televisiva y revisa } \\
\text { sus redes sociales o sus mensajes de texto. }\end{array}$ & $\begin{array}{l}\text { Disminución del alcance de la } \\
\text { publicidad ATL }\end{array}$ & $\begin{array}{l}\text { Incremento de las campañas } \\
\text { BTL }\end{array}$ \\
\hline El crecimiento del uso del smartphones y de Netflix. & Incremento del presupues to para BTL & Aumento de la demanda \\
\hline $\begin{array}{l}\text { El BTL es una de las herramientas con mayor } \\
\text { proyección dentro del mundo de la publicidad }\end{array}$ & $\begin{array}{l}\text { Uso del BTL en la mediana y pequeña } \\
\text { empresa. }\end{array}$ & Aumento de la demanda \\
\hline \multicolumn{3}{|l|}{ TECNOLÓGICO } \\
\hline Equipos de sonidos y luces en constante cambio. & $\begin{array}{l}\text { Mayor informacion de los clientes } \\
\text { sobre los nuevos equipos que salen al } \\
\text { mercado. }\end{array}$ & $\begin{array}{l}\text { Necesidad de renovar los } \\
\text { equipos según los } \\
\text { requerimientos del mercado. }\end{array}$ \\
\hline Mix de música para las campañas y eventos. & Mas opciones de géneros musicales & $\begin{array}{l}\text { Necesidad de renovación de } \\
\text { pistas musicales }\end{array}$ \\
\hline Incremento del uso del internet. & $\begin{array}{l}\text { Incremento de la penetración de los } \\
\text { productos y servicios en el mercado. }\end{array}$ & Mayor difusion de los servicios \\
\hline Realizar compras por internet. & Incremento de ventas & Aumento de la demanda. \\
\hline Portabilidad de la música. & $\begin{array}{l}\text { Mayor número de opciones para la } \\
\text { música }\end{array}$ & $\begin{array}{l}\text { Facilidad de descarga de la } \\
\text { música }\end{array}$ \\
\hline Incremento del comercio electrónico & Incremento $\mathbf{B} 2 \mathrm{~B}, \mathrm{~B} 2 \mathrm{C}$ & Incremento $\mathrm{B} 2 \mathrm{~B}, \mathrm{~B} 2 \mathrm{C}$ \\
\hline \multicolumn{3}{|l|}{$\begin{array}{ll}\text { ECOLÓGICO } \\
\end{array}$} \\
\hline Incremento del consumidor verde. & $\begin{array}{l}\text { Mayor responsabilidad social por parte } \\
\text { de las empresas y consumidores. }\end{array}$ & $\begin{array}{l}\text { Mayor uso de materiales } \\
\text { ecologicos }\end{array}$ \\
\hline Surgimiento del Marketing verde. & $\begin{array}{l}\text { Cambio de estrategia para captar } \\
\text { mayor número de consumidores. }\end{array}$ & $\begin{array}{l}\text { Cambio de estrategia para } \\
\text { captar mayor número de } \\
\text { consumidores y proveedores }\end{array}$ \\
\hline
\end{tabular}

Elaboración propia. 


\subsection{Efecto en la empresa de cada una de las variables del entorno Cuadro 4.5: Variables del entorno y su impacto en las Empresas}

\begin{tabular}{|c|c|c|}
\hline \multicolumn{3}{|c|}{ Efecto Empresa } \\
\hline POLÍTICO-GUBERNAMENTAL & Impacto Empresa & Oportunidad/Amenaza \\
\hline $\begin{array}{l}\text { La creación de nuevos puesto de trabajo por medio la } \\
\text { inversión pública y privada en el Perú. }\end{array}$ & $\begin{array}{l}\text { Contratación de nuevos } \\
\text { trabajadores }\end{array}$ & Oportunidad \\
\hline $\begin{array}{l}\text { Descentralizar Proinversión para ofrecer asistencia } \\
\text { tecnica y fortalecer las capacidades de los Gobiernos } \\
\text { Regionales. }\end{array}$ & Mayor número de contratos. & Oportunidad \\
\hline $\begin{array}{l}\text { Se eliminó el Sistema Nacional de Inversión Pública } \\
\text { (SNIP) y se creó del nuevo sistema Invierte.pe }\end{array}$ & Incremento de la demanda. & Oportunidad \\
\hline $\begin{array}{l}\text { La inversión Pública ha caido en } 14 \text { Regiones en el } \\
\text { último trimestre } 2018 .\end{array}$ & $\begin{array}{l}\text { Disminución de las campañas } \\
\text { de comunicación por parte de } \\
\text { las distintas Regiones. }\end{array}$ & Amenaza \\
\hline $\begin{array}{l}\text { La modernización de la Policía Nacional, la adecuada } \\
\text { gestión de los recursos, como las alianzas con los } \\
\text { municipio }\end{array}$ & $\begin{array}{l}\text { Mayor seguridad para la } \\
\text { empresa cuando realice eventos } \\
\text { en las calles. }\end{array}$ & Oportunidad \\
\hline $\begin{array}{l}\text { En temas de seguridad, el Gobierno piensa seguir con el } \\
\text { plan de recompensas, los mega operativos, la campaña } \\
\text { Barrio seguro y con programas de prevención. }\end{array}$ & Seguridad para los empresarios. & Oportunidad \\
\hline \multicolumn{3}{|l|}{ ECONÓMICO } \\
\hline $\begin{array}{l}\text { Se redujo la proyección del crecimiento del PBI para el } \\
2017 \text { a } 3.8 \% \text {. }\end{array}$ & $\begin{array}{l}\text { Menor crecimiento de la } \\
\text { demanda. }\end{array}$ & Amenaza \\
\hline Efecto Odebrecht en la economia peruana. & Disminucion de la inversión. & Amenaza \\
\hline $\begin{array}{l}\text { La confianza del consumidor para Lima Metropolitana } \\
\text { durante el mes de enero del } 2018 \text { ha subido. }\end{array}$ & Mayor consumo de los clientes. & Oportunidad \\
\hline $\begin{array}{l}\text { El Perú encabeza el ránking de confianza económica en } \\
\text { Latinoamérica. }\end{array}$ & $\begin{array}{l}\text { Mayor inversión por parte de } \\
\text { las empresas. Se incrementa la }\end{array}$ & Oportunidad \\
\hline $\begin{array}{l}\text { Las ventas en los centros comerciales en el Perú } \\
\text { subiran entre el } 6 \% \text { y el } 9 \% \text { durante el } 2018 .\end{array}$ & $\begin{array}{l}\text { Mayor número de campañas } \\
\text { BTL y eventos. }\end{array}$ & Oportunidad \\
\hline $\begin{array}{l}\text { El tipo de cambio tiene una tendencia a la baja en los } \\
\text { próximos meses }\end{array}$ & Mayor ahorro en soles & Oportunidad \\
\hline \multicolumn{3}{|l|}{ LEGAL } \\
\hline Jóvenes en el mercado laboral & $\begin{array}{l}\text { Tener mayor ofertas desde } \\
\text { personal sin experiencia a } \\
\text { expertos en las campañas BTL }\end{array}$ & Oportunidad \\
\hline \multicolumn{3}{|l|}{ CULTURAL } \\
\hline $\begin{array}{l}\text { Los cambios que se han producido en la cultura de } \\
\text { las personas en relación al uso de los medios masivos } \\
\text { de comunicación ha llevado a las empresas adoptar el }\end{array}$ & $\begin{array}{l}\text { Incremento de la demanda de } \\
\text { los servicos de la empresa. }\end{array}$ & Oportunidad \\
\hline $\begin{array}{l}\text { Crecimiento de las inversiones en BTL por parte de las } \\
\text { empresas. }\end{array}$ & Incremento de los clientes. & Oportunidad \\
\hline $\begin{array}{l}\text { La gente deja de ver la publicidad televisiva y revisa sus } \\
\text { redes sociales o sus mensajes de texto. }\end{array}$ & $\begin{array}{l}\text { Permite crear nuevos negocios } \\
\text { y mayor interacción con el }\end{array}$ & Oportunidad \\
\hline El crecimiento del uso del smartphones y de Netflix. & Aumento de la inversión en BTL & Oportunidad \\
\hline $\begin{array}{l}\text { El BTL es una de las herramientas con mayor } \\
\text { proyección dentro del mundo de la publicidad }\end{array}$ & $\begin{array}{l}\text { Mayor demanda por parte de } \\
\text { las empresas públicas y }\end{array}$ & Oportunidad \\
\hline \multicolumn{3}{|l|}{$\begin{array}{r}\text { TECNOLÓGICO } \\
\end{array}$} \\
\hline Equipos de sonidos y de luces en constante cambio. & $\begin{array}{l}\text { Renovación de los equipos de } \\
\text { luces y sonidos cada dos años. }\end{array}$ & Oportunidad \\
\hline Mix de música para las campañas y eventos. & Constante cambio de música. & Oportunidad \\
\hline Incremento del uso del internet. & $\begin{array}{l}\text { Mejor comunicación de los } \\
\text { servicios de la empresa. }\end{array}$ & Oportunidad \\
\hline Comprar por Internet. & $\begin{array}{l}\text { Incremento de la compra y } \\
\text { venta de servicios por internet. }\end{array}$ & Oportunidad \\
\hline Portabilidad de la música. & Llevar la música a todas. & Oportunidad \\
\hline Incremento del comercio electrónico & Aumento de la demanda. & Oportunidad \\
\hline \multicolumn{3}{|l|}{ ECOLÓGICO } \\
\hline Incremento del consumidor verde. & $\begin{array}{l}\text { Mejor uso de los residuos de la } \\
\text { empresa. }\end{array}$ & Oportunidad \\
\hline Surgimiento del Marketing verde. & $\begin{array}{l}\text { Identificación de los clientes } \\
\text { verdes. }\end{array}$ & Oportunidad \\
\hline
\end{tabular}

Elaboración propia. 


\subsection{Oportunidades y Amenazas}

Cuadro 4.6: Cuadro resumen de Oportunidades y Amenazas

\begin{tabular}{|c|c|}
\hline OP0RTUNIDADES & AMENAZAS \\
\hline 01. La creación de nuevos puesto de trabajo por medio la inversión pública y privada en el Perú. & A1. Efecto Odebrecht en la economia peruana. \\
\hline $\begin{array}{l}\text { 02. Descentralizar Proinversión para ofrecer asistencia tecnica y fortalecer las capacidades de } \\
\text { los Gobiernos Regionales. }\end{array}$ & A2. Incremento de la inflación en los últimos meses. \\
\hline $\begin{array}{l}\text { 03. Se eliminó el Sistema Nacional de Inversión Pública (SNIP) y se creó del nuevo sistema } \\
\text { Invierte.pe }\end{array}$ & A3. Conflicto entre el Poder Ejecutivo y el Poder Legislativo. \\
\hline $\begin{array}{l}\text { 04. Las ventas en los centros comerciales en el Perú subiran entre el } 6 \% \text { y el } \\
9 \% \text { durante el } 2018 .\end{array}$ & A4.La inversión pública habría caído 12\% en marzo por problemas polticos \\
\hline $\begin{array}{l}\text { 05. La confianza del consumidor para Lima Metropolitana durante el mes de enero del } 2018 \text { ha } \\
\text { subido. }\end{array}$ & A5. Desaceleración de la economía nacional durante el 2017. \\
\hline $\begin{array}{l}\text { 06. La modernización de la Policía Nacional, la adecuada gestión de los recursos, como las } \\
\text { alianzas con los municipio }\end{array}$ & A6. Existen actualmente 17 empresas de BTL conocidas en el Perú. \\
\hline $\begin{array}{l}\text { 07. En temas de seguridad, el Gobierno piensa seguir con el plan de recompensas, los mega } \\
\text { operativos, la campaña Barrio seguro y con programas de prevención. }\end{array}$ & $\begin{array}{l}\text { A7. Concentración de clientes por parte de unas pocas empresas de BTL. } \\
\text { la compra de su competencia. }\end{array}$ \\
\hline 08. El Perú encabeza el ránking de confianza económica en Latinoamérica. & A8. Existencia de empresas de BTL extranieras en el mercado local. \\
\hline 09. En el período 207 - 2018, contarán con 9 centro comerciales adicionales. & $\begin{array}{l}\text { A9. Minima demanda en realizacion de campañas BTL en la mayoria de regiones del } \\
\text { país. }\end{array}$ \\
\hline 010. El tipo de cambio tiene una tendencia a la baja en los próximos meses & A10. Adquisición de compañías pequeñas de BTL por grupos económicos. \\
\hline 011.Crecimiento de las inversiones en BTL por parte de las empresas. & A11. Productos Sustitutos. \\
\hline 012. Surgimiento de los consumidores verdes. & A12. Informalidad en el sector BTL. \\
\hline 013. El marketing verde como nueva tendencia. & \\
\hline 014. El uso del internet como medio para hacer publicidad. & \\
\hline 015. Desarrollo de redes sociales. & \\
\hline
\end{tabular}

\section{Elaboración Propia.}




\subsection{Matriz de Evaluación de los Factores Externos EFE}

Después de concretar todas las variables de los factores externos, a continuación hay que resumir y evaluar la información de los seis factores. La elaboración de una matriz EFE, consiste en lo siguientes pasos:

1. Realizar una lista de los factores críticos, abarcando tanto oportunidades como amenazas.

2. Asignar un peso relativo a cada factor: 0.0 (no es importante) a 1.0 (muy importante). A partir de este punto, se puede asignar un peso mayor a las oportunidades que las amenazas. La suma de todas las variables debe dar un total de 1.0

3. Determinar una calificación de 1 a 4 a cada uno de las variables, donde 4 es una respuesta muy superior, 3 , una respuesta superior a la media, 2, una respuesta a media y 1 , una respuesta mala. Estas calificaciones se basan en la superioridad de la empresa.

4. Multiplicar el peso relativo con su respectiva calificación para obtener una calificación ponderada.

5. Sumar las calificaciones ponderadas de cada variable, ya que finalmente determinaría el total ponderado de la empresa.

6. Al final, las cantidades de oportunidades y amenazas clave incluidas en el cuadro EFE, el total ponderado más alto que puede tener una empresa es 4.0 y el más bajo es 1.0. El valor promedio ponderado es 2.5 Un promedio ponderado de valor 4.0 indicaría que la empresa está respondiendo de una manera excelente frente a las oportunidades y amenazas de la industria de Publicidad. Un promedio ponderado de valor 1.0 indicaría que la empresa está respondiendo de manera negativa ante las oportunidades y no minimizando las amenazas.

Según la tabla final de la Matriz EFE, Naranja Producciones S.A.C, tiene un puntaje final 2.91; eso quiere decir que la empresa está por encima de la media en su esfuerzo por generar más oportunidades y minimizar las amenazas.

Por otra parte, se puede observar en el cuadro EFE que la 09 cuenta con clasificación del 4 y una ponderación del 0.800 , debido a que los dueños de la empresa Naranja Producciones S.A.C., consideran que el crecimiento de las ventas de los centros comerciales es un indicador que las empresas van a invertir mas dinero en campañas BTL para poder captar un mayor número de clientes. 
También la O8 cuenta con una clasificación del 4 y tiene una ponderación del 0.160, porque la información obtenida en los diferentes diarios indican que la confianza en el sector empresarial es la economía es más alta que sus similares en la region.

Por otra parte, la 01 también cuenta con clasificación 4 porque al ver mas inversión pública y privada en el país, se crearian mas puestos de trabajo, que propiciarian un incremento en el consumo nacional, lo que llevaría a las empresas a invertir mas en campañas BTL.

Asimismo, el resultado de la Matriz EFE se ha obtenido a partir de la información y el análisis de la opinión de expertos externos y directivos de la empresa Naranja Producciones S.A.C.. 
Cuadro 4.7: Factores Externos claves de Naranja Producciones S.A.C.

\begin{tabular}{|c|c|c|c|}
\hline \multicolumn{4}{|c|}{ FACTORES EXTERNOS CLAVES - NARANJAPRODUCCIONES SAC. } \\
\hline OPORTUNIDADES & VALOR & CLASIFICACIÓN & VALOR PONDERADO \\
\hline 01. La creación de nuevos puesto de trabajo por medio la inversión pública y privada en el Perú. & 0.015 & 4 & 0.060 \\
\hline $\begin{array}{l}\text { O2. Descentralizar Proinversión para ofrecer asistencia tecnica y fortalecer las capacidades de los } \\
\text { Gobiernos Regionales. }\end{array}$ & 0.020 & 3 & 0.060 \\
\hline 03. Se eliminó el Sistema Nacional de Inversión Pública (SNIP) y se creó del nuevo sistema Invierte.pe & 0.020 & 3 & 0.060 \\
\hline $\begin{array}{l}\text { 04. Las ventas en los centros comerciales en el Perú subiran entre el } 6 \% \text { y el } \\
\text { 9\% durante el } 2018 .\end{array}$ & 0.020 & 3 & 0.060 \\
\hline 05. La confianza del consumidor para Lima Metropolitana durante el mes de enero del 2018 ha subido. & 0.015 & 2 & 0.030 \\
\hline $\begin{array}{l}\text { 06. La modernización de la Policía Nacional, la adecuada gestión de los recursos, como las alianzas } \\
\text { con los municipio }\end{array}$ & 0.015 & 3 & 0.045 \\
\hline $\begin{array}{l}\text { 07. En temas de seguridad, el Gobierno piensa seguir con el plan de recompensas, los mega } \\
\text { operativos, la campaña Barrio seguro y con programas de prevención. }\end{array}$ & 0.150 & 3 & 0.450 \\
\hline 08. El Perú encabeza el ránking de confianza económica en Latinoamérica. & 0.040 & 4 & 0.160 \\
\hline 09. En el período 207 - 2018, contarán con 9 centro comerciales adicionales. & 0.200 & 4 & 0.800 \\
\hline 010. El tipo de cambio tiene una tendencia a la baja en los próximos meses & 0.020 & 3 & 0.060 \\
\hline 011.Crecimiento de las inversiones en BTL por parte de las empresas. & 0.100 & 3 & 0.300 \\
\hline 012. Surgimiento de los consumidores verdes. & 0.015 & 3 & 0.045 \\
\hline 013. El marketing verde como nueva tendencia. & 0.030 & 3 & 0.090 \\
\hline 014. El uso del internet como medio para hacer publicidad. & 0.050 & 3 & 0.150 \\
\hline 015. Desarrollo de redes sociales. & 0.050 & 3 & 0.150 \\
\hline \multicolumn{4}{|l|}{ AMENAZAS } \\
\hline A1. Efecto Odebrecht en la economia peruana. & 0.010 & 1 & 0.010 \\
\hline A2. Incremento de la inflación en los últimos meses. & 0.010 & 2 & 0.020 \\
\hline A3. Conflicto entre el Poder Ejecutivo y el Poder Legislativo. & 0.010 & 2 & 0.020 \\
\hline A4.La inversión pública habría caído 12\% en marzo por problemas políticos & 0.010 & 1 & 0.010 \\
\hline A5. Desaceleración de la economía nacional durante el 2017. & 0.020 & 2 & 0.040 \\
\hline A6. Existen actualmente 17 empresas de BTL conocidas en el Perú. & 0.020 & 1 & 0.020 \\
\hline $\begin{array}{l}\text { A7. Concentración de clientes por parte de unas pocas empresas de BTL. } \\
\text { la compra de su competencia. }\end{array}$ & 0.020 & 1 & 0.020 \\
\hline A8. Existencia de empresas de BTL extranjeras en el mercado local. & 0.010 & 1 & 0.010 \\
\hline A9. Minima demanda en realizacion de campañas BTL en la mayoria de regiones del país. & 0.020 & 1 & 0.020 \\
\hline A10. Adquisición de compañías pequeñas de BTL por grupos económicos. & 0.010 & 2 & 0.020 \\
\hline A11. Productos Sustitutos. & 0.050 & 2 & 0.100 \\
\hline A12. Informalidad en el sector BTL. & 0.050 & 2 & 0.100 \\
\hline
\end{tabular}

1.000

2.91

Elaboración Propia 


\section{Capítulo V}

\section{Análisis de la Industria}

\subsection{Descripción del Mercado (demanda) e Industria (oferta)}

EL BTL está alcanzado un mayor protagonismo en el mundo. La empresa Visual Trade indica que: "....actualmente en el mundo el $70 \%$ del presupuesto de publicidad se dirige al sector BTL" 71 .

En el Perú, la empresa MD Group indica que: "El presupuesto promedio que asigna una empresa peruana a una campaña de Marketing BTL (Below The Line) en el mercado local es de aproximadamente $S / 45,000 \ldots .72$.

La investigación realizada por la empresa MD Group se revela que: “...siete de cada diez empresas en el Perú realizan acciones de Marketing BTL. De ellas, el 66\% realiza eventos, el $60 \%$ invierte en activaciones, mientras que el $54 \%$ utiliza el correo directo o el volanteo" 73 .

De las empresas que realizan BTL en el Perú, MD Group informa que: “... poco más de la mitad de las empresas peruanas (53\%) invierten en BTL menos de $\mathrm{S} / 30,000$, seguido de un 37\% que invierte entre $S / 30,000$ a S/ 50,000, mientras que hay un $10 \%$ de empresas cuya inversión en estas acciones va de S/ 50,000 a S/ 100,000"74.

\subsection{Descripción de las cinco fuerzas competitivas de la industria}

Con la finalidad de poder realizar un correcto análisis de la estrategia competitiva de Naranja Producciones S.A.C., primero deberemos de relacionar la empresa con su entorno ya que existen fuerzas que pueden influir en su desarrollo, tal como lo indica Michael Porter en su libro Estrategia Competitiva : “... cuando se conocen las causas de la presión competitiva, se evidencian las fuerzas y debilidades principales de la compañía, se

\footnotetext{
71 VISUAL TRADE.” El futuro (hoy) del sector”. En: La Guía del Marketing 2014. (en línea).PE, 232, (citado 20 octubre 2014). Disponible en: http://www.mdgroup.com.pe/guia_marketing.html

${ }^{72}$ MD Group, articulo en Diario Gestión. (en línea), Jueves, 29 de mayo del 2014. Disponible: http://gestion.pe/empresas/empresasperuanas-destinan-s-45000-promedio-campanas-btl-2098810

${ }^{73}$ MD Group, articulo en Diario Gestión. (en línea), Jueves, 29 de mayo del 2014. Disponible: http://gestion.pe/empresas/empresasperuanas-destinan-s-45000-promedio-campanas-btl-2098810

${ }^{74}$ MD Group, articulo en Diario Gestión. (en línea), Jueves, 29 de mayo del 2014. Disponible: http://gestion.pe/empresas/empresasperuanas-destinan-s-45000-promedio-campanas-btl-2098810
} 
consolida su posicionamiento en el sector industrial, se aclaran los aspectos en que los cambios estratégicos producirán los mejores resultados y se descubren las áreas donde las tendencias de la industria tendrán mayor importancia como oportunidades y riesgos..." ${ }^{75}$.

\section{llustración 5.1: Fuerzas que impulsan la competencia en la industria}

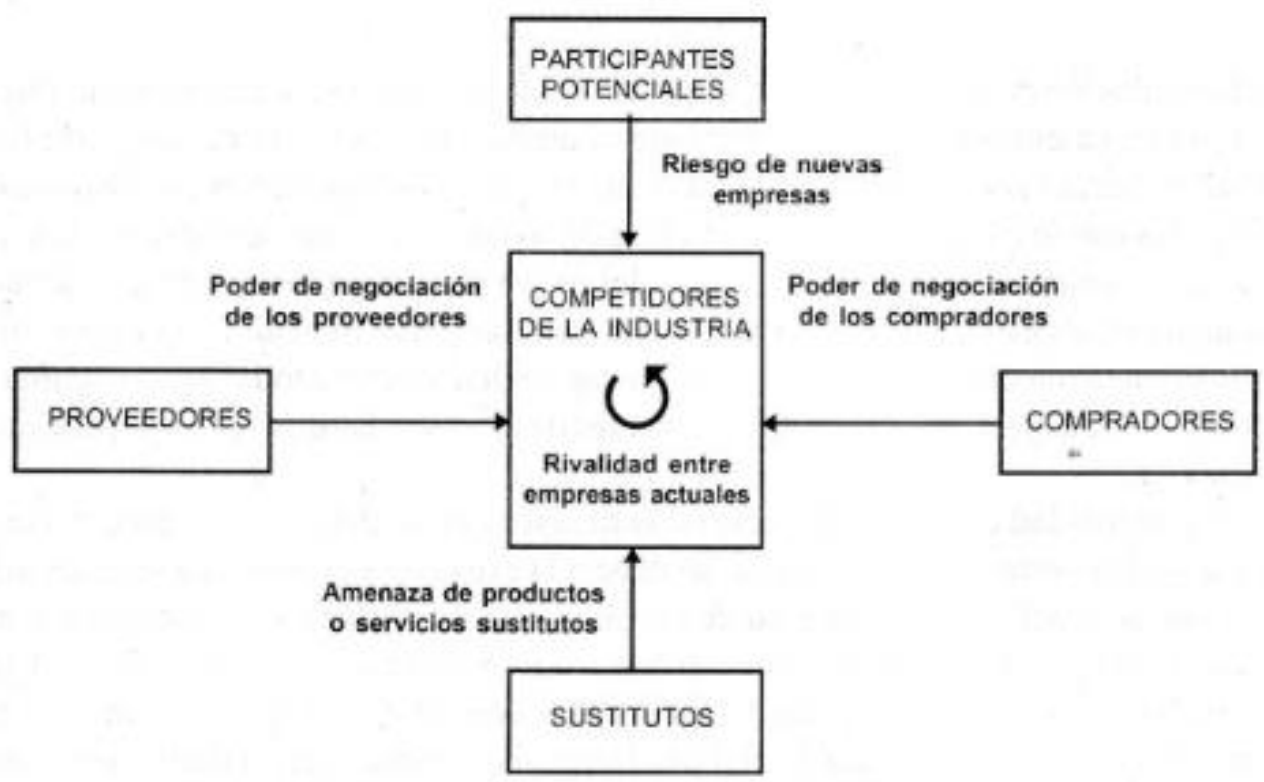

Fuente: PORTER, Michael. Estrategia Competitiva "Técnicas para el análisis de los sectores industriales y de la competencia". 38va ed. México DF.: Patricia, 2008.p 20

Tanto como los compradores (clientes), proveedores, participantes potenciales y los sustitutos, son potenciales "competidores" de la empresa Naranja Producciones S.A.C., su importancia dependerá de las circunstancias del momento, teniendo en cuenta que todos ellos forman una "rivalidad ampliada", las cuales rigen la intensidad de la competencia y la rentabilidad del sector de la industria, ya sea de bienes o servicios.

\subsubsection{Amenaza de productos o servicios sustitutivos}

El surgimiento de sustitutos es un sector del mercado que puede quitarle a las empresas clientes, participación de mercado y utilidades. Por otro lado, Michael Porter nos dice que: "Los sustitutos limitan los rendimientos potenciales de un sector industrial, pues

\footnotetext{
${ }^{75}$ PORTER, Michael. Estrategia Competitiva "Técnicas para el análisis de los sectores industriales y de la competencia”. 38va ed. México DF.: Patricia, 2008.p 20.
} 
imponen un techo a los precios que pueden cobrarse rentablemente en él"76. Al aparecer algún sustituto en el sector del BTL, las empresas como Naranja Producciones S.A.C.., pueden dejar de recibir esos ingresos que van a captar las empresas que ofrecen servicios similares.

En el sector del BTL en el Perú existen varias empresas que brindan servicios sustitutos o complementarios. Por otra parte, hay empresas que solo brindan el servicio de merchandising, el servicio de disfraces, el servicio de carritos snacks, el servicios de catering, el servicio agencias de promotores o modelos, haciéndole competencia a la empresa Naranja Producciones S.A.C., quienes ofrecen paquetes de servicios para la realización de las campañas de BTL que tienen como complemento varios de los servicios ya mencionados. Muchos clientes podrían optar por la contratación de empresas que le brinden servicios puntuales, en vez de contratar a una productora que pueda llevar a cabo toda la realización de la campaña de BTL.

En el mercado actual, existen varios sustitutos que se analizarán a continuación:

- Las vallas y paneles publicitarios. - Las "Activaciones BTL" que consisten en el empleo de creatividad en medios no masivos para realizar el mercadeo de un producto dirigido a un público objetivo, podrían ser reemplazados por vallas y paneles publicitarios si es que los colocan en sitios estratégicamente ubicados, donde hay concurrencia del público objetico. Actualmente, muchos paneles se colocan en paraderos o en avenidas transitadas, pero si la competencia realiza un estudio para saber en dónde se ubica el público objetivo, podría hacerle la competencia al servicio de activaciones en el punto de contacto. La ventaja de las activaciones es que se tiene contacto directo con los clientes, logrando que tengan una experiencia de compra más dinámica y satisfactoria. Los paneles o las vallas publicitarias no interactúan con los clientes y de ellos dependerá sí leen la información impresa en estos paneles y vallas publicitarias.

- El mailing. - El envío de mailing o e.mailing, mediante el uso de base de datos de personas debidamente segmentadas por alguna característica en común, pueden reemplazar a los flyers o brochures que se entregan directamente al público en las Activaciones BTL. Muchas empresas, al no entender el significado de una campaña BTL, pueden pensar que enviando mailing logrará el mismo resultado utilizando flyers o

\footnotetext{
${ }^{76}$ PORTER, Michael. Estrategia Competitiva "Técnicas para el análisis de los sectores industriales y de la competencia". 38va ed. México DF.: Patricia, 2008.p 39.
} 
brochures en el punto de ventas. Esta herramienta es complementaria a la campaña BTL que se esté lanzando, es decir, que solamente entregando flyers no se lograrán resultados sorprendentes. Si durante la campaña BTL se lograr atraer la atención del público objetivo, los flyers y los brochures lograrán su objetivo de brindar una información adicional a los consumidores. El uso de mailing puede ser más barato, pero no se sabrá si logra los resultados esperados.

- Promotores de la misma empresa. - El poner a personal de la empresa en un evento como anfitrión o modelo, podría reemplazar a los modelos, anfitriones y promotores (personal especializado y de acuerdo a las características que desea el cliente) que ofrece Naranja Producciones S.A.C. para los eventos. Muchas empresas, al querer ahorrar en costos, pueden colocar a sus propios trabajadores como modelos, anfitriones o promotores, a pesar que no cuentan con las habilidades necesarias para promover la fidelización o la venta de los productos o servicios.

- Áreas de RRHH o GDH de las empresas. - Los eventos corporativos, deportivos, aniversarios e integración, pueden ser realizados por las áreas de RRH o GDH (Gestión y Desarrollo humano) de las mismas empresas. De esta manera, podrían reemplazar el servicio de "Endomarketing" que ofrece Naranja Producciones S.A.C.

\subsubsection{Amenaza de nuevos competidores}

Básicamente, está compuesto por la aparición de nuevas empresas que se encuentren interesadas en incursionar en el negocio de BTL, lo cual es fácil de hacer si conoces el medio en el cual se desarrolla el negocio, conoces a los proveedores y cuentas con mucha creatividad para sugerir las estrategias necesarias que puedan satisfacer las expectativas del cliente.

Por otra parte, Michael Porter nos dice que: "El riesgo de que ingresen más participantes en una industria dependerá de las barreras actuales contra la entrada y también de la reacción previsible por parte de las empresas ya establecidas. El riesgo será escaso si las barreras son importantes o si las nuevas empresas esperan una gran represalia de los competidores bien consolidados" 77 . En el mercado actual de empresas de

\footnotetext{
77 PORTER, Michael. Estrategia Competitiva “Técnicas para el análisis de los sectores industriales y de la competencia”. 38va ed. México DF.: Patricia, 2008.p 39.
} 
BTL, las barreras de ingreso son grandes, porque el mercado actual es muy competitivo, al contar con empresas ya consolidadas y con gran prestigio a nivel nacional.

Estas barreras que se analizarán a continuación, ponen limitaciones al ingreso de nuevas empresas al sector.

- El valor de la marca. - Todos los años se aperturan nuevas empresas de BTL, pero a pesar que este sector está creciendo arduamente, no significa que todas las empresas que incursionan tengan el mismo éxito. El mercado actual ya cuenta con un gran número de empresas reconocidas y con un valor de marca sólido. Empresas como FCB Mayo, Grey Group Perú, JW Thompson, Rocoto Producciones, Chirimoya BTL, Yellow BTL, Moving Pack, AKM Warketing, SIVAL, Glenda Yaker Eventos Especiales, Garwich BBDO, Marketing Alterno, 360 BTL, OB 460, Mercadotecnia, Chok MKT y Transit Media, son las empresas más reconocidas del sector. Muchas de las que se inician contratan los servicios de estas empresas de BTL por su trayectoria, experiencia, por el trabajo ya realizado anteriormente y por la creatividad demostrada hasta el momento. Por citar un ejemplo, la empresa FCB Mayo ha ganado el Premio Creatividad Innovación Televisiva 2014. Además, también la empresa FCB Mayo ha ganado dos leones de bronce en la categoría Direct (publicidad directa) en el Festival de Cannes Lions 2014. Muchas empresas están dispuestas a pagar precios muy elevados por los servicios ofrecidos por estas empresas galardonas internacionalmente. Por tal motivo, las nacientes empresas tienen una fuerte barrera de entrada, sí es que no cuentan con experiencia previa en el sector $\mathrm{o}$, si no cuentan con una red de contactos fuerte que las apoyen para ingresar en este sector que tiene grandes competidores en publicidad en ATL y BTL.

- Los requisitos de capital. - El capital para ingresar a este sector es bajo al comienzo, pero las empresas que deseen ingresar deberán contar con una capital suficiente para poder hacerle frente a los niveles de inversión que se necesitan para realizar una campaña de BTL. En el caso de Naranja Producciones S.A.C, ellos cuentan con clientes que solicitan campañas de hasta 5 UITs en el sector salud, pero hay varios clientes que solicitan campañas con una inversión de S/ 20,000 o de hasta S/ 200,000 nuevos soles. Las empresas que contratan los servicios de BTL, pagan por el servicio a los 30, 40 y hasta 45 días y los proveedores, solicitan el pago de sus servicios y productos al contado, sí es que no eres una gran empresa del sector. Este desfase entre la fecha entre las cuentas de pago y las cuentas por (ciclo de conversión del efectivo) cobrar obliga a muchas empresas a asociarse entre ellas, para juntar sus capitales y de esta 
manera, atender los requerimientos de sus clientes. Si los nuevos competidores no cuentan con posibles empresas para asociarse, o con un capital suficiente para atender la demanda, no podrán permanecer en actividad durante mucho tiempo.

- El acceso a la distribución. - El acceso a los canales de distribución con los que puede contar una empresa son varios, siendo algunos de bajo costo, como el uso de redes sociales, la creación de una web, el uso del correo electrónico para enviar la cartera de servicios con el que puede contar una empresa de BTL, son algunos ejemplos. En el caso de Naranja Producciones S.A.C, ellos cuentan con una web para sus campañas BTL y una web para su marca Castillo Mágico. Además, cuenta con una cuenta de Facebook y de Twiter, tanto para la empresa como para su marca Castillo Mágico. Por otra parte, una manera de llegar más rápido a las empresas que solicitan los servicios de BTL, es mediante una red de contactos eficiente. En el caso de Naranja Producciones S.A.C, los directivos de la empresa al haber trabajado por años en el sector como modelos y anfitriones, han podido relacionarse y conocer a un gran número de gerentes y jefes de Marketing o de Productos. De esta manera, han podido cerrar varios contratos.

- Ventajas de la curva de aprendizaje. - Los inversionistas que desean incursionar en la creación de una empresa de BTL y no cuenta con experiencia previa en el sector, como el haber trabajado como anfitriones, modelos, proveedores de servicios o como gerentes o jefes de productos, que tengan relación directa con el BTL, tendrán dificultad para poder aprender cómo funciona la producción de las campañas BTL. Por el contrario, si los inversionistas han trabajado directamente o indirectamente en campañas BTL se les hará más fácil el poder incursionar con una empresa. Con el conocimiento previo del sector, podrán desarrollar lineamientos que podrán ser perfeccionados al analizar a las empresas que ya están funcionando. En el caso de Naranja Producciones S.A.C, al ser contratados por una empresa de BTL más grande, llegan a asimilar y aprender su logística y su proceso de elaboración de las campañas. Como la mayoría de las pequeñas empresas de BTL trabajan para empresas de BTL más grande, las más pequeñas pueden desarrollar una curva de aprendizaje que les será útil.

- Diferenciación del producto. - Al ser un mercado donde cada año ingresan nuevas empresas y donde, actualmente, ya existen 17 empresas grandes y consolidadas, la diferenciación es importante para lograr la fidelización y el poder destacar, entre tantas 
empresas en el sector. Actualmente, ofrecer los mismos servicios que las demás empresas, sin un toque de diferenciación, no va lograr que la empresa llegue a posicionarse en el mercado de empresas de BTL. Las empresas más grandes, al contar con creativos de alto nivel y con ello, poder desarrollar conceptos en BTL totalmente novedosos, los ha llevado a consolidarse y poder establecer un precio alto a sus clientes. Las demás empresas que no cuenten con un servicio diferenciado, tendrán que competir en un mercado de precios para poder conseguir clientes.

La diferenciación del bien o servicio tal como lo menciona Michael Porter en su libro Estrategia Competitiva es: “...las empresas ya establecidas gozan de identificación de marca y lealtad de los consumidores, obtenidas por medio de la publicidad, el servicio al cliente, la diferencia de producto ..."78 de la que podemos rescatar sobre todo el punto de "diferenciación del producto" en la que Naranja Producciones S.A.C. conoce muy bien la importancia de ofrecer un excelente servicio ya que de esta manera deja en alto la imagen de la empresa y alza la valla ante potenciales competidores, adicionalmente sirve como un medio de publicidad a costo cero.

Se puede concluir que, el ingreso de potenciales competidores es bajo si no cuentan con experiencia previa y con capital suficiente para poder hacer frente a campañas de gran alcance.

\subsubsection{El poder de negociación de los compradores o clientes}

El poder de negociación de los compradores o clientes es importante, ya que ellos pueden enfrentar a las empresas para que ofrezcan el mejor servicio o producto al mejor precio. Michael Porter nos dice que: "Los compradores compiten con la industria cuando la obligan a reducir los precios, cuando negocian una mejor calidad o más servicios y cuando enfrentan los rivales entre si" 79

En ese sentido, los clientes tienen un poder de negociación bastante alto, ya que hay muchas empresas que pueden brindar servicios similares a los que ofrece Naranja Producciones S.A.C. y muchas veces lo expresan durante la negociación del precio o del requerimiento del paquete de servicios que desean a cambio del presupuesto que tienen

\footnotetext{
${ }^{78}$ PORTER, Michael. Estrategia Competitiva “Técnicas para el análisis de los sectores industriales y de la competencia”. 38va ed. México DF.: Patricia, 2008.p 25.

${ }^{79}$ PORTER, Michael. Estrategia Competitiva "Técnicas para el análisis de los sectores industriales y de la competencia". 38va ed. México DF.: Patricia, 2008.p 40.
} 
asignado para las campañas BTL, por lo que Naranja Producciones S.A.C., a través de su ejecutivo de ventas, hace mención del prestigio ganado por la empresa, el profesionalismo con el que realizan su trabajo, las cartas de recomendación que tienen de otras empresas a las que han brindado sus servicios e incluso se hace mención del informe al término del servicio, el cual incluye un documento escrito acompañado de un sustento fotográfico y audio visual (videos especialmente editados) que se le entrega al cliente, tal como lo mencionan los directivos de Naranja Producciones S.A.C., en la entrevista realizada el 14 de octubre del 2014.

A continuación se detallan los elementos de análisis que intervienen en este punto.

- Diferenciación. - Los clientes al contar con un gran abanico de empresas de BTL, puede escoger la que mejor crean conveniente. El poder de negociación de los clientes dependerá del tamaño y reconocimiento de la empresa de BTL. Si la empresa de BTL es FCB Mayo o Chirimoya BTL, estas empresas ofrecen sus servicios a un precio alto, al contar con un equipo grande de creativos, que pueden desarrollar campañas de alto nivel de creatividad, que consigan fidelizar a los clientes de las empresas que las contratan. Además, al ser una empresa grande pueden manejar campañas de gran envergadura y ofrecer plazos de pago a sus clientes hasta de 60 días. En el caso de empresas pequeñas como Naranja Producciones, cuenta con costos bajos para ofrecer precios competitivos a sus clientes, para poder lograr una mayor participación en el sector. Muchas empresas del Estado buscarán el mejor precio para poder realizar alguna campaña en su sector.

- Información acerca del proveedor. - Las empresas tienen conocimiento de los precios del sector, debido a que muchas empresas de BTL envían sus portafolios de servicios, para concretar citas de negocios. Por otra parte, las empresas que han hecho uso del BTL, durante años ya cuentan con el conocimiento de los precios suben o bajan en el sector. Lo que es determinante a la hora de contratar el servicio es el nivel de creatividad de la campaña a realizar o el precio del servicio, sí la empresa de BTL que lo ofrece es pequeña y no muy conocida.

- La posibilidad de integración vertical hacia atrás. - El poder de negociación de las empresas para querer hacer toda la producción de las campañas BTL es bajo. Para poder llevar a cabo una producción de algún evento o campaña BTL se necesita a personal con las habilidades necesarias para poder realizar la coordinación con cada 
uno de los proveedores, además de contar con una lista de proveedores eficientes y de altos estándares de calidad. Por otra parte, la empresa debería de contar con un equipo de creativos, que puedan crear una campaña de gran impacto.

- Sensibilidad del comprador al precio. - En este punto hay que dividir a las empresas de BTL en grandes y pequeñas. En el caso de las empresas como FCB Mayo, el precio es alto y los clientes que los contratan lo hacen por su prestigio y experiencia en el mercado nacional. En cambio, en las empresas de BTL pequeñas están sujetas al precio. Los clientes negociarán el precio y la fecha de pago. Si la fecha de pago es muy prolongada, las empresas de BTL pequeñas no contarán con capital necesario para asumir sus responsabilidades con sus proveedores. En el caso de Naranja Producciones S.A.C, al contar con su marca de Castillo Mágico cuentan con efectivo semanal, para poder hacer frente a sus obligaciones financieras. El poder de negociación de los clientes en este punto es alto.

Los principales clientes de Naranja Producciones S.A.C. se pueden clasificar en empresas privadas y entidades públicas.

Según lo conservado con los dueños de la empresa Naranja Producciones S.A.C., por un tema de contactos y de forma fortuita se dio la oportunidad de trabajar para el Ministerio de Salud. Empezaron a trabajar con uno de los comunicadores del Ministerio de Salud y debido al buen trabajo y servicio realizado fueron haciéndose de un mercado dentro del MINSA. Posteriormente, fueron conociendo a más comunicadores y fue uno de ellos quien los refirió al Seguro Integral de Salud y desde ese día ha seguido trabajando con ambas instituciones del Estado Peruano.

También, por un tema de contactos, la empresa Naranja Producciones empezó a trabajar para Petro Perú. Una observación que nos dieron los directivos de Naranja Producciones S.A.C. es que, todas las empresas del Estado tienen personas claves en cada área y cada una es independiente de la otra, es decir, que cada área maneja su propio presupuesto para eventos y es autónomo es su decisión de contratación.

\subsubsection{El poder de negociación de los proveedores o vendedores}

El poder de negociación de los proveedores es un punto importante, pues si los proveedores de servicios o productos son pocos, estos podrían controlar los precios del 
mercado, haciendo que las empresas de BTL eleven el precio final a los clientes. Por tal motivo, Michael Porter nos dice que: "Los proveedores pueden ejercer poder de negociación sobre los participantes de una industria, si amenazan en elevar los precios o disminuir la calidad de los bienes y servicios que ofrecen. De ese modo, los más poderosos reducen drásticamente la rentabilidad en una industria incapaz de recuperar los incrementos de costos con sus precios" 80 .

En el caso del sector del BTL el poder de los proveedores es bajo como se observará a continuación:

- Análisis de concentración de proveedores. - En la actualidad no existe una concentración o monopolio de los proveedores, debido a que existen varias empresas que brindan los servicios que contratan las empresas de BTL. Si una empresa desea contratar el servicio de impresiones para realizar material merchandising, lo puede encargar a las galerías que existen en la avenida Wilson y, si desean confeccionar disfraces o trajes para los anfitriones o promotores, las empresas de BTL podrían ir al emporio comercial de Gamarra. Existe una vasta oferta de proveedores de diferentes calidades. La mayor dificultad que puede surgir a la hora de contratar a un proveedor es si cumplirá con el contrato pactado respecto a la fecha de entrega de los materiales o servicios estipulados. En el caso de la empresa Naranja Producciones S.A.C. los directivos cuentas con una base de datos de proveedores y trabajan con empresas referidas.

- Diferenciación de insumos. - En el mercado actual existen varios proveedores de servicios y productos. Por tal motivo, se puede encontrar una gran variedad de precios y de calidad de servicios en las empresas proveedoras. No hay una gran diferenciación entre los proveedores, pero se debe realizar una selección cuidadosa de estas empresas, para poder contratarlas a la hora de llevar a cabo la realización de una campaña. En el caso de Naranja Producciones S.A.C., cuenta con varios proveedores del mismo producto o servicio, y puede evaluar cuál de ellos tiene el mejor precio, en cambio, en el punto donde el proveedor tiene un mayor nivel de negociación es sobre el plazo de pago, debido a que la mayoría de ellos sólo acepta el pago al contado, lo cual le quita liquidez a la empresa Naranja Producciones S.A.C. Un punto delicado es

\footnotetext{
${ }^{80}$ PORTER, Michael. Estrategia Competitiva “Técnicas para el análisis de los sectores industriales y de la competencia”. 38va ed. México DF.: Patricia, 2008.p 40.
} 
que sus clientes le pueden pagar en 45 días, mientras que Naranja Producciones S.A.C. tiene que pagar a sus proveedores el mismo día que adquiere sus servicios. Las políticas de pago de sus clientes y las políticas de cobro de sus proveedores crean una situación delicada, porque le quita liquidez a la empresa.

- Costos de cambio. - En el caso que Naranja Producciones S.A.C. tenga que cambiar de proveedor de servicios o de productos por diferentes circunstancias, no habría ningún inconveniente de hacer dicho cambio, porque en el mercado actual existen varias empresas que brindan el mismo servicio. Además, muchos proveedores trabajan con otras empresas y se puede solicitar proveedores referidos a las demás empresas BTL. Como en este sector las empresas BTL se asocian para poder llevar a cabo producciones de gran envergadura, no es de extrañar que compartan proveedores o se refieran proveedores.

- Rivalidad interna entre empresas de BTL. - La rivalidad es baja. Las empresas proveedoras trabajan con varias empresas de BTL. Esto sucede entre todas las empresas, desde las más grandes hasta las más pequeñas, pero no existe una rivalidad entre las empresas por los proveedores, ya que existen varios en la actualidad. En el caso de Naranja Producciones S.A.C, cuenta con una base de datos de proveedores, pero trabajan, por lo general, con las mismas empresas proveedoras, debido a que ya cuentan con la experiencia previa de su trabajo; pero también han trabajado con los proveedores de la empresa Mangosta S.A.C., con la cual se asocian de vez en cuando para eventos que sobrepasan su capacidad de respuesta.

\subsubsection{Competencia en el mismo sector}

El nivel competencia entre las empresas define cómo se van a expresar los precios, los servicios o productos a oferta y las estrategias que las empresas van a lanzar al mercado. Es en este sentido que el señor Michael Porte nos dice que: "La rivalidad se debe a que uno o más competidores se sienten presionados o ven la oportunidad de mejorar su posición. En la generalidad de las industrias, las tácticas competitivas de una compañía influyen profundamente en las otras y, por tanto, provocan represalias o esfuerzos por contrarrestarlas; en otras palabras las compañías son mutuamente dependientes" ${ }^{81}$.

\footnotetext{
${ }^{81}$ PORTER, Michael. Estrategia Competitiva "Técnicas para el análisis de los sectores industriales y de la competencia". 38va ed. México DF.: Patricia, 2008.p 33
} 
Por otra parte, la rivalidad actual entre las empresas del sector es alta, porque el principal objetivo de las empresas de BTL es obtener el mayor número de cuentas de las empresas más grandes del país, porque significa mayores ingresos para sus bolsillos. Por tal motivo, se podrá observar a continuación las barreras de ingreso a este sector por parte de la competencia, y para ello deberemos de analizar los siguientes elementos:

- Alto número de competidores. - Cada día aparecen más empresas BTL más competitivas cada día. En la actualidad, existen 17 grandes empresas de BTL en el país, como la renombrada y galardonada empresa FCB Mayo. Muchas empresas del sector ofrecen los servicios de ATL y BTL o solamente el de BTL. Las empresas más grandes como son FC Mayo, Grey Group Perú, JW Thompson, Akm Warketing, Chirmoya BTL, Yelow BTL en muchos casos subcontratan a otras empresas BTL para que se encarguen de la producción del evento, debido a que las empresas más grandes se encargan de la parte creativa de la campaña. La competencia está dada por las empresas existentes y que prestan servicios BTL, tal como lo realiza Naranja Producciones S.A.C., y generalmente están dadas en función al precio y la innovación de nuevos servicios. La competencia entre estas empresas es fuerte, porque cada día deben invertir más en creativos y desarrollar un factor diferencial que los aleje de la competencia.

- Condiciones de costos. - Los costos que maneja Naranja Producciones son bajos y pueden hasta ofrecerlos a los mismos proveedores que utilizan varias empresas grandes del sector. El costo más alto se encuentra en la contratación de personal creativo, para que ellos se dediquen al desarrollo de las campañas de BTL. Muchas empresas, como es el caso de Naranja Producciones S.A.C., no cuentan con área creativa y son los mismos directivos que se encargan de llevar a cabo el diseño de las campañas. Esta situación la viven varias empresas pequeñas y medianas del sector. Caso contrario son las empresas como FCB Mayo, Chirimoya BTL o Yellow BTL, que cuentan con sus propias áreas creativas. Las empresas más grandes del sector cuentan con un grupo de creativos que les permite ofrecer campañas innovadoras y de gran impacto para sus clientes.

- Grupos empresariales. - Este año se realizó la adquisición de una empresa muy importante en el sector. La empresa Grey Group Perú compro a la empresa peruana más grande de publicidad llamada Circus Perú. La empresa Grey es una empresa 
fundada en el año 1917 y que se encuentra en todo el mundo. Por otra parte, en el mercado nacional se encuentra la empresa JW Thompson con sedes en varias ciudades a nivel internacional. Ambas empresas son extranjeras y con una gran presencia en el mercado local y mundial. Por el lado empresarial peruano, está la empresa FCB Mayo con sedes en Perú, Colombia, Ecuador y Chile. Esto demuestra que las empresas de BTL en el Perú, están gestando un sector muy competitivo y crean una gran barrera de ingreso a nuevas empresas.

- Ritmo de crecimiento de la industria. - Como se analizó anteriormente, el sector del BTL en el país está creciendo de manera rápida como lo menciona Jorge Jara, Director de Operaciones BTL Trade de la agencia FCB Mayo por la InfoMarketing, quien indicó que: “...en una reunión de la ANDA, se mencionó que los principales anunciantes destinaban casi un 50\% de su presupuesto a acciones de BTL"82. También una similar opinión tiene la señorita Desirée Taboada, Directora Comercial del Grupo Lucky dice que: “...señala que la inversión en BTL en el Perú ocupa un $40 \%$ del total de los presupuestos de marketing de las empresas, mientras el ATL alcanza un 60\%"83. Esto demuestra que el BTL está teniendo una mayor participación en los presupuestos de las empresas del país, lo cual lleva a que las empresas cuentan con un escenario propicio para seguir creciendo. A pesar que la competencia es cada día más fuerte, el crecimiento del presupuesto del BTL dentro de las empresas es un indicador positivo. Si deseamos saber el monto invertido en BTL, el señor Jorge Jara, gerente general de Periscopio nos dice que: “...si preguntas montos de inversión, el Perú invierte US\$700 millones en publicidad y 200 millones más para BTL" ${ }^{84}$. Esta cifra de 200 millones de dólares representaría un $28.6 \%$ del monto total que se invierte en el mercado peruano.

Se puede concluir que las barreras de ingreso por parte del poder de la competencia son fuertes porque, en la actualidad, ya existen las siguientes empresas como: FCB MAYO Perú, Yellow BTL, Chirimoya BTL, Moving Pack, AKM Warketing, Publicis Perú - Perú, SIVAL, Glenda Yaker Eventos Especiales, Garwich BBDO, Marketing Alterno, 360 BTL, OB 460, Mercadotecnia, Chok y Transit Media, y otras más, sin contar a Naranja

\footnotetext{
82 “El BTL en Perú es un adolescente por S.A.C.ar su DNI". En: InfoMarketing. (en línea) PE, domingo, 09 de noviembre del 2014. Disponible: http://www.infomarketing.pe/btl-int.php?id=4

83“Especial BTL: Haciendo Camino al andar". En: InfoMarketing. (en línea) PE, domingo, 09 de noviembre del 2014. Disponible: http://www.infomarketing.pe/btl-int.php?id=8

84 "Empresas peruanas invertirán más de US\$ 900 millones en servicios de Marketing y Publicidad durante 2013". En: BizNews. (en línea) PE, domingo, 09 de noviembre del 2014. Disponible: http://biznews.pe/entrevistas/jorge-jara-gerente-general-periscopio-internetno-es-medio-alternativo-es-medio
} 
Producciones S.A.C. Además, las empresas más grandes cuentan con un área creativa que les permite desarrollar producciones de mayor alcance. Por otra parte, el surgimiento de grupos empresariales, como es el caso de la empresa Grey Perú que compro a la empresa Circus Perú, demuestra que el sector está acomodándose. Por último, una ventaja a favor de todas las empresas de BTL, es que, el presupuesto que las empresas están destinando a esta actividad ha crecido años tras año, lo cual crea grandes oportunidades de negocio.

Por otra parte, El Ojo de Iberoamérica premió a las Mejor Agencias de la región en la temporada 2013-2014, en donde se hizo un ranking con las 50 mejores empresas de publicidad de la región Iberoamericana. De este ranking se puede apreciar que solo 4 agencias de publicidad del Perú figuran en esta lista. Según la página web de El Ojo de Iberoamérica dice que: "Este año, la más galardonada fue The Cyranos McCann, la compañía con menos de dos años, que es liderada por Leandro Raposo, Pablo Colonnese y Federico Duberti, entre otros" 85

Tabla 5.1: Agencias del Año por país y su puntaje

\begin{tabular}{|l|l|}
\hline \multicolumn{2}{|c|}{ Agencia del Año - País - Puntos } \\
\hline 1. The Cyranos McCann- España - 170 & 26. Latinworks - EE.UU - 33 \\
\hline 2. Del Campo S\&S - Argentina - 167 & 26. Ponce - Argentina - 33 \\
\hline 3. Ogilvy \& Mather Brasil - Brasil - 157 & 29. Circus Arg./México - 30 \\
\hline 4. Ogilvy \& Mather Argentina - Argentina - 150 & 29. McCann Madrid - España - 30 \\
\hline 5. Ogilvy \& Mather Colombia - Colombia - 119 & 29. DDB México - México - 30 \\
\hline 6. FCB Brasil - Brasil - 113 & 32. Leo Burnett Colombiana - Colombia - 28 \\
\hline 7. Grupo Gallegos - EEUU - 103 & 33. Y\&R Argentina - Argentina - 27 \\
\hline 8. Loducca - Brasil - 80 & 34. Cheil Iberia - España - 26 \\
\hline 9. LOLA - España - 69 & 34. DON Argentina - 26 \\
\hline 10. DDB Brasil - Brasil - 67 & 36. Borghi/Lowe - Brasil - 25 \\
\hline 11. Almap BBDO - Brasil - 62 & 36. Santa Clara - Brasil - 25 \\
\hline 12. McCann ErickSon Lima - Perú - 60 & 36. Fahrenheit DDB - Perú - 25 \\
\hline 13. Young \& Rubicam Brasil - Brasil - 56 & 39. Ogilvy \& Mather CR - Costa Rica - 24 \\
\hline 14. DAVID Miami - EE.UU - 55 & 39. Simple Chile - 24 \\
\hline 15. Lowe/SSP3 - Colombia - 54 & 39. BBDO Chile - Chile - 24 \\
\hline 15. Ogilvy Mexico - México - 54 & 42. Publicis Perú - Perú - 22 \\
\hline 17. Sancho BBDO - Colombia - 50 & 42. BBDO México - México - 22 \\
\hline 18. Prolam Young \& Rubicam - Chile - 49 & 44. ONIRIATBWA - Paraguay - 21 \\
\hline 18. JWT Brasil - Brasil - 49 & 44. DDB Latina Puerto Rico - Puerto Rico - 21 \\
\hline 20. TBWA - España - 48 & 44. Leo Burnett Costa Rica - Costa Rica - 21 \\
\hline 21. DDB España - España - 46 & 44. Lew Lara TBWA - Brasil - 21 \\
\hline 21. Leo Burnett Argentina - Argentina - 46 & 48. JWT San Juan - Puerto Rico - 20 \\
\hline 23. Geometry Global Colombia - Colombia - 44 & 48. DAVID Buenos Aires - Argentina - 20 \\
\hline 24. Y\&R Colombia - Colombia - 37 & 50. TBWA Buenos Aires - Argentina - 19 \\
\hline 25. Grey Argentina - Argentina - 34 & 50. Isobar Brasil - Brasil - 19 \\
\hline 26. FCB Mayo - Perú - 33 & 52. Leo Burnett Tailor Made - Brasil - 18 \\
\hline & \\
\hline
\end{tabular}

\section{Elaboración Propia.}

85 "El Ranking de las Mejores Agencias de El Ojo 2014". En: El Ojo de Iberoamérica. (en línea), 2014. Disponible: http://www.elojodeiberoamerica.com/el-ranking-de-las-mejores-agencias-de-el-ojo-2014/ 
Se puede observar que solo cuatro agencias de publicidad peruanas han sido consideradas entre las cincuenta agencias más importantes, pero hay que destacar que de las cuatro agencias de publicidad, solamente una es peruana (FCB Mayo), las otras tres agencias son extranjeras con sede en el Perú. Por otra parte, de las cuatro agencias solo dos se dedican al BTL además del ATL.

\section{Tabla 5.2: Agencias peruanas}

\begin{tabular}{|l|c|}
\hline \multicolumn{2}{|c|}{ Agencias Peruanas } \\
\hline 12. McCann ErickSon Lima - Perú - 60 & ATL \\
\hline 26. FCB Mayo - Perú - 33 & ATL y BTL \\
\hline 36. Fahrenheit DDB - Perú - 25 & ATL \\
\hline 42. Publicis Perú - Perú - 22 & ATL y BTL \\
\hline
\end{tabular}

Elaboración Propia.

\subsection{Matriz de atractividad de cada una de las cinco fuerzas.}

A partir del análisis de las fuerzas competitivas de la industria en la sección anterior, se reúnen los elementos revisados de cada una de ellas en una matriz de atractividad, donde el grado de ésta alcanzado en la industria es inversamente proporcional al poder que tenga cada una de las fuerzas. Cada uno de los elementos analizados en las respectivas fuerzas, tienen un grado de atractividad particular para la industria, por lo cual se está asignando un grado que varía de 1 a 5 , siendo 1: si no resulta nada atractivo y 5 : si resulta muy atractivo. Además, como la relevancia de cada elemento dentro de la fuerza no es la misma, también se está asignado a cada elemento un factor de ponderación cuya suma total es igual a 1.

Asimismo, el resultado de la Matriz de atractividad se ha obtenido a partir de la información y el análisis de la opinión de expertos externos y directivos de la empresa Naranja Producciones S.A.C.. 


\subsubsection{Poder de negociación de los clientes y consumidores}

La matriz de atractividad para el poder de negociación de los clientes y consumidores se muestra en cuadro 5.1.

Cuadro 5.1: Matriz de atractividad para el poder de negocio de los clientes y consumidores

\begin{tabular}{|c|c|c|l|c|c|}
\hline $\begin{array}{c}\text { Elementos de } \\
\text { análisis }\end{array}$ & Poder & $\begin{array}{c}\text { Factor de } \\
\text { Relevancia }\end{array}$ & $\begin{array}{l}\text { Criterios que lo hacen } \\
\text { poco atractivo }\end{array}$ & $\begin{array}{c}\text { Grado de } \\
\text { atractividad } \\
(1 \text { a 5) }\end{array}$ & $\begin{array}{l}\text { Criterios que lo hacen } \\
\text { muy atractivo }\end{array}$ \\
\hline
\end{tabular}

Las empresas que contratan el servicio de

a) Diferenciación Medio 0.3 BTL pagan mas por la campaña cuando la empresa es reconocida y Varias empresas como las públicas buscan un servicio con prestigio. bueno pero a menor precio.

La experiencia de las empresas grandes que contratan los servicios de las empresas de BTL ya 4 tienen en su poder los precios que se manejan en el sector.

Las empresas que contratan los servicios de BTL podrían llevar a 3 cabo la producción de las campañas.

Las empresas del sector público buscan el mejor precio a la hora de 2 contratar los servicios de una empresa de BTL.
Las micros y pequeñas empresas que no hacen uso del BTL aún son un mercado potencial para ingresar con precios atractivos.

La complejidad de llevar a cabo la campaña es una barrera para muchas empresas que no cuentan con el conocimiento previo.

Las empresas privadas buscan sobre todo creatividad en las campañas y si el proveedor de BTL es conocido y renombrado, estarán dispuestos a paga el precio pactado.

\begin{tabular}{c|c|c|c|}
\hline Resultado & Medio & 1 & 3.1 \\
\hline
\end{tabular}

Elaboración propia.

El grado de atractividad es 3.1. Esto indica que el poder de negocioación de los clientes y consumidores es media y atractiva para el mercado. 


\subsubsection{Poder de negociación de los proveedores}

La matriz de atractividad para el poder de negociación de los proveedores se muestra en el siguiente cuadro.

\section{Cuadro 5.2: Matriz de atractividad para el poder de negociación de los proveedores}

\begin{tabular}{|c|c|c|c|c|c|c|}
\hline & $\begin{array}{l}\text { Elementos de } \\
\text { análisis }\end{array}$ & Poder & $\begin{array}{l}\text { Factor de } \\
\text { Relevancia }\end{array}$ & $\begin{array}{l}\text { Criterios que lo hacen } \\
\text { poco atractivo }\end{array}$ & $\begin{array}{c}\text { Grado de } \\
\text { atractividad } \\
(1 \text { a 5) } \\
\end{array}$ & $\begin{array}{l}\text { Criterios que lo hacen } \\
\text { muy atractivo }\end{array}$ \\
\hline a) & $\begin{array}{l}\text { Diferenciación } \\
\text { de insumos }\end{array}$ & Bajo & 0.3 & $\begin{array}{l}\text { La competencia puede } \\
\text { contratar los servicios de } \\
\text { los proveedores de } \\
\text { Naranja Producciones } \\
\text { SAC. }\end{array}$ & 3 & $\begin{array}{l}\text { Una gran cantidad de } \\
\text { proveedores de todos los } \\
\text { rubros. }\end{array}$ \\
\hline b) & $\begin{array}{l}\text { Rivalidad } \\
\text { interna entre } \\
\text { empresas de } \\
\text { BTL }\end{array}$ & Medio & 0.5 & $\begin{array}{l}\text { Existen varias empresas } \\
\text { proveedoras, pero no } \\
\text { todas cuentan con la } \\
\text { misma calidad. }\end{array}$ & 4 & $\begin{array}{l}\text { La existencia de base de } \\
\text { datos de proveedores, y los } \\
\text { referidos existentes en el } \\
\text { sector. }\end{array}$ \\
\hline c) & $\begin{array}{l}\text { Análisis de } \\
\text { concentración } \\
\text { de proveedores }\end{array}$ & Bajo & 0.2 & $\begin{array}{l}\text { Muchas empresas } \\
\text { proveedoras de servicios } \\
\text { o productos no cuentan } \\
\text { con las herramientas } \\
\text { necesarias para cumplir } \\
\text { con los requerimientos } \\
\text { de las empresas de BTL. }\end{array}$ & 3 & $\begin{array}{l}\text { Existen una gran variedad } \\
\text { de proveedores ubicados en } \\
\text { grandes emporios } \\
\text { comerciales. }\end{array}$ \\
\hline & Resultado & Medio & 1 & & 3.5 & \\
\hline
\end{tabular}

Elaboración propia.

El grado de atractividad para los proveedores es de 3.5. Esto indica que el poder de negociación de proveedores en el sector BTL es relativamente alta.

\subsubsection{Amenaza del ingreso de nuevos competidores}

La matriz de atractividad para el poder de negociación de los competidores se muestra en el siguiente cuadro: 


\section{Cuadro 5.3: Matriz de atractividad para la amenaza de nuevos competidores}

\begin{tabular}{|c|l|c|l|c|l|}
\hline $\begin{array}{c}\text { Elementos de } \\
\text { análisis }\end{array}$ & Poder & $\begin{array}{c}\text { Factor de } \\
\text { Relevancia }\end{array}$ & $\begin{array}{l}\text { Criterios que lo hacen } \\
\text { poco atractivo }\end{array}$ & $\begin{array}{c}\text { Grado de } \\
\text { atractividad } \\
(\mathbf{1} \text { a 5 })\end{array}$ & $\begin{array}{l}\text { Criterios que lo hacen } \\
\text { muy atractivo }\end{array}$ \\
\hline
\end{tabular}
El valor de la Alto
marca

b) Los requisitos Alto
de capital

c) $\begin{aligned} & \text { El acceso a la } \\ & \text { distribución }\end{aligned}$ Bajo

Ventajas de la

d) curva de Medio aprendizaje

e) Diferenciación
del producto
Empresas con trayectoria

en el mercado y

galardonadas con

premios internacionales.

Las campañas de BTLde

0.2 las cuentas mas grandes

requieren de una

inversión fuerte.

Todas las empresas de

0.2

BTL utilizan redes

sociales y Webs.

Las que no cuenten con exeperiencia previa tendran dificultades en adaptarse.

Las empresas de BTL mas grandes ya cuentan con la identificación de marca y la lealtad de los consumidores.
Muchas micros y pequeñas empresas no pueden contratar los servicios de 4 grandes compañias de BTL. Buscan los servicios de empresas de BTL mas pequeñas.

La posibilidad de asociarse con otras empresas BTL y

4 la existencia de clientes como el Estado que solicitan campañas de hasta 3 UITs.

La red de contactos que 3 puedan tener los directivos de la empresa.

El poder trabajar para empresas de BTL mas

4 grande permite el aprendizaje sobre las campañas de BTL.

Las empresas de BTL

3 tienen identificadas las necesidades de los clientes.

\section{Resultado}

Medio

1

3.6

Elaboración propia.

El grado de atractividad para los nuevos competidores es 3.6. Esto indica que el poder de negociación es relativamente alta y atractiva para el mercado. 


\subsubsection{Amenaza de productos sustitutos}

La matriz de atractividad respecto de la amenaza de productos sustitutos se muestra en el siguiente cuadro:

Cuadro 5.4: Matriz de atractividad para la amenaza de productos sustitutos

\begin{tabular}{|c|l|l|l|c|l|}
\hline $\begin{array}{c}\text { Elementos de } \\
\text { análisis }\end{array}$ & Poder & $\begin{array}{c}\text { Factor de } \\
\text { Relevancia }\end{array}$ & $\begin{array}{l}\text { Criterios que lo hacen } \\
\text { poco atractivo }\end{array}$ & $\begin{array}{c}\text { Grado de } \\
\text { atractividad } \\
(\mathbf{1} \text { a 5) }\end{array}$ & $\begin{array}{l}\text { Criterios que lo hacen } \\
\text { muy atractivo }\end{array}$ \\
\hline
\end{tabular}

Las vallas y

a) paneles Bajo

publicitarios
Ubicarlos

estratégicamente en todo

Lima
Puede que el publico objetivo no circule en las avenidades en donde se ubiquen las vallas y paneles publicitarios.

Necesidad de una base de datos. b) Mailing

Bajo

0.1

Reemplaza a los flyers

Reemplazo de los

Promotores de

c) la misma Medio

empresa

0.7

anfitriones con el

personal de la misma

empresa contratante

3

con la preparación que

cuenta un modelo, anfitrion

o promotor de eventos.

Las áreas de RRHH o GDH

Áreas de RRHH

d) o GDH de las Alto

empresas

Evento corporativo

personalizado no cuentan con la logistica

y la capacidad de

produccion de una empresa de BTL.

\begin{tabular}{l|l|l|l} 
Resultado & Medio & 1 & 3.2
\end{tabular}

Elaboración propia.

El grado de atractividad es 3.2. Esto indica que el poder de atractividad para el poder de los sustitutos es relativamente alta y atractiva para el mercado. 


\title{
5.3.5. Rivalidad de los Competidores
}

La matriz de atractividad respecto de la rivalidad de los competidores se muestra en el siguiente cuadro:

Cuadro 5.5: Matriz de atractividad para la rivalidad de los competidores

\begin{tabular}{|c|l|c|l|c|l|}
\hline $\begin{array}{c}\text { Elementos de } \\
\text { análisis }\end{array}$ & Poder & $\begin{array}{c}\text { Factor de } \\
\text { Relevancia }\end{array}$ & $\begin{array}{l}\text { Criterios que lo hacen } \\
\text { poco atractivo }\end{array}$ & $\begin{array}{c}\text { Grado de } \\
\text { atractividad } \\
(\mathbf{1} \text { a 5) }\end{array}$ & $\begin{array}{l}\text { Criterios que lo hacen } \\
\text { muy atractivo }\end{array}$ \\
\hline
\end{tabular}
alto número de
competidores
0.5
Actualmente existen 17
empresas de BTL grandes 3 en el Perú.
Las empresas grandes cuentan con precios elevados que no pueden ser cubiertos por las micro y pequeñas empresas.
$\begin{array}{llll}\text { b) } \begin{array}{l}\text { Condiciones de } \\ \text { costos }\end{array} \text { Alto } & 0.05 & \begin{array}{l}\text { Alto costo de } \\ \text { contratación de personal } 3\end{array}\end{array}$ creativo.

Crecimiento del númerode instituciones que imparten carreras de publicidad.

\author{
La posibilidad de \\ asociación por parte de las \\ pequeñas empresas de BTL \\ para poder llevar a cabo \\ producciones de mayor \\ envergadura.
}

Se ha iniciado la compra
estratégica de empresas 3
claves del sector.

La posbilidad de que solo un pequeño grupo de El presupuesto asignado a empresas de BTL este las campañas BTL en el captando la inversión en 2 Perú se ha incrementado campañas de BTL por parte de los clientes. d) crecimiento de bajo 0.05 la industria

\begin{tabular}{|c|c|c|c|}
\hline Resultado & Medio & 1 & 2.95 \\
\hline
\end{tabular}

Elaboración propia.

El grado de atractividad en la rivalidad entre competidores es 2.95. Esto indica que es relativamente medio y atractiva para el mercado. 


\subsection{Análisis del Grado de atractividad de la industria}

Al consolidar el grado de atractividad de las cinco fuerzas se aprecia que en general la atractividad de la industria es de nivel medio.

\section{Cuadro 5.6: Matriz de atractividad de la Industria}

\begin{tabular}{llccc}
\multicolumn{1}{c}{ Fuerzas competitivas } & Poder & Ponderación & Nivel de Atractividad & $\begin{array}{c}\text { Nivel de } \\
\text { atractividad } \\
\text { ponderado }\end{array}$ \\
\hline $\begin{array}{l}\text { Poder de negociación de los clientes y } \\
\text { consumidores }\end{array}$ & Medio & 0.1 & 3.1 & 0.31 \\
Poder de negociación de los proveedores & Medio & 0.1 & 3.5 & 0.35 \\
Amenaza de productos sustitutos & Medio & 0.2 & 3.6 & 0.72 \\
Amenaza de ingreso de nuevos competidores & Medio & 0.1 & 3.2 & 0.32 \\
Rivalidad de los competidores & Medio & 0.5 & 2.95 & 1.475 \\
\hline \multicolumn{1}{c}{ Resultado ponderado } & Medio & $\mathbf{l}$ & $\mathbf{3 . 1 7 5}$ \\
\hline
\end{tabular}

Elaboración propia.

\subsection{Matriz de Perfil Competitivo MPC}

La Matriz del perfil competitivo MPC, nos dice cómo está una empresa en relación a su competencia directa dentro de la industria publicitaria. cabe resaltar que el grupo estratégico con quienes va a compararse son las empresas de BTL que tienen los mismos factores en su entorno; asimismo estas empresas han trabajado directa o indirectamente en un evento, puesto que así puede lograrse comparar de forma más directa. Las empresas son Chirimoya BTL, Roho BTL, Mangosta Comunicaciones, Rocoto Producciones.

Con la información obtenida, la empresa puede llevar a cabo las estrategias, que estarán basadas a partir del posicionamiento de la competencia.

Para realizar la matriz se debe de seleccionar un conjunto de factores críticos de éxito, los cuales se han tomado en su mayoría de la sección anterior. A cada uno de estos factores críticos de éxito, se le asigna un peso relativo por su influencia en la industria, cuya suma total es igual a 1. Luego, por cada factor elegido se clasifica, tanto a Naranja Producciones S.A.C. como a la competencia.

De acuerdo al análisis realizado en la sección anterior, asignándoles por cada factor crítico de éxito un valor relativo a su fortalezas y debilidades, donde 4: indica una 
fortaleza principal, 3: una fortaleza menor, 2: una debilidad menor y 1: una debilidad principal. Con estas clasificaciones y los pesos relativos de cada factor, se obtienen puntuaciones ponderadas y un valor total para cada instituto analizado, que representa su perfil competitivo frente a los otros.

Asimismo, el resultado de la Matriz de Perfil Competitivo MPC se ha obtenido a partir de la información y el análisis de la opinión de expertos externos y directivos de la empresa Naranja Producciones S.A.C..

En la tabla 5.7 se han consignado los siguientes factores críticos: 
Tabla 5.7: Matriz del perfil competitivo (MPC)

\begin{tabular}{|c|c|c|c|c|c|c|c|c|c|c|c|}
\hline \multirow[b]{2}{*}{ Factores críticos de éxito } & \multirow[b]{2}{*}{ Peso } & \multicolumn{2}{|c|}{$\begin{array}{c}\text { NARANJA } \\
\text { PRODUCCIONES S.AC. } \\
\end{array}$} & \multicolumn{2}{|c|}{ CHIRIMOYABTL } & \multicolumn{2}{|c|}{ ROHO BTL } & \multicolumn{2}{|c|}{$\begin{array}{c}\text { MANGOSTA } \\
\text { COMUNICACIONES } \\
\end{array}$} & \multicolumn{2}{|c|}{ ROCOTO PRODUCCIONES } \\
\hline & & Clasificación & Ponderación & Clasificación & Ponderación & Clasificación & Ponderación & Clasificación & Ponderación & Clasificación & Ponderación \\
\hline $\begin{array}{l}\text { 1) Prestigio y consolidación de la } \\
\text { marca de las empresas BTL en } \\
\text { el Perú. }\end{array}$ & 0.2 & 2 & 0.4 & 3 & 0.6 & 4 & 0.8 & 3 & 0.6 & 3 & 0.6 \\
\hline $\begin{array}{l}\text { 2) Nivel de inversión para } \\
\text { realizar campañas de BTL de } \\
\text { gran envergadura. }\end{array}$ & 0.1 & 2 & 0.2 & 3 & 0.3 & 3 & 0.3 & 3 & 0.3 & 3 & 0.3 \\
\hline $\begin{array}{l}\text { 4) Proveedores de servicios y } \\
\text { productos de calidad. }\end{array}$ & 0.04 & 3 & 0.12 & 3 & 0.12 & 3 & 0.12 & 3 & 0.12 & 3 & 0.12 \\
\hline $\begin{array}{l}\text { 5) Diferenciación de los servicios } \\
\text { que brinda las empresas de } \\
\text { BTL. }\end{array}$ & 0.1 & 2 & 0.2 & 3 & 0.3 & 4 & 0.4 & 3 & 0.3 & 3 & 0.3 \\
\hline $\begin{array}{l}\text { 6) Personal calificado para el } \\
\text { área } \\
\text { creativa. }\end{array}$ & 0.3 & 1 & 0.3 & 3 & 0.9 & 3 & 0.9 & 2 & 0.6 & 3 & 0.9 \\
\hline $\begin{array}{l}\text { 7) Capacidad instalada en } \\
\text { infraestructura y de recursos } \\
\text { humano. }\end{array}$ & 0.02 & 3 & 0.06 & 3 & 0.06 & 4 & 0.08 & 3 & 0.06 & 3 & 0.06 \\
\hline $\begin{array}{l}\text { 8) Capacidad de cobertura de } \\
\text { eventos y campañas a nivel } \\
\text { nacional }\end{array}$ & 0.05 & 3 & 0.15 & 3 & 0.15 & 4 & 0.2 & 4 & 0.2 & 3 & 0.15 \\
\hline $\begin{array}{l}\text { 9) Personal con preparación } \\
\text { académica en el sector. }\end{array}$ & 0.15 & 2 & 0.3 & 3 & 0.45 & 3 & 0.45 & 3 & 0.45 & 3 & 0.45 \\
\hline Totales ponderados & 1 & & 1.85 & & 3 & & 3.37 & & 2.75 & & 3 \\
\hline
\end{tabular}

\section{Elaboración propia.}


En la tabla 5.7, se puede observar una lista de factores críticos con pesos y ponderaciones a las diferentes empresas.

\section{Prestigio y consolidación de la marca de las empresas BTL en el Perú.}

Este factor es el más importantes, teniendo un peso de 0.2 , porque las empresas al contar con el prestigio y consolidación de la marca, podrán lograr posicionarse en el mercado objetivo. De esta manera, la empresa Roho Producciones cuenta con esta fortaleza (puntaje 4) debido a que es una empresa reconocida en el mercado por sus eventos con concepto muy creativos. Asimismo, las empresas Chirimoya BTL, Rocoto Producciones y Mangosta Comunicaciones tienen puntaje 3 y con puntaje 2 Naranja Producciones S.A.C.

\section{Nivel de inversión para realizar campañas de BTL de gran envergadura.}

Las empresas de BTL, para llevar a cabo producciones de mayor envergadura, deben de contar con capital de trabajo importante, para así lograr cumplir con los requerimientos de los clientes. De esta manera, el peso con el que cuenta este factor es de 0.1. La empresa que destaca más en este factor es la empresa son Chirimoya BTL, Roho BTL, Mangosta Comunicaciones, Rocoto Producciones y Rocoto Producciones con puntaje 3. Naranja Producciones S.A.C. cuenta con puntaje 2.

\section{Diversidad de servicios y paquetes ofrecidos por las empresas de BTL.}

La diversidad de servicios y paquetes de las empresas de BTL, es un factor necesario para las empresas (peso 0.04), para poder ofrecer una diversidad de servicios complementarios que apoyen la producción de las campañas BTL. Es de todas las empresas que cuenta con un puntaje de 3.

\section{Proveedores de servicios y productos de calidad.}

Un factor necesario e importante el de contar con proveedores de servicios y de productos de calidad (peso 0.04). De esta manera, las empresas de BTL pueden cumplir con los tiempos establecidos en los contratos. Se puede apreciar que, en este factor todas las empresas comparadas cuentan con un puntaje de 3 , porque cada una de ellas cuenta con proveedores buenos que ofrecen servicios de calidad. 


\section{Diferenciación de los servicios que brinda las empresas de BTL}

La diferenciación que existe actualmente entre las empresas por los servicios ofrecidos a sus cliente es un factor relevante (peso 0.1 ), porque al existir en la actualidad 17 empresas reconocidas en el mercado nacional, es importante que ellas se puedan diferenciar entre sí para lograr posicionarse en el mercado objetivo. Las empresas que cuenta con una mayor diferenciación es Roho BTL con un puntaje de 4, seguida de Chirimoya BTL, Mangosta Comunicaciones y Rocoto Producciones con puntaje 3 y Naranja Producciones S.A.C. con puntaje 2.

\section{Personal calificado para el área creativa}

La existencia de un personal creativo en la empresa es de suma importancia porque las campañas BTL se elaboran a partir del trabajo del equipo del creativo (peso 0.3). Muchas empresas podrán contar con equipo de proveedores de calidad, pero si no cuentan con un personal que desarrolle la estructura temática de la campaña, no se logrará los objetivos de los clientes. En este sentido, las empresas Chirimoya BTL, Rocoto Producciones y Roho BTL cuentan con puntaje 3, Mangosta Producciones un puntaje 2 y Naranja Producciones S.A.C. con el mínimo puntaje de 1.

\section{Capacidad instalada en infraestructura y de recursos humano}

Este factor también es muy importante (peso 0.02) debido a que al contar con una capacidad instalada adecuada y un equipo de personas profesionales, las empresas de BTL podrán atender de manera óptima a sus clientes. De este modo, la empresa Roho Producciones cuenta con un puntaje de 4, las empresas Chirimoya BTL, Mangosta Comunicaciones, Rocoto Producciones y Naranja Producciones S.A.C. con un puntaje de 3. Cada una de las empresas cuenta con oficinas equipadas para atender a sus carteras de clientes y con el personal necesario para poder hacer frente a sus requerimientos.

\section{Capacidad de cobertura de eventos y campañas a nivel nacional}

Este factor nos indica el poder atender a los clientes en los diferentes partes del país, teniendo un (peso 0.05), de esta forma las empresas tienen la capacidad logística y de proveedores necesarios podrán atender a los clientes en provincia. 
Las empresa Roho BTL y Mangosta Comunicaciones tienen puntaje 4 y las empresas Chirimoya BTL, Rocoto Producciones y Naranja Producciones S.A.C. con un puntaje de 3 .

\section{Personal con preparación académica en el sector.}

Este factor es importante porque al contar con personal que tenga una preparación académica de excelencia (peso 0.15) para poder desarrollar las campañas de BTL y eventos según los requerimientos de los clientes. Se puede apreciar que, en este factor todas las empresas comparadas cuentan con un puntaje de 3. Sin embargo, Naranja Producciones S.A.C cuenta con puntaje 2.

Se puede concluir a partir de la Matriz del Perfil Competitivo (MPC) que la empresa Naranja Producciones S.A.C., debe:

- Desarrollar una imagen sólida frente a sus competidores (Chirimoya BTL, Roho BTL, Mangosta Producciones y Rocoto Producciones) mediante el desarrollo de plataforma virtual, redes sociales y marketing de boca a boca.

- Buscar alianzas estratégicas con otras empresas y/o proveedores para que así Naranja Producciones S.A.C. pueda participar en licitaciones de mayor envergadura y estar a la altura de las grandes empresas de publicidad de marketing BTL.

- Tener servicios orientados al diseño y creatividad para cada evento solicitado con los requerimientos propios del cliente.

- Tener una base de datos actualizada de proveedores principales que cumplan con ciertas especificaciones (calidad de servicio, calidad de productos, tiempo de entrega, entre otros).

- Las empresas de BTL no solo deben dedicarse al desarrollo logístico de las campañas, sino también buscar una diferenciación en el desarrollo y diseño de estas campañas, esta diferenciación les va a permitir posicionarse en el mercado.

- Contar con la infraestructura, personal, herramientas y base de datos de los trabajadores independientes adecuados para que así fácilmente se puedan contactar con ellos de acuerdo al tamaño del evento. 
- Las empresas de BTL tienen que tener la capacidad de hacer eventos en cualquier punto del país, para lo cual debe tener un contacto en las principales ciudades del interior del país permitiéndole así poder contactarse con proveedores y trabajadores independientes que participarán en el evento. De esta manera, permitirá reducir sus costos ya que el personal o el proveedor no se tendrá que movilizarse desde Lima hacia el interior del país.

- Finalmente, las empresas de BTL deben contar con colaboradores debidamente capacitados y con las carreras afines para así dar mayor aporte en las campañas propuestas. 


\section{Capítulo VI}

\section{Análisis Interno}

Cuando hacemos referencia al análisis interno de una empresa, debemos tener presente conceptos como Cadena de Valor, las cinco fuerzas de Porter, la Matriz EFI, entre otras. Se analizará la empresa Naranja Producciones S.A.C. para poder definir su estructura de "Cadena de Valor".

\subsection{Descripción de las actividades de la cadena de valor de la empresa}

El señor Michael Porter afirma: “...la cadena de valor como un instrumento para identificar el modo de generar más valor para los clientes". De esta manera, la empresa Naranja Producciones S.A.C. podrá lograr la mejor manera de generar valor a sus clientes. Además, el señor Michael Porter nos dice que: "La cadena de valor refleja nueve actividades estratégicamente relevantes, que generan costo y valor en un negocio específico". Por tal motivo, la Cadena de Valor está compuesta por una serie de eslabones, y en el caso de una empresa de servicios uno de los cambios más resaltantes radica en la organización de los eslabones primarios (parte inferior). Adicionalmente, presenta una sub clasificación, la cual se basa en actividades controlables y no controlables, tal como se puede apreciar en la siguiente ilustración:

\section{Gráfico 6.1: Cadena de Valor para servicios}

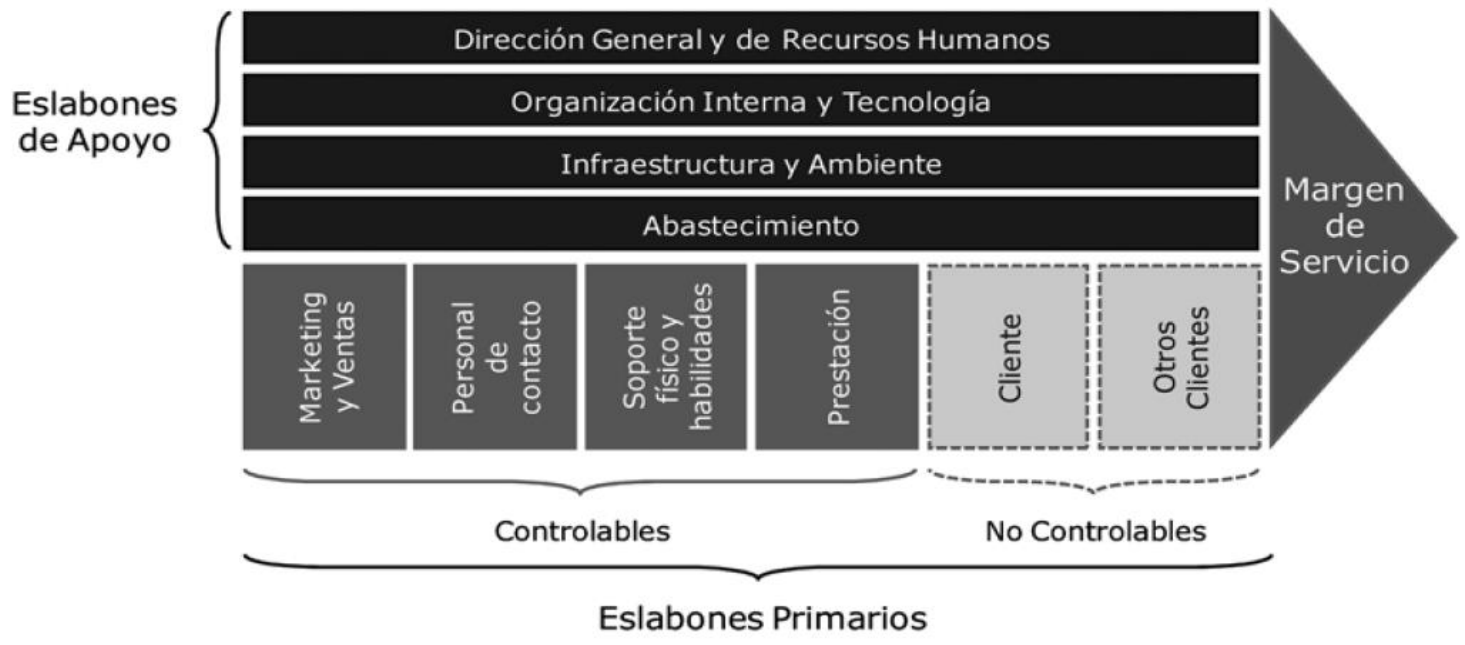

Fuente: EIGLIER, Pierre. LANGEARD, Eric. Servucción. MCGRAW HILL 


\subsubsection{Marketing y Ventas}

Se define como un punto de entrada dentro de la Cadena de Valor y está compuesta por la publicidad, la fuerza de ventas, promoción, estrategias y todo lo relacionado a mejorar las ventas de la empresa.

En el caso de Naranja Producciones S.A.C. es una de las actividades principales debido a que de ella depende la venta de sus servicios. Por tal motivo cuenta con las siguientes herramientas para llevar a cabo una venta:

a. Páginas Webs. - La empresa cuenta con dos páginas web, una para Naranja Producciones S.AC. y otra para la marca Castillo Mágico. La página de Naranja Producciones S.A.C. comprende las siguientes opciones: Home, Naranja Producciones, Servicios, Naranjeando, Confiaron en nosotros, Contáctenos. Estas opciones permiten explicar a los clientes los servicios que la empresa ofrece, las empresas que han trabajado con ellos, en donde se puede observar diferentes imágenes de las campañas realizadas y en cómo se pueden contactar con ellos. La página web de la marca Castillo Mágico cuenta con las opciones: Inicio, Nosotros, Servicios, Paquetes, Para Empresas, fotos y contáctenos. Estas opciones facilitan a los clientes el poder conocer a Castillo Mágico, comunicar los servicios con los que cuenta la empresa, los paquetes que posee para las familias y empresas, imágenes de los eventos realizados y números telefónicos para que los clientes puedan comunicarse con la empresa. Ambas páginas Web son uno de los medios de presentación que tiene la empresa Naranja Producciones S.A.C. para lograr contactar a los clientes.

b. Redes Sociales. - La empresa tiene una cuenta de Facebook para Naranja Producciones S.A.C. y otra cuenta para la marca Castillo Mágico. Por medio de las redes sociales, ambas pueden ofrecer sus paquetes a los clientes, tener comunicación directa con las personas y empresas que deseen solicitar sus servicios, llevar a cabo convocatorias para realizar castings de modelos, anfitriones, promotores, bailarines, actores, etc. Además, pueden solicitar nuevos proveedores de servicios y de productos, comunicar cada una de sus campañas y eventos a realizar a toda su red de contactos, colgar las fotos de todas sus campañas y eventos por fechas, actualizar sus paquetes de servicios, comunicar noticias importantes de la empresa y llevar un seguimiento de las personas que hacen like a sus publicaciones. Las redes sociales han sido una gran ayuda para Naranja Producciones, pues le permite comunicar sus servicios y cerrar 
contratos. Por otra parte, la red social de Facebook cuenta con un messenger que facilita a la empresa mantener una comunicación constante y en línea con sus clientes.

c. Correo electrónico. - Naranja Producciones S.A.C. cuenta con una base de datos de empresas que solicitan los servicios de una productora de eventos y campañas BTL. Con esta base la empresa envía correos a los futuros clientes. Estos correos contienen una carta de presentación y la cartera de servicios que ofrecen. Si los clientes lo consideran conveniente se llegará a concretar una cita para poder realizar una presentación más exhaustiva de los servicios que la empresa ofrece, como también de las campañas y eventos que han realizado hasta el momento.

d. Equipo de ventas. - La empresa cuenta con un Gerente Comercial y un Asistente de Marketing, ambos se encargan de la captación, cotización y el cierre de los contratos. El equipo de ventas utiliza la página web, las redes sociales y el correo electrónico, para captar a los clientes y poder cerrar los contratos de los eventos y campañas BTL.

\subsubsection{Personal de Contacto}

Está compuesto por el personal que interviene directamente en la prestación del servicio e interactúa con el cliente. Es uno de los eslabones más importante porque influye en el cuidado y la calidad del servicio que ofrece.

Para el caso de Naranja Producciones S.A.C., al estar enfocado al marketing BTL, no sólo interactúa con el cliente, sino también con el público al momento de ofrecer sus servicios, los cuales siempre son monitoreados por los directivos de la empresa. En el caso de campañas para distintos clientes en simultaneo, siempre delegan la responsabilidad a su socio estratégico (dueño de la empresa Mangosta Producciones S.A.C. quien ofrece servicios complementarios a las campañas BTL).

De esta manera, cuando un cliente contacta a la empresa lo puede hacer por la página Web, por las redes sociales, por correo electrónico y por teléfono. Las personas que están a cargo de los medios de comunicación de la empresa son los directivos de Naranja Producciones. Ellos tienen el primer contacto con los clientes y son quienes profundizan sobre los servicios que ofrece la empresa. Luego que los directivos han cerrado el contrato, empieza la elaboración del evento y campaña BTL. Es ahí que el asistente de Marketing y el Asistente de Producción tienen contacto con el cliente, para 
poder canalizar los requerimientos adicionales que vayan surgiendo durante la producción, además, de supervisar que los eventos y campañas se lleven a cabo como se había planeado.

\subsubsection{Soporte físico y habilidades}

Son todos los elementos o habilidades necesarias para ofrecer el servicio, por ejemplo, en un banco serían las tarjetas de débito o crédito, en un restaurant las mesas, sillas y vajilla. En el caso de Naranja Producciones S.A.C., la empresa cuenta con los siguientes elementos:

a. Soporte físico. - La empresa Naranja Producciones S.A.C., para poder llevar a cabo unas campañas de BTL o algún evento, cuenta con: disfraces, trajes para los eventos, carritos snacks, equipos de sonido, luces, dos automóviles, juegos didácticos para eventos y campañas, computadoras, soportes para banners y un equipo de proveedores de servicios y productos complementarios para poder satisfacer las necesidades de cada uno de sus clientes.

b. Habilidades. - Los directivos de la empresa cuenta con el conocimiento necesario para poder llevar a cabo las campañas de BTL y eventos. Este conocimiento lo han obtenido por su experiencia previa en el sector. Ambos directivos, han trabajado como modelos y anfitriones de otras empresas de BTL, con lo cual fueron aprendiendo poco a poco la logística y la dinámica de trabajo de las empresas de BTL. Además, ambos directivos son profesionales, siendo el señor Cesar Hugo Jaén Seminario Licenciado en Economía y la señorita Sherilyn San Román Bachiller en Comunicaciones.

\subsubsection{Prestación}

Este eslabón se refiere al concepto mismo del servicio, a la solución que ofrece la empresa ante las necesidades de sus clientes, teniendo presente que siempre se debe ofrecer un servicio que nos diferencie de la competencia.

En el caso de Naranja Producciones, la empresa tiene como propuesta de valor, el poder utilizar los recursos que emplean en sus show de Castillo Mágico, en sus eventos o campañas BTL, como son los clowns, la risoterapia, juegos y animaciones temáticas, entre 
otros. Además de contar con precios bajos y ofrecer el mismo nivel de servicio que la competencia.

\subsubsection{Clientes}

Los clientes constituyen una variable humana que condiciona e interviene en la calidad del servicio que se brinda, sirve incluso de retro alimentación (con apoyo del personal de contacto) para redefinir los requerimientos y nuevas características que deberá de cumplir el servicio con el transcurrir del tiempo. Por ejemplo, un cliente habitual que siempre nos contrata y que siempre está satisfecho con nuestros servicios, no es lo mismo que un nuevo cliente al cual hay que impactar y generar un momento memorable que lo haga pensar en volvernos a contratar.

En el caso de Naranja Producciones S.A.C. que trabaja con empresas privadas y públicas, debe de diferenciar las necesidades de estos dos sectores. Lo que buscan las empresas privadas, al llevar a cabo campañas BTL, es la fidelización, el posicionamiento y la captación de nuevos clientes; en cambio, las empresas públicas tienen como objetivo comunicar e informar a la población los programas sociales, o, en el caso del MINSA, se propone conunicar las campañas de prevención de enfermedades. Cada grupo de clientes tiene sus propias necesidades, las cuales deben ser atendidas de la mejor manera por Naranja Producciones S.A.C.

\subsubsection{Otros Clientes}

Los principales clientes son las empresas que buscan a Naranja Producciones S.A.C. para producir una campaña BTL, pero también existen otros clientes como son las otras empresas de BTL de gran envergadura que se encargan de realizar la parte creativa de la campaña y que contratan a otras empresas de BTL de menor tamaño para que hagan la producción y la logística. Por tal motivo, Naranja Producciones S.A.C. busca ofrecer el mismo servicio de producción que las empresas de BTL que los contratan. Es muy importante que las empresas de mayor envergadura vean que la empresa que subcontrata para que realice la logística y producción y cumpla con los requerimientos de los clientes. 


\subsubsection{Dirección General y de Recursos Humanos}

La visión de la empresa debe ser socializada entre todos los integrantes de la organización, a través del área de Recursos Humanos, a tal grado que se pueda lograr una comprensión y compromiso de la misma entre todos los colaboradores, para ello deberá de contar con el auspicio de la Dirección General. Asimismo, debe quedar completamente claro que la razón de ser de la organización son nuestros clientes.

En el caso de Naranja Producciones S.A.C., los Directivos no han definido una cultura organizacional clara en la empresa. Lo que se ha podido apreciar en las diferentes reuniones es que no se ha reforzado la comunicación de la Misión, Visión y los Valores de la organización. A pesar de esta carencia de comunicación de los factores que dirigen la vida de una empresa, los Directivos de Naranja Producciones S.A.C. se enfocan en mejorar la atención a los clientes, estandarizar el servicio brindado en las diferentes campañas y eventos, trabajar siempre con el mismo equipo de modelos, anfitriones, promotoras, bailarines y actores, que ya conocen la manera de trabajar de la empresa; buscan incentivar la buena atención a los clientes con premiaciones a los miembros del equipo de la empresa. Por otra parte, se busca canalizar las sugerencias de los clientes, sus inquietudes, reclamos y quejas que puedan surgir.

\subsubsection{Organización interna y de Tecnología}

Está orientado a definir la estructura organizativa de la empresa y funciones de cada puesto. En el caso de Naranja Producciones, tienen definida la estructura organizacional, la cual está conformada por un Gerente General, un Gerente Comercial, un Productor General de eventos asociado, un Asistente de Marketing y un Asistente de Producción, pero aún no están definidas las funciones de cada puesto. Además, tampoco está contemplada la creación del área creativa que se encargaría de desarrollar las ideas que se plasmen en los eventos y campañas BTL.

\subsubsection{Infraestructura y Ambiente}

Está referido básicamente al lugar donde se desarrolla el servicio. En el caso de Naranja Producciones está determinado por las instalaciones geográficas donde se brinda la campaña BTL. Por tal motivo, Naranja Producciones S.A.C. cuenta con una oficina y un almacén en el distrito de la Molina en donde desarrollan cada una de sus actividades. En 
esta oficina, la empresa atiende a sus clientes, coordina los eventos y campañas y lleva a cabo los ensayos de los mismos, En su almacén guardan todos sus disfraces, trajes, carritos snacks, los juegos didácticos, y todos los materiales a utilizar durante las campañas de BTL.

\subsubsection{Abastecimiento}

Este eslabón se refiere a la compra de materiales, insumos y recursos necesarios para brindar el servicio (incluso capacitaciones). En el caso de Naranja Producciones está compuesto por todos los productos y servicios que compran para poder desarrollar las diferentes campañas BTL. Por tal motivo, la empresa cuenta con una lista de proveedores establecida y con quienes han trabajado en los últimos años por su experiencia y nivel de servicio o producto.

Cada vez que Naranja Producciones S.A.C. cierra un contrato, se comunica con sus proveedores para ir coordinando la entrega de los productos o, la prestación de los servicios complementarios que la empresa ofrece a sus clientes.

Por otra parte, en los eventos y campañas de gran envergadura, la empresa Naranja Producciones S.A.C. se asocia con Mangosta Producciones para poder contar con una lista de proveedores más amplia y de esta manera atender a sus clientes satisfactoriamente.

\subsubsection{Margen del Servicio}

Es la suma de los aportes de cada uno de los eslabones antes mencionados y que percibe el cliente al momento de ofrecerle el servicio, podemos decir que es el momento cumbre de la relación, ya que logra que el cliente los vuelva a contratar.

La empresa Naranja Producciones busca desarrollar un servicio prácticamente igual a la de las empresas grandes como FCB Mayo, Grey Perú o Chirimoya BTL, pero a un precio menor al trabajar con casi los mismos proveedores o similares. Es por este motivo, que muchas veces las empresas grandes del sector los subcontratan para que Naranja Producciones S.A.C. se dedique a desarrollar la logística de las producciones. 
El beneficio obtenido por los clientes es el poder contratar un servicio similar al de las grandes empresas de BTL, pero a un precio menor. Es seguro que la desventaja con la que cuenta Naranja Producciones S.A.C, es el no poder contar con un área creativa que desarrolle las ideas y conceptos al mismo nivel que las empresas de mayor envergadura.

\subsection{Indicadores de cada una de las actividades de la cadena de valor.}

A continuación, se podrá apreciar los principales indicadores que maneja la empresa Naranja Producciones S.A.C, para medir sus servicios: 
Cuadro 6.1: Indicadores de cada actividad de la Cadena de Valor

\begin{tabular}{|c|c|c|c|c|}
\hline $\begin{array}{l}\text { Eslabón de la Cadena de } \\
\text { Valor }\end{array}$ & Indicadores & Valor & Clasificación & $\begin{array}{c}\text { Valor } \\
\text { Ponderación } \\
\end{array}$ \\
\hline \multirow{6}{*}{ Marketing y Ventas } & $\begin{array}{l}\begin{array}{c}\text { Cantidad de reuniones pre venta. (correo, teléfono, } \\
\text { presencial). }\end{array} \\
\end{array}$ & 3 & 0.2 & 0.6 \\
\hline & $\begin{array}{l}\text { Cantidad de contratos celebrados en forma mensual, } \\
\text { trimestral y anual (2012:39;2013: } 75,2014: 170,2015: 477 \text { y } \\
2016: 670 \text {. }\end{array}$ & 3 & 0.15 & 0.45 \\
\hline & \begin{tabular}{|l|}
$\quad$ Monto facturado anual. \\
\end{tabular} & 3 & 0.1 & 0.3 \\
\hline & Porcentaje de variación con respecto al año anterior del $15 \%$ & 2 & 0.15 & 0.3 \\
\hline & $\begin{array}{l}\text { Información de redes sociales: incrementar seguidores en } \\
\text { Facebook de } 96 \text { a } 160 \text { mensual e incrementar los suscriptores del } \\
\text { canal de Youtube de } 65 \text { a } 110 \text { mensual. }\end{array}$ & 2 & 0.15 & 0.3 \\
\hline & $\begin{array}{l}\text { Indice de Efectividad: Clientes que contratan el servicio/ } \\
\text { clientes visitados. }\end{array}$ & 3 & 0.25 & 0.75 \\
\hline & \begin{tabular}{|l|l} 
Total Marketing y Ventas \\
\end{tabular} & & 1 & 2.7 \\
\hline \multirow{3}{*}{ Personal de Contacto } & $\begin{array}{l}\text { - Cantidad de rotación de personal y personal contratado en forma } \\
\text { recurrente (por buen desempeño) }\end{array}$ & 2 & 0.6 & 1.2 \\
\hline & $\begin{array}{l}\text { Cantidad de personal contratado por evento por recibo de } \\
\text { honorario. }\end{array}$ & 2 & 0.4 & 0.8 \\
\hline & Total Personal de contacto & & 1 & 2 \\
\hline \multirow{7}{*}{ Soporte fisico y habilidades } & Se cuenta con una oficina y un almacén & 3 & 0.2 & 0.6 \\
\hline & Cuentan con vestuario & 3 & 0.1 & 0.3 \\
\hline & Luces y equipos de sonido & 2 & 0.15 & 0.3 \\
\hline & Carritos snack para brandearlos & 3 & 0.15 & 0.45 \\
\hline & Movilidad propia & 2 & 0.2 & 0.4 \\
\hline & Habilidades y competencias de cada personal contratado. & 2 & 0.2 & 0.4 \\
\hline & Total sopote Físico y Habilidades & & 1 & 2.45 \\
\hline \multirow{4}{*}{ Prestación } & \begin{tabular}{|l|l|} 
& Mediciones cuantitativas de la calidad de servicio \\
\end{tabular} & 2 & 0.3 & 0.6 \\
\hline & $\begin{array}{l}\text { Informe de campaña realizada indicando el nivel de } \\
\text { Creatividad u originalidad del servicio }\end{array}$ & 3 & 0.5 & 1.5 \\
\hline & 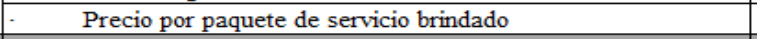 & 2 & 0.2 & 0.4 \\
\hline & Total Presentación & & 1 & 2.5 \\
\hline \multirow{4}{*}{ Clientes } & $\begin{array}{ll} & \text { Nro. De clientes nuevos } \\
\end{array}$ & 3 & 0.5 & 1.5 \\
\hline & \begin{tabular}{|l|}
$\quad$ Nro. De clientes recurrentes \\
\end{tabular} & 2 & 0.3 & 0.6 \\
\hline & $\begin{array}{l}\text { Nro. De veces que se brindó el servicio al mismo cliente } \\
\text { durante el año }\end{array}$ & 3 & 0.2 & 0.6 \\
\hline & \begin{tabular}{|l|l|} 
Total Clientes \\
\end{tabular} & & 1 & 2.7 \\
\hline \multirow{3}{*}{ Otros Clientes } & Nro. De empresas BTL que subcontratan el servicio de BTL & 3 & 0.6 & 1.8 \\
\hline & $\begin{array}{l}\text { Atención a clientes a partir de la asociación con otras } \\
\text { empresas BTL }\end{array}$ & 3 & 0.4 & 1.2 \\
\hline & Total Otras clientes & & 1 & 3 \\
\hline \multirow{4}{*}{$\begin{array}{l}\text { Dirección General y de } \\
\text { Recursos Humanos }\end{array}$} & $\begin{array}{l}\text { Nro. De rotación de personal independiente (modelos, } \\
\text { anfitriones, bailarines, etc) por lo que es dificil difundir la visión y } \\
\text { misión de la empresa. }\end{array}$ & 2 & 0.7 & 1.4 \\
\hline & \begin{tabular}{|l|l|}
$\quad$ Nro. De encuestados por temas de clima laboral \\
\end{tabular} & 1 & 0.15 & 0.15 \\
\hline & $\begin{array}{l}\text { Nro. De campañas para difundir los valores y clima de la } \\
\text { empresa }\end{array}$ & 1 & 0.15 & 0.15 \\
\hline & \begin{tabular}{|l|l} 
Total Dirección General y de Recursos Humanos \\
\end{tabular} & & 1 & 1.7 \\
\hline \multirow{3}{*}{$\begin{array}{l}\text { Organización interna y de } \\
\text { Tecnologia }\end{array}$} & Nro. De personas fijas en la empresa & 2 & 0.5 & 1 \\
\hline & Nro. De áreas & 1 & 0.5 & 0.5 \\
\hline & Total Organización interna y de Tecnología & & 1 & 1.5 \\
\hline \multirow[t]{3}{*}{ Infraestructura y Ambiente } & \begin{tabular}{|ll} 
& Nro. De lugares distintos donde pueden ofrecer los servicios \\
BTL
\end{tabular} & 2 & 0.6 & 1.2 \\
\hline & $\begin{array}{ll}-\quad \text { Locales anexos de oficina } \\
\end{array}$ & 2 & 0.4 & 0.8 \\
\hline & \begin{tabular}{|l|l|} 
Total Infraestructura y Ambiente \\
\end{tabular} & & 1 & 2 \\
\hline \multirow[t]{3}{*}{ Abastecimiento } & \begin{tabular}{|l} 
Nro. De proveedores de toldos, trabajos gráficos, \\
audiovisuales, catering, muñecos.
\end{tabular} & 3 & 0.7 & 2.1 \\
\hline & \begin{tabular}{|l|}
$\quad$ Nro. De proveedores en provincia \\
\end{tabular} & 1 & 0.3 & 0.3 \\
\hline & Total Abastecimiento & & 1 & 2.4 \\
\hline \multirow{4}{*}{ Margen del Servicio } & \begin{tabular}{|l|}
$\quad$ Nro. De clientes satisfechos \\
\end{tabular} & 3 & 0.5 & 1.5 \\
\hline & $\begin{array}{l}\text { Porcentaje de satisfacción del cliente con respecto al servicio } \\
\text { brindado. }\end{array}$ & 3 & 0.3 & 0.9 \\
\hline & $\begin{array}{l}\text { Nro. De clientes que presentaron algún reclamo o } \\
\text { insatisfacción del servicio }\end{array}$ & 2 & 0.2 & 0.4 \\
\hline & \begin{tabular}{|l|l|} 
Total Margen del Servicio \\
\end{tabular} & & 1 & 2.8 \\
\hline
\end{tabular}

\section{Elaboración Propia.}


Según el cuadro 6.1 podemos observar que el puntaje final es de 2.8, eso significa que la empresa Naranja Producciones S.A.C., está ligeramente por encima de 2.5.

\subsection{Benchmarking y comparación con los líderes de la industria de cada una de} las actividades de la cadena de valor

El benchmarking es una de las prácticas más populares de negocio, ya que no se limita a ningún área de la empresa; para ello esta herramienta consiste en comparar la empresa Naranja Producciones S.A.C. con las organizaciones líderes de la industria, en este caso serían dos empresas: Grey Group Perú y FCB Mayo.

El siguiente cuadro expresará la importancia de cada una de las empresas según su modalidad de servicios.

Cuadro 6.2: Benchmarking competitivo Naranja Producciones S.A.C.

\begin{tabular}{|l|c|c|c|}
\hline \multicolumn{1}{|c|}{ Eslabón de la Cadena de Valor } & $\begin{array}{c}\text { Naranja } \\
\text { Producciones }\end{array}$ & $\begin{array}{c}\text { Grey Group } \\
\text { Perú }\end{array}$ & FCB Mayo \\
\hline Fecha de inicio de actividades & 2013 & 2007 & 2006 \\
\hline Cobertura: Lima & $\mathrm{X}$ & $\mathrm{X}$ & $\mathrm{X}$ \\
\hline Página Web & $\mathrm{X}$ & $\mathrm{X}$ & $\mathrm{X}$ \\
\hline Red Social & $\mathrm{X}$ & $\mathrm{X}$ & $\mathrm{X}$ \\
\hline Blog & - & $\mathrm{X}$ & $\mathrm{X}$ \\
\hline Servicios Variados & $\mathrm{X}$ & $\mathrm{X}$ & $\mathrm{X}$ \\
\hline Responsabilidad Social & - & $\mathrm{ND}$ & $\mathrm{ND}$ \\
\hline Premios & 6 & $\mathrm{X}$ & $\mathrm{X}$ \\
\hline $\begin{array}{l}\text { Personal de Contacto Planilla } \\
\text { (colaboradores) }\end{array}$ & 251 & 210 \\
\hline $\begin{array}{l}\text { Personal de Contacto Rotativo } \\
\text { (colaboradores) }\end{array}$ & $\mathrm{Mayor} 20$ & $\mathrm{Mayor} 30$ & $\mathrm{Mayor} 50$ \\
\hline Soporte físico y habilidades & - & $\mathrm{X}$ & $\mathrm{X}$ \\
\hline Clientes Nacionales & $\mathrm{X}$ & $\mathrm{X}$ & $\mathrm{X}$ \\
\hline Clientes Internacionales & - & $\mathrm{X}$ & $\mathrm{X}$ \\
\hline Dirección General y de Recursos Humano & - & $\mathrm{X}$ & $\mathrm{X}$ \\
\hline Organización interna y de Tecnología & - & $\mathrm{X}$ & $\mathrm{X}$ \\
\hline Infraestructura y Ambiente & $\mathrm{X}$ & $\mathrm{X}$ & $\mathrm{X}$ \\
\hline Abastecimiento & $\mathrm{X}$ & $\mathrm{X}$ \\
\hline
\end{tabular}

Leyenda: (X) cuenta con el ítem mencionado; (-) no cuenta con el ítem mencionado; (ND) No Determinado.

Elaboración Propia. 
En el cuadro 6.2 se puede ver que Naranja Producciones S.A.C., es una empresa muy joven en comparación a las décadas de trayectoria de su competencia, empresas que poseen mucha experiencia de trabajo en Lima Metropolitana y Callao. Sin embargo, Naranja Producciones S.A.C. busca atraer nuevas miradas de los clientes de mayor envergadura.

En tal sentido, las organizaciones no sólo ejercen una publicidad boca a boca, sino que buscan un apoyo en la web con una página interactiva, Facebook, Twitter y últimamente, grupos en Whatsapp. Y en la actualidad, los blogs son un complemento de las empresas, para que se expresen libremente y propongan nuevas ideas a los internautas.

Actualmente, los competidores para ser mejores en la industria de la publicidad deben contar con premios de excelencia, buena imagen corporativa y trabajos realizados, entre otros. Esta situación conlleva a forjarse como empresa de Responsabilidad Social, que es una acción mundial de ayudar tanto al planeta como a sus habitantes.

Ser una empresa nueva en el mercado es, necesariamente, diversificarse en diferentes servicios para poder competir con las grandes empresas de publicidad. Para lograrlo, el BTL es la activación primordial para estar al lado del cliente, ayudarlo, aumentar sus posibilidades de ventas al interactuar con o el posible cliente; pero todo ello se logrará si se tiene un buen equipo de personal que desarrolle un servicio $A 1$, tanto directo como eventual.

Sobre los clientes tipo Gloria, BCP, Ministerios, entre otros, estas son empresas muy especiales ya que son nacionales y siempre quieren posicionarse, como las mejores, en la mente del consumidor. De igual manera, están las internacionales como 3M, Nestle, P\&G ... que buscan siempre a nuevas empresas publicitarias para que las apoyen en diferentes tipos de campañas. Al respecto, la empresa Naranja Producciones S.A.C. debería apuntar teniendo una pequeña cuenta para ofrecerles sus servicios..

Sobre la organización, las empresas competidoras ya cuentan con áreas mejores diseñadas para dar mejor servicio a sus clientes, como por ejemplo, el área creativa que es muy importante para las futuras ideas. Sin embargo, Naranja Producciones S.A.C. todavía está en proceso de contar con personal dedicado netamente a dicha área, pues en su organización todos apoyan en las diferentes áreas; sin embargo, por ser pequeña no 
se abastece frente a varios clientes. Del mismo modo, en la infraestructura deben contar con un espacio o localización céntrica y de fácil acceso y así, poder generar un mayor tráfico de clientes para que requieran de sus servicios.

Por último, sobre el abastecimiento de proveedores, todas las empresas de BTL trabajan casi con los mismos proveedores. Para ello, Naranja Producciones S.A.C. debería buscar nuevos proveedores para tener un mejor apoyo y no esperar ser atendido quedándole poco tiempo para organizar los eventos de sus clientes.

\subsection{Determinar las competencias de la empresa.}

Naranja Producciones S.A.C. busca satisfacer las necesidades de las empresas al desarrollar eventos y campañas BTL, para que sus clientes puedan lograr la fidelización y, comunicar a su público objetivo los beneficios que tienen sus productos y servicios. Es de esta manera, que la empresa brinda un servicio de calidad a bajo costo, al utilizar los mismos proveedores o proveedores similares durante la producción de sus eventos y campañas BTL.

Naranja Producciones S.A.C. se orienta a superar las expectativas de sus clientes al desarrollar eventos y campañas personalizadas. Para poder conseguir esto, la empresa se preocupa por contar con un equipo de colaboradores dinámico, profesional, creativo y proactivo. Para lograrlo, la empresa se preocupa de brindar un ambiente de trabajo óptimo que motiva la competencia sana mediante premios anuales al colaborador más comprometido con la empresa.

Para Naranja Producciones S.A.C. es muy importante segmentar a sus clientes para poder identificar sus necesidades y de esta manera atenderlos, según sus requerimientos. La empresa los ha ubicado según su procedencia, ya sea de las empresas públicas o privadas, además, en estas últimas existen dos grupos, como las empresas de BTL que subcontratan los servicios de producción de eventos y campañas BTL de Naranja Producciones S.A.C, y las que pertenecen a diferentes sectores que necesitan implementar el BTL para retener, fidelizar y captar nuevos clientes. En el primer grupo, están todas las empresas del Estado como el MINSA, Petro Perú, entre otras, con quienes tienen un largo tiempo trabajando. En el segundo grupo, están las empresas de inversión privada como Edyficar. En cada uno de los segmentos en el que está Naranja Producciones 
S.A.C., la empresa busca identificar los requerimientos y satisfacer a sus clientes, superando sus expectativas.

Analizar el mercado actual ayudará a identificar nuevos segmentos de mercados aun no explorados. Por lo general, las empresas de BTL se dedican a captar a los clientes de mayor envergadura como son los grupos empresariales, pero existe un sector como las micro y pequeñas empresas que no cuentan con el capital necesario para poder invertir en ATL. Aunque este sector no tiene mucho conocimiento sobre el tema, será la habilidad de las empresas como el caso de Naranja Producciones S.A.C., en poder explicarles las bondades de una herramienta de menor costo, pero de un alcance mayor.

Las competencias de la empresa Naranja Producciones S.A.C. para poder atender a sus clientes de manera eficiente, son:

a. La estructura de costos de la empresa les permite crear paquetes personalizados para cada uno de sus clientes, es decir, que la empresa Naranja Producciones S.A.C. tiene la capacidad de modificar sus paquetes de acuerdo a los requerimientos de los clientes.

b. Los gerentes de la empresa cuenta con la experiencia necesaria en el rubro, además, los colaboradores cuentan con carreras relacionadas al mundo de la publicidad y marketing. Por otra parte, es un equipo motivado y comprometido, lo cual se demuestra en cada una de las campañas realizadas hasta el momento. Además, los directivos de la empresa hacen una premiación al año, invitando a sus colaboradores para lograr un sentimiento de identidad con la empresa. También los directivos se dedican a motivar a su equipo y orientarlo en cada campaña que se les presenta.

c. Por el lado de los proveedores, la empresa cuenta con un equipo calificado, siendo muchos de ellos los mismos proveedores de varias empresas grandes del sector. Además, la relación que existe actualmente con los proveedores es óptima, siendo socios estratégicos de Naranja Producciones S.A.C. Aquéllos tienen la capacidad de poder responder rápidamente ante los requerimientos de último momento de los clientes.

\subsection{Identificación y determinación de las ventajas competitivas de la empresa.}

La identificación y determinación de las ventajas competitivas de la Naranja Producciones S.A.C. son producto del análisis de la cadena de valor que se ha realizado anteriormente. Se han podido identificar las siguientes ventajas competitivas: 
a. Control de costos: cuenta con proveedores de excelente servicio y a bajo costo que les permite ofrecer la misma calidad de servicios que la competencia.

b. Innovación: utilizar los recursos que emplean en sus shows de Castillo Mágico en sus eventos o campañas BTL, como son la utilización de clowns, la risoterapia, juegos y animaciones temáticas, entre otros.

c. Servicio diferenciado: la atención es personalizada desde el primer contacto con el cliente, manteniendo una comunicación constante para poder cumplir con los requerimientos. Además, para poder sobrepasar las expectativas de sus clientes.

d. Experiencia: cuenta con gerentes especializados en entregar un servicio concreto y excelente a sus clientes; asimismo los colaboradores están capacitados en resolver problemas en plena actividad del evento.

La ventaja competitiva de Naranja Producciones S.A.C. está basada en la innovación, el control de costos, servicio diferenciado y experiencia 


\begin{tabular}{|c|c|c|c|c|c|}
\hline Donde poner el Foco & Valor & Raro & Inimitable & Organización & Implicación Estégica \\
\hline $\begin{array}{l}\text { Excelentes proveedores a bajo costo en toda } \\
\text { la ciudad de Lima }\end{array}$ & $\mathrm{Si}$ & No & No & No & $\begin{array}{l}\text { Paridad competitiva. } \mathrm{Ni} \\
\text { suma ni resta }\end{array}$ \\
\hline $\begin{array}{l}\text { Mantiene una comunicación constante con sus } \\
\text { clientes. }\end{array}$ & Si & No & No & No & $\begin{array}{l}\text { Paridad competitiva. } \mathrm{Ni} \\
\text { suma ni resta }\end{array}$ \\
\hline $\begin{array}{l}\text { Cuenta con Página Web, Redes Sociales y } \\
\text { Correo Institucional. }\end{array}$ & No & No & No & No & Des ventaja competitiva \\
\hline $\begin{array}{l}\text { Cuenta con materiales y equipos propios para } \\
\text { llevar a cabo la producción de eventos } \\
\text { pequeños. }\end{array}$ & Si & No & No & No & $\begin{array}{l}\text { Paridad competitiva. Ni } \\
\text { suma ni resta }\end{array}$ \\
\hline $\begin{array}{l}\text { Cuentan con una red de contactos en el Sector } \\
\text { Público. }\end{array}$ & $\mathrm{Si}$ & $\mathrm{Si}$ & No & No & $\begin{array}{l}\text { Ventaja competitiva } \\
\text { temporal }\end{array}$ \\
\hline $\begin{array}{l}\text { Cuentan con socios como Mangosta para } \\
\text { realizar grandes campañas de hasta S/. } 450 \text { mil } \\
\text { soles. }\end{array}$ & Si & $\mathrm{Si}$ & No & No & $\begin{array}{l}\text { Ventaja competitiva } \\
\text { temporal }\end{array}$ \\
\hline $\begin{array}{l}\text { Capacidad logística para llevar acabo hasta } 2 \\
\text { grandes eventos al mismo tiempo de hasta } \\
1000 \text { personas. }\end{array}$ & Si & Si & No & No & $\begin{array}{l}\text { Ventaja competitiva } \\
\text { temporal }\end{array}$ \\
\hline $\begin{array}{l}\text { La señora Shery Román, cuenta con estudios } \\
\text { de diseño gráfico publicitario. }\end{array}$ & $\mathrm{Si}$ & $\mathrm{Si}$ & $\mathrm{Si}$ & No & $\begin{array}{l}\text { Ventaja competitiva aún por } \\
\text { explorar }\end{array}$ \\
\hline $\begin{array}{l}\text { Utiliza recursos empleado en sus shows de } \\
\text { Castillo Mágico como risoterapia, clown, etc. }\end{array}$ & $\mathrm{Si}$ & $\mathrm{Si}$ & $\mathrm{Si}$ & No & $\begin{array}{l}\text { Ventaja competitiva aún por } \\
\text { explorar }\end{array}$ \\
\hline $\begin{array}{l}\text { Ellos cuentan con amplia capacidad creativa } \\
\text { para la elaboración de campañas BTL. }\end{array}$ & Si & $\mathrm{Si}$ & Si & $\mathrm{Si}$ & $\begin{array}{l}\text { Ventaja sostenible en el } \\
\text { tiempo }\end{array}$ \\
\hline
\end{tabular}

Elaboración propia 


\subsection{Matriz de Evaluación de los Factores Internos EFI.}

Esta es una herramienta que nos ayudará a formular estrategias por medio del análisis de las fortalezas y debilidades más importantes dentro de las áreas funcionales de la empresa.

Primero, se debe hacer una lista de las fortalezas y debilidades más relevantes, luego, otorgar un valor relativo a cada factor, sumando todo 1.00.

Segundo, sería asignar una clasificación a cada fortaleza y debilidad listada, teniendo presente lo siguiente:

1 - Gran Debilidad

2 - Debilidad

3 - Fortaleza

4 - Gran Fortaleza

Tercero, se debe multiplicar el valor relativo con la calificación asignada para determinar un valor ponderado a cada factor de la lista.

Por último, se deben sumar los valores ponderados de cada una de las fortalezas y debilidades para poder determinar el valor ponderado de la empresa.

Los totales ponderados por debajo de 2.5, caracterizan a las empresas que son débiles en lo interno. Por otra parte, las calificaciones por arriba de 2.5 , indican una posición interna fuerte.

En el caso de Naranja producciones S.A.C. se puede observar que tiene una posición interna débil, debido a que el puntaje ponderado final es de 2.46 lo cual es un indicador desfavorable para la empresa. En este sentido, Naranja Producciones S.A.C. debe desarrollar un área creativa para desarrollar campañas con mayor valor agregado y de esta manera, ser reconocidos como una empresa creativa e innovadora.

Se puede observar que el Know How de los Directivos tiene una clasificación de 4 debido a que la mayor fortaleza que cuenta la empresa es el conocimiento del sector que 
poseen los socios. Este Know How fue adquirido durante los años que los socios fueron anfitriones de diferentes marcas.

Otra fortaleza es la cartera amplia de proveedores que cuenta con una clasificación de 4 puntos porque para poder atender de manera óptima a los clientes en toda la ciudad de Lima Metropolitana, se debe de contar con alianzas estratégicas con diferentes proveedores como por ejemplo, de toldos, de catering, equipos de audio y sonidos, entre otros.

Además, la asociación estratégica con Mangosta Producciones cuenta con una clasificación de 3 puntos, debido a que es uno de los principales socios de Naranja Producciones S.A.C. a la hora de llevar acabo diferentes campañas BTL. La empresa Mangosta Producciones es una empresa que cuenta con varios clientes reconocidos en el mercado nacional y que en muchas ocasiones solicitan llevar a cabo campañas BTL de gran tamaño, escapando de la capacidad logística de Mangosta. Es de esta manera que la empresa en mención busca siempre asociarse con Naranja Producciones S.A.C., para distribuirse las producciones y la inversión monetaria de las grandes campañas BTL.

Asimismo, el resultado de la Matriz EFI se ha obtenido a partir de la información y el análisis de la opinión de expertos externos y directivos de la empresa Naranja Producciones S.A.C.. 
Cuadro 6.3: Matriz EFI

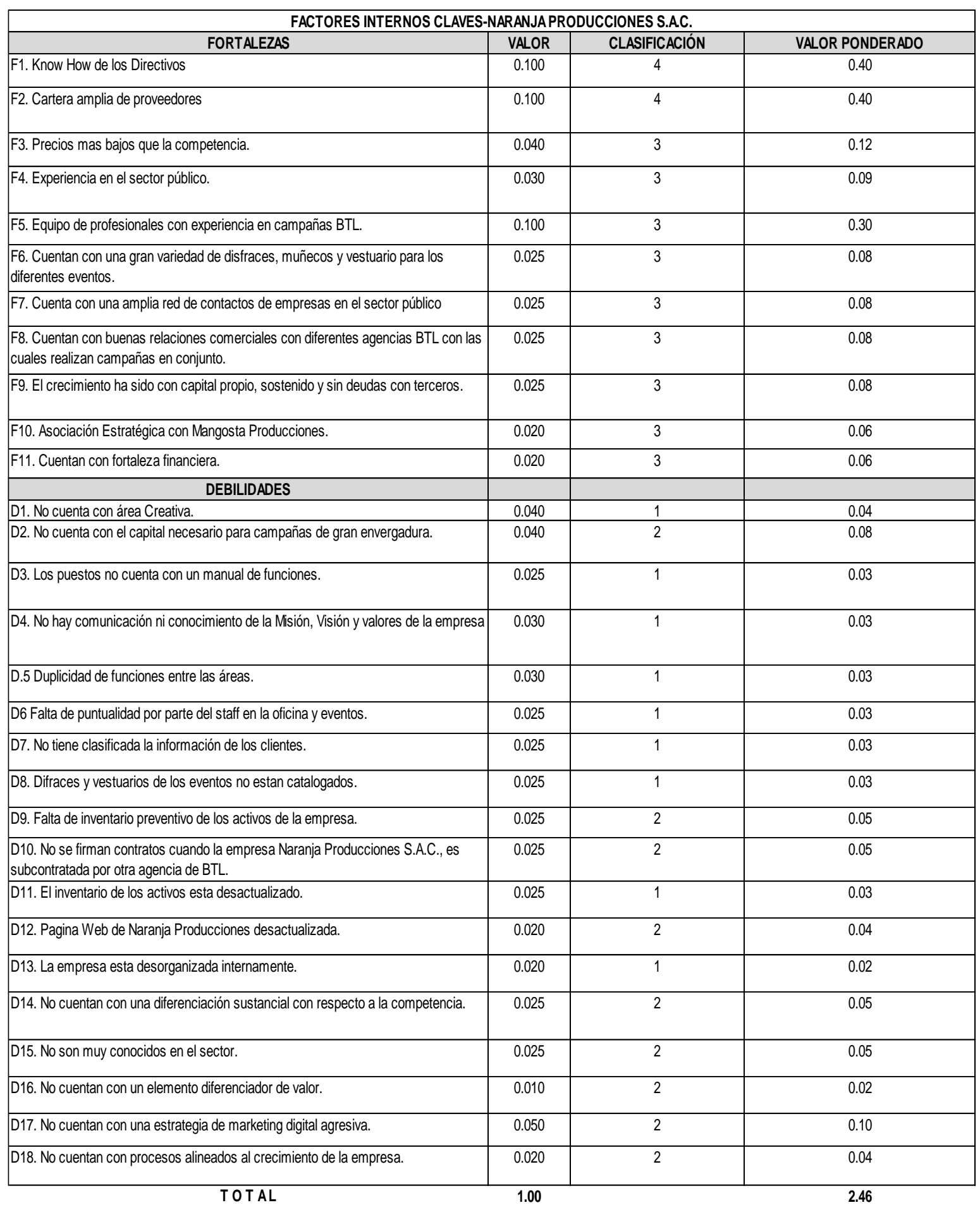

Elaboración Propia. 


\section{Capítulo VII}

\section{Formulación de los Objetivos y Diseño de las estrategias}

En este nuevo capítulo se van a determinar los objetivos estratégicos de Naranja Producciones S.A.C. para los próximos 5 años.

Para poder lograr la misión de la empresa se deberá cumplir con los objetivos estratégicos. Estos objetivos deberán ser consistentes con la misión y visión de Naranja Producciones S.A.C., así como el análisis interno y externo de la empresa, permitiendo lograr una ventaja competitiva. Cada una de las áreas de la empresa, deberá de trabajar para alcanzar los objetivos estratégicos.

\subsection{Alcance y planeamiento de los objetivos estratégicos}

Los objetivos estratégicos son esenciales y elementales para alcanzar el éxito de la empresa. Cada una de las áreas de la empresa, deberá de desempeñar tareas específicas dentro de un tiempo determinado para lograr sus objetivos.

En el siguiente punto se desarrollarán los objetivos que hemos señalado para la empresa Naranja Producciones S.A.C..

\subsubsection{Objetivos Estratégicos}

a. Incrementar la participación de mercado de la empresa.

b. Incrementar la rentabilidad de la empresa.

c. Incentivar y motivar el desarrollo personal y profesional de los colaboradores, para fidelizarlos a la organización.

d. Incrementar la posición competitiva de la empresa.

e. Reorganizar los procesos de la empresa.

\subsubsection{Análisis de los objetivos estratégicos}

Los objetivos estratégicos de la empresa Naranja Producciones S.A.C. están orientados a conseguir el cumplimiento de la misión y visión que se ha desarrollado para 
la empresa. Por tal motivo, el análisis de los objetivos estratégicos se lleva a cabo en base a la visión y misión que se ha desarrollado para Naranja Producciones S.A.C..

Estos objetivos estratégicos la deben ayudar a conseguir la visión de ser reconocida a nivel nacional como una empresa líder, por eso debe de trabajar en su misión de brindar un servicio de shows y campañas BTL de manera creativa y personalizada.

A continuación, explicaremos cada uno de los objetivos estratégicos señalados:

a. Incrementar la participación de mercado de la empresa. - Este objetivo está orientado a aumentar la presencia de la empresa en el sector BTL. De esta manera, Naranja Producciones S.A.C. incrementaría sus ventas y su cartera de clientes mediante la fidelización.

b. Incrementar la rentabilidad de la empresa por medio de la optimización de procesos. - Este objetivo está orientado en reducir la duplicidad de procesos y de tiempos durante el pre y post producción de los eventos y campaña de BTL, como también los procesos internos de la empresa. Por lo tanto, se optimizan los recursos de la empresa.

c. Incentivar y motivar el desarrollo personal y profesional de los colaboradores, para fidelizarlos a la organización.- como una empresa productora de campañas BTL, un factor importante para el desarrollo óptimo de los colaboradores, es la adecuada capacitación y desarrollo profesional de cada uno de los miembros de la empresa. Por tal motivo, la empresa debe de programar capacitaciones relacionadas a las campañas BTL.

d. Incrementar la posición competitiva de la empresa. - Actualmente Naranja Producciones S.A.C., trabaja con Roho Producciones, Mangosta Comunicaciones y con la Agencia Synapsis. Sería óptimo que la empresa busque trabajar con más agencias de publicidad para aumentar su participación en el mercado local.

e. Reorganizar los procesos de la empresa. (equipos, disfraces, Vehículos, utilería).Con el pasar de los años, Naranja Producciones S.A.C. ha aumentado su número de clientes, por tal motivo, debería de renovar y adquirir nuevos equipos, disfraces y todo 
lo necesario para poder brindar un buen servicio. Además, de replantear cada uno de sus procesos, para mejorar el tiempo de atención a los clientes.

\subsection{Diseño y formulación de estrategias}

Para poder elaborar una estrategia es recomendable la colaboración de los miembros de la empresa. Fred David nos dice que: "La identificación y la evaluación de las alternativas de estrategias deben permitir la participación de los gerentes y empleados que elaboraron con anterioridad las declaraciones de la visión y la misión de la empresa, llevaron a cabo la auditoría externa y condujeron la auditoría interna"86. Esto ayudará a que los gerentes y empleados puedan comprender lo que la empresa hace y cómo lo hace. Además, ayudará a que los colaboradores se comprometan con el cumplimiento de los objetivos de la organización.

Por otra parte, la elaboración de las estrategias no tiene en cuenta todas las opciones que puedan existir. Fred David nos comenta que: "Los estrategas nunca toman en consideración todas las alternativas posibles que podrían beneficiar a la empresa porque existe un número infinito de acciones posibles y de maneras de implantar dichas acciones; por lo tanto, es necesario crear una serie fácil de manejar las alternativas de estrategias más atractivas y determinar las ventajas, las desventajas, las correlaciones, los costos y los beneficios de estas estrategias"87. Es en tal sentido, que es necesario buscar o crear una alternativa fácil para la selección de las nuevas estrategias que la empresa va seguir.

Por otra parte, en este capítulo se implementará un conjunto de herramientas para poder analizar las alternativas que la empresa Naranja Producciones S.A.C. tiene para la elaboración de sus estrategias. Además, se empleará el modelo del Océano Azul de W. Chan Kim y de Renée Mauborgne, como una herramienta para elaborar y crear ideas innovadoras.

\footnotetext{
86 David, Fred. Conceptos de Administración Estratégica. 9na ed. México DF.: Perason Educación, 2003. p.198

${ }^{87}$ David, Fred. Conceptos de Administración Estratégica. 9na ed. México DF.: Perason Educación, 2003. p.197
} 


\subsubsection{Modelo Océano Azul}

En el libro "La Estrategia del Océano Azul" de W. Chan Kim y Renée Mauborgne explican que: "Los océanos rojos representan a todas las industrias existentes en la actualidad. Es el espacio conocido del mercado. Los océanos azules representan a todas las industrias que no existen actualmente. Es el espacio desconocido del mercado"88. Como se puede apreciar, en los océanos rojos las fronteras o los límites del mercado ya están definidas. En estos mercados las empresas buscan de superar a su competencia, logrando una mayor participación en el mercado ya existente. Por otra parte, el océano azul son los espacios de mercados aún no aprovechados, en donde existe una demanda aún no atendida.

Con el modelo Océano Azul se podrán identificar nuevos espacios de mercados aún no explorados por la competencia, en donde la empresa podrá aprovechar las oportunidades de negocios.

En el caso de Naranja Producciones S.A.C., la empresa tiene la oportunidad de explorar y encontrar nuevos nichos de mercados aún no aprovechados por la competencia.

\subsubsection{Lienzo de la estrategia actual de la empresa}

La estrategia actual de la empresa está definida en base a los factores críticos de éxito de la Matriz del Perfil Competitivo (MPC), en donde se compara también la información de las empresas más representativas del sector (Chirimoya BTL, Roho BTL, Mangosta Comunicaciones, Rocoto Producciones), representando de esta manera el Océano Rojo (mercado conocido).

\footnotetext{
${ }^{88}$ CHAN KIM, W y MAUBORGNE, Renée. La Estrategia del Océano Azul. 19 ed. Bogotá: Norma, 2005. p. 50
} 
Gráfico 7.1: Lienzo de Naranja Producciones y principales empresas del sector

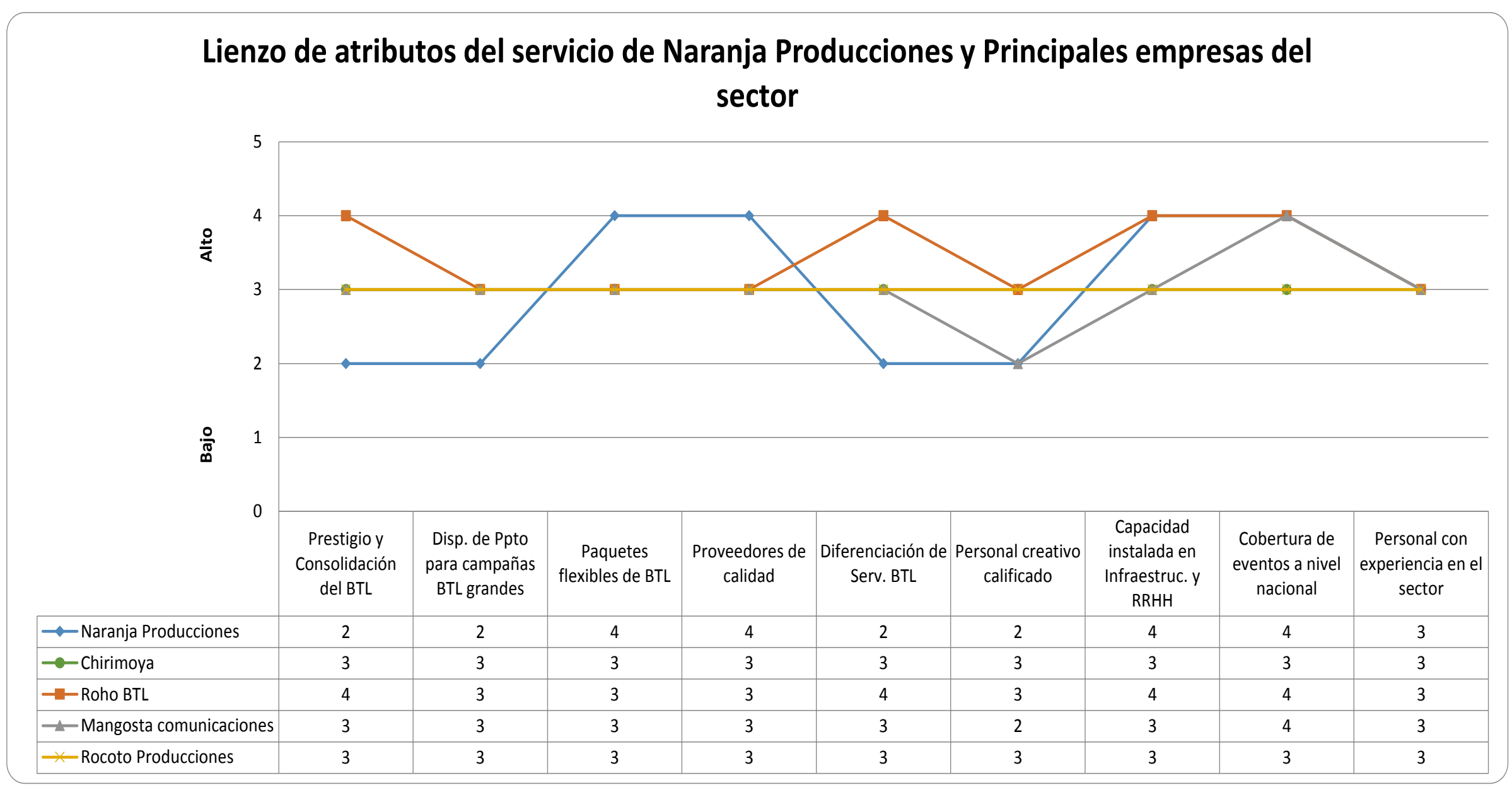

Elaboración Propia. 
Analizando el lienzo actual de la empresa se puede observar en el eje $\mathrm{X}$ las variables más importantes de la industria, y en el eje $\mathrm{Y}$ el valor asignado a cada una de las variables de las distintas empresas analizadas, de donde se concluye lo siguiente:

a. No cuenta con posicionamiento en el sector debido a que tenemos poco tiempo en el mercado (desde el año 2012).

b. El presupuesto que maneja es limitado por lo que no pueden atender campañas grandes muy seguido (hasta hacer caja nuevamente).

c. No cuenta con servicios que nos puedan diferenciar dentro del sector de BTL.

d. Existe deficiencia en el personal creativo, motivo por el cual ofrece servicios similares a la competencia.

e. El personal de la empresa no se encuentra academicamente calificado, pues cuentan con personal con carreras no afines al rubro de la empresa. Es de esta manera, que la empresa Naranja Producciones S.A.C. tiene entre sus colaboradores un estudiante de medicina. Por tal motivo, la empresa debe contar con personal con carreras que aporten con ideas en beneficio de la empresa.

\subsubsection{Lienzo de la estrategia de la industria}

La estrategia de la industria nos ofrece información de la empresa Naranja Producciones S.A.C. con respecto al promedio del sector, en donde una puntuación elevada significa que una empresa ofrece más a los compradores, y por consiguiente, invierte más en esa variable o atributo analizado (es más caro).

De esta manera obtenemos la "Curva de Valor", que representa al "componente básico del cuadro estratégico y constituye una representación gráfica del desempeño relativo de una compañía en lo referente a las variables de la competencia en su industria" 89

\footnotetext{
${ }^{89}$ CHAN KIM, W. y MAUBORGNE, Renée. “La Estrategia del Océano Azul”. 19 ed. Bogotá: Norma, 2005. p. 39
} 


\section{Gráfico 7.2: Lienzo de Naranja Producciones S.A.C. y Promedio de la industria}

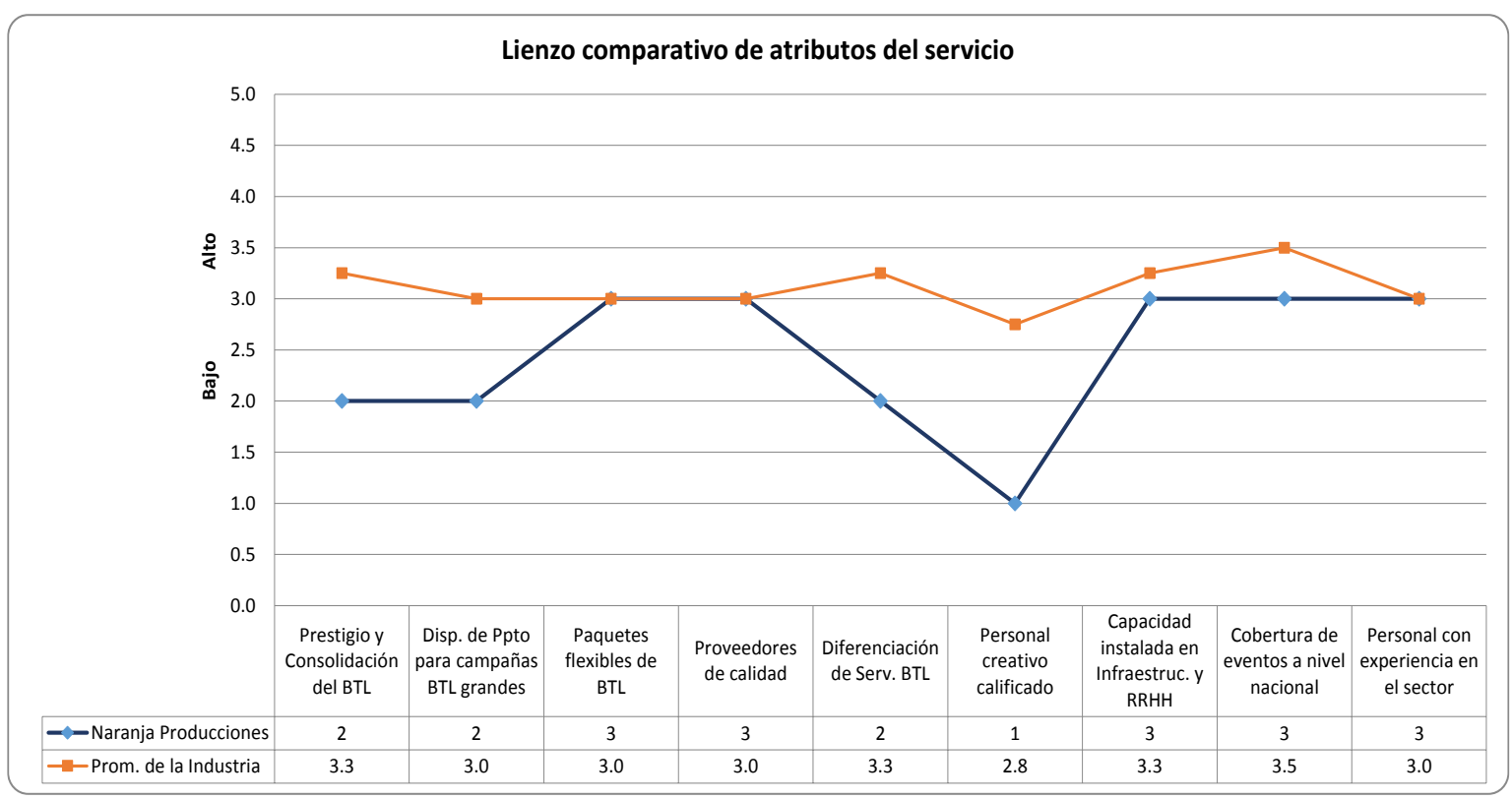

Elaboración propia.

Analizando el lienzo de la estrategia de la industria con respecto a los valores obtenidos por Naranja Producciones S.A.C., observamos una convergencia hasta cierto grado positiva en 3 factores críticos de éxito, con lo cual podemos concluir que se trata de un "Océano Rojo", donde se encuentra la competencia, un sitio en el que todos compiten por una parte del mercado, la cual es difícil de superar. Los atributos (factores críticos de éxito) en convergencia son:

a. Flexibilidad en los paquetes de campañas BTL que se ofrecen a los clientes (dependiendo del presupuesto que tiene la empresa o el tamaño de la campaña).

b. Utilizan proveedores de la misma calidad que utilizan las otras empres ya que pueden contratarlos al disminuir el margen de utilidad.

c. La capacidad instalada en Infraestructura y Recursos Humanos $(R R H H)$ es similar a la de otras empresas, ya que contratan a personal sólo para campañas BTL puntuales (no los tienen en planilla).

Donde sí existe oportunidad de mejora es en el atributo de "Diferenciación de servicios BTL", pues el promedio de la industria es de 3.5 puntos, y Naranja Producciones está en 2.0 puntos, lo cual le permitiría crecer teniendo la siguiente meta:

a. En primer lugar, crecer y llegar a tener una puntuación similar a la industria. 
b. En segundo lugar, tiene la oportunidad de superar el promedio de la industria, la cual es de 3.5 puntos.

Otro atributo importante que se debe fortalecer es el "Personal calificado para el área creativa” lo cual ayudará a diferenciar la calidad del servicio.

Para lograr esta "Diferenciación" debería definirse una estrategia de fortalecimiento de este atributo, mediante la asistencia a charlas de medio ambiente, suscribirse a bloggers de foros internacionales para tener en consideración la tendencia del mercado, incorporación de profesionales altamente capacitados que aporten ideas innovadoras con temas relacionados al medio ambiente, responsabilidad social (puntos que están ganando más adeptos y generando conciencia en las personas y empresas). Difundir estos cambios entre sus clientes y potenciales clientes, generando así un diferencial que le permitiría a Naranja Producciones S.A.C., crear ese "Océano Azul" que es su objetivo.

\subsubsection{Matriz (eliminar, reducir, incrementar, crear).}

En el esquema de las cuatro acciones se analizan los atributos de valor identificados en el Lienzo de la estrategia y se toman distintas acciones tales como: eliminar, reducir, incrementar, crear o hasta incluso se puede tomar la decisión de no hacer, tal como se muestra en el cuadro 7.1. Esta información se toma como input para la matriz "eliminar, reducir, incrementar y crear".

Esta matriz "estimula a las compañías no sólo a realizar las cuatro preguntas del esquema, sino, también, a actuar con respecto a esas cuatro preguntas, a fin de crear una nueva curva de valor." 90

Gracias a la siguiente matriz podemos determinar las acciones a realizar en cada uno de los atributos, pudiendo ser: eliminar, reducir, incrementar, crear o hasta incluso no hacer nada (dejando vacío el cuadrante respectivo).

El resultado de implementar estas acciones nos ayudará a separarnos del océano rojo (competencia) y crear un océano azul, generando así un sinnúmero de oportunidades y diferenciarnos de la competencia.

\footnotetext{
${ }^{90}$ CHAN KIM, W y MAUBORGNE, Renée. La Estrategia del Océano Azul. 19 ed. Bogotá: Norma, 2055. p. 50
} 
Cuadro 7.1: Matriz eliminar, reducir, incrementar, crear

\begin{tabular}{|l|l|}
\hline ELIMINAR & \multicolumn{1}{|c|}{ INCREMENTAR } \\
\hline & $\begin{array}{l}\text { 1) Prestigio y consolidación de la marca de las } \\
\text { empresas BTL en el Perú. } \\
\text { 2) Nivel de inversión para realizar campañas de } \\
\text { BTL de gran envergadura. } \\
\text { 5) Diferenciación de los servicios que brinda las } \\
\text { empresas de BTL. } \\
\text { 6) Personal calificado para el área creativa. } \\
\text { 8) Capacidad de cobertura de eventos y campañas } \\
\text { a nivel nacional. } \\
\text { 9) Personal con preparación académica en el } \\
\text { sector. }\end{array}$ \\
\hline REDUCIR & \begin{tabular}{l} 
CREAR \\
\hline
\end{tabular} \\
\hline & $\begin{array}{l}\text { 3) Diversidad de servicios y } \\
\text { paquetes ofrecidos por las empresas de BTL. } \\
\text { 7) Capacidad instalada en } \\
\text { infraestructura y de recursos humano. }\end{array}$ \\
\hline
\end{tabular}

Elaboración propia.

\subsubsection{Lienzo de la nueva estrategia considerada}

En el gráfico 7.3 se muestra el lienzo propuesto para la empresa Naranja Producciones S.A.C. en donde se deberá resaltar con una circunferencia los cambios a implementarse en los atributos analizados, los cuales se detallan a continuación:

- Incrementar el prestigio y consolidación de la empresa en campañas BTL

- Incrementar la disponibilidad de presupuesto de inversión en campañas BTL de gran envergadura.

- Incrementar la diferenciación de servicios BTL 
- Incrementar la contratación de personal creativo calificado.

- Incrementar la contratación de personal freelance con experiencia en el sector.

- Crear diversidad de servicios y paquetes ofrecidos por las empresas de BTL.

- Crear capacidad instalada en infraestructura y de recursos humano.

\section{Gráfico 7.3: Lienzo propuesto}

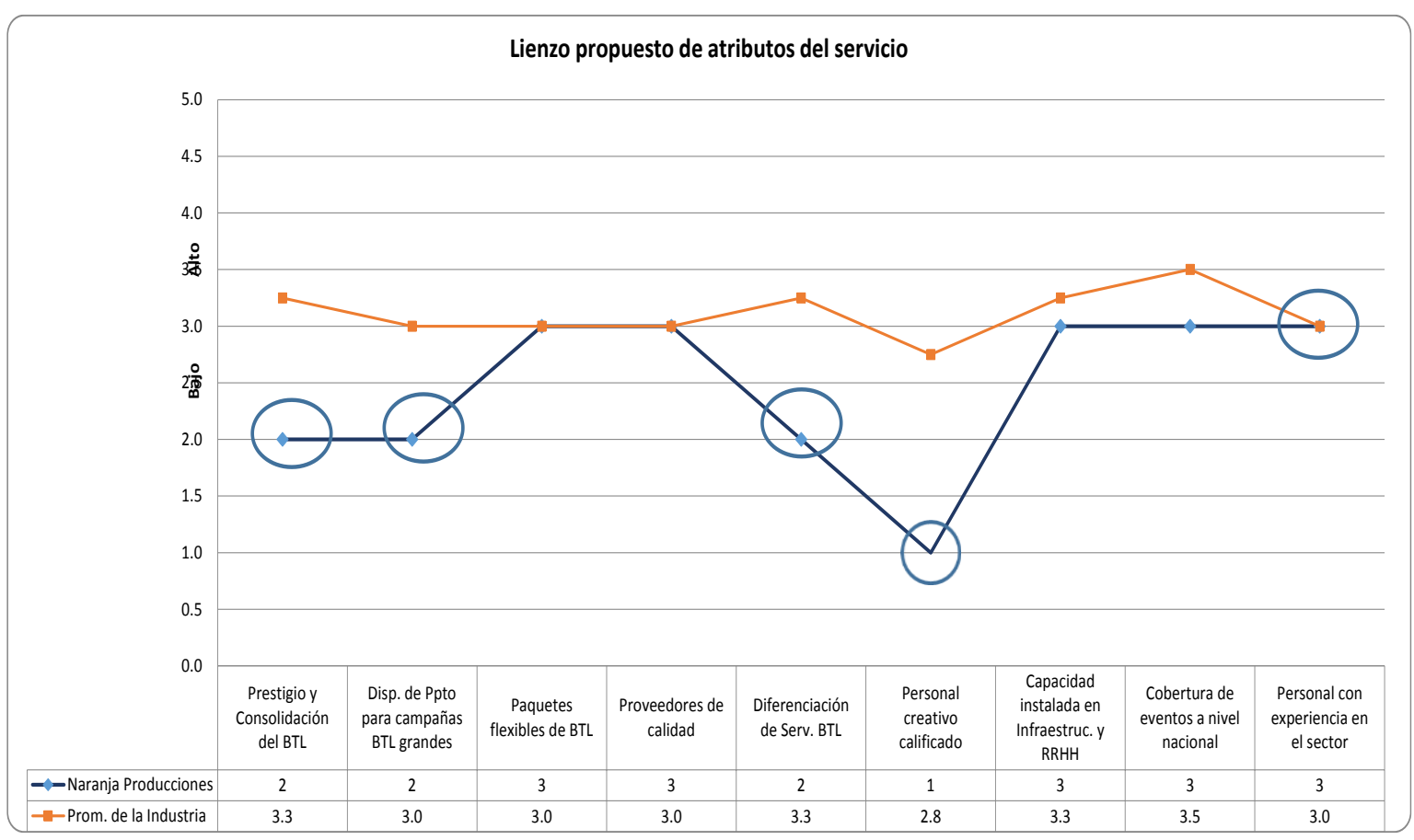

Elaboración Propia.

\subsubsection{Matrices de formulación de estrategias}

Con el apoyo del esquema de toma de decisiones de tres etapas, tal como se puede apreciar en la figura 7.1, "Las herramientas que presenta este esquema se aplican a las empresas de todos tamaños y tipos y ayudan a los estrategas a identificar, evaluar y seleccionar las estrategias"91.

\footnotetext{
${ }^{91}$ David, Fred. Conceptos de Administración Estratégica. 9na ed. México DF.: Perason Educación, 2003. p.198
} 


\section{Ilustración 7.1: Esquema analítico para la formulación de la estrategia}

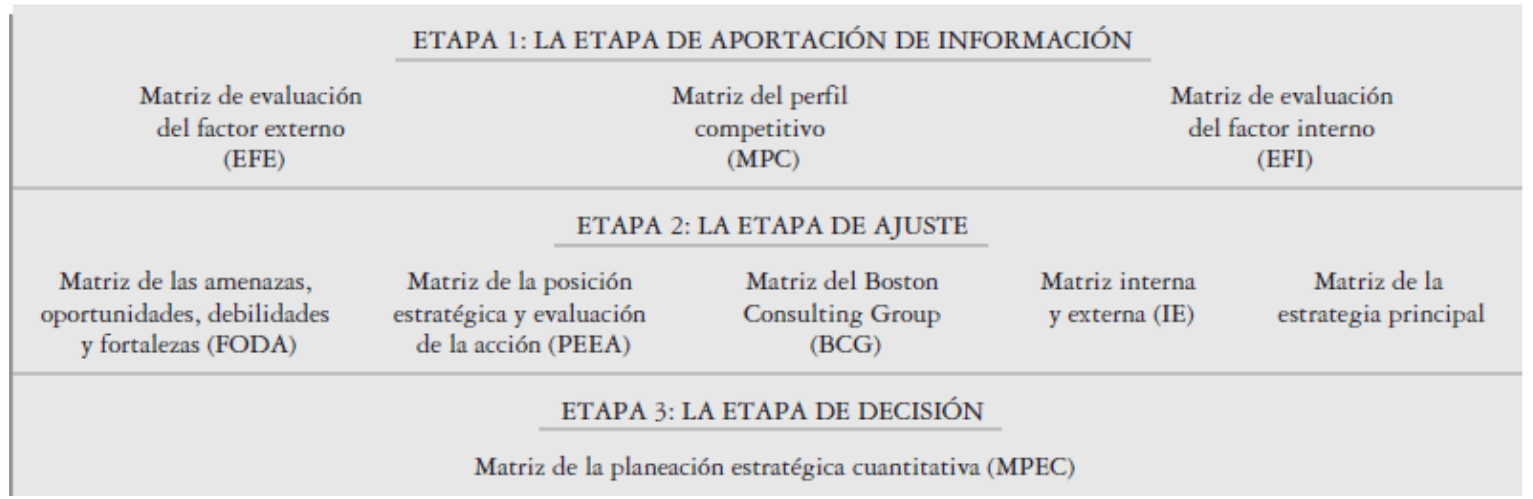

Resumiendo brevemente la estructura del esquema mencionado podemos indicar que:

- La Etapa 1, resume la información inicial necesaria para formular estrategias.

- La Etapa 2, se centra en la creación de alternativas estratégicas posibles por medio del ajuste de los factores internos y externos claves.

- La etapa 3, utiliza la información de la Etapa 1, para evaluar con objetividad las alternativas de estrategias posibles que fueron identificadas en la Etapa 2, mostrando de esta manera el grado relativo de atracción de las alternativas de estrategias.

\subsubsection{Matriz FODA}

La matriz de las amenazas, oportunidades, debilidades y fortalezas (FODA), esta matriz es una herramienta que permite la elaboración de estrategias de fortalezas y estrategias de oportunidades (FO), estrategias de debilidades y oportunidades (DO), estrategias de fortalezas y amenazas (FA), y estrategias de debilidades y amenazas (DA).

Fred David en su libro Conceptos de Administración Estratégica nos dice que: "Las estrategias FO utilizan las fortalezas internas de una empresa para aprovechar las oportunidades externas"92. De esta manera, cuando una empresa tenga debilidades relevantes, deberá vencerlas y transformarlas en fortalezas; cuando tenga que enfrentar amenazas, tendrá de evitarlas para enfocarse en las oportunidades del mercado.

Fred David en su libro Conceptos de Administración Estratégica nos dice que: "Las estrategias DO tienen como objetivo mejorar las debilidades internas al aprovechar las

\footnotetext{
${ }^{92}$ David, Fred.(2003) Conceptos de Administración Estratégica. 9na ed. México DF.: Perason Educación, p.200
} 
oportunidades externas"93. Esto puede ocasionar que las empresas encuentren oportunidades relevantes en el mercado, pero tal vez tengan una debilidad importante que evite que puedan aprovechar estas oportunidades.

Fred David en su libro Conceptos de Administración Estratégica nos dice que: "Las estrategias FA usan las fortalezas de una empresa para evitar o reducir el impacto de las amenazas externas"94. Esto permite que las empresas puedan utilizar las fortalezas que tengan para hacer frente a las amenazas que puedan surgir en el mercado.

Fred David en su libro Conceptos de Administración Estratégica nos dice que: "Las estrategias DA son tácticas defensivas que tienen como propósito reducir las debilidades internas y evitar las amenazas externas"95. Cuando una empresa tenga debilidades importantes y deba hacer frente a muchas amenazas en el mercado, deberá llevar a cabo estrategias que le permitan supervivir en el mercado. Estas estrategias podrían fusionarse con las otras empresas, como la reducción de gastos, declarar la bancarrota o llevar a cabo la liquidación de la empresa.

En el siguiente cuadro 7.2, se muestra la matriz FODA de la empresa Naranja Producciones S.A.C.. Las amenazas, oportunidades, debilidades y fortalezas se obtienen de la matriz EFE y la matriz EFI realizadas anteriormente.

\footnotetext{
${ }^{93}$ David, Fred. (2003) Conceptos de Administración Estratégica. 9na ed. México DF.: Perason Educación, p.200

${ }^{94}$ David, Fred. (2003) Conceptos de Administración Estratégica. 9na ed. México DF.: Perason Educación, p.201

${ }^{95}$ David, Fred. (2003) Conceptos de Administración Estratégica. 9na ed. México DF.: Perason Educación, p.201
} 
Cuadro 7.2: Matriz FODA

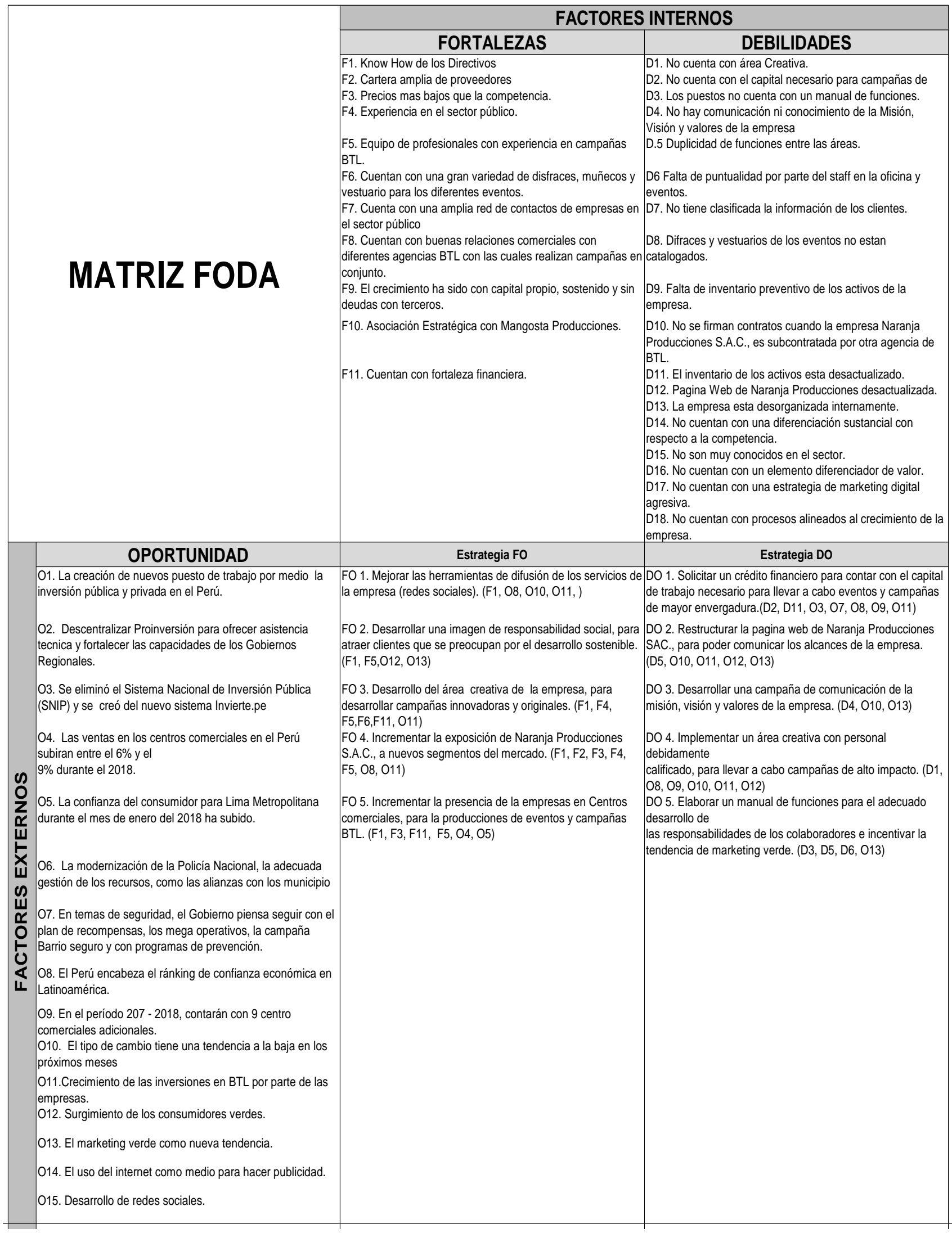




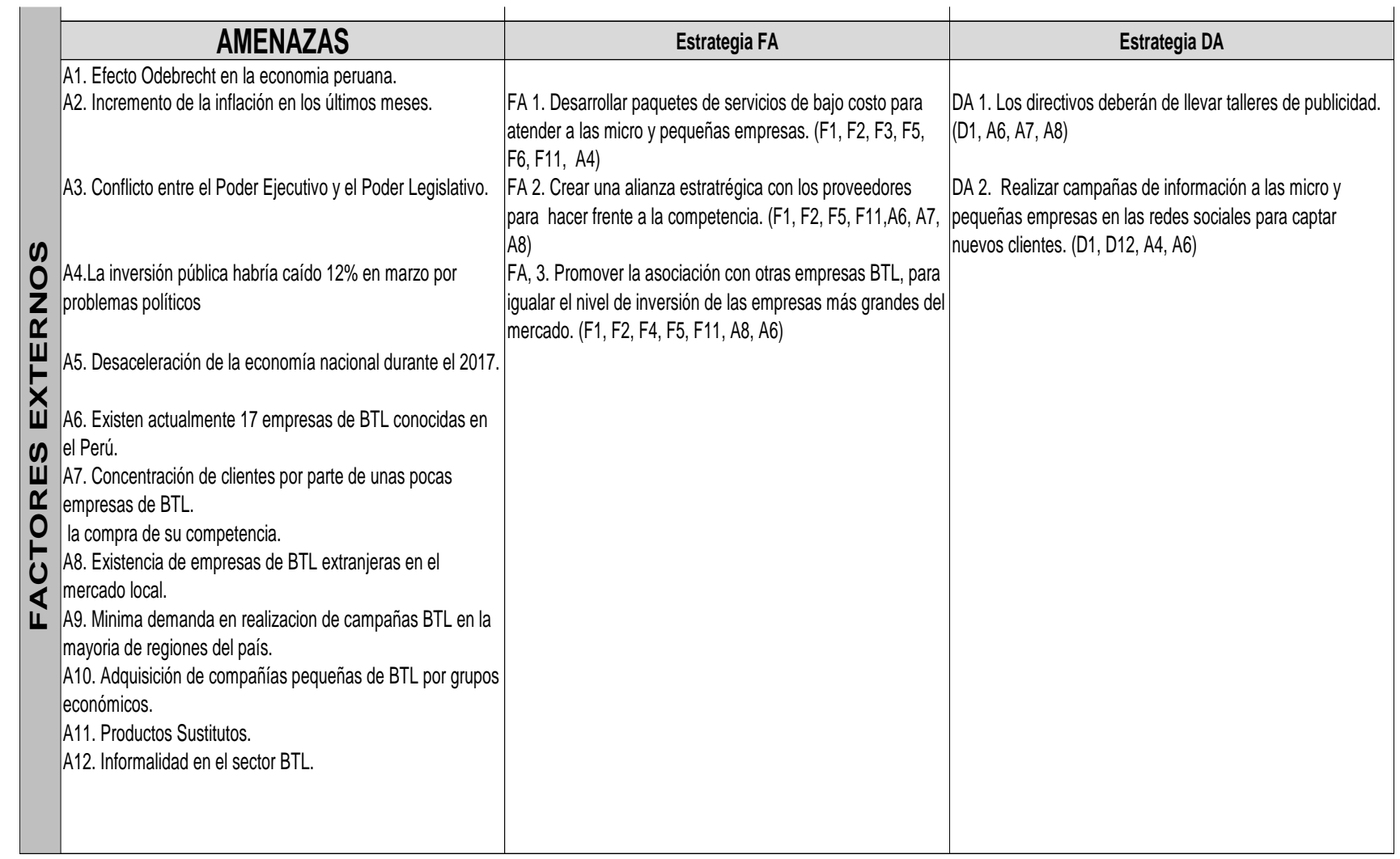

Elaboración Propia

Analizando la Matriz mostrada, se puede apreciar que se debe trabajar más en nuestras oportunidades que da el mercado apoyándonos en nuestras fortalezas.

\subsubsection{Matriz PEYEA}

La matriz de la posición estratégica y la evaluación de la acción (PEYEA es una estrategia que combina factores internos y externos de la empresa. Los factores internos son las fuerzas financieras $[\mathrm{FF}]$ y la ventaja competitiva $[\mathrm{VC}]$ y los factores externos son la estabilidad del ambiente $[E A]$ y la fuerza de la industria $[\mathrm{FI}]$. Con esta herramienta se busca identificar cuál es la estrategia más apropiada en relación a los objetivos perseguidos.

Para poder llevar a cabo una matriz PEYEA se deberán seguir las siguientes indicaciones:

1. Se debe seleccionar un conjunto de variables que incluyan la fuerza financiera (FF), la ventaja competitiva (VC), la estabilidad del ambiente (EA) y la fuerza de la industria (FI).

2. A los factores FF y FI se les asignará un valor numérico de +1 (peor) a +6 (mejor) a cada una de las variables. A los factores VC, EA se les asignará un valor numérico de -1 (mejor) -6 (peor) a cada una de las variables. 
3. Luego se debe calcular la calificación promedio de FF, VC, EA, y FI sumando los valores dados a las variables de cada dimensión y dividiéndolas entre la cantidad de variables incluidas en la dimensión respectiva.

4. Después se debe de colocar el promedio de FF, VC, EA, y FI en el eje correspondiente de la matriz PEYEA.

5. Sumar las dos calificaciones del eje $X y$ anotar el punto resultante en $X$. Sumar las dos calificaciones del eje $Y$. Anotar la intersección del nuevo punto $X Y$.

6. Trazar un vector direccional del origen de la matriz PEYEA por el nuevo punto de la intersección. Este vector revelará el tipo de la estrategia recomendable para la organización agresiva, competitiva, defensiva o conservadora.

\section{Cuadro 7.1: La Matriz PEYEA}

\begin{tabular}{|c|c|c|c|}
\hline \multicolumn{4}{|c|}{ Matriz Peyea } \\
\hline \multicolumn{2}{|r|}{ Fuerzas } & Calificación & Promedio \\
\hline \multirow{7}{*}{ Fuerza Financiera } & Liquidez & 5 & \\
\hline & Capital de trabajo & 5 & \\
\hline & Flujos de efectivo & 4 & \\
\hline & Facilidad para salir & & \\
\hline & del mercado & 5 & \\
\hline & Riesgos implicitos & & \\
\hline & del negocio & 4 & 23 \\
\hline \multirow{5}{*}{ Ventaja Competitiva } & Participación en el mercado & -5 & \\
\hline & Calidad del producto & -2 & \\
\hline & Ciclo de vida del producto & -2 & \\
\hline & Lealtad de los clientes & -3 & \\
\hline & Control sobre los proveedores y distribuidores & -2 & -14 \\
\hline \multirow{5}{*}{ Estabilidad del Ambiente } & Tasa de inflación & -2 & \\
\hline & Variabilidad de la demanda & -2 & \\
\hline & Escala de precios de productos competidores & -2 & \\
\hline & Barreras para entrar en el mercado & -5 & \\
\hline & Presión competitiva & -4 & -15 \\
\hline \multirow{2}{*}{ Fuerza de la Industria } & Potencial de crecimiento & 6 & \\
\hline & Intensidad de capital & 4 & 10 \\
\hline
\end{tabular}

\section{Elaboración Propia.}

En el caso de la empresa Naranja Producciones S.A.C., se entrevistó a los directivos de la empresa, para poder realizar la Matriz PEYEA. 
Conclusión:

El promedio para la EA: $-15 / 5=-3$

El promedio para la VC: $-14 / 5=-2.8$

El promedio para la $\mathrm{Fl}: 10 / 2=5$

El promedio para la $\mathrm{FF}: 23 / 5=4.6$

El vector direccional: eje $\mathrm{X}: \mathrm{VC}+\mathrm{FI}=(-2.8)+5=2.2$

$Y: E A+F F=(-3)+4.6=1.6$

Gráfico7.1: Matriz PEYEA de Naranja Producciones S.A.C.

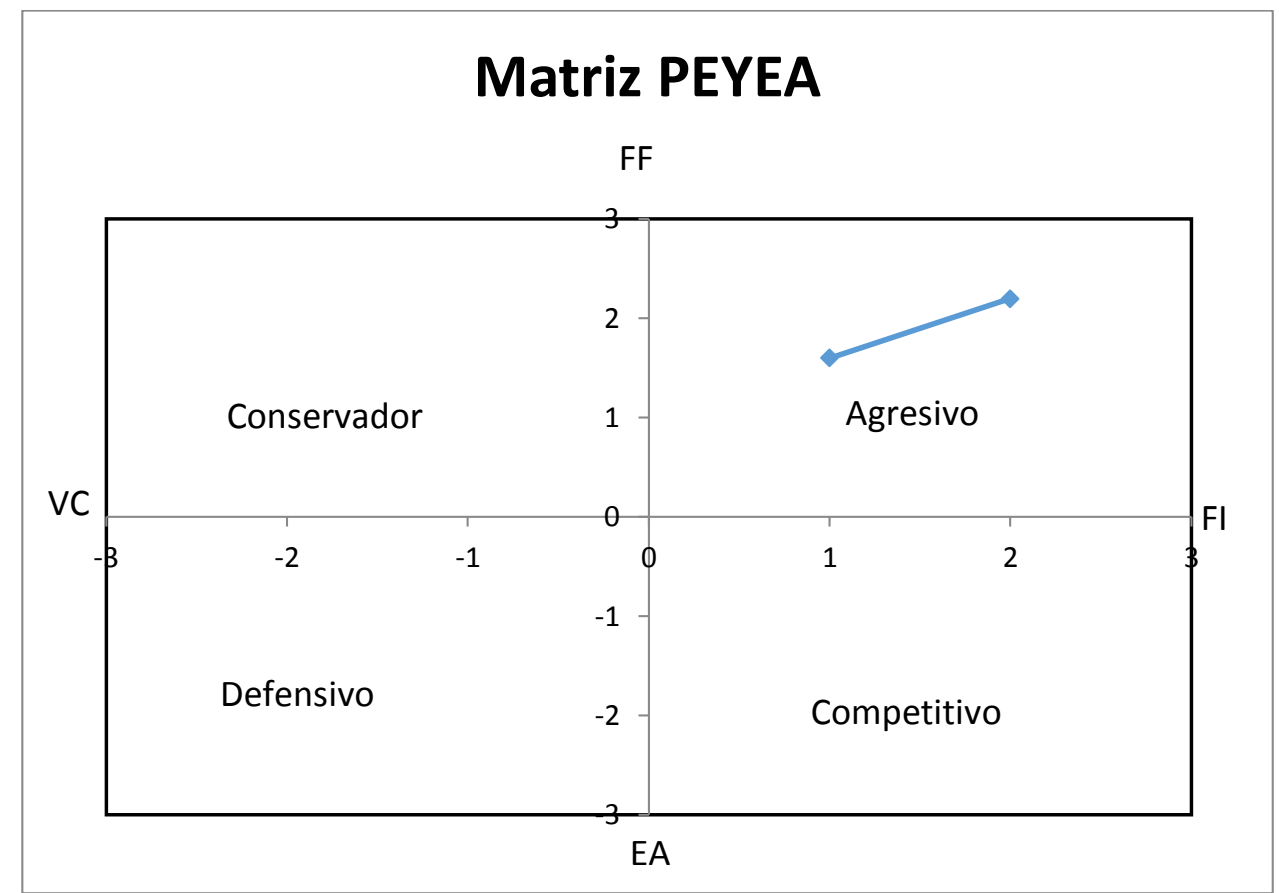

Elaboración Propia.

La empresa Naranja Producciones S.A.C., debería seguir una estrategia del tipo agresiva. Esto significa que la empresa puede utilizar sus fortalezas internas para poder aprovechar las oportunidades externas y superar sus debilidades internas y evitar amenazas externas. De esta manera, la empresa podría utilizar las estrategias de penetración de mercado, el desarrollo de productos, la integración hacia adelante, integración hacia atrás, integración horizontal, diversificación en conglomerados, y diversificación concéntrica y diversificación horizontal. 


\subsubsection{Matriz Interna Externa}

El señor Fred David en su libro Concepto de administración Estrategia dice que: "La matriz Interna y Externa (IE) ubica las diversas divisiones de una empresa en un esquema de nueve"96. Por otra parte, el señor Fred David dice que: "La matriz IE es similar a la matriz BCG, ya que ambas herramientas registran las divisiones de una empresa en un diagrama esquemático; éste es el motivo por el que ambas se conocen como matrices de cartera"97.

La matriz Interna y Externa se formula a partir de los puntajes ponderados del EFI, el cual es el eje $X$ y los puntajes ponderados del EFE, el cual es el eje $Y$ dentro de la matriz IE.

Por otro lado, un puntaje ponderado de EFI de 1.0 a 1.99 representa una posición interna débil; un puntaje de 2.0 a 2.99 se considera promedio, y un puntaje de 3.0 a 4.0 se considera como fuerte. Por el lado del EFE, un puntaje total ponderado de 1.0 a 1.99 se considera bajo; un puntaje de 2.0 a 2.99 se considera medio, y un puntaje de 3.0 a4.0 alto.

La matriz Interna y Externa se puede dividir en 3 regiones. En el siguiente gráfico, se puede apreciar que en la primera región de color celeste está conformado por cuadrante I, II y IV. Si alguna división cae en esta región podríamos decir que está en una posición de crecer y construir. Las estrategia a seguir serían las intensivas y las de integración. La segunda región de color verde está conformada por los cuadrantes III, V y VII. Si alguna división cae en esta región podríamos decir que está en una posición de retener y mantener. La estrategia sería la penetración en el mercado y el desarrollo de productos. La tercera región de color amarillo está conformada por los cuadrantes VI, VIII y IX. Si alguna división cae en esta región podríamos decir que está en una posición de cosechar o desinvertir. La estrategia sería la defensiva.

Bajo este modelo se llevó a cabo la matriz Interna y Externa de Naranja Producciones S.A.C., la cual se puede apreciar en la siguiente tabla.

El valor considerado en el eje $X$ es el promedio del puntaje ponderado de la matriz EFI, el cual fue del 2.46. En el eje $Y$ se ha considerado el valor promedio del puntaje

\footnotetext{
${ }^{96}$ David, Fred. (2003) Conceptos de Administración Estratégica. 9na ed. México DF.: Perason Educación, p.211

${ }^{97}$ David, Fred. (2003) Conceptos de Administración Estratégica. 9na ed. México DF.: Perason Educación, p.211
} 
ponderado de la matriz EFE, el cual fue de 2.91. Ambos puntajes ponderado son de las matrices EFI y EFE de Naranja Producciones S.A.C. Con los puntajes ponderados se puede concluir que la empresa se ubica en el cuadrante $\mathrm{V}$, a la cual le corresponde la posición de retener y mantener, bajo la estrategia de penetración en el mercado y el desarrollo de productos.

\section{Gráfico 7.4: Matriz Interna y Externa (IE)}

\begin{tabular}{|c|c|c|c|c|c|}
\hline & & & Puntaje & Total Ponder & ado de EFI \\
\hline & & & $\begin{array}{l}\text { Fuerte } \\
\qquad 3.0 \mathrm{a} 4.0\end{array}$ & $\begin{array}{l}\text { Promedio } \\
2.0 \text { a } 2.99\end{array}$ & $\begin{array}{l}\text { Débil } \\
1.0 \text { a } 1.99\end{array}$ \\
\hline & & 4.0 & 3.0 & 2.0 & 1.0 \\
\hline & $\begin{array}{c}\text { Alto } \\
3.0 \text { a } 4.0\end{array}$ & 3.0 & I & II & III \\
\hline Puntaje Total Ponderado de EFE & $\begin{array}{c}\text { Medio } \\
2.0 \text { a } 2.99\end{array}$ & 2.0 & IV & v & VI \\
\hline & $\begin{array}{c}\text { Bajo } \\
1.0 \text { a } 1.99\end{array}$ & 1.0 & VII & VIII & IX \\
\hline
\end{tabular}

Fuente: David, Fred R. Concepto de administración estratégica. 14 ed. México D.F.: Pearson Educación, 2013. Cap. 6.

Gráfico 7.5: Matriz IE de Naranja Producciones S.A.C.

\begin{tabular}{|c|c|c|c|c|c|}
\hline & & & PUNTAJE TO & TAL PONDERAD & O EFI \\
\hline & & & $\begin{array}{c}\text { Fuerte } \\
3.00 \text { a } 3.99\end{array}$ & $\begin{array}{c}\text { Medio } \\
2.00 \text { a } 2.99\end{array}$ & $\begin{array}{c}\text { Bajo } \\
1.00 \text { a } 1.99\end{array}$ \\
\hline & & 4.00 & 3.00 & 2.00 & 1.00 \\
\hline PUNTAJE TOTAL PONDERADO EFE & $\begin{array}{c}\text { Alto } \\
3.00-3.99\end{array}$ & 3.00 & 1 & II & III \\
\hline & $\begin{array}{c}\text { Medio } \\
2.00 \text { a } 2.99\end{array}$ & 2.46 & IV & $\begin{array}{l}\text { 2.91;2.46 } \\
\text { P }\end{array}$ & VI \\
\hline & $\begin{array}{c}\text { Bajo } \\
1.00 \text { a } 1.99\end{array}$ & 1.00 & VII & VIII & IX \\
\hline
\end{tabular}

Elaboración Propia. 


\subsubsection{Matriz Boston Consulting Group}

"Esta matriz toma en cuenta no solamente el índice de crecimiento de los productos, sino también la participación relativa que cada producto de la empresa tiene en un Mercado"98

Esta matriz cuenta con dos ejes. El eje de las abscisas le corresponde a la participación relativa de mercado y el de las ordenadas le corresponde al crecimiento del producto. La matriz BCG cuenta con cuatro cuadrantes, conformador por:

a. La estrella.- "Negocios o productos de alta participación y de alto crecimiento"99.

b. Vaca.- "Negocios o productos de alta participación y de bajo crecimiento" ${ }^{100}$.

c. Interrogante.- "Unidades de negocios de baja participación en mercados de alto crecimiento"101.

d. Perro.- "Negocios y productos de bajo crecimiento y baja participación" ${ }^{102}$.

\footnotetext{
${ }^{98}$ ARELLANO, Rolando. Marketing, Enfoque para Americalatina. 1er ed. México: Pearson autorización de México, 2010. P 336. ${ }^{99}$ KOTLER, Philip. ARMSTRONG, Gary. Marketing, Versión para Latinoamérica. 11ra ed. México D.F.: Pearson Educación de México, 2007. P. 42.

${ }^{100}$ KOTLER, Philip. ARMSTRONG, Gary. Marketing, Versión para Latinoamérica. 11ra ed. México D.F.: Pearson Educación de México, 2007. P. 42.

${ }^{101}$ KOTLER, Philip. ARMSTRONG, Gary. Marketing, Versión para Latinoamérica. 11ra ed. México D.F.: Pearson Educación de México, 2007. P. 42.

${ }^{102}$ KOTLER, Philip. ARMSTRONG, Gary. Marketing, Versión para Latinoamérica. 11ra ed. México D.F.: Pearson Educación de México, 2007. P. 42.
} 
Ilustración 7.2: Matriz BCG para Naranja Producciones S.A.C.

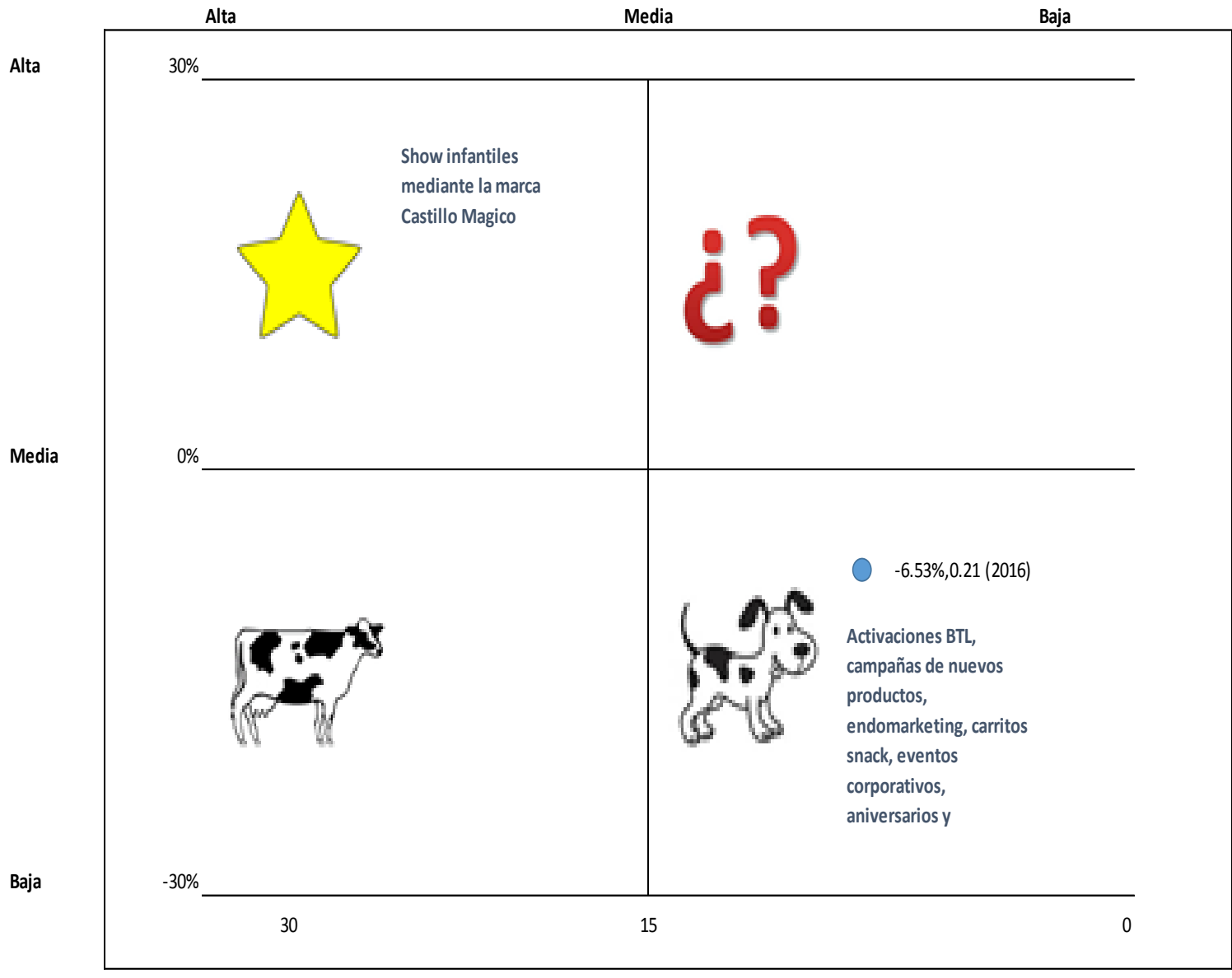

Elaboración Propia.

\section{Cuadro 7.5: Participación de mercado}

\begin{tabular}{|l|c|}
\hline \multicolumn{1}{|c|}{ Empresas B TL } & Número de Clientes \\
\hline FCB Mayo & 24 \\
\hline Circus Grey & 11 \\
\hline Vayas & 20 \\
\hline Roho & 11 \\
\hline Boom & 23 \\
\hline Naranja Producciones SAC & 5 \\
\hline
\end{tabular}

Elaboración Propia.

Para poder desarrollar la Matriz BCG, hemos de trabajar con la participación relativa de la empresa comparada al líder. Por tal motivo, dividiremos 5 entre 24, lo cual nos dará como resultado 0.21 . 
Ilustración 7.3: Matriz BCG

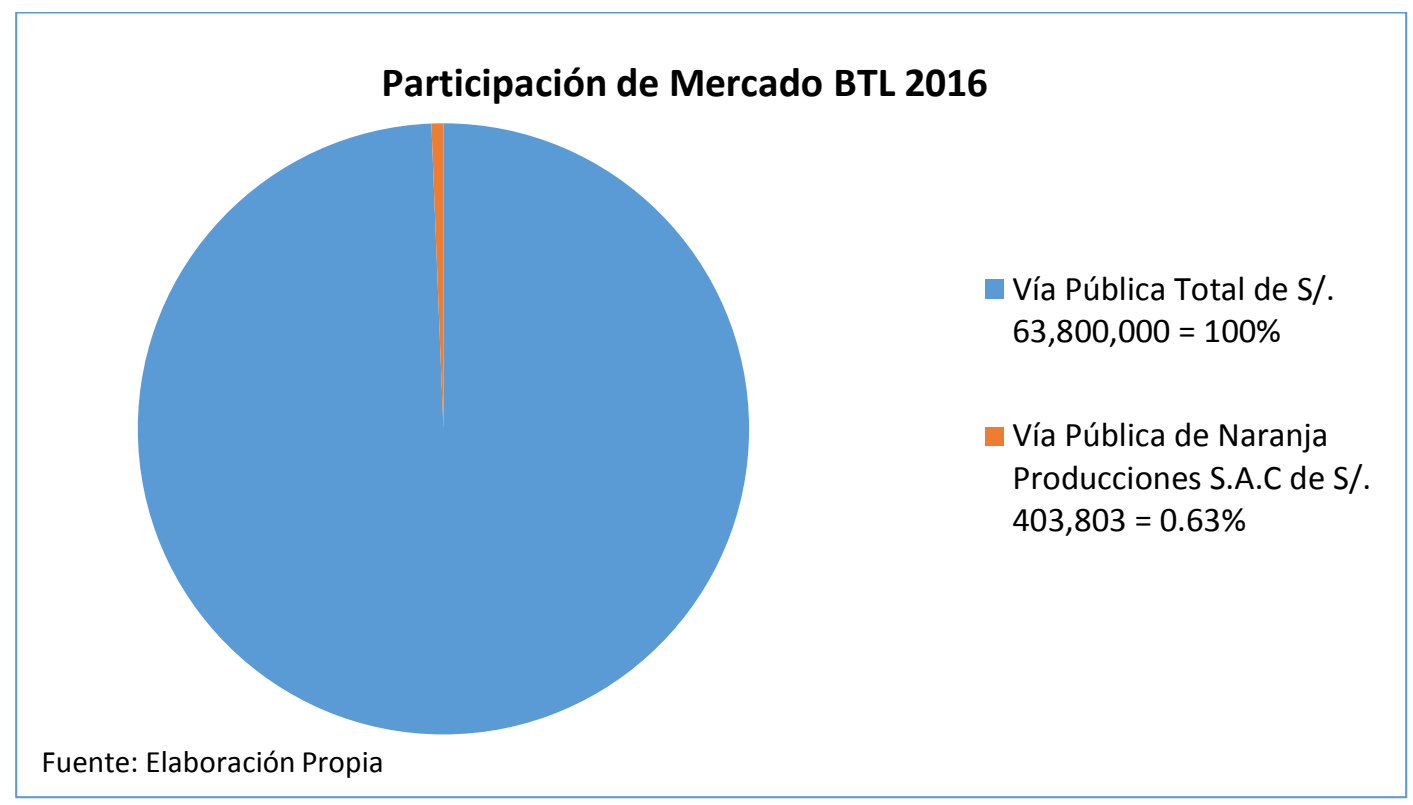

Matriz BCG de los servicios brindados por Naranja Producciones S.A.C..

La empresa Naranja Producciones S.A.C. cuenta con una participación muy pequeña en el mercado actual, a pesar que cada mes cuentan con más clientes.

Dentro de la Matriz BCG podemos ubicar los siguientes servicios de la empresa.

Perro.- Consideramos que el servicio de BTL está en el cuadrante del Perro porque la participación relativa del mercado de la empresa es de apenas el $0.21 \%$ y aunque el crecimiento del mercado fue el $2 \%$ durante el 2016 ( $\$ / .725$ millones), este no es tan alto como en años pasados, debido a que durante el 2015, hubo un descrecimiento de $4.7 \%$ (\$/.711 millones). Este descenso se contrapone al crecimiento continuo que tuvo el sector desde el 2012 hasta el 2014.

Otro servicio complementario a los shows y campañas BTL es el servicio de la marca Dulcemanía que posee Naranja Producciones S.A.C.. Este servicio consiste en el alquiler de carritos snack a las empresas como son los carritos de pop corn, carritos de algodón, carritos de hot dog, panchos, carritos de helados, carritos de raspadillas, chorizos, manzanas acarameladas, entre otros. Estos carritos se decoran con la marca propia del cliente. Es un mercado de alto crecimiento especialmente a finales del año como son los meses de noviembre y diciembre. Consideramos que este servicio también está en el cuadrante de la interrogante, porque es un mercado de alto crecimiento, pero cuentan con una participación casi nula, debido que recién han implementado este servicio. Debido a 
que no se encuentra con datos sobre alquiler de carritos snacks, hemos elaborado el BCG para este segmento bajo nuestra opinión cualitativa.

Estrella.- El mercado actual no cuenta con información cuantitativa de shows infantiles por tal motivo hemos realizado este cuadrante mediante nuestra opinión a partir de lo conversado con el dueño de la empresa; aunque se puede precisar que las ventas del 2017 la percepción que tiene los dueños de Naranja Producciones S.A.C. es que han bajado la ventas.

El servicio de la marca Castillo Mágico de Naranja Producciones S.A.C. está en el cuadrante de la estrella porque la demanda y el crecimiento de este sector es alto y su participación ha ido creciendo año a año.

Evaluando esta matriz podríamos concluir que la empresa debería implementar las estrategias de penetración de mercados, desarrollo del mercado, de productos y desinversión.

\subsubsection{Matriz de la Gran Estrategia}

La Matriz de la Gran estrategia (GE) ayudará a evaluar y definir las estrategias apropiadas para la empresa. En esta matriz se pueden observar cuatro cuadrantes, en donde se explica detalladamente cada una de las estrategias necesarias para poder llevar a cabo una posición competitiva fuerte o débil (eje horizontal) frente a un crecimiento rápido o lento del mercado (eje vertical) 


\section{Gráfico 7.6: Matriz de la Gran Estrategia (GE)}

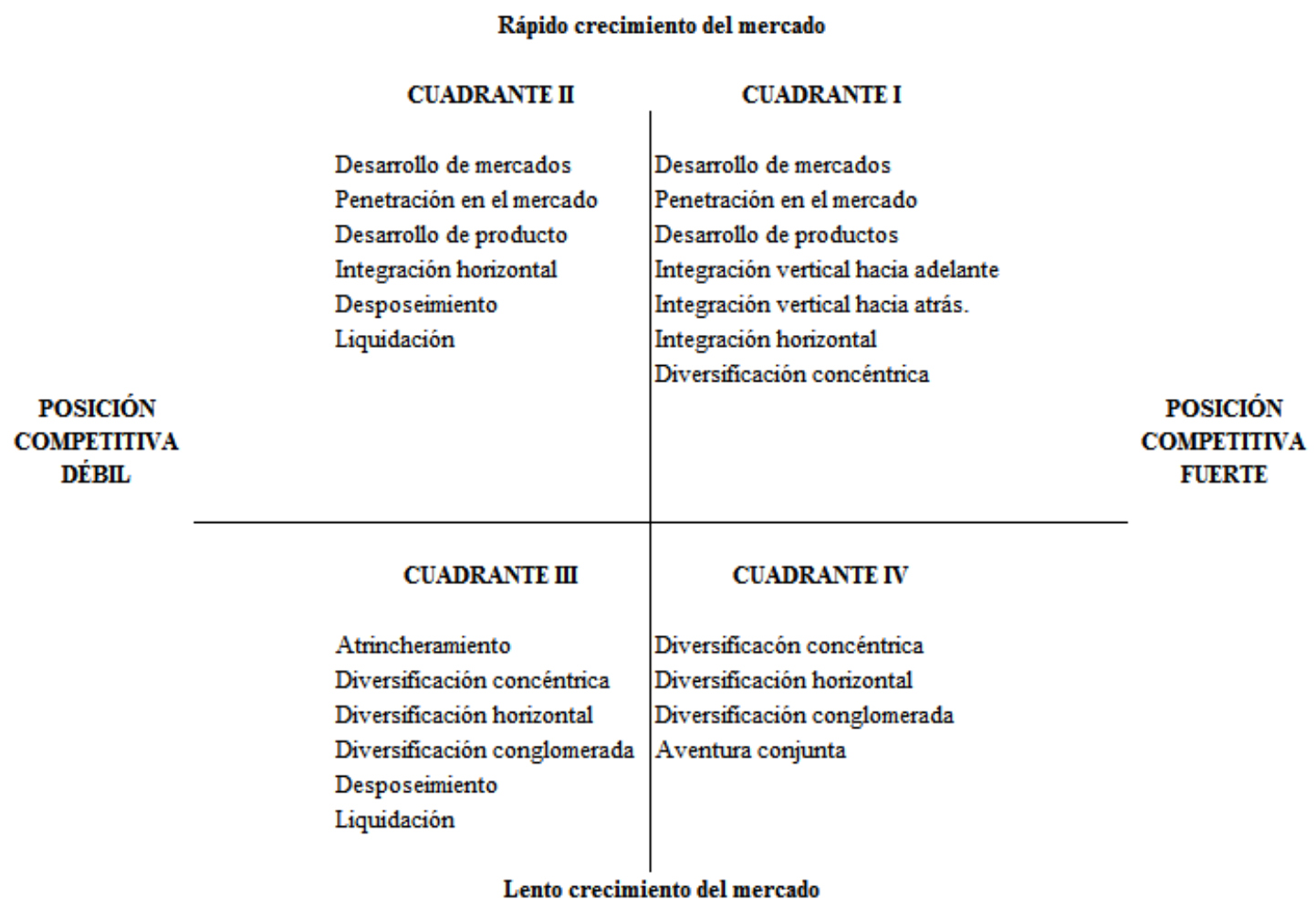

\section{Elaboración Propia.}

Analizando la tabla anterior, podemos inferir que la empresa Naranja Producciones S.A.C. se ubica en el cuadrante I debido a que el crecimiento del mercado es rápido como se ha podido apreciar en los capítulos anteriores y además cuenta con una fuerte posición competitiva. Por tal motivo, se debería llevar a cabo las estrategias de penetración en el mercado, el desarrollo del mercado y el desarrollo de servicios como lo ha estado haciendo hasta el momento. Con estas estrategias Naranja Producciones S.A.C. deberá buscar la fidelización de sus actuales clientes, además, de poder lograr captar nuevos clientes en el mercado actual y en nuevos mercados, como la atención de las micro y pequeñas empresas.

\subsection{Resumen de las Estrategias Formuladas}

Se puede concluir que cada una de las matrices desarrolladas con anterioridad han permitido la formulación de un conjunto de estrategias que permitirán la consecución de los objetivos estratégicos que se ha planteado para la empresa Naranja Producciones S.A.C.. 
En cada una de las matrices se ha podido determinar las siguientes estrategias: Penetración de mercados, desarrollo de mercado, desarrollo de productos, Integración hacia adelante, Integración hacia atrás, Integración horizontal, diversificación en conglomerados, diversificación concéntrica, diversificación horizontal, desinversión y diferenciación relacionada. De todas las estrategias mencionadas, la estrategia seleccionada ha sido la de penetración de mercados.

Cuadro 7.6: Matriz de Resultados

\begin{tabular}{|l|c|c|c|c|c|}
\cline { 2 - 4 } \multicolumn{1}{c|}{} & \multicolumn{3}{c|}{ Matriz de Resultados } & \multicolumn{1}{c}{} \\
\hline \multicolumn{1}{|c|}{ ESTRATEGIAS } & PEYEA & $\mathrm{IE}$ & $\mathrm{BCG}$ & $\mathrm{GE}$ & TOTAL \\
\hline Penetración de mercados & $\mathrm{X}$ & $\mathrm{X}$ & $\mathrm{X}$ & $\mathrm{X}$ & 5 \\
\hline Desarrollo de mercado & & & $\mathrm{X}$ & $\mathrm{X}$ & 2 \\
\hline Desarrollo de productos & $\mathrm{X}$ & $\mathrm{X}$ & $\mathrm{X}$ & $\mathrm{X}$ & 4 \\
\hline Integración hacia adelante & $\mathrm{X}$ & & & $\mathrm{X}$ & 2 \\
\hline Integración hacia atrás & $\mathrm{X}$ & & & $\mathrm{X}$ & 2 \\
\hline Integración horizontal & $\mathrm{X}$ & & & $\mathrm{X}$ & 2 \\
\hline Diversificación en conglomerados & $\mathrm{X}$ & & & & 1 \\
\hline Diversificación concéntrica & $\mathrm{X}$ & & & $\mathrm{X}$ & 2 \\
\hline Diversificación horizontal & $\mathrm{X}$ & & & & 1 \\
\hline Desinversión & & & $\mathrm{X}$ & & 1 \\
\hline Diferenciación relacionada & & & & & 1 \\
\hline
\end{tabular}

Elaboración Propia. 


\section{Capítulo VIII}

\section{Selección de la Estrategia}

En el capítulo anterior se desarrolló un conjunto de estrategias para la empresa Naranja Producciones S.A.C. para los próximos 4 años. Estas estrategias se han basado en las fortalezas y oportunidades que tiene la empresa para poder contrarrestar las amenazas del entorno y para poder disminuir sus debilidades y poder lograr la misión que se ha planteado a la empresa.

El señor Fred David, en su libro Conceptos Administración Estratégica nos dice que: "El análisis y la selección de la estrategia intentan determinar los cursos alternativos de acción que permitirán a la empresa lograr su misión y objetivos”103. Por tal motivo, es importante un análisis minucioso para poder seleccionar una estrategia adecuada que nos ayude a conseguir la misión y los objetivos planteados por la empresa. La elección de una o varias alternativas de estrategias posibles tiene como propósito determinar las medias y acciones más adecuadas para que Naranja Producciones S.A.C. pueda conseguir sus objetivos y su misión.

En este nuevo capítulo desarrollaremos el método de factores estratégicos claves, el de los escenarios y la matriz de planeación estratégica cuantitativa. Estas herramientas nos permitirán y ayudaran a seleccionar las acciones más adecuadas para la empresa Naranja Producciones S.A.C.

\subsection{Métodos Factores Estratégicos Claves}

Como se ha podido apreciar el capítulo 7 se ha dedicado al análisis, creación y desarrollo de diferentes estrategias. Estas estrategias se formularon mediante el análisis del sector y de la empresa Naranja producciones S.A.C. para poder llevar a cabo las estrategias más apropiadas para la situación actual de la empresa.

Sin embargo, las herramientas utilizadas para la formulación de estas nuevas estrategias han generado un número diferente de estas. Por tal motivo, se deberá seleccionar una de ellas en base a ciertos criterios que se desarrollarán a continuación.

${ }^{103}$ David, Fred. Conceptos de Administración Estratégica. 9na ed. México DF.: Perason Educación, 2003. p.196 


\subsubsection{Criterios de selección}

Las herramientas utilizadas como la estrategia del océano azul, la matriz PEYEA, la matriz interna y externa, el BCG y la matriz de la Gran Estrategia han permitido la formulación de un conjunto de estrategias posibles, sin embargo, llevar a cabo todas las estrategias formuladas por las diferentes matrices, podrían hacer que Naranja Producciones S.A.C. no pueda implementar cada una de ellas de la mejor manera, es por tal motivo, que se deberá seleccionar las estrategias más rentables para la empresa mediante la elaboración de la Matriz de Planeación Estratégica Cuantitativa MPEC.

\subsubsection{Matriz de selección}

Para poder desarrollar la matriz de selección, debemos de identificar las estrategias que han surgido durante el desarrollo de la matriz PEYEA, la matriz Interna y Externa, la matriz BCG y la de la Gran Estrategia con los criterios de selección o los Factores Principales de Éxito (FPE) comunes a ellas. Luego se contabilizará el número de veces que se han repetido cada una de las estrategias en las matrices desarrolladas.

En la siguiente tabla se presentará la matriz de resultados, la cual cuenta con una columna en donde se ubican todas las estrategias desarrolladas en las diferentes matrices y una fila en donde se ubican cada uno de los modelos desarrollados. De esta manera podremos escoger las tres estrategias con mayor impacto en cada una de las matrices desarrolladas.

Como se puede observar las estrategias de penetración de mercados, de desarrollo de mercado y la de desarrollo de producto han sido las estrategias que se han repetido más veces en los diferentes modelos que se han desarrollado anteriormente.

Por otra parte, para desarrollar la Matriz de selección, se deberá de determinar los criterios de selección o los llamados Factores principales de éxito (FPE). Los señores Peteraf Thompson y Stricklan Gamble en su libro Administración Estratégica dicen que: "Los factores principales de éxito (FPE) de una industria son los factores competitivos que más afectan la capacidad de sus miembros para prosperar en el mercado: los elementos particulares de la estrategia, atributos del producto, recursos, competencias, capacidades competitivas y logros comerciales que representan la diferencia entre un competidor fuerte 
y uno débil, y en ocasiones, entre pérdida y ganancia"104. Por tal motivo, se deberá de seleccionar los factores competitivos que las empresas deberán de tener para lograr el éxito en el mercado de las empresas de BTL.

Además, los autores para poder elaborar las (FPE) El señor Peteraf Thompson y Stricklan Gamble en su libro Administración Estratégica dicen que los factores básicos de éxito se pueden obtener al realizarse tres preguntas. La primera pregunta que se debe de realizar es: “¿Con qué bases los compradores del producto de la industria eligen entre las marcas competidoras de los vendedores? Es decir, ¿cuáles de los atributos del producto y las características del servicio son fundamentales?"105. En esta pregunta las empresas deben de analizar cuáles son los atributos que los clientes buscan a la hora de escoger a una empresa para que elabore las campañas de BTL. La segunda pregunta sería: "Por la naturaleza de la rivalidad competitiva y de las fuerzas competitivas en el mercado. ¿Qué recursos y capacidades competitivas necesita una empresa para tener éxito en el mercado?"106. Es decir, qué capacidades debería tener las empresas de BTL para ser competitivas en el mercado actual. Y la última pregunta sería: “¿Qué deficiencias es casi seguro que pongan a una empresa en una desventaja competitiva significativa?" ${ }^{107}$. Cual serían las debilidades que deberían tener las empresas para estar en desventaja en comparación a la competencia. Contestando cada una de estas tres preguntas se podrá escoger los factores principales de éxitos del mercado.

En el cuadro 8.2 se analizará la matriz de selección.

\footnotetext{
104 THOMPSON, Peteraf y GAMBLE, Stricklan. Administración Estratégica. 18va ed. México DF.: McGraw-Hill/Interamericana Editores, 2012. p. 82

${ }^{105}$ THOMPSON, Peteraf y GAMBLE, Stricklan. Administración Estratégica. 18va ed. México DF.: McGraw-Hill/Interamericana Editores, 2012. p. 83

${ }^{106}$ THOMPSON, Peteraf y GAMBLE, Stricklan. Administración Estratégica. 18va ed. México DF.: McGraw-Hill/Interamericana Editores, 2012. p. 83

${ }_{107}$ THOMPSON, Peteraf y GAMBLE, Stricklan. Administración Estratégica. 18va ed. México DF.: McGraw-Hill/Interamericana Editores, 2012. p. 83
} 
Cuadro 8.1: Matriz de selección

\begin{tabular}{|c|c|c|c|c|c|c|c|}
\hline \multirow{2}{*}{$\begin{array}{l}\text { Criterios de } \\
\text { Selección }\end{array}$} & \multirow[b]{2}{*}{ Peso } & \multicolumn{4}{|c|}{ Matriz de selección } & \multirow[b]{2}{*}{$\begin{array}{l}\text { E3: Desarrollo } \\
\text { de Productos }\end{array}$} & \multirow[b]{2}{*}{ P.P. } \\
\hline & & $\begin{array}{c}\text { E1: } \\
\text { Penetración } \\
\text { de Mercado }\end{array}$ & P.P. & \begin{tabular}{|c|} 
E2: \\
Desarrollo \\
de \\
Mercado \\
\end{tabular} & P.P. & & \\
\hline $\begin{array}{c}\text { Participación de } \\
\text { Mercado }\end{array}$ & 0.1 & 5 & 0.5 & 4 & 0.4 & 5 & 0.5 \\
\hline Ventaja competitiva & 0.2 & 5 & 1 & 5 & 1 & 5 & 1 \\
\hline $\begin{array}{c}\text { Red de proveedores } \\
\text { de productos y } \\
\text { servicios }\end{array}$ & 0.05 & 4 & 0.2 & 4 & 0.2 & 4 & 0.2 \\
\hline Costos & 0.05 & 4 & 0.2 & 4 & 0.2 & 3 & 0.15 \\
\hline Precios & 0.05 & 4 & 0.2 & 3 & 0.15 & 4 & 0.2 \\
\hline $\begin{array}{c}\text { Equipo de } \\
\text { profesionales } \\
\text { creativos } \\
\end{array}$ & 0.2 & 4 & 0.8 & 4 & 0.8 & 4 & 0.8 \\
\hline Imagen Corporativa & 0.1 & 5 & 0.5 & 4 & 0.4 & 4 & 0.4 \\
\hline Tiempo de entrega & 0.05 & 4 & 0.2 & 4 & 0.2 & 4 & 0.2 \\
\hline $\begin{array}{l}\text { Disponibilidad de } \\
\text { inversión. }\end{array}$ & 0.2 & 4 & 0.8 & 3 & 0.6 & 4 & 0.8 \\
\hline $\begin{array}{l}\text { Clasificación de } \\
\text { Fortaleza General }\end{array}$ & $\mathbf{1}$ & 39 & 4.4 & 35 & 3.95 & 37 & 4.25 \\
\hline
\end{tabular}

Elaboración Propia.

A continuación, explicaremos cada uno de los criterios de selección:

Participación de Mercado: En el mercado actual, las empresas Chirimoya BTL, FBC Mayo y Grey Perú son las empresas con mayor participación en el mercado según el criterio de Naranja Producciones S.A.C; por tal motivo nuestra empresa debe aumentar su participación actual que es de $0.63 \%$ para poder tener mayor facturación, mayor presencia en el mercado y ser más conocido en el sector.

Ventaja Competitiva: En el mercado actual, las empresas Chirimoya BTL, FBC Mayo y Grey Perú cuentan con área creativa y diseñadores que pueden crear diferentes campañas en el sector. Según lo conversado con César Jaén Seminario de Naranja Producciones S.A.C., empresas como Directv; sólo contrata empresas creativas para la elaboración de sus campañas y contrata otras empresas productoras para la ejecución de dichas campañas; si alguna empresa productora le ofrece a Directv llevar acabo la creación de una activación, esta empresa no lo permite debido a que se basa mucho a la experiencia en la creación de todo un breaf de campaña. Es por ello, que la ventaja competitiva es importante porque de esa manera las empresas del sector escogen a sus proveedores. 
Red de proveedores de productos y servicios: La ejecución de una idea creativa debe estar sustentada con un staff de proveedores de productos y servicios que puedan llevar a cabo en los tiempos requeridos, y bajo estrictas normas de calidad para el desarrollo e implementación de las campañas. Las empresas productoras, no cuentan con equipos e implementos propios para llevar a cabo los eventos, es por tal motivo que subcontratan a diferentes empresas que puedan proveer equipos de sonido, grupo electrógenos, luces, entre otros.

Costos: Es muy importante tener costos competitivos a comparación de las empresas del sector, debido a que muchos clientes buscan un servicio de calidad prevalece siempre el precio más bajo a la hora de presentar una cotización. Un ejemplo muy claro se ve en el sector público, ya que muchas veces la empresa seleccionada para proveer algún servicio a la institución pública es el precio más bajo entre los postores, por otra parte en el sector privado también se ha observado, que muchas veces las áreas de marketing, recursos humanos y responsabilidad social; cuentan con un presupuesto fijo para la realización de sus campañas y eventos; pero muchas veces Naranja Producciones S.A.C. ha tenido que rechazar porque el margen de utilidad es muy bajo.

Precios: Se debe contar con un precio competitivo para la ejecución de diferentes proyectos, sin embargo este es uno de los factores a tener presente para contar con un proveedor.

Equipo de profesionales creativos: Es un punto importante, ya que toda buena idea se crea a partir de la colaboración de cada una de las personas que se encuentran en el área creativa. Muchas veces los clientes, contratan a la empresas de BTL por su staff y la por la cantidad de campañas creadas por ellos. Muchas empresas del sector, entre ellas Circus Grey, han ganado varios premios en el extranjero que respaldan su trabajo.

Imagen Corporativa: Este punto es un factor relevante debido a que una imagen corporativa mala, afectaría el nombre de la empresa, servicios, proveedores y futuras contrataciones.

Tiempo de entrega: El incumplimiento de la fecha pactada entre la empresa BTL y el cliente puede terminar con la relación comercial que estas empresas tengan. Es por eso que es muy importante cumplir con los tiempos pactados que se estipulan en los contratos 
firmados entre las partes. Es por eso que las empresas BTL deben de seleccionar de manera cuidadosa a sus proveedores de productos y servicios, para que los tiempos estipulados se cumplan con cabalidad.

Disponibilidad de Inversión: Las empresas BTL muchas veces no cuentan con el capital necesario para llevar a cabo una campaña. Por tal motivo, en algunas ocasiones no pueden postular a una campaña que supere su capacidad financiera. En el caso de Naranja Producciones S.A.C., en algunas ocasiones se asocia con otras empresas BTL para poder llevar a cabo una activación que este fuera de su alcance económico, para no perder al cliente.

Clasificación de Fortaleza General: En este punto engloba los factores más relevantes que una empresa puede tener en comparación de sus competidores a la hora de conseguir un cliente.

Como se puede observar la estrategia más fuerte es la estrategia de Penetración de mercados. La empresa Naranja Producciones S.A.C. deberá de poner mayor énfasis en esta estrategia.

\subsection{Métodos de Escenarios}

El método de selección de escenarios será útil a la hora de seleccionar la estrategia que la empresa deberá de implementar. Este método busca determinar los distintos escenarios que la empresa podría afrontar en el futuro. Estos escenarios se podrán obtener por medio de las matrices EFE y EFI realizadas en capítulos anteriores. Se deberá de contrastar cada una de las estrategias seleccionadas con los diferentes escenarios para poder escoger la mejor estrategia a implementar en el futuro.

\subsubsection{Descripción de escenarios considerados}

Para la elaboración de los escenarios se tomará en consideración los escenarios optimistas, el conservador y el pesimista.

A continuación será una descripción de cada uno de los escenarios ya mencionados: 


\section{Escenario Optimista del 2018 - 2021}

- Situación económica.- La macroeconomía del Perú se mantiene en crecimiento constante y en crecimiento con un PBI superior al 5\% anual, y la confianza del sector empresarial y de los consumidores se mantiene a la alza.

- Política y regulación.- Desburocratización de los permisos municipales para realizar campañas y eventos en la vía pública.

- Grado de competencia.- Barreras de entrada fuertes, como nivel de inversión para implementar las instalaciones y equipos para las empresas, alto nivel de capital de trabajo para llevar a cabo campañas de BTL de gran envergadura de BTL.

- Mercado.- Incremento de la demanda por parte de las micro y pequeñas empresas para llevar a cabo campañas de BTL.

\section{Escenario conservador del 2018 - 2021:}

- Situación económica.- La macroeconomía del Perú se mantiene estable. El Banco Central de Reserva (BCR), Julio Velarde, pronostica que el PBI del Perú: “...recortó su estimado de crecimiento de la economía peruana de 4,2\% a 4\% para este 2018 . El anterior estimado fue proyectado en diciembre del 2017"108. "El Fondo Monetario Internacional (FMI) elevó de 3,8\% a 4\% su estimado de crecimiento del Perú para este año en su último informe de perspectivas de la economía mundial, publicado hoy; lo cual está en línea con las proyecciones oficiales del gobierno." ${ }^{109}$.

- Política y regulación.- Se mantiene la regularización municipal igual hasta el momento.

- Grado de competencia.- Se mantiene la misma cantidad de empresas de BTL en el mercado nacional. No varía significativamente el ingreso de nuevas empresas al sector.

- Mercado.- Las micros y pequeñas empresas se mantienen sin aumentar la demanda de los servicios de BTL de las empresas del sector. Las empresas públicas y privadas mantienen el mismo nivel de demanda hasta el momento.

\footnotetext{
${ }^{108}$ BCR, BCR redujo su estimado de crecimiento del PBI para el 2018, En: Diario El Comercio. [en línea]. PE. 2018. [citado 15 abril 2018]. Disponible en: https://elcomercio.pe/economia/peru/bcr-recorto-estimado-crecimiento-pbi-2018-noticia-506747 ${ }^{109}$ FMI sube proyección de crecimiento de Perú a 4\% para el 2018. En: Diario El Comercio. [en línea]. PE. 2018. [citado 15 abril 2018]. Disponible en: https://elcomercio.pe/economia/peru/fmi-sube-proyeccion-crecimiento-peru-4-2018-noticia-491977
} 


\section{Escenario pesimista del 2018 - 2021:}

- Situación económica.- La economía peruana desacelera y el PBI cae a sus peores índices de los últimos 10 años. La confianza de los inversionistas se deteriora y las inversiones emigran a otros países de la región. La confianza del consumidor cae y por consecuencia la demanda de productos y servicios disminuye. Las empresas dejan de vender y a solicitar los servicios de las empresas de publicidad de ATL y BTL.

- Política y regulación.- La burocracia y los requisitos para permisos se elevan, haciendo más caro y complejo el poder realizar eventos y campañas en vías públicas.

- Grado de competencia.- Las barreras de ingreso se hacen más fáciles y se incrementa el número de empresas que ofrecen los servicios de BTL en el mercado local. Las empresas más grandes del sector empiezan a comprar a las empresas más pequeñas.

- Mercado.- La demanda disminuye y el presupuesto de las empresas para campañas BTL disminuye

\subsubsection{Comparación de Estrategias con escenarios}

Se compara las estrategias de penetración de mercados, de desarrollo de mercados y de desarrollo de productos con cada uno de los tres escenarios que se han analizado en el punto anterior. En el siguiente cuadro se ha calificado las estrategias con muy desfavorable, desfavorable, indiferente, favorable y muy favorable.

\section{Cuadro 8.2: Comparación de Estrategias con escenarios}

\begin{tabular}{|l|c|c|c|}
\hline \multicolumn{1}{|c|}{ Estrategias } & Escenario 1 & Escenario 2 & Escenario 3 \\
\cline { 2 - 4 } & Optimista & Conservador & Pesimista \\
\hline $\begin{array}{l}\text { E1: Penetración } \\
\text { de Mercado }\end{array}$ & Muy Favorable & Favorable & Desfavorable \\
\hline $\begin{array}{l}\text { E2: Desarrollo de } \\
\text { Mercado }\end{array}$ & Muy Favorable & Favorable & Muy desfavorable \\
\hline $\begin{array}{l}\text { E3: Desarrolloo de } \\
\text { Producto }\end{array}$ & Muy Favorable & Indiferente & Muy desfavorable \\
\hline
\end{tabular}

\section{Elaboración Propia.}

Se puede concluir que en un escenario optimista la empresa podría implementar cada una de las tres estrategias mencionadas anteriormente. Sería de gran impacto para 
la empresa el poder llevar a cabo estas estrategias para lograr incrementar su participación de mercado, como su posicionamiento y fidelización en el sector de BTL. En un escenario conservador sería favorable la implementación de la estrategia de penetración de mercados y el de desarrollo d de los mismos para seguir creciendo en el sector. En un escenario pesimista la empresa debería de tener cuidado de llevar a cabo las estrategias, debido a que la inversión sería importante y en escenario pesimista, tal vez la empresa no podría recuperar la inversión realizada.

\subsection{Matriz de Planeación Estratégica Cuantitativa MPEC}

La MPEC es una herramienta que nos permitirá escoger la mejor alternativa entre las estrategias obtenidas por medio de las matrices EFE, EFI, del perfil competitivo, FODA, PEYEA, BCG, IE y de la estrategia principal. Fred David en su libro Concepto de administración estratégica no dice que: "La MPEC es una herramienta que permite a los estrategas evaluar alternativas de estrategias con objetividad, con base en los factores de éxito crítico, tanto externos como internos, identificados con anterioridad"110. Esta matriz determina el atractivo de las estrategias para aprovechar o mejorar los factores éxitos críticos externos e internos.

Para poder elaborar la MPEC se debe emplear las oportunidades y amenazas, así como de las fortalezas y debilidades del EFE y EFI en la columna izquierda de la MPEC. También se deben de emplear los valores obtenidos en el EFE y el EFI. En la fila superior estará conformada por las estrategias factibles obtenidas en las matrices explicadas anteriormente. Luego se determinarán los puntajes de atracción. El rango de los puntajes de atracción son de $1=\sin$ atractivo, 2 = algo atractivo, $3=$ más o menos atractivo y $4=$ muy atractivo. Se debe de multiplicar los valores con los puntajes del grado de atracción en cada columna. Se suma los puntajes totales del grado de atracción de cada columna de estrategias de la MPEC. La suma de los puntajes totales del grado de atracción muestra cuál estrategia es más atractiva en cada serie de alternativas. Los puntajes altos indican estrategias más atractivas, considerando todos los factores externos e internos relevantes que pudieran afectar las decisiones estratégicas.

${ }^{110}$ David, Fred. Conceptos de Administración Estratégica. 9na ed. México DF.: Pearson Educación, 2003. p.216 
En el caso de Naranja Producciones S.A.C. se puede apreciar que la estrategia más atractiva sería la estrategia de Penetración de Mercado con 7.02 seguida por desarrollo de mercado y desarrollo de producto con 6.48 y 6.285 respectivamente. 
Cuadro 8.3: MPEC

\begin{tabular}{|c|c|c|c|c|c|c|c|}
\hline \multicolumn{8}{|c|}{ La matriz de la planeación estratégica cuantitativa (MPEC) } \\
\hline Factores claves & \multirow{2}{*}{ Peso } & \multirow{2}{*}{$\begin{array}{l}\text { E1: Penetración } \\
\text { de Mercado }\end{array}$} & \multirow{2}{*}{ P.P. } & \multirow{2}{*}{$\begin{array}{l}\text { E2: Desarrollo } \\
\text { de Mercado }\end{array}$} & \multirow{2}{*}{ P.P. } & \multirow{2}{*}{$\begin{array}{l}\text { E3: Desarrollo } \\
\text { de Productos }\end{array}$} & \multirow{2}{*}{ P.P. } \\
\hline Oportunidades & & & & & & & \\
\hline $\begin{array}{l}\text { O1. La creación de nuevos puesto de trabajo } \\
\text { por medio la inversión pública y privada en el } \\
\text { Perú. }\end{array}$ & 0.015 & 4 & 0.06 & 3 & 0.045 & 3 & 0.045 \\
\hline $\begin{array}{l}\text { O2. Descentralizar Proinversión para ofrecer } \\
\text { asistencia tecnica y fortalecer las capacidades } \\
\text { de los Gobiernos Regionales. }\end{array}$ & 0.02 & 3 & 0.06 & 3 & 0.06 & 3 & 0.06 \\
\hline $\begin{array}{l}\text { O3. Se eliminó el Sistema Nacional de Inversión } \\
\text { Pública (SNIP) y se creó del nuevo sistema } \\
\text { Invierte.pe }\end{array}$ & 0.02 & 4 & 0.08 & 3 & 0.06 & 3 & 0.06 \\
\hline $\begin{array}{l}\text { O4. Las ventas en los centros comerciales en el } \\
\text { Perú subiran entre el } 6 \% \text { y el } \\
9 \% \text { durante el } 2018 \text {. }\end{array}$ & 0.020 & 3 & 0.06 & 3 & 0.06 & 3 & 0.06 \\
\hline $\begin{array}{l}\text { O5. La confianza del consumidor para Lima } \\
\text { Metropolitana durante el mes de enero del } 2018 \\
\text { ha subido. }\end{array}$ & 0.015 & 4 & 0.06 & 4 & 0.06 & 3 & 0.045 \\
\hline $\begin{array}{l}\text { O6. La modernización de la Policía Nacional, la } \\
\text { adecuada gestión de los recursos, como las } \\
\text { alianzas con los municipio }\end{array}$ & 0.015 & 4 & 0.06 & 4 & 0.06 & 4 & 0.06 \\
\hline $\begin{array}{l}\text { O7. En temas de seguridad, el Gobierno piensa } \\
\text { seguir con el plan de recompensas, los mega } \\
\text { operativos, la campaña Barrio seguro y con } \\
\text { programas de prevención. }\end{array}$ & 0.150 & 4 & 0.6 & 4 & 0.6 & 4 & 0.6 \\
\hline $\begin{array}{l}\text { O8. El Perú encabeza el ránking de confianza } \\
\text { económica en Latinoamérica. }\end{array}$ & 0.040 & 4 & 0.16 & 4 & 0.16 & 4 & 0.16 \\
\hline $\begin{array}{l}\text { O9. En el período } 207 \text { - 2018, contarán con } 9 \\
\text { centro comerciales adicionales. }\end{array}$ & 0.200 & 3 & 0.6 & 4 & 0.8 & 4 & 0.8 \\
\hline $\begin{array}{l}\text { O10. El tipo de cambio tiene una tendencia a la } \\
\text { baja en los próximos meses }\end{array}$ & 0.020 & 3 & 0.06 & 3 & 0.06 & 3 & 0.06 \\
\hline $\begin{array}{l}\text { O11.Crecimiento de las inversiones en BTL por } \\
\text { parte de las empresas. }\end{array}$ & 0.100 & 3 & 0.3 & 3 & 0.3 & 4 & 0.4 \\
\hline O12. Surgimiento de los consumidores verdes. & 0.015 & 3 & 0.045 & 3 & 0.045 & 3 & 0.045 \\
\hline O13. El marketing verde como nueva tendencia. & 0.030 & 3 & 0.09 & 3 & 0.09 & 3 & 0.09 \\
\hline $\begin{array}{l}\text { O14. El uso del internet como medio para hacer } \\
\text { publicidad. }\end{array}$ & 0.050 & 4 & 0.2 & 3 & 0.15 & 3 & 0.15 \\
\hline O15. Desarrollo de redes sociales. & 0.050 & 4 & 0.2 & 3 & 0.15 & 3 & 0.15 \\
\hline \multicolumn{8}{|l|}{ Amenazas } \\
\hline A1. Efecto Odebrecht en la economia peruana. & 0.010 & 3 & 0.03 & 3 & 0.03 & 3 & 0.03 \\
\hline $\begin{array}{l}\text { A2. Incremento de la inflación en los últimos } \\
\text { meses. }\end{array}$ & 0.010 & 3 & 0.03 & 2 & 0.02 & 2 & 0.02 \\
\hline $\begin{array}{l}\text { A3. Conflicto entre el Poder Ejecutivo y el Poder } \\
\text { Legislativo. }\end{array}$ & 0.010 & 3 & 0.03 & 3 & 0.03 & 3 & 0.03 \\
\hline $\begin{array}{l}\text { A4.La inversión pública habría caído } 12 \% \text { en } \\
\text { marzo por problemas políticos }\end{array}$ & 0.010 & 4 & 0.04 & 4 & 0.04 & 3 & 0.03 \\
\hline $\begin{array}{l}\text { A5. Desaceleración de la economía nacional } \\
\text { durante el } 2017 .\end{array}$ & 0.020 & 4 & 0.08 & 3 & 0.06 & 3 & 0.06 \\
\hline $\begin{array}{l}\text { A6. Existen actualmente } 17 \text { empresas de BTL } \\
\text { conocidas en el Perú. }\end{array}$ & 0.020 & 4 & 0.08 & 2 & 0.04 & 4 & 0.08 \\
\hline $\begin{array}{l}\text { A7. Concentración de clientes por parte de unas } \\
\text { pocas empresas de BTL. } \\
\text { la compra de su competencia. }\end{array}$ & 0.020 & 4 & 0.08 & 2 & 0.04 & 3 & 0.06 \\
\hline $\begin{array}{l}\text { A8. Existencia de empresas de BTL extranjeras } \\
\text { en el mercado local. }\end{array}$ & 0.010 & 4 & 0.04 & 2 & 0.02 & 3 & 0.03 \\
\hline $\begin{array}{l}\text { A9. Minima demanda en realizacion de } \\
\text { campañas BTL en la mayoria de regiones del } \\
\text { país. }\end{array}$ & 0.020 & 3 & 0.06 & 2 & 0.04 & 2 & 0.04 \\
\hline $\begin{array}{l}\text { A10. Adquisición de compañías pequeñas de } \\
\text { BTL por grupos económicos. }\end{array}$ & 0.010 & 3 & 0.03 & 3 & 0.03 & 2 & 0.02 \\
\hline A11. Productos Sustitutos. & 0.050 & 3 & 0.15 & 3 & 0.15 & 3 & 0.15 \\
\hline A12. Informalidad en el sector BTL. & 0.050 & 3 & 0.15 & 3 & 0.15 & 2 & 0.1 \\
\hline
\end{tabular}

\section{Elaboración Propia.}




\section{Cuadro 8.4: Grado de atracción}

\begin{tabular}{|c|c|c|c|c|c|c|c|}
\hline Fortalezas & & & & & & & \\
\hline F1. Know How de los Directivos & 0.100 & 4 & 0.4 & 4 & 0.4 & 4 & 0.4 \\
\hline F2. Cartera amplia de proveedores & 0.100 & 4 & 0.4 & 4 & 0.4 & 2 & 0.2 \\
\hline F3. Precios mas bajos que la competencia. & 0.040 & 3 & 0.12 & 4 & 0.16 & 3 & 0.12 \\
\hline F4. Experiencia en el sector público. & 0.030 & 3 & 0.09 & 2 & 0.06 & 2 & 0.06 \\
\hline $\begin{array}{l}\text { F5. Equipo de profesionales con experiencia en } \\
\text { campañas BTL. }\end{array}$ & 0.100 & 4 & 0.4 & 4 & 0.4 & 4 & 0.4 \\
\hline $\begin{array}{l}\text { F6. Cuentan con una gran variedad de } \\
\text { disfraces, muñecos y vestuario para los }\end{array}$ & 0.025 & 4 & 0.1 & 2 & 0.05 & 3 & 0.075 \\
\hline $\begin{array}{l}\text { F7. Cuenta con una amplia red de contactos de } \\
\text { empresas en el sector público }\end{array}$ & 0.025 & 4 & 0.1 & 3 & 0.075 & 3 & 0.075 \\
\hline $\begin{array}{l}\text { F8. Cuentan con buenas relaciones comerciales } \\
\text { con diferentes agencias BTL con las cuales } \\
\text { realizan campañas en conjunto. }\end{array}$ & 0.025 & 4 & 0.1 & 3 & 0.075 & 3 & 0.075 \\
\hline $\begin{array}{l}\text { F9. El crecimiento ha sido con capital propio, } \\
\text { sostenido y sin deudas con terceros. }\end{array}$ & 0.025 & 4 & 0.1 & 3 & 0.075 & 3 & 0.075 \\
\hline $\begin{array}{l}\text { F10. Asociación Estratégica con Mangosta } \\
\text { Producciones. }\end{array}$ & 0.020 & 3 & 0.06 & 2 & 0.04 & 2 & 0.04 \\
\hline F11. Cuentan con fortaleza financiera. & 0.020 & 4 & 0.08 & 3 & 0.06 & 2 & 0.04 \\
\hline \multicolumn{8}{|l|}{ Debilidades } \\
\hline D1. No cuenta con área Creativa. & 0.040 & 4 & 0.16 & 4 & 0.16 & 4 & 0.16 \\
\hline $\begin{array}{l}\text { D2. No cuenta con el capital necesario para } \\
\text { campañas de gran envergadura. }\end{array}$ & 0.040 & 4 & 0.16 & 4 & 0.16 & 4 & 0.16 \\
\hline $\begin{array}{l}\text { D3. Los puestos no cuenta con un manual de } \\
\text { funciones. }\end{array}$ & 0.025 & 3 & 0.075 & 3 & 0.075 & 3 & 0.075 \\
\hline $\begin{array}{l}\text { D4. No hay comunicación ni conocimiento de la } \\
\text { Misión, Visión y valores de la empresa }\end{array}$ & 0.030 & 3 & 0.09 & 3 & 0.09 & 3 & 0.09 \\
\hline D.5 Duplicidad de funciones entre las áreas. & 0.030 & 3 & 0.09 & 3 & 0.09 & 3 & 0.09 \\
\hline $\begin{array}{l}\text { D6 Falta de puntualidad por parte del staff en la } \\
\text { oficina y eventos. }\end{array}$ & 0.025 & 3 & 0.075 & 3 & 0.075 & 3 & 0.075 \\
\hline $\begin{array}{l}\text { D7. No tiene clasificada la información de los } \\
\text { clientes. }\end{array}$ & 0.025 & 3 & 0.075 & 2 & 0.05 & 2 & 0.05 \\
\hline $\begin{array}{l}\text { D8. Difraces y vestuarios de los eventos no } \\
\text { estan catalogados. }\end{array}$ & 0.025 & 2 & 0.05 & 2 & 0.05 & 2 & 0.05 \\
\hline $\begin{array}{l}\text { D9. Falta de inventario preventivo de los activos } \\
\text { de la empresa. }\end{array}$ & 0.025 & 3 & 0.075 & 2 & 0.05 & 2 & 0.05 \\
\hline $\begin{array}{l}\text { D10. No se firman contratos cuando la empresa } \\
\text { Naranja Producciones S.A.C., es subcontratada } \\
\text { por otra agencia de BTL. }\end{array}$ & 0.025 & 3 & 0.075 & 3 & 0.075 & 3 & 0.075 \\
\hline $\begin{array}{l}\text { D11. El inventario de los activos esta } \\
\text { desactualizado. }\end{array}$ & 0.025 & 3 & 0.075 & 3 & 0.075 & 3 & 0.075 \\
\hline $\begin{array}{l}\text { D12. Pagina Web de Naranja Producciones } \\
\text { desactualizada. }\end{array}$ & 0.020 & 3 & 0.06 & 3 & 0.06 & 2 & 0.04 \\
\hline $\begin{array}{l}\text { D13. La empresa esta desorganizada } \\
\text { internamente. }\end{array}$ & 0.020 & 4 & 0.08 & 2 & 0.04 & 2 & 0.04 \\
\hline $\begin{array}{l}\text { D14. No cuentan con una diferenciación } \\
\text { sustancial con respecto a la competencia. }\end{array}$ & 0.025 & 3 & 0.075 & 3 & 0.075 & 2 & 0.05 \\
\hline D15. No son muy conocidos en el sector. & 0.025 & 4 & 0.1 & 2 & 0.05 & 2 & 0.05 \\
\hline $\begin{array}{l}\text { D16. No cuentan con un elemento diferenciador } \\
\text { de valor. }\end{array}$ & 0.010 & 4 & 0.04 & 2 & 0.02 & 2 & 0.02 \\
\hline $\begin{array}{l}\text { D17. No cuentan con una estrategia de } \\
\text { marketing digital agresiva. }\end{array}$ & 0.050 & 4 & 0.2 & 2 & 0.1 & 2 & 0.1 \\
\hline $\begin{array}{l}\text { D18. No cuentan con procesos alineados al } \\
\text { crecimiento de la empresa. }\end{array}$ & 0.020 & 4 & 0.08 & 2 & 0.04 & 2 & 0.04 \\
\hline $\begin{array}{l}\text { Suma del puntaje total del grado de atracción } \\
\text { (SPTA) }\end{array}$ & 1.995 & & 7.02 & & 6.48 & & 6.285 \\
\hline
\end{tabular}

\section{Elaboración Propia.}




\subsection{Descripción de estrategia seleccionada}

La estrategia seleccionada es la de penetración de mercados, la cual consiste en incrementar la participación de la empresa en los productos y servicios actuales, haciendo que los clientes compren más productos, atrayéndolos de la competencia y también hacer lo mismo con los clientes potenciales. El señor Fred David nos dice que "Una estrategia de penetración en el mercado intenta aumentar la participación de los productos o servicios presentes en los mercados actuales a través de mayores esfuerzos de mercadotecnia" ${ }^{111}$. Para poder realizar esta estrategia la empresa deberá de aumentar el número de vendedores, aumentar el presupuesto en publicidad, realizar promociones o aumentar las actividades publicitarias.

\subsection{Descripción de estrategia contingente}

La estrategia de contingencia para la empresa Naranja Producciones S.A.C. sería la de desarrollo de mercados. El señor Fred David nos dice que "El desarrollo de mercados implica la introducción de los productos o servicios presentes en nuevas áreas geográficas"112. De esta manera, la empresa busca nuevos mercados para vender sus productos y servicios.

El señor Fred David nos dice que "La penetración en el mercado y el desarrollo de mercados y de productos se denomina en ocasiones estrategias intensivas porque exigen la realización de esfuerzos intensivos para mejorar la posición competitiva de una empresa en relación con los productos existentes". Esto quiere decir que se deberá invertir más en recursos para poder llevar a cabo estas estrategias y a la vez buscar nuevos clientes como micros y pequeñas empresas.

Para Naranja Producciones S.A.C., la estrategia de integración no es considerada porque los dueños de la empresa no tienen visto integrarse con sus proveedores y menos con sus clientes a un corto plazo. De igual manera, la estrategia de diversificación, no está observada porque la empresa trabaja en un área muy específica y especializada que es el BTL.

\footnotetext{
${ }^{111}$ David, Fred. (2003) Conceptos de Administración Estratégica. 9na ed. México DF.: Perason Educación, p.165

${ }^{112}$ David, Fred. (2003) Conceptos de Administración Estratégica. 9na ed. México DF.: Pearson Educación, p.165
} 


\section{Capítulo IX}

\section{Implantación de la Estrategia}

Con la finalidad de poder implementar la estrategia seleccionada, utilizaremos el Cuadro de Mando Integral (CMI), conocido también como Balanced Scorecard (BSC), el cual transforma la visión y estrategia de la empresa en un conjunto de objetivos e indicadores organizados en 4 perspectivas diferentes: Finanzas, Clientes, Procesos internos y Formación y crecimiento.

\section{Gráfico 9.1: Indicadores del Balanced Scorecard}

\section{Finanzas}

- Rendimiento sobre las

inversiones

- Valor añadido

Procesos

Internos

- Calidad

- Tiempos de respuesta

- Coste

- Introducción nuevos productos

\section{Clientes}

- Satisfacción

- Retención

- Cuota de mercado

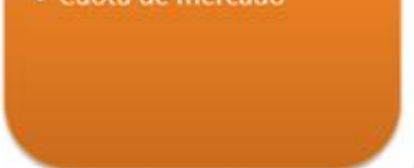

\section{Formación y} Crecimiento

- Satisfacción de los empleados

- Disponibilidad de los

Sistemas de

Información

Fuente:http://www.cmigestion.es/2012/cuadro-de-mando-integral/el-cuadro-de-mando-integral-i-que-es-ypara-que-sirve/

Las cuatro perspectivas del Balanced Scorecard permitirán un equilibrio entre los objetivos de corto y largo plazo, entre los resultados antes y después de la ejecución de los propósitos, obteniendo de esta manera una estrategia integrada. 
Tal como lo menciona Robert Kaplan y David P Norton en su libro, "el Cuadro de Mando Integral debe ser utilizado como un sistema de comunicación, de información y formación"113

a. Perspectiva Financiera: los indicadores financieros son importantes para la empresa, ya que resumen las consecuencias económicas. Las medidas de actuación financiera indican si la estrategia de una empresa, la práctica y ejecución contribuyen a una mejora mínima indispensable. Los objetivos financieros se basan en la rentabilidad, ventas o la generación de clash flow.

b. Perspectiva del cliente: los indicadores fundamentales incluyen la satisfacción del cliente, retención del cliente, adquisición de nuevos clientes, rentabilidad de los clientes, entre otros. Asimismo, la perspectiva de los clientes permite que los directivos propongan nuevas estrategias basadas en el mercado que es más competitivo hoy en día.

c. Perspectiva del proceso interno: la habilidad de muchas empresas en gestionar procesos exitosos que no entorpezcan a los procesos de la organización y hace ver que los directivos busquen gestionar las operaciones ya existentes de una forma eficiente, consistente y tangible.

d. Perspectiva de formación y crecimiento: Esta perspectiva busca, en tiempo real, una información fiable e importante para los clientes y los principales procesos internos que, a su vez, faciliten a los empleados una búsqueda de prontas respuestas para decisiones de cada día.

\subsection{Mapa de la Estrategia}

El mapa de la estrategia representa el modelo que sigue la empresa para cumplir con un objetivo estratégico. Para ello, se utilizan perspectivas, objetivos y relaciones causaefecto. Los mapas estratégicos representan la conversión de los activos intangibles en resultados tangibles.

\footnotetext{
${ }^{113}$ Kaplan Robert y Norton David. Cuadro de Mando Integral. Pag 39
} 


\subsection{Objetivos específicos según el mapa de la estrategia}

Analizando el mapa estratégico con mayor detalle podremos definir los objetivos estratégicos, conocidos también como específicos, al igual que sus indicadores, metas, iniciativas y área responsable, tal como se puede apreciar en el cuadro 9.2

\subsection{Indicadores para cada uno de los objetivos específicos}

Los indicadores son herramientas que permitirán medir los objetivos. Estos indicadores son observables y medibles, los cuales medirán las variaciones que puedan suceder. Debe haber como mínimo un indicador para cada objetivo, el cual debe estar debidamente enfocado, ser claro y especifico. 
Gráfico 9.2: Mapa estratégico de Naranja Producciones S.A.C

\section{MAPA ESTRATÉGICO}

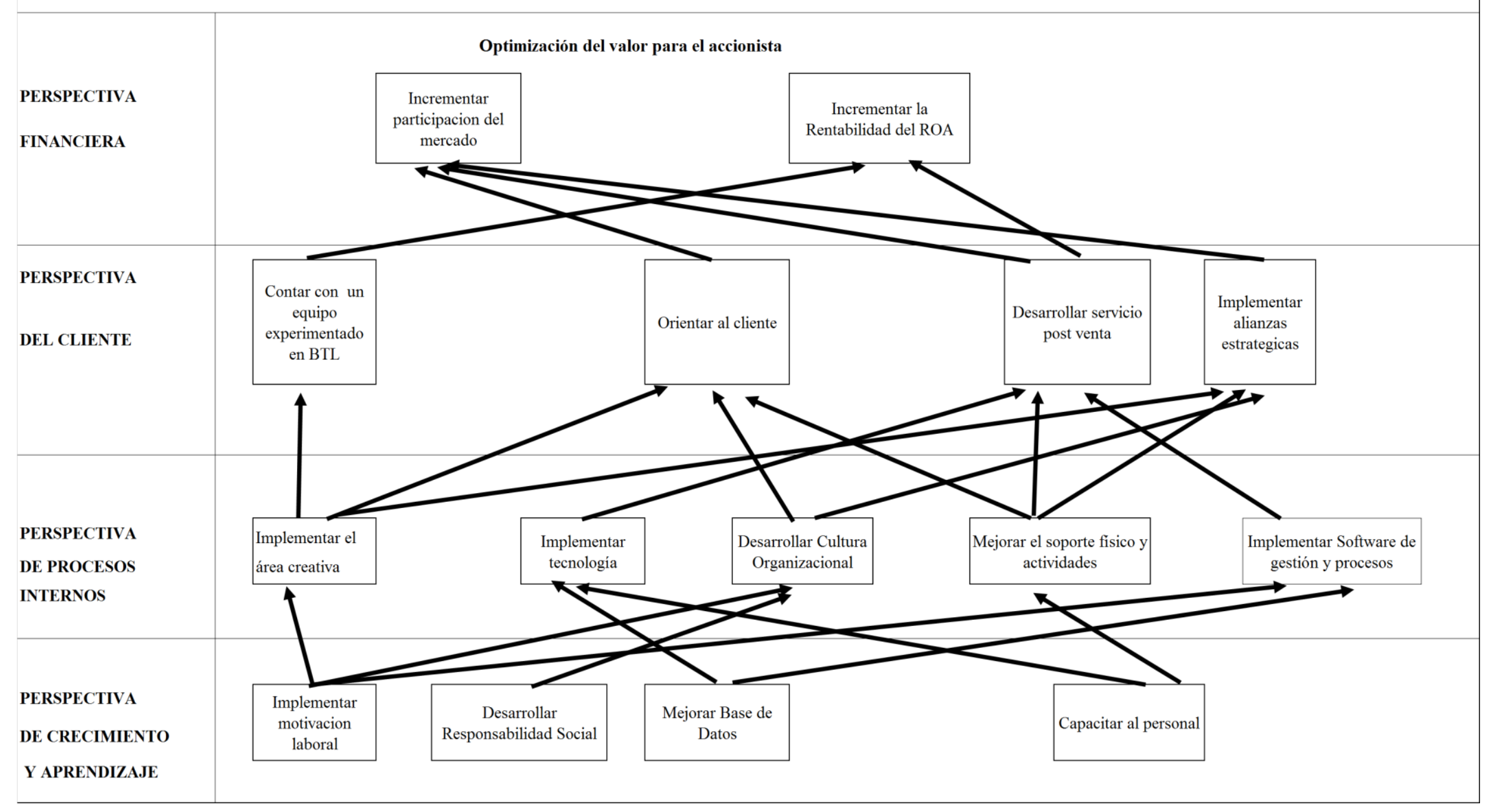

Elaboración Propia. 


\subsection{Metas para cada uno de los objetivos específicos}

Las metas son los valores que deben de alcanzar los indicadores en un periodo determinado. Los señores Robert S. Kaplan y David P. Norton en su libro Cuadro de mando Integral dice que: "Los directivos deben fijar unas metas ambiciosas para indicadores que todos los empleados puedan aceptar y hacer suyas. Las interrelaciones de causa-efecto en el cuadro de mando ayudan a identificar los inductores críticos que permitirán una actuación decisiva en importantes indicadores del resultado, especialmente en los financieros y del cliente"114. De esta manera, se deberán de implementar metas ambiciosas para lograr los indicadores planteados.

\subsection{Iniciativas (acciones a llevar a cabo para cada uno de los objetivos específicos)}

Después de desarrollar las metas para los indicadores, los directivos de las empresas deben de analizar si las iniciativas actuales permitirán alcanzar las metas o si será necesario crear nuevas iniciativas. Los señores Robert S. Kaplan y David P. Norton en su libro Cuadro de mando Integral dice que: "Los directivos identifican las iniciativas que aportan sinergias a los objetivos estratégicos de otras unidades de negocio"115.

\footnotetext{
${ }^{114}$ KAPLAN, Robert S. y NORTON, David P. Cuadro de Mando Integral. 2da ed. Barcelona: Ediciones Gestión 2000, 2002. p.238. ${ }^{115}$ KAPLAN, Robert S. y NORTON, David P. Cuadro de Mando Integral. 2da ed. Barcelona: Ediciones Gestión 2000, 2002. p.240
} 
Cuadro 9.1: Objetivos, indicadores, metas, iniciativas y responsables para las perspectivas del mapa estratégico

\begin{tabular}{|c|c|c|c|c|c|c|c|c|c|}
\hline Perspectiva & Objetivo Estratégico & Indicador & Año Base 2017 & $\begin{array}{l}\text { Meta } \\
2018\end{array}$ & $\begin{array}{l}\text { Meta } \\
2019\end{array}$ & $\begin{array}{l}\text { Meta } \\
2020\end{array}$ & $\begin{array}{l}\text { Meta } \\
2021\end{array}$ & Iniciativa Estratégica & Responsable \\
\hline \multirow{2}{*}{$\begin{array}{l}\text { PERSPECTIVA } \\
\text { FINANCIERA }\end{array}$} & $\begin{array}{l}\text { Incrementar } \\
\text { participación de } \\
\text { mercado }\end{array}$ & $\begin{array}{l}\text { Variación de } \% \\
\text { crecimiento ventas }\end{array}$ & $>=15 \%$ & $17 \%$ & $18 \%$ & $19 \%$ & $20 \%$ & $\begin{array}{l}\text { Implementar plan: } \\
\text { consolidar la empresa, } \\
\text { Área Creativa, prestigio }\end{array}$ & Gerencia Comercial \\
\hline & $\begin{array}{l}\text { Incrementar la } \\
\text { Rentabilidad ROA }\end{array}$ & $\begin{array}{l}\text { Variación \% } \\
\text { utilidades }\end{array}$ & $>=30 \%$ & $30 \%$ & $33 \%$ & $35 \%$ & $38 \%$ & $\begin{array}{l}\text { Invertir en nuevos } \\
\text { activos }\end{array}$ & Gerencia General \\
\hline \multirow{3}{*}{$\begin{array}{l}\text { PERSPECTIVA DEL } \\
\text { CLIENTE }\end{array}$} & $\begin{array}{l}\text { Incrementar Alianzas } \\
\text { Estratégicas }\end{array}$ & $\begin{array}{l}\text { \#Número de } \\
\text { Alianzas } \\
\text { Estratégicas al año }\end{array}$ & 1 feria al año & & 1 & 1 & 1 & $\begin{array}{l}\text { Participar en Feria Expo } \\
\text { Marketing }\end{array}$ & Gerencia Comercial \\
\hline & Orientación al cliente & $\begin{array}{l}\text { \% contratos } \\
\text { cerrados/cotizacion } \\
\text { es enviadas }\end{array}$ & $\begin{array}{l}>=695 \text { eventos } \\
\text { año base }\end{array}$ & 725 & 755 & 798 & 815 & $\begin{array}{l}\text { Evaluación de la Base } \\
\text { de Datos }\end{array}$ & Gerencia Comercial \\
\hline & Servicio de Post venta & $\begin{array}{l}\text { \# visitas Post } \\
\text { Venta }\end{array}$ & $\begin{array}{l}>=80 \% \text { visitas en } \\
\text { comparación año } \\
\text { base }\end{array}$ & $35 \%$ & $55 \%$ & $68 \%$ & $79 \%$ & $\begin{array}{l}\text { Creación de encuestas } \\
\text { de calidad de servicios, } \\
\text { informe después del } \\
\text { servicio }\end{array}$ & $\begin{array}{c}\text { Producción General } \\
\text { de Eventos }\end{array}$ \\
\hline \multirow{6}{*}{$\begin{array}{l}\text { PERSPECTIVA DE } \\
\text { PROCESOS } \\
\text { INTERNOS }\end{array}$} & $\begin{array}{l}\text { Soporte Fisico y } \\
\text { Actividades } \\
\end{array}$ & \#Proveedores & $\begin{array}{l}>=20 \\
\text { proveedores }\end{array}$ & 15 & 16 & 18 & 20 & $\begin{array}{l}\text { Evaluación y registro en } \\
\text { base de datos }\end{array}$ & Gerencia General \\
\hline & $\begin{array}{l}\text { Implementación Área } \\
\text { Creativa }\end{array}$ & $\begin{array}{l}\text { \#Colaboradores del } \\
\text { área creativa } \\
\text { durante el año }\end{array}$ & 1 creativo & 1 & & & & \begin{tabular}{|l|} 
Reclutar a un \\
coordinador para el área \\
creativa con cartera de \\
clientes
\end{tabular} & Gerencia General \\
\hline & $\begin{array}{l}\text { Fortalecer el Área } \\
\text { Creativa }\end{array}$ & \begin{tabular}{|l} 
\#Asistentea del \\
área creativa \\
durante el año \\
\end{tabular} & 2 asistentes & 1 & & & 1 & $\begin{array}{l}\text { Reclutar a dos asistentes } \\
\text { creativos }\end{array}$ & Gerencia Comercial \\
\hline & $\begin{array}{l}\text { Implementación } \\
\text { Tecnológica }\end{array}$ & $\begin{array}{l}\text { \#Equipos } \\
\text { Renovados }\end{array}$ & $\begin{array}{l}\text { Renovar equipos } \\
\text { cada } 5 \text { años y } \\
\text { mantenimiento } \\
\text { cada } 1 \text { año }\end{array}$ & 1 & & & & $\begin{array}{l}\text { Renovar los equipos } \\
\text { para poder implementar } \\
\text { los nuevos programas } \\
\text { (Adobe y Photoshop) }\end{array}$ & Gerencia Comercial \\
\hline & Cultura Organizacional & \begin{tabular}{|l|} 
Encuesta de Clima \\
Laboral
\end{tabular} & 1 encuesta & 1 & & & & $\begin{array}{l}\text { Premiación al mejor } \\
\text { trabajador. }\end{array}$ & Gerencia Comercial \\
\hline & $\begin{array}{l}\text { Implementar un } \\
\text { Software de Gestión y } \\
\text { Procesos }\end{array}$ & $\begin{array}{l}\text { Adquisición y } \\
\text { \#Actualizaciones }\end{array}$ & $>=1$ compra & 1 & & & & $\begin{array}{l}\text { Implementar un } \\
\text { software para gestión } \\
\text { administrativa }\end{array}$ & Gerencia General \\
\hline \multirow{4}{*}{$\begin{array}{l}\text { PERSPECTIVA DE } \\
\text { CRECIMIENTO Y } \\
\text { APRENDIZAJE }\end{array}$} & $\begin{array}{l}\text { Integración y } \\
\text { Motivación Laboral }\end{array}$ & $\begin{array}{l}\text { \#Reuniones de } \\
\text { Integración } \\
\text { fuera del trabajo }\end{array}$ & 2 veces al año & 2 & 2 & 2 & 2 & $\begin{array}{l}\text { Realización de } \\
\text { actividades de } \\
\text { integración cada seis } \\
\text { meses } \\
\end{array}$ & Gerencia Comercial \\
\hline & $\begin{array}{l}\text { Mejorar la Base de } \\
\text { Datos }\end{array}$ & $\begin{array}{l}\text { \%Implementación } \\
\text { de } \\
\text { Gestión } \\
\text { información }\end{array}$ & Junio de 2018 & $\begin{array}{c}\text { Imple- } \\
\text { mentación }\end{array}$ & & & & $\begin{array}{l}\text { Creación de un plan de } \\
\text { CRM (base de datos, } \\
\text { clientes, fechas } \\
\text { importantes, principales } \\
\text { clientes) }\end{array}$ & Gerencia Comercial \\
\hline & Capacitación Personal & $\begin{array}{l}\text { \#Capacitaciones } \\
\text { \#Talleres }\end{array}$ & 1 Taller & 1 & & & & $\begin{array}{l}\text { Capacitar al personal en } \\
\text { desarrollo de eventos } \\
\text { corporativos }\end{array}$ & Gerencia Comercial \\
\hline & $\begin{array}{l}\text { Capacitación a } \\
\text { Gerencia }\end{array}$ & $\begin{array}{l}\text { \#Capacitaciones en } \\
\text { Branding }\end{array}$ & 1 Taller & 1 & & & & $\begin{array}{l}\text { Capacitar al Gerente } \\
\text { General y Gerente } \\
\text { Comercial en Branding }\end{array}$ & Gerencia General \\
\hline
\end{tabular}




\subsubsection{Estrategias}

Las estrategias son acciones que se planifican para poder lograr en un determinado tiempo un conjunto de objetivos. Los señores Robert S. Kaplan y David P. Norton en su libro Cuadro de mando Integral dicen que: "La estrategia planeada, aunque se haya iniciado con la mejor de las intenciones y con la mejor información disponible, puede que ya no sea apropiada o válida para las condiciones actuales" ${ }^{116}$. Por tal motivo, se debe de llevar a cabo un feedback para poder replantear las estrategias.

\subsubsection{Programas}

El programa será el plan que la empresa diseñará de manera exclusiva y única para llevar a cabo un proyecto dentro de la empresa.

\subsubsection{Políticas}

Son lineamientos que guiaran el accionar de las personas para poder llevar a cabo las estrategias.

\subsubsection{Reglas}

Es una normativa que indicará al colaborador de la empresa que es lo que puede o no puede hacer.

\subsubsection{Procedimiento}

Es una serie de procesos o acciones que la empresa deberá llevar a cabo para terminar una tarea.

\subsection{Responsable de cada una de las iniciativas}

${ }^{116}$ KAPLAN, Robert S. y NORTON, David P. Cuadro de Mando Integral. 2da ed. Barcelona: Ediciones Gestión 2000, 2002. p.263 
Con la finalidad de poder definir el área responsable de implementar cada una de las iniciativas que se han definido para Naranja Producciones S.A.C. durante el período 2018 - 2021 se ha elaborado un cuadro con el área asignada.

\subsection{Presupuesto de cada una de las iniciativas}

A continuación detallamos el presupuesto que se tiene asignado para cada una de las iniciativas para los próximos 5 años. 


\section{Cuadro 9.2: Presupuesto para las iniciativas del mapa estratégico}

\begin{tabular}{|c|c|c|c|c|}
\hline Iniciativas & 2018 & 2019 & 2020 & 2021 \\
\hline $\begin{array}{l}\text { Realizar actividades de } \\
\text { integración cada sies meses, } \\
\text { para fortalecer el compromiso de } \\
\text { los colaboradores con la } \\
\text { empresa. }\end{array}$ & 1050 & 750 & 750 & 750 \\
\hline $\begin{array}{l}\text { *Almuerzo de integración fuera de } \\
\text { oficina }\end{array}$ & -400 & -400 & -400 & -400 \\
\hline *Sorteo de regalos & -350 & -350 & -350 & -350 \\
\hline *Premiación al mejor trabajador & -300 & & & \\
\hline $\begin{array}{l}\text { Reclutar a un coordinador del } \\
\text { área creativa con cartera de } \\
\text { clientes. Sueldo fijo más } \\
\text { comisión ( } 2 \%^{\star} \text { campaña) }\end{array}$ & 42,510 & 42,510 & 42,510 & 44,510 \\
\hline${ }^{*}$ Sueldo Anual & 42,510 & 42,510 & 42,510 & 42,510 \\
\hline *Incremento del sueldo & - & & & 2,518 \\
\hline $\begin{array}{l}\text { Capacitar al Gerente General y al } \\
\text { Gerente Comercial }\end{array}$ & 1460 & & & \\
\hline $\begin{array}{l}\text { *Capacitar en Branding a los dos } \\
\text { gerentes }\end{array}$ & 1,460 & & & \\
\hline $\begin{array}{l}\text { Capacitación al personal en } \\
\text { el desarrollo de eventos } \\
\text { corporativos }\end{array}$ & 2500 & & & \\
\hline${ }^{*}$ Capacitación para dos personas & 2,500 & & & \\
\hline Participar en Feria Expo Marketin & $\mathbf{g}$ & 4,000 & 4,000 & 4,000 \\
\hline *Participar en Feria Expo Marketing & & 4,000 & 4,000 & 4,000 \\
\hline $\begin{array}{l}\text { Reclutamiento y selección de un } \\
\text { nuevo Asistente de Producción } \\
\text { con especialización en } \\
\text { Marketing }\end{array}$ & 17,626 & 17,626 & 17,626 & 40,288 \\
\hline${ }^{*}$ Sueldo Anual creativo 1 & 17,626 & 17,626 & 17,626 & 17,626 \\
\hline *Incremento del sueldo & - & - & - & 2,518 \\
\hline${ }^{*}$ Sueldo Anual creativo 2 & & & & 17,626 \\
\hline *Incremento del sueldo & & & - & 2,518 \\
\hline $\begin{array}{l}\text { Renovar los equipos para poder } \\
\text { implementar los programas de } \\
\text { diseño como Adobe Illustrator y } \\
\text { Photoshop }\end{array}$ & 10,900 & 500 & 500 & 500 \\
\hline *Renovar 4 laptops & 8,400 & & & \\
\hline *Renovar 2 computadora escritorio & 2,000 & & & \\
\hline Mantenimiento anual & $-\quad 500$ & $-\quad 500$ & $-\quad 500$ & 500 \\
\hline $\begin{array}{l}\text { Implementar un plan de CRM } \\
\text { (base de datos clientes, fechas } \\
\text { importantes, de numero de }\end{array}$ & 600 & 600 & 600 & 600 \\
\hline *Nuevo programa & 600 & $\begin{array}{ll}- & 600 \\
\end{array}$ & \begin{tabular}{|r}
- \\
-
\end{tabular} & -600 \\
\hline $\begin{array}{l}\text { Implementar una base de datos } \\
\text { de proveedores }\end{array}$ & 60 & 60 & 60 & 60 \\
\hline${ }^{*}$ Nuevo programa & 60 & 60 & 60 & 60 \\
\hline $\begin{array}{l}\text { Implementar la oficina con } \\
\text { nuevos modulares. }\end{array}$ & 8,000 & & & \\
\hline${ }^{*}$ Muebles, sillas, estantes & 8,000 & & & \\
\hline $\begin{array}{l}\text { Implementar un software de } \\
\text { Gestión Administrativa }\end{array}$ & 5,854 & & & \\
\hline Software & $-\quad 5,854$ & & & \\
\hline TOTAL & $\mathrm{S} / .90,560$ & $\mathrm{~S} / .48,420$ & $\mathrm{~S} / .66,046$ & $\mathrm{~S} / .90,708$ \\
\hline
\end{tabular}




\subsection{Cronograma de cada una de las iniciativas}

Con la finalidad de poder describir las iniciativas asociadas durante un período de tiempo, tomaremos como unidad de medida períodos trimestrales durante un lapso de 5 años (2018 al 2021).

Adicionalmente, para una rápida identificación de las iniciativas durante este período de tiempo (2018-2021) se han aplicado colores distintos entre cada uno de las iniciativas. 
Cuadro 9.3: Cronograma de implementación de las iniciativas del mapa estratégico para Naranja Producciones S.A.C.

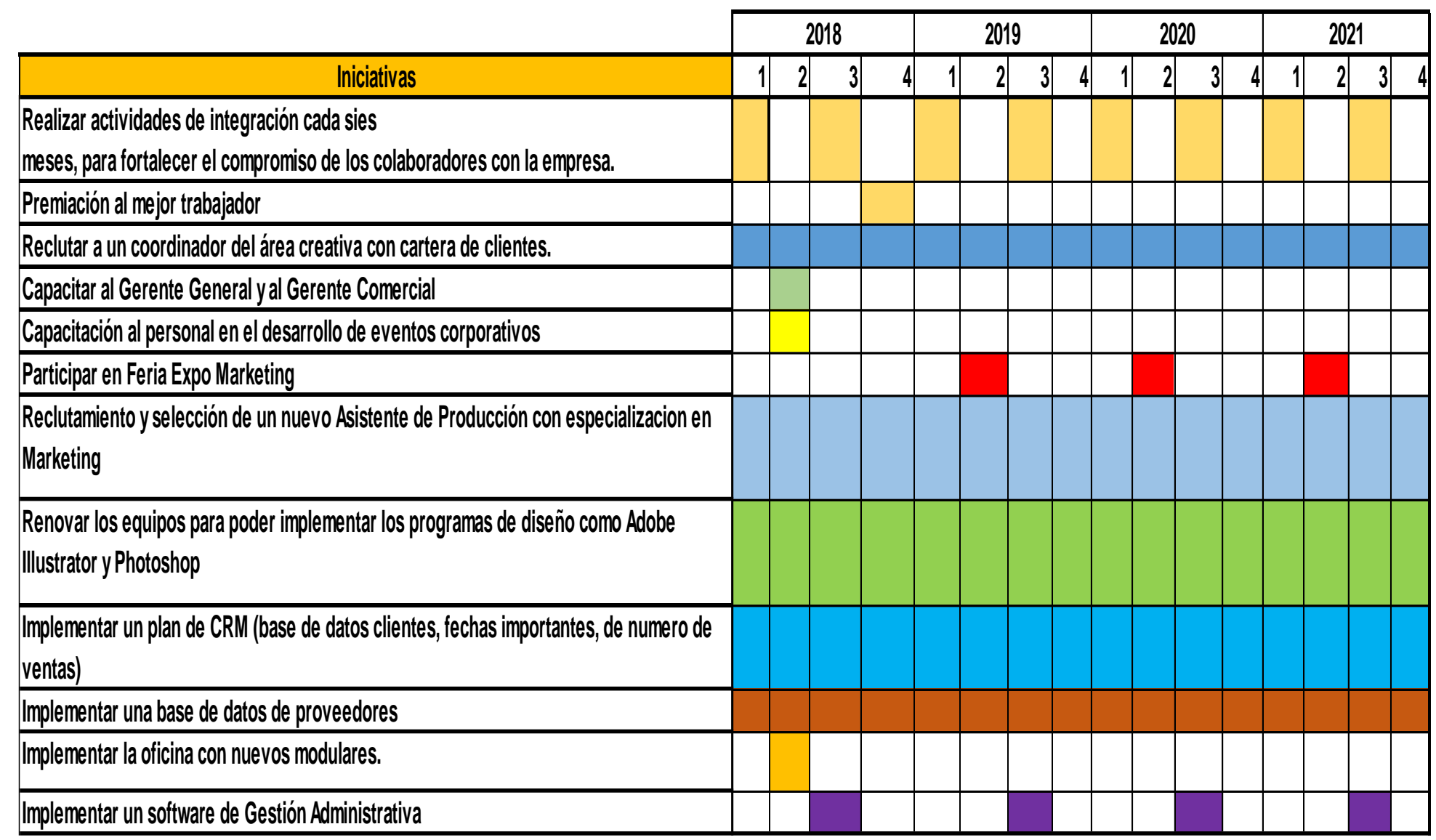

Elaboración Propia 


\section{Capítulo X}

\section{Evaluación}

El señor Fred David nos dice que: "La evaluación estratégica es esencial para tener la seguridad de que los objetivos establecidos se logren"117. Sin esta evaluación no se podrá saber si los objetivos se van a lograr. En el presente capítulo se analizará si la estrategia planteada es viable para Naranja Producciones S.A.C. También sostiene que: "La evaluación de la estrategia es importante porque las empresas enfrentan ambientes dinámicos donde los factores externos e internos cambian a menudo de manera rápida y drástica"118. Por tal motivo, es importante la evaluación de la estrategia desarrollada.

\subsection{Evaluación Cualitativa}

Así mismo, afirma al respeto que: “(...) la evaluación de la estrategia debe tener un enfoque tanto a largo como a corto plazo"119. De esta manera, se sabrá si la estrategia seleccionada es la adecuada para el logro por los objetivos.

\subsubsection{Criterios de Evaluación}

Del mismo modo, Fred David nos dice que: "Las actividades de evaluación de la estrategia se deben realizar en forma continua, más que al final de periodos específicos de tiempo o justo después de que los problemas ocurran"120.

Además, expresa que: "Richard Rumelt ofreció cuatro criterios para evaluar una estrategia: la congruencia, la concordancia, la viabilidad y la ventaja" ${ }^{121}$. Estos criterios permitirán evaluar la estrategia planteada anteriormente.

Por otra parte, expone que: "(...) la congruencia y la ventaja se basan sobre todo en la evaluación externa de una empresa, mientras que la concordancia y la viabilidad se basan principalmente en una evaluación interna"122.

\footnotetext{
${ }^{117}$ David, Fred. (2003) Conceptos de Administración Estratégica. 9na ed. México DF.: Perason Educación,. p.300

${ }^{118}$ David, Fred. (2003) Conceptos de Administración Estratégica. 9na ed. México DF.: Perason Educación, p.300

${ }^{119}$ David, Fred. (2003) Conceptos de Administración Estratégica. 9na ed. México DF.: Perason Educación, p.300

${ }^{120}$ David, Fred. (2003) Conceptos de Administración Estratégica. 9na ed. México DF.: Pearson Educación, p.304

${ }^{121}$ David, Fred. (2003) Conceptos de Administración Estratégica. 9na ed. México DF.: Pearson Educación, p.300

${ }^{122}$ David, Fred. Conceptos de Administración Estratégica. 9na ed. México DF.: Pearson Educación, 2003. p.300
} 


\subsubsection{Comparación de la estrategia con los criterios}

A continuación analizaremos la estrategia planteada con cada uno de los criterios desarrollados por Richard Rumelt:

- Congruencia: En las empresas las estrategias no deben tener metas incongruentes con las políticas y reglamentos de la empresa. Por tal motivo, la empresa Naranja Producciones S.A.C. no debe desarrollar metras o estrategias que incumplan con sus políticas y reglamentos internos que cuestionen la implementación de estas. Si existe alguna congruencia se deberá revisar la viabilidad de las estrategias y sus metas. La estrategia que se ha planteado para que la empresa pueda lograr los objetivos estratégicos desarrollados está en concordancia con las políticas y con la misión y visión de Naranja Producciones S.A.C.

- Concordancia: Las estrategias se deben adaptar a las tendencias del ambiente externo y a cambios importantes que suceden en el entorno. Las tendencias que se tomarán en cuenta son las analizadas y desarrolladas durante el capítulo IV. Por tal motivo, la estrategia planteada para Naranja Producciones está en concordancia con las tendencias del ambiente externo que se analizaron anteriormente.

- Viabilidad: En este punto la empresa analizará si la estrategia considerada es viable con los recursos humanos, físicos y financieros con los cuales cuenta. Por tal motivo, la empresa Naranja Producciones S.A.C. deberá de analizar si cuenta con los recursos para poder desarrollar la estrategia planteada. Como se analizó anteriormente, en el ciclo de vida del producto, la empresa se encuentra en una etapa de crecimiento, en donde deberá de invertir en recursos necesarios para poder seguir creciendo sin comprometer la viabilidad del negocio.

- Ventaja: La estrategia debe crear y mantener una ventaja competitiva en un mercado determinado. Las ventajas competitivas son el resultado de tres aspectos: recursos, habilidades y posición. De esta manera, la estrategia de penetración de mercados desarrollada para Naranja Producciones S.A.C. creará una ventaja competitiva en comparación a la competencia. 


\subsection{Evaluación Financiera de la Estrategia}

Una manera de calcular la utilidad de una empresa es por medio de la ganancia por acción (GPA), la cual refleja la ganancia obtenida por cada acción durante el periodo. Por otra parte, el maximizar las utilidades de la empresa no significa que el precio de las acciones vaya a incrementar. Lawrence Gitman afirma que: “(...) ¿maximizar las utilidades trae consigo el precio más alto posible de las acciones? Con frecuencia la respuesta es "NO", por lo menos a causa de tres razones"123.

- Tiempo.- Al respecto sostiene que: “(...) la recepción de fondos más rápida es preferible que una más tardía"124.

- Flujo de efectivo. -Sobre este aspecto expresa que: "Las utilidades no necesariamente generan flujos de efectivo disponibles para los accionistas. No hay garantía de que el consejo directivo incremente los dividendos cuando las utilidades aumentan"125.

- Riesgos. - En este sentido nos dice que: "El hecho de maximizar las utilidades también ignora el riesgo, es decir, la posibilidad de que los resultados reales difieran de los esperados. Una condición básica de la administración financiera es que exista un equilibrio entre el rendimiento (flujo de efectivo) y el riesgo"126. Es decir, que los resultados esperados lleguen a diferir de los resultados obtenidos. También, que: “(...) los accionistas tienen aversión al riesgo, es decir, deben recibir una compensación por un riesgo mayor"127. En conclusión, los inversionistas esperan rendimientos más altos con inversiones más riesgosas.

\subsubsection{Proyección de Estados Financieros (situación actual y con la nueva estrategia)}

Con la finalidad de poder realizar una proyección del Estado Financiero de la empresa Naranja Producciones S.A.C. para el periodo 2018 al 2021, haremos uso de la información obtenida del Balance General, del Estado de Resultados (conocido también

\footnotetext{
${ }^{123}$ GITMAN, Lawrence J. ZUTTER, Chad J. Principios de Administración Financiera. 12da ed. Naucalpan de Juárez: Perason Educación, 2012. p.10

${ }^{124}$ GITMAN, Lawrence J. ZUTTER, Chad J. Principios de Administración Financiera. 12da ed. Naucalpan de Juárez: Perason Educación, 2012. p.10

${ }^{125}$ GITMAN, Lawrence J. ZUTTER, Chad J. Principios de Administración Financiera. 12da ed. Naucalpan de Juárez: Perason Educación, 2012. p.11

${ }^{126}$ GITMAN, Lawrence J. ZUTTER, Chad J. Principios de Administración Financiera. 12da ed. Naucalpan de Juárez: Perason Educación, 2012. p.11

127 GITMAN, Lawrence J. ZUTTER, Chad J. Principios de Administración Financiera. 12da ed. Naucalpan de Juárez: Perason Educación, 2012. p.11
} 
como estado de Ganancias y Pérdidas) y del Estado de Flujo de Efectivo de los años 2018 al 2021.

Adicionalmente, tendremos en cuenta la variación obtenida actualmente (crecimiento del 15\%) y aplicando la nueva estrategia en donde se espera tener un crecimiento del 17\%, 18\%, 19\% y 20\% durante los años 2018, 2019, 2020 y 2021 respectivamente.

\subsubsection{Estado de resultados (situación actual y con la nueva estrategia)}

Con la finalidad de poder realizar una proyección del Estado de Resultados de la empresa Naranja Producciones S.A.C.. para el periodo 2018, se utilizó la información obtenida del Estado de Ganancias y Pérdidas de los años 2016 y 2017.

Adicionalmente, presentaremos dos escenarios: en el primero se mostrará un crecimiento considerando el momento actual (crecimiento de las ventas de 2016 al 2017 en $15 \%$ como se muestra en el cuadro 10.3), en el segundo se mostrará un crecimiento considerando la nueva estrategia a partir del año 2018 (crecimiento esperado del 17\% para dicho periodo). Asimismo, con o sin estrategia, las ventas van a incrementar, solamente que en el segundo caso van a incrementar mucho menos.

En el Estado de Resultados del 2017 se puede apreciar que la empresa tiene una utilidad neta después de impuesto del $15 \%$ en relación a las ventas totales, el cual es un porcentaje bajo para el sector, debido a que la empresa no está utilizando sus recursos de manera óptima. Además, sus Gastos administrativos y Gastos de Ventas representan el $43 \%$ y el $16 \%$ de sus ventas anuales del 2016 , lo cual es relativamente alto y esto se debe a que la empresa cuenta con personal que no cumple con el perfil profesional que necesita para poder mejorar su productividad.

Para poder calcular el Estado de Resultados del 2017 sin estrategia, se utilizará el $15 \%$ de crecimiento de las ventas que hubo entre el 2016 al 2017, para poder realizar la proyección de las ventas del 2018. Por otra parte, la relación entre los Costos de ventas, Gastos de administrativos y Gastos de ventas con las ventas totales del 2017 son del 19\%, $43 \%$ y $16 \%$ respectivamente. Estos porcentajes se mantendrán constantes para poder calcular los costos y gastos del 2018 en relación a sus ventas proyectadas. 
En el cuadro 10.1 se puede observar el Estado de Resultados proyectado del 2018, el cual obtiene una utilidad neta de S/80,683. La utilidad neta del 2018 es del $15 \%$ en relación a las ventas proyectadas del mismo año.

\section{Cuadro 10.1: Estado de Resultados (situación actual)}

\begin{tabular}{|c|c|c|c|c|c|c|c|}
\hline S/. Nuevos Soles & $\%$ & 2016 & 2017 & 2018 & 2019 & 2020 & 2021 \\
\hline Ventas & $15 \%$ & 403,803 & 464,373 & 534,029 & 614,134 & 706,254 & 812,192 \\
\hline Costo Ventas & $19 \%$ & $-76,723$ & $-88,231$ & $-101,466$ & $-116,685$ & $-134,188$ & $-154,316$ \\
\hline Utilidad Bruta & & 327,080 & 376,142 & 432,564 & 497,448 & 572,066 & 657,876 \\
\hline \multicolumn{8}{|l|}{ Gastos Operativos } \\
\hline Gastos Administrativos & $43 \%$ & $-173,635$ & $-199,681$ & $-229,633$ & $-264,078$ & $-303,689$ & $-349,243$ \\
\hline Gastos de Ventas & $16 \%$ & $-64,608$ & $-74,300$ & $-85,445$ & $-98,261$ & $-113,001$ & $-129,951$ \\
\hline Depreación & & $-5,427$ & $-5,427$ & $-5,427$ & $-5,427$ & $-5,427$ & $-5,427$ \\
\hline Utilidad Operativa & & 83,410 & 96,735 & 112,059 & 129,682 & 149,949 & 173,255 \\
\hline \multicolumn{8}{|l|}{ Gastos Financieros } \\
\hline \multicolumn{8}{|l|}{ Otros Ingresos } \\
\hline Utilidad neta antes de impuestos & & 83,410 & 96,735 & 112,059 & 129,682 & 149,949 & 173,255 \\
\hline Impuesto a la Renta (28\%) & & $-23,355$ & $-27,086$ & $-31,377$ & $-36,311$ & $-41,986$ & $-48,511$ \\
\hline Utilidad neta después de impuestos & & 60,055 & 69,649 & 80,683 & 93,371 & 107,963 & 124,744 \\
\hline Utilidades retenidad & & 30,028 & 34,825 & 40,341 & 46,686 & 53,982 & 62,372 \\
\hline Asignacion de dividendos & & $30,027.60$ & $34,824.66$ & $40,341.41$ & $46,685.68$ & $53,981.59$ & $62,371.89$ \\
\hline
\end{tabular}

\section{Elaboración propia.}

Por otra parte, al implementar la inversión en el capital humano, se espera que la productividad de los colaboradores se incremente, lo cual se vería reflejado en un mayor nivel de ventas y en una reducción de los gastos administrativos y en los gastos de ventas en $35 \%$ y $14 \%$ respectivamente como se observa en el cuadro 10.2. Además, al invertir en la contratación de personal que cuente con el perfil del colaborador que la empresa necesita, se espera poder desarrollar un área creativa que le permita a la empresa el poder captar cuentas de clientes con un mayor valor monetario. De esta manera la empresa, dejaría de ser solamente un operador logístico de campañas BTL y se convertiría en un creador de campañas y eventos. Esto permitiría a la empresa poder incrementar sus ventas en un 17\%, 18\%, 19\% y 20\% anual durante los años 2018, 2019, 2020 y 2021 respectivamente. Por otra parte, en las entrevistas con a los expertos del sector, resalto que las estrategias implementadas por la competencia impactarían entre un $15 \%$ a un $25 \%$ en sus ventas.

Actualmente la economía del país se ha contraído desde el año 2012 debido a la caída del precio de las materias primas, lo cual está llevando a las empresas a reducir su presupuesto en campañas ATL e incrementando sus campañas en BTL. 
Para poder calcular el Estado de Resultados con estrategia, se consideraría el 17\%, $18 \%, 19 \%$ y $20 \%$ como incremento de las ventas totales para los años 2018, 2019, 2019 y 2021 respectivamente y se reducirá los gastos administrativos y gastos de ventas en $35 \%$ y 14\% respectivamente. En el cuadro 10.2 se puede observar cómo quedaría el nuevo Estado de Resultados.

La utilidad neta en el Estado de Resultados con estrategia 2018 sería de S/ 129,097. En este resultado se puede apreciar que la empresa tiene una utilidad neta después de impuesto del $24 \%$ en relación a las ventas totales. Este incremento sería alto para un sector de servicios. Si comparamos la relación de la utilidad neta con las ventas totales del 2018 del Estado de Resultados sin estrategia y con estrategia, se puede observar que habido un incremento del $8.65 \%$.

\section{Cuadro 10.2: Estado de Resultados (con estrategia)}

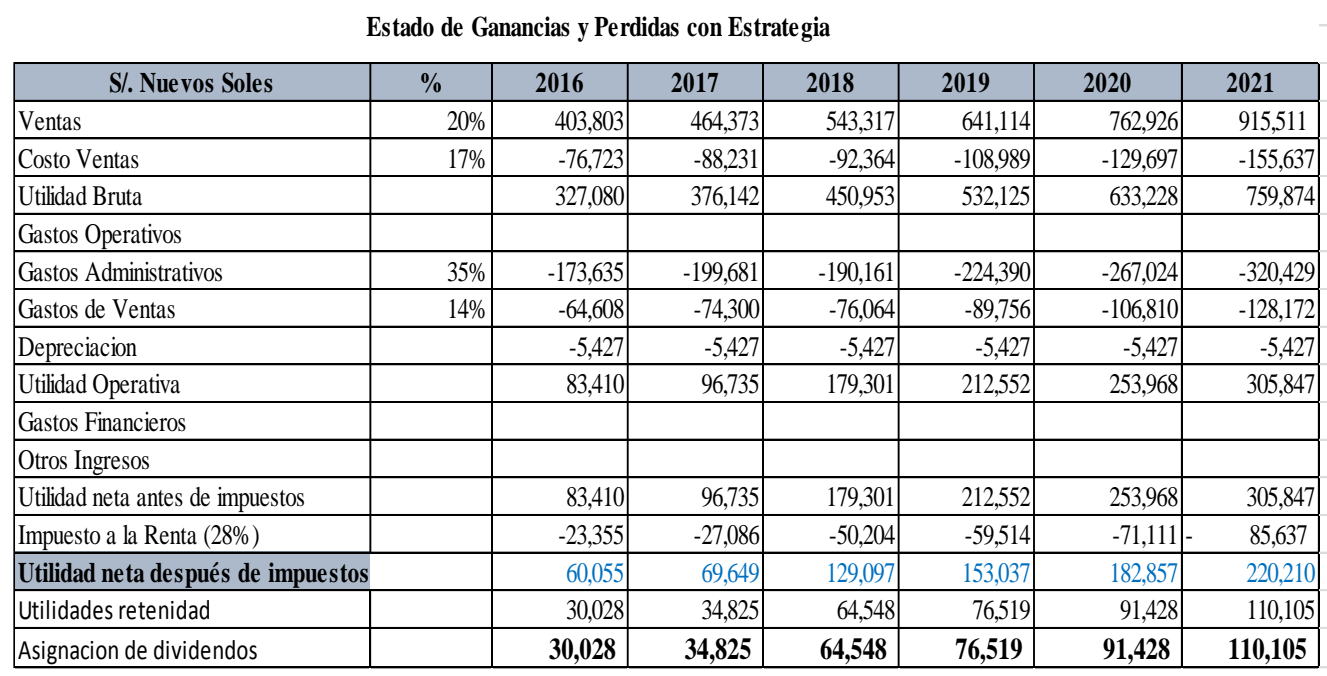

\section{Elaboración Propia.}

\subsubsection{Balance General (situación actual y con la nueva estrategia)}

El Balance General en uno de los Estados Financieros que se utiliza en la Contabilidad, y nos muestra la situación financiera de la empresa en una fecha determinada. Muestra los bienes, derechos y obligaciones.

A continuación mostramos en el cuadro 10.4 el Balance General de la empresa Naranja Producciones S.A.C. del periodo 2018 con respecto al escenario actual, y en el cuadro 10.6 mostraremos el Balance General utilizando la nueva estrategia, en la cual 
tendríamos un crecimiento en ventas del 17\%, 18\%, 19\% y 20\% en los años 2018,2019 , 2020 y 2021 respectivamente.

Cuadro 10.3: Flujo de caja (escenario actual)

Flujo de caja, situación actual proyectada

\begin{tabular}{|c|c|c|c|c|c|c|c|c|c|}
\hline Ingresos & 2013 & 2014 & 2015 & 2016 & 2017 & 2018 & 2019 & 2020 & 2021 \\
\hline Saldo inicial & & 5,297 & 5,036 & 3,471 & 13,713 & 25,263 & 38,317 & 54,208 & 72,253 \\
\hline Ventas & 142,575 & 300,114 & 351,133 & 403,803 & 464,373 & 534,029 & 614,134 & 706,254 & 812,192 \\
\hline \multicolumn{10}{|l|}{ Egresos } \\
\hline Gastos Administrativos & 71,442 & 126,720 & 151,900 & 173,635 & 199,681 & 229,633 & 264,078 & 303,689 & 349,243 \\
\hline Costos de ventas & 25,645 & 65,325 & 67,583 & 76,723 & 88,231 & 101,466 & 116,685 & 134,188 & 154,316 \\
\hline Gastos de venta & 23,542 & 48,532 & 54,352 & 64,608 & 74,300 & 85,445 & 98,261 & 113,001 & 129,951 \\
\hline Renta & 5,686 & 16,060 & 20,124 & 23,355 & 27,086 & 31,377 & 36,311 & 41,986 & 41,986 \\
\hline IGV & 21,557 & 43,216 & 48,667 & 55,240 & 63,526 & 73,055 & 82,908 & 95,344 & 109,646 \\
\hline Total egresos & 147,872 & 299,853 & 342,626 & 393,561 & 452,823 & 520,975 & 598,244 & 688,208 & 785,141 \\
\hline Saldo de caja & 5,297 & 5,036 & 3,471 & 13,713 & 25,263 & 38,317 & 54,208 & 72,253 & 99,304 \\
\hline
\end{tabular}

Fuente: Flujo de caja de Naranja Producciones S.A.C.

Elaboración Propia

Cuadro 10.4: Estado de Situación Financiera (escenario actual)

NARANJA PRODUCCIONES SAC

BALANCE GENERAL SIN ESTRATEGIA

\begin{tabular}{|c|c|c|c|c|c|c|c|c|c|}
\hline ACTIVO & 2013 & 2014 & 2015 & 2016 & 2017 & 2018 & 2019 & 2020 & 2021 \\
\hline Activo Corriente & $\mathrm{S} /$. & & & & & & & & \\
\hline Caja/ Banco & $-5,297$ & 5,036 & 3,471 & 13,713 & 25,263 & 38,317 & 54,208 & 72,253 & 99,304 \\
\hline Cuentas por cobrar & 4,455 & 9,379 & 10,973 & 12,619 & 14,512 & 16,688 & 19,192 & 22,070 & 25,381 \\
\hline \multicolumn{10}{|l|}{ Inventarios } \\
\hline \multicolumn{10}{|l|}{ Otros activos corrientes } \\
\hline TOTAL ACTIVOS CORRIENTES & 842 & 4,342 & 14,444 & 26,331 & 39,774 & \begin{tabular}{|c|c|c|}
55,006 \\
\end{tabular} & 73,399 & 94,324 & 124,685 \\
\hline Activo Fijo & 25,075 & 43,516 & 59,288 & 78,283 & 100,528 & 126,630 & 156,064 & 190,433 & 223,954 \\
\hline & & & & & & & & & \\
\hline TOTAL ACTIVOS & 24,234 & 47,858 & 73,732 & 104,614 & 140,302 & 181,636 & 229,463 & 284,757 & 348,639 \\
\hline \multicolumn{10}{|l|}{ PASIVO Y PATRIMONIO } \\
\hline Pasivo Corriente & S/. & & & & & & & & \\
\hline Ctas. Por pagar & 1,923 & 4,899 & 4,899 & 5,754 & 6,617 & 7,610 & 8,751 & 10,064 & 11,574 \\
\hline \multicolumn{10}{|l|}{ Deuda banco corto plazo } \\
\hline \multicolumn{10}{|l|}{ Otros pasivos } \\
\hline TOTAL PASIVOS CORRIENTES & 1,923 & 4,899 & 4,899 & 5,754 & 6,617 & 7,610 & 8,751 & 10,064 & 11,574 \\
\hline \multicolumn{10}{|l|}{ Deuda a largo plazo } \\
\hline \multicolumn{10}{|l|}{ Otros pasivos largo plazo } \\
\hline TOTAL PASIVOS & 1,923 & 4,899 & 4,899 & 5,754 & 6,617 & 7,610 & 8,751 & 10,064 & 11,574 \\
\hline CAPITAL SOCIAL & 15,000 & 15,000 & 15,000 & 15,000 & 15,000 & 15,000 & 15,000 & 15,000 & 15,000 \\
\hline RESULTADO ACUMULADO & & 7,310 & 27,959 & 53,832 & 83,860 & 118,684 & 159,026 & 205,712 & 259,693 \\
\hline RESULTADO DEL EJERCICIO & 7,310 & 20,649 & 25,874 & 30,028 & 34,825 & 40,341 & 46,686 & 53,982 & 62,372 \\
\hline PATRIMONIO & 22,310 & 42,959 & 68,832 & 98,860 & 133,684 & 174,026 & 220,712 & 274,693 & 337,065 \\
\hline TOTAL PASIVO Y PATRIMONIO & 24,234 & 47,858 & 73,732 & 104,614 & 140,302 & 181,636 & 229,463 & 284,757 & 348,639 \\
\hline
\end{tabular}

Fuente: Balance General de Naranja Producciones S.A.C.

Elaboración Propia 
Para analizar el Estado de Situación Financiera y el Estado de Resultados se debe de emplear las ratios financieras para poder observar si la empresa Naranja Producciones S.A.C. está operando correctamente.

En la tabla 10.1 se han presentado las principales razones financieros que se han obtenido de los estados financieros de Naranja Producciones S.A.C. En donde se puede aprecia que la deuda acorto plazo es cubierta por el activo a corto plazo por 4.58 veces. Esto significa que La ratio de liquidez es muy alto y que hay un exceso de activos que no están siendo utilizados para obtener una mayor rentabilidad. La fórmula indica que este ratio debe ser mayor a 1 , pero la empresa lo sobrepasa.

Por otra parte, la empresa cuenta con una prueba defensiva del $238 \%$ que significa que la empresa cuenta con la de liquidez necesaria para funcionar sin utilizar sus flujos de ventas, lo cual demuestra que Naranja Producciones S.A.C. cuenta con una caja y bancos estable para hacer frente al pasivo corriente.

La rotación de activos totales nos indica que la empresa está colocando entre sus clientes 3.89 veces el valor de lo invertido en activos totales, lo cual podría ser mayor si la empresa incremente las ventas, producto de la nueva estrategia que va implementar.

La rotación del activo fijo nos indica que la empresa está colocando entre sus clientes 5.22 veces el valor de lo invertido en activos fijos, lo cual es muy positivo, porque significa que la empresa está recuperando cada solo en 5.22 cada vez que invierte en algún activo fijo para la empresa.

En La ratio de la estructura de capital, nos muestra que por cada sol invertido por los accionistas el $6 \%$ es aportado por los acreedores. Esta ratio la empresa debería de subirlo urgentemente, porque significa que hay un exceso de capitales ociosos, lo cual reduce la rentabilidad de la empresa. La ratio de endeudamiento debería estar entre los 40 y $60 \%$.

La ratio de la razón de endeudamiento del Activo no lo tienen controlado, porque indica que el 6\% del Activo Total es financiado por los acreedores de la empresa. Es un indicador que está muy bajo, lo cual significa que la empresa cuenta con un excedente de capitales propios por encima de lo recomendable. Este indicador debería estar entre el $40 \%$ y el $60 \%$. Debido a que, si es mayor a $60 \%$, el financiamiento de la empresa estaría 
bajo control de terceros y si es menor al $40 \%$ significaría que hay un exceso de capital propio de la empresa sin ser invertido.

Hasta el momento el ROE de la empresa ha sido alto, debido a que por cada sol que la empresa ha invertido ha obtenido una ganancia del $61 \%$ sobre el patrimonio.

El ROA es del $58 \%$ lo cual demuestra que los activos totales han tenido un buen rendimiento durante el año 2016. La inversión en activos en la empresa es un buen generador de ingresos. Esto también se ve reflejado en La ratio Utilidad Activo, debido a que la empresa ha generado una utilidad del $79 \%$ por cada sol invertido en activos.

En La ratio Utilidad venta se puede apreciar que por cada sol vendido se ha obtenido una utilidad antes de impuesto del $21 \%$. Es alta, pero debería ser más alta para el nivel de ingresos que la empresa tiene, pero un mal uso de sus recursos los ha llevado a bajar sus beneficios. Esto se acentúa en La ratio de Margen Neto de utilidad, porque se observa que por cada sol vendido se ha obtenido una utilidad neta del 15\%. Es muy baja esta utilidad en comparación a lo rápido que la empresa ha ido creciendo en los últimos años.

El nivel de endeudamiento que tiene una empresa en relación a sus acreedores es muy importante, para saber si cuenta con capacidad para hacerle frente con su patrimonio. Actualmente el endeudamiento a corto plazo es del $6 \%$ del patrimonio total, el cual es muy bajo. Al tener una ratio de endeudamiento al corto plazo tan bajo, le permite tener mayor liquidez a mediano plazo.

La empresa actualmente solo tiene deuda con sus acreedores, lo cual se observa en La ratio de endeudamiento total, el cual está en $6 \%$, que significa que de la deuda de la empresa está bajo control de los acreedores en ese porcentaje. 
Tabla 10.1 Ratios Financieros 2016

\begin{tabular}{|c|c|c|c|}
\hline Ratio & Calculo & Significado & Naranja Producciones SAC \\
\hline \multicolumn{4}{|l|}{ Analisis de Liquidez } \\
\hline Ratio de Liquidez corriente & $\frac{\text { Activo Corriente }}{\text { Pasivo Corriente }}$ & $\begin{array}{l}\text { La deuda a corto plazo es cubierta por } 4.89 \text { veces } \\
\text { por el activo corriente de la empresa. }\end{array}$ & 4.58 \\
\hline Prueba Defensiva & $\frac{\text { Caja Bancos }}{\text { Pasivo Corriente }}$ & $\begin{array}{l}\text { La empresa cuenta con el } 270 \% \text { de liquidez para } \\
\text { funcionar sin utilizar sus flujos de ventas. }\end{array}$ & $238 \%$ \\
\hline \multicolumn{4}{|l|}{ Analisis de Gestión } \\
\hline Rotación de caja y Bancos & $\frac{\text { Caja y bancos x } 360}{\text { Ventas }}$ & $\begin{array}{l}\text { La empresa cuenta con liquidez para cubrir en } 13.84 \\
\text { dias las ventas. }\end{array}$ & 12.23 \\
\hline Rotación de Activos Totales & $\frac{\text { Ventas }}{\text { Activos Totales }}$ & $\begin{array}{l}\text { Nos indica que la empresa está colocando entre sus } \\
\text { clientes } 3.83 \text { veces el valor de lo invertido en activos } \\
\text { totales. }\end{array}$ & 3.89 \\
\hline \multicolumn{4}{|l|}{ Ratios de Solvencia } \\
\hline Estructura del Capital & $\frac{\text { Pasivo Total }}{\text { Patrimonio }}$ & $\begin{array}{l}\text { Nos muestra que por cada sol invertido por los } \\
\text { accionistas el } 6 \% \text { es aportado por los acreedores. }\end{array}$ & $6 \%$ \\
\hline Razón de endeudamiento & $\frac{\text { Pasivo Total }}{\text { Activo Total }}$ & $\begin{array}{l}\text { Indica que el 5\% del Activo Total es financiado por } \\
\text { los acreedores de la empresa. }\end{array}$ & $6 \%$ \\
\hline \multicolumn{4}{|l|}{ Analisis de Rentabilidad } \\
\hline Utilidad Activo & $\frac{\text { UT. antes de intereses e impuestos }}{\text { Activo }}$ & $\begin{array}{l}\text { Nos indica que la empresa ha generado una utilidad } \\
\text { del } 79 \% \text { por cada sol invertido en activos. }\end{array}$ & $80 \%$ \\
\hline Utilidad Ventas & $\frac{\text { UT. antes de intereses e impuestos }}{\text { Ventas }}$ & $\begin{array}{l}\text { Quiere decir que por cada sol vendido se ha } \\
\text { obtenido una utilidad antes de impuesto del } 21 \%\end{array}$ & $21 \%$ \\
\hline Margen Neto de Utilidad & $\frac{\text { Utilidad Netas }}{\text { Ventas Netas }}$ & $\begin{array}{l}\text { Quiere decir que por cada sol vendido se ha } \\
\text { obtenido una utilidad neta del } 15 \%\end{array}$ & $15 \%$ \\
\hline \multicolumn{4}{|l|}{ Ratios de endeudamiento } \\
\hline Ratio de endeudamiento a corto plazo & $\frac{\text { Pasivo Corriente }}{\text { Patrimonio }}$ & $\begin{array}{l}\text { El endeudamiento a corto plazo es del } 6 \% \text { del } \\
\text { patrimonio total. }\end{array}$ & $6 \%$ \\
\hline Ratio de endeudamiento total & $\frac{\text { Pasivo Total }}{\text { Patrimonio }}$ & $\begin{array}{l}\text { Nos indica que el } 6 \% \text { de la deuda de la empresa } \\
\text { está bajo control de los acreedores. }\end{array}$ & $6 \%$ \\
\hline Ratio de endeudamiento de Activo & $\frac{\text { Pasivo Total }}{\text { Activo Total }}$ & $\begin{array}{l}\text { Solo el 5\% del activo total es financiado por el } \\
\text { pasivo total de la empresa. }\end{array}$ & $6 \%$ \\
\hline
\end{tabular}

\section{Elaboración Propia.}


Cuadro 10.5: Flujo de caja (con estrategia)

Flujo de caja con estrategia

\begin{tabular}{|c|c|c|c|c|c|c|c|c|c|}
\hline Ingresos & 2013 & 2014 & 2015 & 2016 & 2017 & 2018 & 2019 & 2020 & 2021 \\
\hline Saldo inicial & & 5,297 & 5,036 & 3,471 & 13,713 & 25,263 & 85,460 & 190,299 & 327,126 \\
\hline Ventas & 142,575 & 300,114 & 351,133 & 403,803 & 464,373 & 543,317 & 641,114 & 762,926 & 915510.771 \\
\hline \multicolumn{10}{|l|}{ Egresos } \\
\hline Gastos Administrativos & 71,442 & 126,720 & 151,900 & 173,635 & 199,681 & 190,161 & 224,390 & 267,024 & $-320,429$ \\
\hline Costos de ventas & 25,645 & 65,325 & 67,583 & 76,723 & 88,231 & 92,364 & 89,756 & 106,810 & $-155,637$ \\
\hline Gastos de venta & 23,542 & 48,532 & 54,352 & 64,608 & 74,300 & 76,064 & 76,064 & 89,756 & $-128,172$ \\
\hline Renta & 5,686 & 16,060 & 20,124 & 23,355 & 27,086 & 50,204 & 59,514 & 59,514 & 85,637 \\
\hline IGV & 21,557 & 43,216 & 48,667 & 55,240 & 63,526 & 74,326 & 86,550 & 102,995 & 123,594 \\
\hline Total egresos & 147,872 & 299,853 & 342,626 & 393,561 & 452,823 & 483,119 & 536,275 & 626,099 & 813,468 \\
\hline Saldo de caja & 5,297 & 5,036 & 3,471 & 13,713 & 25,263 & 85,460 & 190,299 & 327,126 & 429,169 \\
\hline
\end{tabular}

Fuente: Flujo de Caja de Naranja Producciones S.A.C.

Elaboración Propia

Cuadro 10.6: Estado de Situación Financiera (escenario con la nueva estrategia)

NARANJA PRODUCCIONES SAC

BALANCE GENERAL CON ESTRATEGIA

\begin{tabular}{|c|c|c|c|c|c|c|c|c|c|}
\hline ACTIVO & 2013 & 2014 & 2015 & 2016 & 2017 & 2018 & 2019 & 2020 & 2021 \\
\hline Activo Corriente & S/. & & & & & & & & \\
\hline Caja/ Banco & - 5,297 & 5,036 & 3,471 & 13,713 & 25,263 & 85,460 & 190,299 & 327,126 & 429,169 \\
\hline Cuentas por cobrar & 4,455 & 9,379 & 10,973 & 12,619 & 14,512 & 16,979 & 20,035 & 23,841 & 28,610 \\
\hline \multicolumn{10}{|l|}{ Inventarios } \\
\hline \multicolumn{10}{|l|}{ Otros activos corrientes } \\
\hline TOTAL ACTIVOS CORRIENTES & 842 & 4,342 & 14,444 & 26,331 & 39,774 & 102,439 & 210,334 & 350,967 & 457,778 \\
\hline Activo Fijo & 25,076 & 43,516 & 59,457 & 78,283 & 100,528 & 219,825 & 158,907 & 195,907 & 225,906 \\
\hline & & & & & & & & & \\
\hline TOTAL ACTIVOS & 24,234 & 47,858 & 73,901 & 104,614 & 140,302 & 322,264 & 369,241 & & \\
\hline \multicolumn{10}{|l|}{ PASIVO Y PATRIMONIO } \\
\hline Pasivo Corriente & $\mathrm{S} /$. & & & & & & & & \\
\hline Ctas. Por pagar & 1,923 & 4,899 & 5,069 & 5,754 & 6,617 & 6,927 & 8,174 & 9,727 & 11,673 \\
\hline Deuda banco corto plazo & & & & & & 117,104 & 86,315 & 170,967 & 195,727 \\
\hline \multicolumn{10}{|l|}{ Otros pasivos } \\
\hline TOTAL PASIVOS CORRIENTES & 1,923 & 4,899 & 5,069 & 5,754 & 6,617 & 124,031 & 94,489 & 180,694 & 207,400 \\
\hline \multicolumn{10}{|l|}{ Deuda a largo plazo } \\
\hline \multicolumn{10}{|l|}{ Otros pasivos largo plazo } \\
\hline TOTAL PASIVOS & 1,923 & 4,899 & 5,069 & 5,754 & 6,617 & 124,031 & 94,489 & 180,694 & 207,400 \\
\hline CAPITAL SOCIAL & 15,000 & 15,000 & 15,000 & 15,000 & 15,000 & 15,000 & 15,000 & 15,000 & 15,000 \\
\hline RESULTADO ACUMULADO & & 7,310 & 27,959 & 53,832 & 83,860 & 118,684 & 183,233 & 259,751 & 351,180 \\
\hline RESULTADO DEL EJERCICIO & 7,310 & 20,649 & 25,874 & 30,028 & 34,825 & 64,548 & 76,519 & 91,428 & 110,105 \\
\hline PATRIMONIO & 22,310 & 42,959 & 68,832 & 98,860 & 133,684 & 198,233 & 274,751 & 366,180 & 476,285 \\
\hline TOTAL PASIVO Y PATRIMONIO & 24,234 & 47,858 & 73,901 & 104,614 & 140,302 & 322,264 & 369,241 & 546,874 & 683,684 \\
\hline
\end{tabular}

Fuente: Balance General de Naranja Producciones S.A.C.

Elaboración Propia.

\subsubsection{Flujo de efectivo (situación actual y con la nueva estrategia)}

A continuación se detalla el flujo de Efectivo de la empresa Naranja Producciones S.A.C. en el escenario actual para el período 2018 al 2021 (ver cuadro 10.7).

El crecimiento esperado de las ventas totales es del $15 \%$ anual con respecto al año anterior. Como Naranja Producciones S.A.C. no tiene contemplado invertir dinero en el periodo 2018 al 2021, tampoco podría aumentar su capacidad operativa. 
Por otra parte, los costos de ventas, los gastos administrativos y los gastos de ventas se calculan contemplando que mantienen la misma proporción del año 2017 (19\%, $43 \%$ y $16 \%$ de las ventas totales).

\section{Cuadro 10.7: Flujo de Efectivo (escenario actual)}

Flujo de efectivo proyectado escenario 1: sin estrategia

\begin{tabular}{|l|r|r|r|r|r|r|}
\hline \multicolumn{1}{|c|}{ S/. Nuevos Soles } & \multicolumn{1}{c|}{$\mathbf{\%}$} & \multicolumn{1}{c|}{$\mathbf{2 0 1 7}$} & \multicolumn{1}{c|}{$\mathbf{2 0 1 8}$} & \multicolumn{1}{c|}{$\mathbf{2 0 1 9}$} & \multicolumn{1}{c|}{$\mathbf{2 0 2 0}$} & \multicolumn{1}{c|}{$\mathbf{2 0 2 1}$} \\
\hline Ventas & $15 \%$ & 464,373 & 534,029 & 614,134 & 706,254 & 812,192 \\
\hline Costo Operativo & $19 \%$ & $-89,392$ & $-102,801$ & $-118,221$ & $-135,954$ & $-156,347$ \\
\hline Gastos Administrativos & $43 \%$ & $-199,681$ & $-229,633$ & $-264,078$ & $-303,689$ & $-349,243$ \\
\hline Gastos de Ventas & $16 \%$ & $-74,300$ & $-85,445$ & $-98,261$ & $-113,001$ & $-129,951$ \\
\hline Depreciación & & $-5,427$ & $-5,427$ & $-5,427$ & $-5,427$ & $-5,427$ \\
\hline EBIT & & 95,574 & 110,724 & 128,147 & 148,183 & 171,225 \\
\hline Impuestos (28\%) & & $-26,761$ & $-31,003$ & $-35,881$ & $-41,491$ & $-47,943$ \\
\hline NOPAT & & 68,813 & 79,722 & 92,266 & 106,692 & 123,282 \\
\hline Depreciacion & & 5,427 & 5,427 & 5,427 & 5,427 & 5,427 \\
\hline FEN = FEL & & 74,240 & 85,149 & 97,693 & 112,119 & 128,709 \\
\hline VP & & & 73,032 & 71,868 & 70,744 & 69,655 \\
\hline VAN & & $\mathbf{2 8 5 , 2 9 9 . 3 2}$ & & & & \\
\hline
\end{tabular}

Elaboración Propia.

A continuación se detalla el flujo de Efectivo de la empresa Naranja Producciones S.A.C. en el escenario con estrategia para el período 2018 al 2021 (ver cuadro 10.8).

Como se indicó anteriormente, el crecimiento de las ventas será del 17\%, 18\%, 19\% y $20 \%$ anual en los años 2018, 2019, 2020 y 2021 respectivamente al implementar el flujo de inversión para poder llevar acabo las estrategias. Al incrementarse la productividad de los colaboradores, se reducirá los costos de ventas, gastos administrativos y gastos de ventas en $17 \%, 35 \%$ y $14 \%$ respectivamente.

EI NOPAT sería de S/ 68,813, S/ 129,097, S/153,037, S/ 182,857, y S/ 220,210 de los años 2017, 2018, 2019, 2020 y 2021 respectivamente. Con este incremento en las ventas en $17 \%, 18 \%, 19 \%$ y $20 \%$ en el periodo de 2018 al 2021 , la empresa lograría una mayor participación de ventas en el mercado actual. 
Cuadro 10.8: Flujo de Efectivo (escenario con la nueva estrategia)

Flujo de efectivo proyectado escenario 2: con estrategia

\begin{tabular}{|l|r|r|r|r|r|r|}
\hline \multicolumn{1}{|c|}{ S/. Nuevos Soles } & $\mathbf{6}$ & $\mathbf{2 0 1 7}$ & \multicolumn{1}{c|}{$\mathbf{2 0 1 8}$} & \multicolumn{1}{c|}{$\mathbf{2 0 1 9}$} & \multicolumn{1}{c|}{$\mathbf{2 0 2 0}$} & $\mathbf{2 0 2 1}$ \\
\hline Ventas & $17 \%, 18 \%, 19 \%$ y 20\% & 464,373 & 543,317 & 641,114 & 762,926 & 915,511 \\
\hline Costo Operativo & $17 \%$ & $-89,392$ & $-92,364$ & $-108,989$ & $-129,697$ & $-155,637$ \\
\hline Gastos Administrativos & $35 \%$ & $-199,681$ & $-190,161$ & $-224,390$ & $-267,024$ & $-320,429$ \\
\hline Gastos de Ventas & $14 \%$ & $-74,300$ & $-76,064$ & $-89,756$ & $-106,810$ & $-128,172$ \\
\hline Depreciacion & & $-5,427$ & $-5,427$ & $-5,427$ & $-5,427$ & $-5,427$ \\
\hline EBIT & & 95,574 & 179,301 & 212,552 & 253,968 & 305,847 \\
\hline Impuestos (28\%) & & $-26,761$ & $-50,204$ & $-59,514$ & $-71,111$ & $-85,637$ \\
\hline NOPAT & & 68,813 & 129,097 & 153,037 & 182,857 & 220,210 \\
\hline Depreciacion & & 5,427 & 5,427 & 5,427 & 5,427 & 5,427 \\
\hline FEN=FEL & & 74,240 & 134,524 & 158,464 & 188,284 & 225,637 \\
\hline flujo de Inversión & & & $-90,560$ & $-48,420$ & $-66,046$ & $-90,708$ \\
\hline VP & & & $115,381.13$ & $116,574.70$ & $118,801.60$ & $122,111.19$ \\
\hline VAN & & $\mathbf{4 7 2 , 8 6 8 . 6 2}$ & & & & \\
\hline
\end{tabular}

Elaboración Propia.

\subsubsection{Proyección de flujos (situación actual y con la nueva estrategia)}

A continuación se detalla el flujo de Efectivo de la empresa Naranja Producciones S.A.C. en el escenario actual para el período 2018 al 2021 (ver cuadro 10.9).

Cuadro 10.9: Flujo de Efectivo (escenario actual)

Flujo de efectivo proyectado escenario 1: sin estrategia

\begin{tabular}{|l|r|r|r|r|r|r|}
\hline \multicolumn{1}{|c|}{ S/. Nuevos Soles } & $\mathbf{~ \% ~}$ & \multicolumn{1}{c|}{$\mathbf{2 0 1 7}$} & \multicolumn{1}{c|}{$\mathbf{2 0 1 8}$} & \multicolumn{1}{c|}{$\mathbf{2 0 1 9}$} & \multicolumn{1}{c|}{$\mathbf{2 0 2 0}$} & $\mathbf{2 0 2 1}$ \\
\hline Ventas & $15 \%$ & 464,373 & 534,029 & 614,134 & 706,254 & 812,192 \\
\hline Costo Operativo & $19 \%$ & $-89,392$ & $-102,801$ & $-118,221$ & $-135,954$ & $-156,347$ \\
\hline Gastos Administrativos & $43 \%$ & $-199,681$ & $-229,633$ & $-264,078$ & $-303,689$ & $-349,243$ \\
\hline Gastos de Ventas & $16 \%$ & $-74,300$ & $-85,445$ & $-98,261$ & $-113,001$ & $-129,951$ \\
\hline Depreciación & & $-5,427$ & $-5,427$ & $-5,427$ & $-5,427$ & $-5,427$ \\
\hline EBIT & & 95,574 & 110,724 & 128,147 & 148,183 & 171,225 \\
\hline Impuestos (28\%) & & $-26,761$ & $-31,003$ & $-35,881$ & $-41,491$ & $-47,943$ \\
\hline NOPAT & & 68,813 & 79,722 & 92,266 & 106,692 & 123,282 \\
\hline Depreciacion & & 5,427 & 5,427 & 5,427 & 5,427 & 5,427 \\
\hline FEN = FEL & & 74,240 & 85,149 & 97,693 & 112,119 & 128,709 \\
\hline VP & & & 73,032 & 71,868 & 70,744 & 69,655 \\
\hline VAN & & $\mathbf{2 8 5 , 2 9 9 . 3 2}$ & & & & \\
\hline
\end{tabular}

Elaboración Propia.

A continuación se detalla el flujo de Efectivo de la empresa Naranja Producciones S.A.C. en el nuevo escenario para el período 2018 al 2021 (ver cuadro 10.10). 
Cuadro 10.10: Flujo de Efectivo (escenario con la nueva estrategia) Flujo de efectivo proyectado escenario 2: con estrategia

\begin{tabular}{|c|c|c|c|c|c|c|}
\hline S/. Nuevos Soles & $\%$ & 2017 & 2018 & 2019 & 2020 & 2021 \\
\hline Ventas & $17 \%, 18 \%, 19 \%$ y $20 \%$ & 464,373 & 543,317 & 641,114 & 762,926 & 915,511 \\
\hline Costo Operativo & $17 \%$ & $-89,392$ & $-92,364$ & $-108,989$ & $-129,697$ & $-155,637$ \\
\hline Gastos de Ventas & $14 \%$ & $-74,300$ & $-76,064$ & $-89,756$ & $-106,810$ & $-128,172$ \\
\hline Depreciacion & & $-5,427$ & $-5,427$ & $-5,427$ & $-5,427$ & $-5,427$ \\
\hline NOPAT & & 68,813 & 129,097 & 153,037 & 182,857 & 220,210 \\
\hline Depreciacion & & 5,427 & 5,427 & 5,427 & 5,427 & 5,427 \\
\hline $\mathrm{FEN}=\mathrm{FEL}$ & & 74,240 & 134,524 & 158,464 & 188,284 & 225,637 \\
\hline flujo de Inversión & & & $-90,560$ & $-48,420$ & $-66,046$ & $-90,708$ \\
\hline
\end{tabular}

Elaboración Propia.

10.2.6. Evaluación Financiera (VAN, TIR y ratios financieros)

EI VAN y el TIR son dos herramientas financieras procedentes de las matemáticas financieras que nos permiten evaluar la rentabilidad de un proyecto de inversión, entendiéndose por proyecto de inversión no solo como la creación de un nuevo negocio, sino también, como inversiones que podemos hacer en un negocio en marcha, tales como el desarrollo de un nuevo producto, la adquisición de nueva maquinaria, el ingreso en un nuevo rubro de negocio, etc.

EI VAN es un indicador financiero que mide los flujos de los futuros ingresos y egresos que tendrá un proyecto para determinar, si luego de descontar la inversión inicial, nos quedaría alguna ganancia. Si el resultado es positivo, el proyecto es viable.

En el caso de Naranja Producciones S.A.C., el VAN es de S/ 285,299.32 en el escenario actual, y de S/ 472,868.62 aplicando la estrategia planteada.

Para poder hallar el VP del Flujo Efectivo Proyectado sin estrategia se debe de hallar primero la Tasa de descuento WACC, pero para poder hallar la WACC, se deberá primero hallar el Kproy. 


\begin{tabular}{|c|c|c|}
\hline Kproy & Costo de capital propio & $R^{\prime}+($ Beta*Prima $)+R p$ \\
\hline Rf & Tasa libre de riesgo & 5.15\% Tasa de bonos de Banco central de EEUU a 30 años \\
\hline$\beta$ & Beta del sector (Advertising) & 0.74 Indice beta de Aswath Damodaran \\
\hline $\mathrm{Rm}-\mathrm{Rf}$ & Prima por riesgo de mercado & $6.380 \%$ Prima riesgo de mercado Indice S\&P $6.8 \%$ volatilidad 250 sesiones en 1 año \\
\hline $\mathrm{RP}$ & Prima por riesgo país & $4.02 \%$ \\
\hline FEEUU & Inflación EEUU & $16.63 \%$ \\
\hline F Perú & Inflación Perú & $2.30 \%$ \\
\hline
\end{tabular}

Elaboración Propia.

\begin{tabular}{|c|c|c|c|}
\hline Ke EEUU Nominal & $\mathrm{RF}+(\mathrm{Rm}-\mathrm{RF}) * \beta$ & $2.92 \%+(3.880 \%) * 0.74=$ & $9.87 \%$ \\
\hline Ke EEUU Real & $\frac{1+\text { Ke EEUU Nom }}{1+\text { Inflación EEUU }} \quad-1$ & $((1+5.79 \%)-/(1+2.10 \%))-1=$ & $-6 \%$ \\
\hline Ke Perú Real & Ke EEUU Real+Riesgo & $\begin{array}{l}\text { Pais Perú+Prima Riesgo Negocio= } \\
\quad 4 \%+1.79 \%+8 \%\end{array}$ & \\
\hline Kd Real & $\frac{1+\text { TEA }}{1+\text { Inflación Perú }}^{-1}$ & $((1+35 \%) /(1+1.36 \%))-1=$ & $31.96 \%$ \\
\hline
\end{tabular}

Elaboración Propia

Se obtiene como resultado el 13.89\% como costo de capital propio, el cual se utilizará en la fórmula de la WACC.

\section{$W A C C=(D / D+E)^{\star} K d^{*}(1+T x)+(E / D+E)^{\star} K p r o y$}

- D: Deuda financiera. CE de S/ 87,500 BCP

- E: Capital aportado por los accionistas. El aporte S/295,734

- Kd: Costo de la deuda financiera. Es del $31.96 \%$

- T: El impuesto pagado sobre las ganancias. Es del 28\%.

- Kproy: Rentabilidad exigida por los accionistas, el cual sería en este caso el costo del capital propio, el cual es del $13.89 \%$

\begin{tabular}{|l|l|r|}
\hline WACC & Costo Promedio Ponderado de Capital & \multicolumn{1}{|c|}{$\mathbf{1 6 . 5 9 \%}$} \\
\hline D & Deuda & PEN 87,500.00 \\
\hline E & Capital propio & PEN 208,234.00 \\
\hline Kd & Costo de la deuda & $28.00 \%$ \\
\hline Tx & Imposición fiscal & $13.89 \%$ \\
\hline Kproy & Costo del Capital propio & \\
\hline
\end{tabular}

Aplicando la fórmula de la WACC se obtiene como tasa de descuento el 16.59\%

\section{Elaboración propia.}

Para hallar el VP se empleará la siguiente formula: 
$V P=K /(1+r)^{n}$

Dónde:

- K es el capital

- R es la tasa de descuento.

Para poder calcular el VP se utilizará los datos del FEN=FEL entre los años 2018 al 2021 como se aprecia en el cuadro 10.5

- $\mathrm{VP}=85,148.57 /(1+16.59 \%)^{\wedge} 1=73,032.11$

- $\mathrm{VP}=97,692.93 /(1+16.59 \%)^{\wedge} 2=71,868.09$

- $\mathrm{VP}=112,118.93 /(1+16.59 \%)^{\wedge} 3=70,743.80$

- $\mathrm{VP}=128,708.84 /(1+16.59 \%)^{\wedge} 4=69,655.32$

Obteniendo como VAN: S/.-10,434.68

Cuadro 10.11: VAN sin estrategia para el período 2018-2021

Flujo de efectivo proyectado escenario 1: sin estrategia

\begin{tabular}{|l|r|r|r|r|r|r|}
\hline \multicolumn{1}{|c|}{ S/. Nuevos Soles } & \% & \multicolumn{1}{c|}{$\mathbf{2 0 1 7}$} & \multicolumn{1}{c|}{$\mathbf{2 0 1 8}$} & \multicolumn{1}{c|}{$\mathbf{2 0 1 9}$} & \multicolumn{1}{c|}{$\mathbf{2 0 2 0}$} & \multicolumn{1}{c|}{$\mathbf{2 0 2 1}$} \\
\hline Ventas & $15 \%$ & 464,373 & 534,029 & 614,134 & 706,254 & 812,192 \\
\hline Costo Operativo & $19 \%$ & $-89,392$ & $-102,801$ & $-118,221$ & $-135,954$ & $-156,347$ \\
\hline Gastos Administrativos & $43 \%$ & $-199,681$ & $-229,633$ & $-264,078$ & $-303,689$ & $-349,243$ \\
\hline Gastos de Ventas & $16 \%$ & $-74,300$ & $-85,445$ & $-98,261$ & $-113,001$ & $-129,951$ \\
\hline Depreciación & & $-5,427$ & $-5,427$ & $-5,427$ & $-5,427$ & $-5,427$ \\
\hline EBIT & & 95,574 & 110,724 & 128,147 & 148,183 & 171,225 \\
\hline Impuestos (28\%) & & $-26,761$ & $-31,003$ & $-35,881$ & $-41,491$ & $-47,943$ \\
\hline NOPAT & & 68,813 & 79,722 & 92,266 & 106,692 & 123,282 \\
\hline Depreciacion & & 5,427 & 5,427 & 5,427 & 5,427 & 5,427 \\
\hline FEN = FEL & & 74,240 & 85,149 & 97,693 & 112,119 & 128,709 \\
\hline VP & & & 73,032 & 71,868 & 70,744 & 69,655 \\
\hline VAN & & $\mathbf{2 8 5 , 2 9 9 . 3 2}$ & & & & \\
\hline
\end{tabular}

Elaboración Propia.

Cuadro 10.12: VAN con estrategia para el período 2018-2021

Flujo de efectivo proyectado escenario 2: con estrategia

\begin{tabular}{|l|r|r|r|r|r|r|}
\hline \multicolumn{1}{|c|}{ S/. Nuevos Soles } & $\mathbf{9}$ & \multicolumn{1}{c|}{$\mathbf{2 0 1 7}$} & \multicolumn{1}{c|}{$\mathbf{2 0 1 8}$} & \multicolumn{1}{c|}{$\mathbf{2 0 1 9}$} & \multicolumn{1}{c|}{$\mathbf{2 0 2 0}$} & \multicolumn{1}{c|}{$\mathbf{2 0 2 1}$} \\
\hline Ventas & $\mathbf{1 7 \% , 1 8 \% , 1 9 \%}$ y 20\% & 464,373 & 543,317 & 641,114 & 762,926 & 915,511 \\
\hline Costo Operativo & $17 \%$ & $-89,392$ & $-92,364$ & $-108,989$ & $-129,697$ & $-155,637$ \\
\hline Gastos Administrativos & $35 \%$ & $-199,681$ & $-190,161$ & $-224,390$ & $-267,024$ & $-320,429$ \\
\hline Gastos de Ventas & $14 \%$ & $-74,300$ & $-76,064$ & $-89,756$ & $-106,810$ & $-128,172$ \\
\hline Depreciacion & & $-5,427$ & $-5,427$ & $-5,427$ & $-5,427$ & $-5,427$ \\
\hline EBIT & & 95,574 & 179,301 & 212,552 & 253,968 & 305,847 \\
\hline Impuestos (28\%) & & $-26,761$ & $-50,204$ & $-59,514$ & $-71,111$ & $-85,637$ \\
\hline NOPAT & & 68,813 & 129,097 & 153,037 & 182,857 & 220,210 \\
\hline Depreciacion & & 5,427 & 5,427 & 5,427 & 5,427 & 5,427 \\
\hline FEN=FEL & & 74,240 & 134,524 & 158,464 & 188,284 & 225,637 \\
\hline flujo de Inversión & & & $-90,560$ & $-48,420$ & $-66,046$ & $-90,708$ \\
\hline VP & & & $115,381.13$ & $116,574.70$ & $118,801.60$ & $122,111.19$ \\
\hline VAN & & $\mathbf{4 7 2 , 8 6 8 . 6 2}$ & & & & \\
\hline
\end{tabular}




\section{Elaboración Propia.}

Para poder calcular el VP del Flujo Proyectado con estrategia se utilizará los datos del FEN=FEL entre los años 2018 al 2021 como se aprecia en el cuadro 10.8. Se seguirá utilizando la misma tasa de descuento del $16.59 \%$.

- $\mathrm{VP}=134,524 /(1+16.59 \%)^{\wedge} 1=115,523.55$

- $\mathrm{VP}=158,464 /(1+16.59 \%)^{\wedge} 2=116,574.70$

- $\mathrm{VP}=188,284 /(1+16.59 \%)^{\wedge} 3=118,801.60$

- $\mathrm{VP}=225,637 /(1+16.59 \%)^{\wedge} 4=122,111.19$

Obteniendo como VAN: S/ 177,134.62

En el cuadro 10.13 se puede observar que el TIR para el periodo 2018-2021 sería del $46 \%$.

Cuadro 10.13: TIR con estrategia para el período 2018-2021

\begin{tabular}{|c|c|}
\hline Periodo & Flujo de fondos \\
\hline $\mathbf{0}$ & $\mathbf{- 2 9 5 , 7 3 4}$ \\
\hline 2017 & \\
\hline 2018 & 134,524 \\
\hline 2019 & 158,464 \\
\hline 2020 & 188,284 \\
\hline 2021 & 225,637 \\
\hline
\end{tabular}

\section{\begin{tabular}{l|l} 
TIR & $\mathbf{4 2 \%}$ \\
\hline
\end{tabular}}

Elaboración Propia.

Se puede concluir que la empresa obtendrá una tasa del retorno del $46 \%$ sí que la empresa implementa la estrategia desarrollada en el capítulo IX. La empresa podría llevar a cabo la estrategia con capital propio y con un préstamo financiero.

Por otra parte, el proyecto es viable, porque el TIR es mayor a la tasa de descuento del $16.59 \%$. 


\section{CONCLUSIONES Y RECOMENDACIONES}

A continuación detallamos las conclusiones y recomendaciones a las que llegamos luego de analizar la información proporcionada por la empresa Naranja Producciones S.A.C.. Así mismo, analizar y evaluar bibliografía de apoyo y profundizar nuestro conocimiento con la finalidad de elaborar el Plan General Aplicado para la empresa durante el período 2018 $-2021$.

\section{Conclusiones:}

1. La empresa MD Group "Empresas peruanas destinan $S / 45,000$ en promedio a campañas BTL y que el 53\% de las empresas destina menos de S/ 30,000 en campañas BTL en el Perú.

2. Las empresas consideran importantes la efectividad $\mathrm{O}$ alcance y la originalidad $\mathrm{o}$ creatividad de una campaña BTL. Además, consideran que el BTL está creciendo.

3. La empresa ha crecido rápidamente, pero está totalmente desorganizada.

4. Cada año ingresan nuevas empresas al mercado y necesitan diferenciarse de la competencia, porque el factor precio no es un diferencial.

5. Las empresas mas grandes del sector cuentan con área creativa, lo cual les da un gran diferencial.

6. Habido un incremento de la inversión en las campañas BTL en los últimos años.

7. La red de contactos en el sector tanto público y privado es muy importante. Contar con los nombres y números de las áreas de logística, comunicación y marketing es de gran importancia.

8. Las empresas de BTL de menor tamaño trabajan en asociación para poder atender la demanda.

9. Hay un gran mercado en el sector de pequeñas y medianas empresas para que estas contraten los servicios de las empresas BTL.

10. Los clientes y consumidores tienen cierta capacidad de negociación, debido a que hay un buen numero de empresas de BTL, pero los clientes y consumidores, no cuenta con la capaidad de llevar acabo dichas campañas.

11. Existe una gran cantidad de proveedores para las empresas de BTL, pero son pocas las que cuentan con productos y servicios de calidad.

12. Las empresas de BTL mas importantes del sector están consolidadas y cuentan con prestigio.

13. Se necesita suficiente liquidez y capital para hacer frente alguna campaña de BTL de mediana y gran tamaño. 
14. Personal creativo y calificado es importante para las empresas de BTL, además, de contar con un área creativa.

15. Las empresas de BTL deben de contar con capacidad de cobertura territorial y contar con proveedores en diferentes zonas.

\section{Recomendaciones:}

1. Recomendamos llevar a cabo este Plan Estratégico, porque creemos que la empresa puede incrementar su participación de mercado, su rentabilidad y su posicionamiento.

2. Desarrollar el recurso humano de la empresa, para poder retener al personal mejor calificado para el puesto. Además, de crear una línea de carrera, que motive a los jóvenes profesionales a optar por quedarse a trabajar en Naranja Producciones S.A.C.

3. Dar mayor importancia al área Creativa y promover su crecimiento en forma sostenida durante el período 2018-2021.

4. Designar un tiempo dentro de la recargada agenda de la empresa para implementar procesos internos de elaboración de Manuales de la Organización y Función de los diferentes puestos en las diversas áreas de la empresa.

5. Implementar herramientas de Administración de Cadena de Suministros (SCM) debido al alto uso de proveedores en cada evento (más de 10 por semana en temporada alta).

6. Capacitar al personal en temas relacionados en campañas BTL y eventos.

7. Implementar una base de datos de proveedores de diferentes puntos de Lima Metropolitana para poder tener una mayor cobertura.

8. Implementar nuevos módulos de trabajo para cada uno de los miembros del equipo de Naranja Producciones S.A.C

9. Renovar e incrementar la capacidad instalada de la empresa como son las laptops, computadoras de escritorio, impresoras, los disfraces, los vehículos, la utilería, entre otros, para poder agilizar el trabajo de cada uno de los miembros del equipo.

10. Organizar reuniones mensuales de fortalecimiento del equipo de trabajo, para poder absolver dudas y hablar de las problemáticas que estén surgiendo dentro de la organización.

11. Trabajar bajo contratos notariados cada vez que tengan que asociarse con otra empresa de publicidad BTL a la hora de llevar a cabo una campaña o evento en conjunto, debido a que se manejan grandes sumas de dinero que no tienen ninguna protección legal. 
12. Desarrollar las relaciones comerciales con otras empresas $B T L$, para que la empresa Naranja Producciones S.A.C., pueda incrementar su participación de mercado y su nivel de ventas.

13. Realizar un cronograma para llevar un mejor registro de las cuentas por cobrar para no quedarse sin liquidez en una nueva campaña. 


\section{ANEXO I: Entrevista personal de la empresa.}

Entrevista realizada a los Directivos de la empresa Naranja Producciones S.A.C. el señor Cesar Hugo Jaén Seminario y Sherylin Román Orosco el martes 14 de octubre de 2014.

Naranja Producciones S.A.C. tiene casi dos años. Castillo mágico tiene 7 años aproximadamente. La web de Castillo Mágico está renovada. Como castillo mágico tiene una sección de BTL para empresas. A veces los clientes prefieren apostar por Castillo Mágico más que por Naranja Producciones S.A.C.., por la antigüedad de la marca.

EI MINSA es su cliente estrella. El ministerio de salud manda hacer merchandising y campañas de comunicación.

Todas las empresas solicitan shows infantiles. En la página web de Castillo Mágico cuentan con una sección para atender a las empresas con shows infantiles para diferentes ocasiones como navidad, el día del niño, también cuenta con una sección para las familias que desean contratar el servicio de Castillo Mágico. Por otra parte, muchas veces cuando ofrecen el servicio de castillo mágico a las empresas, también contratan, eventualmente, después, los otros servicios de naranja producciones. Muchas madres que contratan los servicios de Castillo Mágico son personas que trabajan en diferentes empresas y que en muchos casos contactan a la empresa naranja producciones con las áreas de marketing 0 ventas, para que puedan llevar a cabo campañas de BTL. El servicio de Castillo Mágico sirve como un gancho para naranja producciones, porque ingresa a los hogares en donde los padres de familia trabajan en empresas de diferentes rubros.

Cuentan con bases de datos de los eventos para saber por qué no se cierran o cómo se llevan a cabo. El público objetivo de Castillo Mágico es de NSE B y C. Las empresas competidoras en el servicio de shows infantiles son Bubalina, chiquitines y Shows infantiles Garabatos y Shows infantiles Juguetones. Las empresas que contratan los servicios de shows infantiles siempre mencionan estas cuatro empresas. Siendo la más antigua y con mayor experiencia la empresa Bubalina. Las empresas del Estado pueden contratar sin realizar licitaciones hasta 3 UITs que son aproximadamente $S / 11,150$. Cuando una empresa los contratan por el servicio de shows infantiles, también Naranja Producciones S.A.C. les ofrece los servicios de estructuras metálicas, toldos, escenarios, snack, catering. Además, en fiestas navideñas, también la empresa Naranja Producciones S.A.C. ofrece productos como panetones con el eslogan de la empresa. Para desarrollar un 
sentimiento de identidad entre los colaboradores de las empresas con su empleador. Desarrollan endomarketing, o eventos corporativos, eventos con fuerza de ventas o áreas comerciales. Concar, una campaña endomarketing, con un producto llamada pastilla concardina. La empresa Concar contrata a una empresa para realizar la propuesta creativa, pero contrata a Naranja Producciones S.A.C. para llevar a cabo la propuesta. Una empresa puede contratar a varias empresas, por ejemplo a una empresa para desarrollar la parte creativa y otras empresas para llevarla a cabo. Naranja Producciones S.A.C. cuenta con varios clientes freelance. Los contrata en Lima por lo general. Cuentan con bases de datos de modelos y anfitriones. Las empresas pagan los traslados de todo el equipo. Dependerá del presupuesto de la empresa para ver si se contratan los modelos en Lima o en provincia. Por lo general las personas contratadas para el modelaje o anfitriona son gente joven, debido al nivel de actividad. Utilizan Facebook, para buscar gente que deseen trabajar en la empresa. Generalmente las personas de arte, danza, comunicaciones son los que buscan trabajo en Naranja Producciones S.A.C., ven el perfil de cada persona, para cada puesto. Si encuentran a una bailarina, entonces es seleccionada para eventos de danza o baile. Cuando contratan al personal para los eventos, ellos son evaluados en el primer evento para saber si los contrataran en el futuro. Si en algún evento necesitan más personal, la empresa Naranja Producciones S.A.C. trabaja por medio de los referidos, les avisa a los jóvenes que ya están contratados, para que le avisen a amigos, de esta manera delegan la responsabilidad a dicha persona, para que se encargue de traer a su referido a la empresa. Hay eventos han manejado 70 personas y los requerimientos los realizan antes de 2 días. Entonces se necesita contratar personal de manera rápida y eficiente, por tal motivo, sirve el tema de los referidos. Ahora en el tema del volanteo para empresas del estado como ESSALUD, se debe recoger el material, entregar el material al personal, supervisión y producir el evento.

Los requerimientos de los eventos son en el momento, de un día o dos días antes de realizarse. Son pocas las empresas que planifican con anterioridad los eventos. Una fortaleza es que cuentan con el personal y con el material suficiente para llevar los eventos o campañas BTL encargados.

Cuenta con un productor general Leonardo de la Cruz, quien es dueño de la empresa Mangosta Producciones, él es administrador de empresas y cuenta con 12 años en el sector. Con él desarrollaron un tipo de sinergia, debido a que su empresa tiene sus propias cuentas. Ambos se apoyan en diferentes eventos. El señor Leonardo de la Cruz posee cuentas grandes, pero no tienen personal necesario para llevarlos a cabo. En cambio 
Naranja Producciones S.A.C. cuenta con el personal necesario, pero no cuenta con toda la logística necesaria. Es de esta manera que ambas empresas trabajan juntas en varios eventos. Mangosta Producciones cuenta con 4 autos, con algunos mejores proveedores para ciertos giros y con algunos mejores equipos de audio y sonido. En cambio Naranja Producciones S.A.C. tiene el personal necesario, los proveedores necesarios para otros giros y cuenta con dos carros.

Para cada puesto se evalúa el perfil de la persona. Como trabajan con jóvenes que tienen experiencia en el sector, no existe problema para contratar gente. No pueden contratar a un ingeniero, para algún evento en vivo, pero si lo pueden contratar para el tema de producción. Cuenta con un asistente de Marketing llamado Jorge Seminario.

Todos hacen de todo en la empresa, como lavar los trajes. Hacen informes de los eventos, registros fotográficos y escrito en empresa privada y pública.

Están en régimen especial, llevan dos libro el compras y de ventas. Marco Sotelo, es quien ve el tema web.

César Jaén se encarga de las finanzas y de las cuentas. Shery, de los eventos, producción y cuentas de Facebook, youtube y twiter. En Castillo Mágico les sirve mucho el tema del facebook, en cambio en el tema del BTL de Naranja Producciones, les funciona más el enviar su carta de presentación a las empresas con los servicios brindados y el poder gestionar una cita. En el tema del servicio de Castillo Mágico, son buscados, están saturados y se encuentran posicionados. Cuenta con 20 eventos. En cambio con Naranja Producciones S.A.C. y los eventos BTL trabajan más para captar clientes.

Han incrementado los precios, pero poco. Miden el crecimiento de la empresa con el staff, con el número de clientes que se ha ido incrementado y el número de proveedores.

Los meses de mayor demanda:

De julio a diciembre va creciendo la demanda. En diciembre se vende más que todos los meses. El tema de show infantiles baja en verano. Dan más fuerza al tema de BTL a Naranja Producciones.

El rubro de BTL y entretenimiento tiene para crecer. Empezaron con los show infantiles y después con el tema de BTL, luego brindaron el servicio de decoración, el de snack y 
confitería. Poco a poco se abren los rubros. Cuando la empresa brinda un servicio, van surgiendo más requerimiento de los clientes. El minuto en radio y televisión es cara, el presupuesto de las empresas de marketing están destinando más dinero o presupuesto para realizar BTL en el Perú.

Los directivos no conocen de memoria la misión y visión de la empresa. Consideran que el tema del BTL tiene mucho crecimiento.

Fortalezas de Naranja Producciones S.A.C.:

BTL es más artístico como fidelización de clientes con los clown que lo han aprendido de Castillo Mágico. Cuenta con mano de obra muy barata. Son económicos, tienen un buen staff de proveedores, poseen experiencia y muchos clientes de Castillo Mágico, ahora son de Naranja Producciones S.A.C.. Muchos clientes de Castillo Mágico tienen empresas y los contratan como Naranja Producciones S.A.C. en temas BTL.

Debilidades de Naranja Producciones S.A.C.:

No cuentan con una caja muy amplia para realizar eventos. Los proveedores pueden esperar la cancelación de sus recibos cuando la empresa que los contrata son grandes como Chirimoya BTL, pero Naranja Producciones S.A.C. al ser una empresa en crecimiento, no cuenta con esa venta de pago.

Aspiran a clientes grandes de empresas privadas como Backus, Alicorp o empresas transnacionales de consumo masivo.

La empresa cuenta con merchandising para regalarles a sus clientes con los datos de Naranja Producciones S.A.C..

No solo hacen BTL, sino también, campañas de comunicación internas como externas.

Para crear el nombre de la empresa porque naranja significa alegría, juvenil, refrescante, energía, El eslogan es "Le Sacamos el jugo a tus ideas".

Consideran el nombre de Naranja Producciones S.A.C., para no marcar solo el servicio de BTL, porque también hacen campañas de endomarketing, de producción de eventos de lanzamiento de productos. 
En las empresas privadas, el tema creativo y de calidad; Chirimoya BTL los vence en el tema de creatividad, visual, de diseño y el tema de capacidad de invertir en cada evento. También la empresa Rocoto BTL es una de las grandes del sector.

Sus clientes son las personas del área de comunicaciones, los gerentes de marketing, la gente de rrhh y el área comercial.

\section{Oportunidades de mercado de Naranja Producciones S.A.C..}

Muchos Gobiernos Municipales que no han sido reelegidos tienen el dinero presupuestado. El Estado tienen dinero y no saben en qué gastar, y buscan realizar campañas. Esto sucede mucho en el sector del Estado. Las empresas del Estado buscan realizar eventos en noviembre y diciembre. Durante el mes de octubre les llegó 10 correos por parte de instituciones públicas para realizar eventos. Cuando no pueden facturar como Naranja Producciones S.A.C., facturan como Mangosta Producciones S.A.C., la cual es la empresa de su socio. De igual manera cuando Mangosta Producciones S.A.C. no puede facturar, lo hace con el nombre de Naranja Producciones S.A.C.. Esto sucede por un tema de auditoría que pueda surgir por parte del Estado Peruano.

Hay nuevas empresas que están creciendo, empresas de emprendedores, que no cuentan con el capital suficiente para invertir en ATL, así que invierten en BTL.

En provincia también hay eventos y la competencia es provincia es mucho menor. Se necesita contratar proveedores en provincia para bajar costos. Muchas activaciones se realizan en cusco, Arequipa, Trujillo, Piura y Chiclayo. El norte del país es el que tiene mayor demanda después de Lima. Las ciudades con mayor demanda son: Trujillo, Chiclayo y Piura. Luego Arequipa y cusco. A veces en Huancayo. En Puerto Maldonado no hay casi eventos. Los centros comerciales hacen varios eventos. Para ellos cada emporio comercial o centro comercial es una gran oportunidad. La economía está creciendo y existe liquidez. El pago a proveedores y el cobro a los clientes se realiza en soles. El dólar casi no se emplea en las transacciones comerciales. Antes se pagaba a los modelos anfitriones en dólares. Ahora se paga en soles. Actualmente se paga como 20 dólares por hora a los modelos y anfitriones. 


\section{Amenazas para Naranja Producciones S.A.C.:}

Empresas con mejor estructura financieras que ofrecen cobrar sus cuentas a 90 días. Que tú mismo personal se puede llevar tu Know How. Que otras empresas se roben las ideas y los servicios de Naranja Producciones S.A.C..

No cuentan con manuales de funciones. Tienen pensado realizar un manual para las funciones cuando se realicen los eventos. Todas las funciones hasta el momento son verbales. Como las funciones no están estipuladas, las personas no saben exactamente lo que deben de realizar durante la realización y producciones de los eventos y campañas BTL.

Las empresas del Estado utilizan los términos de referencias de servicios o de compras. En servicios de animación de teatro, de compras de merchandising o de productos. Las empresas se cotizan bajo el brif, en donde están los requerimientos de la campaña.

Hay empresas de BTL que terciarizan. Es decir que delegan toda la producción a otra empresa BTL. Muchas empresas BTL brindan servicios de BTL a otras empresas BTL más grandes. Yelow BTL casi no hace producción, no realizan producción. Ante los clientes ellos hacen la producción, pero en realidad no lo hacen. AKM BTL sí realiza toda la logística, es decir, realizan la creación y también la producción.

Por qué los contratarían: Son una empresa fresca, con experiencia, costo bajo en comparación a otra empresa que ofrece lo mismo que Naranja Producciones S.A.C..

Antes de cerrar el contrato con el proveedor, buscan referencias del mismo dentro del sector. Le hacen la consulta a otras empresas BTL o de eventos para saber si es un proveedor serio y cumple con los tiempos y requerimientos solicitados.

Los servicios más solicitados: Castillo Mágico con los shows infantiles, alquiler de carritos snack, hora loca, los baby showers. Endomarketing, BTL, alquiler de equipo de sonido, eventos corporativos, publicidad en branding.

Un servicio sustituto para Naranja Producciones S.A.C. es la empresa Arrow, que ha traído a Lima un nuevo servicio para hacer BTL, el cual consiste en poner anfitriones quienes juegan con unas flechas grandes para hacer malabares y señalar la dirección del establecimiento comercial. 
Se imaginan a Castillo Mágico en particular, con una renovación de trabajos. Cambio total de los shows, tener un formato al estilo Disney. Ejemplo la empresa Farah y su fábrica de ilusiones que traen todo el formato desde EEUU., cuenta con un gran despliegue de escenarios, con trajes muy novedosos y con los mejores equipos de sonido. Quieren dar un excelente servicio a un precio accesible. Ellos desean seguir en el NSE BC.

Desean crecer en el sector BTL, y tener una casa productora. En donde puedan segmentar los servicios. Contar son una zona de ensayo, un lugar para guardar los equipos, los trajes, tener oficinas separadas y un área creativa especializada.

No pueden conseguir más cuentas, porque no tienen tanta capacidad para atender a todos sus clientes. Actualmente aún siguen ahorrando para hacer más caja. No solicitan préstamos a entidades financieras. Consideran que han triplicado las ventas en comparación del año 2013.No están creciendo de manera muy estructurada, pero aun así están creciendo.

Los directivos consideran que Naranja Producciones S.A.C. tiene un trato directo con el cliente y esto les ayuda a canalizar de manera más rápida y eficiente sus necesidades. 


\section{ANEXO II: Entrevistas clientes y no clientes}

\section{EMPRESA CLIENTE "ESSALUD”}

Contacto el señor Michael Tong- Área de comunicaciones de ESSALUD.

El ministerio de salud contrata los servicios de Naranja Producciones S.A.C., para poder realizar campañas de comunicación de prevención de enfermedades. Como ESSALUD vela por la salud de los peruanos, las campañas que se realizan buscan informar a las personas que van a la red de hospitales las consecuencias de algunas enfermedades, los síntomas y como se puede prevenir el contagio.

El señor Michael Tong puede realizar la convocatoria para realizar una campaña de BTL por vía licitación o por la contratación de menor cuantía, esto sucede cuando las campañas no sobrepasan las 3 UITs que son aproximadamente S/ 11,150.

El señor Michael Tong por lo general realiza campañas que no sobrepasen las 3 UITs, para no realizar una licitación, la cual tomaría demasiado tiempo. Por tal motivo, para realizar la selección de una empresa de BTL, él convoca a 3 empresas con las cuales haya trabajado anteriormente. Muchas de estas empresas trabajaron con otros comunicadores de ESSALUD. Como Naranja Producciones S.A.C., cuenta con tiempo trabajando para diferentes áreas de ESSALUD, existe una confianza y una experiencia previa con la cual cuentan a la hora de realizar la selección.

Las empresas que más renombre tiene en el sector son: Yellow Btl, Moving Pack Eirl, AKM Warketing, SIVAL y Glenda Yaker Eventos Especiales.

Los beneficios que buscan son el poder comunicar oportunamente la información que ESSALUD desea hacer llegar a la población peruana, por medio de campañas de comunicación intensiva.

El señor Tong considera que las campañas BTL se incrementaran en los próximos años, porque es una manera más barata y directa de poder llegar a los usuarios de la red de salud del país. 


\section{EMPRESA CLIENTE “CLUB LA RINCONADA”}

\section{Contacto: El señor Piero Gambini}

El club Rinconada se dedica al rubro del entretenimiento y recreación campestre. En sus instalaciones las familias asociadas pueden realizar diferentes actividades sociales y deportivas. La empresa contrata los servicios de Naranja Producciones S.A.C.., para realizar eventos y campañas de BTL durante diferentes épocas del año.

Los eventos y campañas son en promedio el monto de $S / 8,000$. Se realizan activaciones y anfitrionaje para diferentes tipos de eventos. El club realiza eventos en promedio 1 vez cada dos meses. Para llevar a cabo estas campañas la empresa solicita la cotización de 3 ó 4 empresas, las cuales en algunos casos les enviaron su carta de presentación anteriormente.

Los beneficios que el club busca son la buena atención y comunicación hacia los socios del club. Las empresas que el señor Gambini ha escuchado anteriormente son Yellow Btl, Circus, Glenda Yaker Eventos Especiales y Naranja Producciones S.A.C.. 


\section{EMPRESA CLIENTE “ ROHO PRODUCCIONES S.A.C.” \\ Contacto: Bertarelli Bustamante Carla Patricia}

La empresa Roho Producciones S.A.C, se dedica al rubro de publicidad y eventos, pero a diferencia de Naranja Producciones S.A.C., La empresa en mención es más grande, cuenta con una cartera de clientes de mayor envergadura y no necesita de realizar alianzas con otras empresas de publicidad para poder llevar a cabo sus campañas de publicidad.

El papel que cumple Naranja Producciones S.A.C., es de proveedor de servicio logístico para la empresa Roho Producciones S.A.C., es decir, que la empresa terciariza la implementación de las campañas a otras empresas, en este caso a la empresa Naranja Producciones S.A.C.

Las empresas de publicidad y eventos de mayor tamaño, se dedican al desarrollo creativo de la campaña, pero terciarizan la implementación a otras empresas más pequeñas. Es en estas circunstancias es que la empresa Naranja Producciones S.A.C., ofrece sus servicios a esta empresa.

Durante la realización de la entrevista se puede resaltar, que la empresa Roho S.A.C., contrata los servicios de Naranja Producciones S.A.C., por su capacidad de acción para poder llevar a cabo las campañas y eventos asignados, por su versatilidad a la hora de solucionar los problemas que se presenten durante la realización de los eventos. Además, cuentas con equipos, atuendos, disfraces, personal para realizar las diferentes campañas que se les ofrece.

Por otra parte, los Ejecutivos de Cuentas, solicitan la opinión de Naranja Producciones S.A.C., antes de llevar a cabo la campaña, para saber si se puede mejorar la oferta a los clientes. 


\section{EMPRESA CLIENTE "Mangosta Comunicaciones S.A.C."}

Contacto: Leonardo de La Cruz.

La empresa Mangosta Comunicaciones S.A.C., terciariza algunos servicios a la empresa Naranja Producciones S.A.C.. Algunas veces ambas empresas trabajan como socias, pero en otras ocasiones, la empresa Mangosta Comunicaciones S.A.C., subcontrata a la empresa Naranja Producciones S.A.C., porque ellos cuentan con un mejor equipo audiovisual y con mejores herramientas para llevar acabo el trabajo logístico.

Por lo general, la empresa Magosta Comunicaciones S.A.C., se dedica al desarrollo creativo de las campañas, por tal motivo, cuenta con un área creativa para la elaboración de sus campañas, pero no cuenta con el alcance logístico como Naranja Producciones S.A.C.

En la entrevista se resalta que lo más importante para ellos a la hora de contratar los servicios de Naranja Producciones S.A.C., es la puntualidad y el profesionalismo que la empresa tiene a la hora de llevar acabo las campañas.

La empresa Mangosta Comunicaciones S.A.C., cuenta con clientes como DirecTV y, por tal motivo, es de gran importancia que sus clientes sean atendidos con la mayor prontitud y con la mejor disponibilidad. 


\section{EMPRESA CLIENTE "Campos Abogados e Infraestructura” Contacto: Renzo Seminario Cordova.}

Al ser un estudio de abogados especializado en temas inmobiliarios, la empresa se dedica en realizar conferencias con diferentes empresas del sector. Para esto, Campos Abogados e Infraestructura, contrata los servicios de Naranja Producciones S.A.C., para la contratación de anfitrionas, equipos, coffee break, merchandising, estructuras metálicas, y todos los implementos necesarios para llevar a cabo una conferencia.

Por lo general, el estudio de abogados, envía un correo a sus proveedores para solicitar cotizaciones para determinados eventos, y dependiendo de las propuestas que envían las empresas como Naranja Producciones S.A.C. se toma una decisión.

Se cobra una penalidad del $10 \%$ por demoras en el servicio solicitado, el cual está estipulado en el contrato firmado por las partes. 
NO CLIENTE EMPRESA “EVERANDES S.A.C.”

Contacto la señorita Yessica Delgado, trabaja como Jefa de Gestión de Talentos hace 5 años.

Utiliza empresa de BTL, para dar un estilo diferente de lo que hace durante el año. Sus eventos principales son en setiembre y diciembre, como cierre de año corporativo.

La búsqueda de las empresas son 3 meses antes como máximo 5 empresas. Se tiene como referente la selección: conocidos de los gerentes, colegas o web.

Los proveedores no dan un resumen final, sino esperan a una próxima reunión para preguntar como quedo uno satisfecho sobre el evento.

El beneficio buscado es: optimizar tiempos, ubicar en primer plano sin distractores y respetar el presupuesto. Empresas que conoce son los siguientes: Draming Up, Mediaticae Innova. 


\section{EMPRESA NO CLIENTE “AGROIMEX TRADING”: \\ Contacto la señorita Suley Lincham}

Trabaja en la empresa como Asistente de Gerencia General en el rubro de agro exportación.

Los eventos que asisten son cada 5 meses, principalmente para el calendario agrario de la uva de mesa, palta pre y post cosecha.

Busca empresas BTL, porque es un sector que ayuda a llegar a los clientes, pues van gerentes, jefes y su personal de confianza; y necesitan materiales didácticos para un buen entendimiento de sus productos.

Son buenas las empresas BTL a la medida de la creatividad.

Consideran como máximo 3 empresas para una selección antes de 3 meses del evento. La mayoría de empresas los conoce por web, carteles audiovisuales o referentes en el mundo agroindustrial.

Busca empresas que se encuentre en lima y puedan ir también a los eventos de provincia. Entre Las empresas que conoce son: Studio Manda, Soluciones S.A.C..

El presupuesto es para los 3 eventos principales: Expoalimentaria, Siuva, ADEX. 


\section{EMPRESA NO CLIENTE “UNIVERSIDAD PERUANA DE CIENCIAS APLICADAS - UPC" \\ Contacto Pamela Sanchez, asistente de Marketing.}

En la entrevista realizada a la señorita del área de Marketing de la UPC, nos comentó que el BTL les ayuda a interactuar más con los futuros clientes. Además, que a la hora de escoger un proveedor, ellos ven la cartera de clientes de los proveedores, para observar su experiencia pasada y la calidad de sus servicios. Además, se solicita referencias para saber la puntualidad, el compromiso y la creatividad en las campañas que hayan realizado en el pasado. Por lo general trabajan con tres empresas de BTL para la elaboración de sus campañas.

Para poder llevar a cabo las campañas, la UPC le plantea a la empresa BTL lo que desean conseguir con la campaña y es el proveedor del servicio quien elabora e implementa la campaña en su totalidad.

El fin de estas campañas es mejorar la comunicación que tiene la universidad UPC con sus actuales y futuros alumnos. 


\section{EMPRESA NO CLIENTE "Laberinto BTL" \\ Contacto Jimmy Jaén Seminario, Gerente General}

La empresa Laberinto BTL es una empresa dedicada al rubro de la publicidad BTL como lo indica su nombre, su principal cliente es UBER Perú, por lo cual esta empresa se dedica a realizar varias campañas durante el año.

Según lo conversado con el Gerente de la empresa, Jimmy Jaén Seminario las campañas BTL se han incrementado en un $20 \%$ durante los últimos 2 años. En el caso de su cliente UBER, la publicidad la realiza todos los meses, para poder captar nuevos asociados que hagan el servicio de taxi y a la vez captar nuevos usuarios del servicio.

La empresa UBER hace toda su comunicación por redes sociales o por medio de campañas BTL, no usando medios masivos como radio, televisión o diarios.

Uno de los principales problemas de las empresas del sector como lo indica el Gerente de Laberinto BTL es el tema de la financiación, debido a que muchas empresas no cuentan con historial crediticio y las tasas que brindas las empresas financieras del sector son muy altas, por tal motivo, buscan otro tipo de financiación como es la asociación con otras empresas o el prestarse dinero fuera del sector financiero. 


\section{EMPRESA NO CLIENTE "Sinapsis Productores S.A.C" \\ Contacto Renato Sarmiento, Productor}

La empresa cuenta con clientes como Cencosud y Repsol. Trabajan desde el 2012 y se dedican al desarrollo de campañas BTL.

Según lo conversado con el productor Renato Sarmiento, este sector es bien competitivo, porque existen varias empresas de todos los tamaños; además los clientes que contratan sus servicios son por lo general de consumo masivo, educación, etc. Actualmente la empresa Sinapsis Productores S.A.C. ha sido comprada por otra empresa más grande; debido a que ya no cuentan con liquidez para hacer frente a los pagos y para poder llevar a cabo campañas BTL de mayor envergadura.

Lo que no cabe duda, es que el sector ha crecido en los últimos años, pero como lo indica el productor, el sector es muy informal hasta hoy en día; por ejemplo, desde la contratación de los trabajadores, la financiación, calendarios de labores y la asociación con otras empresas del sector. 


\section{ANEXO III: Focus Group}

El focus group se realizó con 6 empleados de la empresa. Cada uno de las personas que participaron ha estudiado alguna carrera o están estudiando actualmente. Considera que las fortalezas de la empresa porque es innovadora, existe confianza entre los trabajadores, existe un trato horizontal, se delega responsabilidades. La empresa tiene un talento humano cohesionado, unido, responsable cuando se ha delegado la supervisión de los eventos y campañas BTL. Se delega las responsabilidades según las habilidades de las personas, tienen experiencia en el rubro, tiene una buena capacidad instalada. Se capacita a cada uno de los trabajadores en todo, para que se apoyen. Todos se apoyan y colaboran entre sí. La empresa cuenta con una estructura de costos adecuada, que le permite ofrecer precios bajos a los clientes. Cuentan con rapidez para poder atender a los clientes. Además, tienen un amplio staff de colaboradores para eventos y un grupo de proveedores amplia. Por último, existe una atención personalizada. A los clientes se les entrega un registro de los eventos y campañas gratis, para que vean como se realizó el evento.

Debilidades no cuenta con muchos clientes todavía, pero son clientes claves, están saturados, están desorganizados, no cuentan con capital suficiente, para atender campañas de $S / 100,000$. No pueden atender a clientes que pagan a 60 días. A veces tiene 6 eventos al día lo que hace que muchas veces lleguen tarde a los eventos, lo cual conlleva a que se realicen descuentos. No cuenta con área creativa, no tiene a una persona que se dedica al diseño y edición.

Las oportunidades del mercado son: que atienden a clientes de todos los distritos, las familias y las empresas están invirtiendo más en eventos y campañas BTL, el BTL es más barato para las empresas y cuantificable a corto plazo, las empresas medianas y micro están realizando activaciones BTL. Las amenazas en el entorno son: que existen empresas de BTL más grandes. Las empresas grandes cuentan con 6 personas creativas. Las empresas más grandes cuentan con una mayor capacidad instalada. 


\section{Opiniones de Expertos en el Sector:}

\section{Empresa: Tresenraya BTL}

\section{Contacto: Sergio Montes - Asistente Producción}

La empresa cuenta con clientes como Inkafarma, Papas Lays y Remax. Según lo conversado con Sergio Montes, el sector ha crecido desde su punto de vista un $40 \%$. No maneja datos, pero supone que este sector ha estado creciendo años tras año.

Por otra parte, opina que el sector cuenta con varias empresas de BTL que surgen todos los años, pero que también muchas de estas empresas cierran por no contar con liquidez o con una cartera de clientes que les permita subsistir.

Además, nos indica que muchas veces subcontratan a otras empresas BTL para poder atender a sus clientes, debido a que ellos se dedican a desarrollar la idea creativa y que en muchas ocasiones no cuentan con la capacitad de producción necesaria para llevar a cabo varios eventos al mismo tiempo.

\section{Empresa: Tresenraya BTL}

\section{Contacto: Kevin Chiong - Asistente Producción}

Siendo la mano derecha de Sergio Montes, ve día a día lo que pasa con los clientes, por tal motivo, nos explica que en la actualidad hay demanda por parte de las empresas para realizar campañas BTL, pero por otra parte nos dice que las empresas de publicidad BTL no cuenta con el suficiente capital para poder realizar la producción de dichas campañas. Además, el ingreso de nuevas empresas al sector, incrementa la competencia. Muchas veces estas nuevas empresas ofrecen precios menores en comparación a las empresas ya establecidas en el mercado. Un ejemplo claro es lo que sucede con las instituciones públicas, que muchas veces contratan al proveedor que ofrece el menor precio, aunque este brinde un servicio de menor calidad.

Por otra parte, nos indican que el crecimiento del sector si es notorio, pero que no cuentan con cifras oficiales, debido a que no existe información disponible en las revistas o páginas web del sector. 


\section{Empresa: Energigas}

\section{Contacto: Sandra Milla Sandonas - Analista de Bienestar}

La señorita Sandra Milla nos dice que siempre contratan a empresas BTL para realizar eventos, campañas de activación, talleres, comunicación interna, full days, entre otras actividades.

Al terciarizar estas actividades, la empresa se puede enfocar en otros temas, mientras que dejan a los expertos desarrollar los esquemas de trabajo para las diferentes campañas de comunicación que necesita la organización.

Además, nos dice que cada año incrementan el presupuesto de estas actividades, porque ven resultados inmediatos, por otra parte, el costo es menor que invertir en grandes campañas de publicidad.

\section{Empresa: CreativoEPM}

\section{Contacto: Segio Perez Reyez - Asistente Producción}

Sergio Pérez, no comenta que el mundo de BTL ha crecido abruptamente, pues ahora muchos clientes buscan innovar en merchandising, publicidad, nuevos puntos de ventas creativos y productos que sean útiles para el consumidor final; ya que al ver esta nueva necesidad, el cliente es más exigente que en años anteriores. Por tal motivo, las empresas apuestan por el BTL, porque es una herramienta que puede hacer que las empresas lleguen más rápido al consumidor final.

Por otra parte, la demanda a veces es tan grande, que tercerizan varios procesos de producción de un evento a otra empresa BTL más pequeña, que los apoye con el desarrollo de la campaña. De esta manera pueden atender a un mayor número de clientes al mismo tiempo.

Ellos consideran que el sector va seguir creciendo en los próximos años, sí que la coyuntura política lo permite. 


\section{Empresa: Financiera Solución}

Contacto: Giovana Lozada - Gerenta de Marketing.

La Gerente nos cuenta que la empresa está invirtiendo un 35\% en actividades como es el BTL, para poder hacer llegar los beneficios de los productos financieros que ofrece la empresa. Dichas campañas se hacen por lo general en las agencias de la Financiera Solución, en donde se hace participar a los clientes y no clientes en actividades para que conozcan cada uno de los servicios.

El crecimiento ha sido lento, porque siempre han apostado por la comunicación en radios y periódicos para poder llegar a su público objetivo.

Esperan ir incrementando la partida presupuestaría de las campañas BTL cada año, pero eso dependerá de los resultados obtenidos de las campañas. 


\section{ANEXO IV: Cuestionario del Focus Group}

\section{Objetivo del Focus Group.-}

Se utilizará una dinámica que consistirá en una entrevista grupal a los trabajadores de la empresa Naranja Producciones S.A.C., para analizar su opinión y apreciación crítica sobre las campañas y eventos BTL. Mediante esta dinámica grupal se preguntará a los entrevistados que entienden por campaña de BTL y cuál es su razón de contratar una campaña de BTL, frecuencia, gustos, mejoras, entre otros.

\section{Contenidos temáticos.-}

- Conocimiento de la cultura organizacional de la empresa por parte de los colaboradores y directivos de Naranja Producciones S.A.C. (misión, visión y valores).

- Saber la ventaja diferencial de la empresa Naranja Producciones S.A.C.

- El crecimiento del mercado BTL en el mercado nacional.

- Averiguar la competencia de la empresa Naranja Producciones.

- Como se desarrollar la producción de las campañas BTL.

- Saber las fortalezas, oportunidades, debilidades y amenazas que posee la empresa Naranja Producciones S.A.C..

- Saber el nombre de las empresas que contratan los no clientes de Naranja Producciones y el motivo por el cual son contratadas.

- Averiguar el nivel de demanda de las campañas BTL durante el año.

- Saber cuáles son los servicios más demandados a la empresa Naranja Producciones.

\section{Perfil del participante.-}

ASISTENTES (NOMBRES, APELLIDOS):

CARGO:

NOMBRE DE LA EMPRESA:

DURACION:

\section{ANÁLISIS INTERNO}

Presentación:

Buenos días,

Somos alumnos de la ESCUELA DE POSTGRADO UNIVERSIDAD SAN IGNACIO DE LOYOLA que están llevando a cabo su tesis de grado, la cual es un Plan Estratégico sobre la empresa Naranja Producciones. 
Esperamos que nos brinde su sincera opinión en los siguientes puntos a tratar. No hay respuesta mala, las preguntas son abiertas, y sólo buscan saber su punto de vista, en diferentes temas.

Preguntas para el Focus Group para los miembros de Naranja Producciones S.A.C.

1. ¿Dónde han trabajado anteriormente?

2. ¿Qué experiencia tienen trabajando en el rubro?

3. Cuáles son las fortalezas que tiene la empresa Naranja Producciones S.A.C.?

4. ¿Cuáles son las debilidades que tiene la empresa Naranja Producciones S.A.C.?

5. ¿Cuáles son las oportunidades que tiene la empresa Naranja Producciones S.A.C.?

6. ¿Cuáles son las amenazas que tiene la empresa Naranja Producciones S.A.C.?

7. ¿Cómo ven la empresa dentro de 5 años?

8. ¿Cómo se ven ustedes en la empresa dentro de 5 años?

9. ¿Considera que la empresa tiene la posibilidad de crecer?

\section{Check List:}

1. ¿Usted Considera que el sector de la publicidad (BTL) está creciendo?

2. ¿Qué empresas considera que son las más importantes del sector?

3. ¿Cuál es la ventaja diferencial de cada uno de las empresas más importantes del sector?

4. ¿Cuál es la ventaja diferencial que tiene Naranja Producciones S.A.C. con relación a la competencia?

5. ¿Por qué los clientes deberían escoger Naranja Producciones S.A.C.?

6. ¿Cuáles son los servicios sustitutos que tiene el mercado?

7. ¿Por qué decidió trabajar en Naranja Producciones S.A.C.?

8. ¿Usted conoce la visión y misión de empresa?

9. ¿Cuáles son los valores de la empresa Naranja Producciones S.A.C.?

10. ¿Usted tiene conocimiento de sus funciones dentro de la empresa?

11. ¿Nos podría explicar cuáles son tus funciones dentro de Naranja Producciones S.A.C.?

12. ¿Usted Considera que las otras personas del equipo lo apoyan en su trabajo?

13. ¿Con qué área interactúa más antes de desarrollar un evento?

14. ¿Qué mejoras crees que se podrían llevar a cabo en tú área?

15. ¿Nos explicarías como es el proceso desde el inicio del proyecto hasta la culminación del mismo? 
16. ¿Qué mejoras propones para el desarrollo de un proyecto integral, incluyendo todas las áreas?

17. ¿Qué procesos ha identificado dentro de la empresa que se deberían de mejorar?

18. ¿Qué mejoras propondrías para los procesos identificados que no están funcionando correctamente?

19. Cuáles son las fortalezas que tiene la empresa Naranja Producciones S.A.C.?

20. ¿Cuáles son las debilidades que tiene la empresa Naranja Producciones S.A.C.?

21. ¿Cuáles son las oportunidades que tiene la empresa Naranja Producciones S.A.C.?

22. ¿Cuáles son las amenazas que tiene la empresa Naranja Producciones S.A.C.?

23. ¿Cómo ven la empresa dentro de 5 años?

24. ¿Cómo se ven ustedes en la empresa dentro de 5 años?

25. ¿Considera que la empresa tiene la posibilidad de crecer? 


\section{ANEXO V: CUESTIONARIO: Entrevista a Profundidad}

\section{Objetivo de la Entrevista a Profundidad.-}

Se utilizará una dinámica que consistirá en una entrevista personal al segmento objetivo seleccionado, para analizar su opinión y apreciación crítica sobre las campañas y eventos BTL. Mediante esta entrevista se preguntará a los entrevistados que entienden por campaña de BTL y cuál es su razón de contratar una campaña de BTL, frecuencia, gustos, mejoras, entre otros.

\section{Contenidos temáticos.-}

- Saber cuáles son los criterios de selección por parte de las empresas que contratan los servicios de BTL.

- Saber porque las empresas emplean servicios de BTL.

- Averiguar cuál es el proceso de selección de un proveedor de servicios de BTL.

- Averiguar por cuales medios de comunicación las empresas se enteraron de Naranja Producciones.

- Saber cuáles son los beneficios esperados por las empresas que emplean el BTL.

- Saber cuál es el porcentaje del presupuesto que se destina a las campañas BTL y si en el futuro se va incrementar o disminuir este presupuesto.

- Averiguar que proveedores de servicios de campañas BTL ha contratado en el pasado las empresas y si obtuvieron los beneficios esperados.

- Saber cuántas veces al año las empresas contratan los servicios del BTL y las expectativas futuras que tiene sobre esta herramienta en el mercado nacional.

\section{Entrevista a clientes ( 5 clientes)}

ASISTENTES (NOMBRES, APELLIDOS):

CARGO:

NOMBRE DE LA EMPRESA:

DURACION:

Perfil:

Gerentes o jefes del área de Marketing que se dedican a la contratación del servicio de BTL. 


\section{ANÁLISIS EXTERNO}

\section{Presentación:}

Buenos días,

Somos alumnos de la ESCUELA DE POSTGRADO DE LA Universidad San Ignacio de Loyola que están llevando a cabo su tesis de grado, la cual es un Plan Estratégico sobre la empresa Naranja Producciones.

Esperamos que nos brinde su sincera opinión en los siguientes puntos a tratar. No hay respuesta mala, las preguntas son abiertas, y sólo buscan saber su punto de vista, en diferentes temas.

\section{Preguntas:}

1. ¿Por qué buscó servicios de BTL?

2. ¿Usted podría mencionarnos cuáles son los criterios de selección para contratar una empresa BTL?

3. ¿Cuántas empresas considera como máximo para realizar una comparación de servicios para un próximo evento?

4. ¿Durante el año contrata una sola empresa de BTL para realizar todas sus campañas o contrata a diferentes empresas según el tipo de campaña que va realizar?

5. ¿Cuáles son los medios de comunicación que usted utiliza para comunicarse y enterarse de las empresas BTL?

6. ¿Cuáles son los beneficios que usted espera cuándo realiza una campaña BTL?

7. ¿Cómo usted se contactó con Naranja Producciones?

8. ¿Por qué escogió Naranja Producciones?

9. ¿Estuvo satisfecho con el servicio brindado por Naranja Producciones?

10. ¿Usted Logró los beneficios esperados al realizar campañas BTL?

11. ¿Cuál es el presupuesto del año 2014 para las campañas BTL?

12. ¿Ud. Considera aumentar el presupuesto asignado a campañas BTL en el próximo año?

13. ¿Cuántas veces al año contrata estos servicios y en qué temporadas?

14. ¿Qué empresas dedicadas al servicio de BTL conoce actualmente y con cuales ha trabajado en algún momento?

15. ¿Estuvo satisfecho con el servicio brindado por las empresas BTL que ha contrato hasta el momento?

16. ¿Qué expectativas futuras usted tiene sobre el BTL en el mercado nacional?

17. ¿Ud. Recomendaría a Naranja Producciones? 


\section{ANEXO VI: CUESTIONARIO: Entrevista a Profundidad para futuros clientes.}

\section{Objetivo de la Entrevista a Profundidad.-}

Se utilizara una dinámica que consistirá en una entrevista personal al segmento objetivo seleccionado, para analizar su opinión y apreciación crítica sobre las campañas y eventos BTL. Mediante esta entrevista se preguntara a los entrevistados que entienden por campaña de BTL y cuál es su razón de contratar una campaña de BTL, frecuencia, gustos, mejoras, entre otros.

\section{Contenidos temáticos.-}

- Saber cuáles son los criterios de selección por parte de las empresas que contratan los servicios de BTL.

- Saber porque las empresas emplean servicios de BTL.

- Averiguar cuál es el proceso de selección de un proveedor de servicios de BTL.

- Averiguar por cuales medios de comunicación las empresas se enteraron de los servicios de BTL de sus proveedores actuales o pasados.

- Saber el nombre de los proveedores de campañas BTL que emplean o emplearon las empresas.

- Averiguar si las empresas están o no satisfechas con el servicio prestado por los proveedores de campañas BTL.

- Averiguar el nivel de rotación de los proveedores de campañas BTL.

- Saber cuáles son los beneficios esperados por las empresas que emplean el BTL.

- Saber cuál es el porcentaje del presupuesto que se destina a las campañas BTL y si en el futuro se va incrementar o disminuir este presupuesto.

- Averiguar que proveedores de servicios de campañas BTL ha contratado en el pasado las empresas y si obtuvieron los beneficios esperados.

- Entrevista a futuros clientes:

ASISTENTES (NOMBRES, APELLIDOS):

CARGO:

NOMBRE DE LA EMPRESA:

DURACION:

Perfil:

Gerentes o jefes del área de Marketing que se dedican a la contratación del servicio de BTL. 


\section{Presentación:}

Buenos días,

Somos alumnos de la ESCUELA DE POSTGRADO DE LA Universidad San Ignacio de Loyola que están llevando a cabo su tesis de grado, la cual es un Plan Estratégico sobre la empresa Naranja Producciones.

Esperamos que nos brinde su sincera opinión en los siguientes puntos a tratar. No hay respuesta mala, las preguntas son abiertas, y solo buscan saber su punto de vista, en diferentes temas.

\section{Preguntas:}

1. ¿Por qué buscó servicios de BTL?

2. ¿Qué opinión tiene sobre las campañas BTL?

3. ¿Usted podría mencionarnos cuáles son los criterios de selección para contratar una empresa BTL?

4. ¿Cuáles son los criterios para invitar a una empresa de BTL a un proceso de selección?

5. ¿Cuántas empresas considera como máximo para realizar una comparación de servicios para un próximo evento?

6. ¿Durante el año contrata una sola empresa de BTL para realizar todas sus campañas o contrata a diferentes empresas según el tipo de campaña que va realizar?

7. ¿Cada vez que realizan una convocatoria de selección de algún proveedor para realizar una campaña de BTL, se promueve la rotación de estos proveedores, para que exista una mayor oferta o siempre se realizar la convocatoria a los mismos proveedores cada vez que se realiza una campaña?

8. ¿Cuáles son los medios de comunicación que usted utiliza para comunicarse y enterarse de las empresas BTL?

9. ¿Cuáles son los beneficios que usted espera cuándo realiza una campaña BTL?

10. ¿Qué empresas conoces para el servicio de campaña de BTL?

11. ¿Qué empresas ha utilizado para dichos servicios?

12. ¿Cómo se llama la última empresa que contrato para realizar campañas BTL?

13. ¿Qué opinión a favor y contra tiene usted sobre la última empresa que contrató?

14. ¿Cuantas veces al año usted rota de proveedor de servicios de BTL?

15. ¿Cuántas veces al año usted contrata este servicio?

16. ¿Cuáles son los meses de mayor demanda del servicio de BTL? 
17. ¿En qué medios usted se enteró de las empresas de BTL?

18. ¿usted recomendaría a la última empresa de BTL que contrató?

19. ¿Cuál es el presupuesto del año 2014 para las campañas BTL?

20. ¿Ud. Considera aumentar el presupuesto asignado a campañas BTL en el próximo año? 


\section{ANEXO VII: TRANSCRIPCIÓN LITERAL: Entrevista al personal de la empresa}

\section{Gerente General: Sherylin Roman Orosco}

Preguntas para el Focus Group para los miembros de Naranja Producciones S.A.C.

1. ¿Dónde han trabajado anteriormente?

He trabajado como anfitriona y modelos de varias marcas conocidas.

2. ¿Qué experiencia tienen trabajando en el rubro?

Mi experiencia en el rubro es de varios años, ya que cuento con datos de clientes potenciales, proveedores de los servicios, ideas de servicios entre show infantes, baby showers, hora loca, entre otros.

3. Cuáles son las fortalezas que tiene la empresa Naranja Producciones S.A.C.?

Las fortalezas que puede contar Naranja Producciones S.A.C. es de tener contactos de primera mano, proveedores especializados, trabajadores que tienen experiencia en el rubro y diferenciación en cada uno de sus servicios.

4. ¿Cuáles son las debilidades que tiene la empresa Naranja Producciones S.A.C.?

Las debilidades que encuentro es la falta de organización entre los miembros, falta de liquidez para eventos más grandes, pérdida de contratos por no contar con personal para eventos de fines de semana, vestimenta antigua por falta de algún cambio tela.

5. ¿Cuáles son las oportunidades que tiene la empresa Naranja Producciones S.A.C.? Las oportunidades que puede tener Naranja Producciones S.A.C. es de crecer en otros partes del Perú, generar nuevos clientes en cada cambio de gobierno y que el BTL es mucho más barato que realizarlo en medios tradicionales.

6. ¿Cuáles son las amenazas que tiene la empresa Naranja Producciones S.A.C.?

Las amenazas que cuenta la empresa es de competir con otras empresas más pequeñas, pues estas dan al cliente cotizaciones mucho más baratas y con poca calidad; mientras que empresas grandes pueden dar la misma cotización que Naranja Producciones S.A.C. pero tienen mejores propuestas creativas para el evento.

7. ¿Cómo ven la empresa dentro de 5 años?

Nos vemos dentro de 5 años como una empresa muy consolidada, con un área creativa netamente en servicios, una oficina mejor implementada y contar con mayor staff de trabajo a tiempo completo.

8. ¿Cómo se ven ustedes en la empresa dentro de 5 años?

Me veo con más tiempo en generar nuevas ideas, tener mi staff de bailarinas con coreografías para cada evento y seguir creciendo como empresaria.

9. ¿Considera que la empresa tiene la posibilidad de crecer? 
Si considero que la empresa crezca a un largo plazo, la cuestión es dar mayor seguridad en cada actividad y contar con una buena cartera de clientes.

\section{Check List:}

1. ¿Usted Considera que el sector de la publicidad (BTL) está creciendo?

Sí, el sector crece rápidamente, el cliente no ve que tan creativa es la idea, sino cuanto están cotizando la campaña.

2. ¿Qué empresas considera que son las más importantes del sector?

Las empresas que veo más importante es Grey Perú.

3. ¿Cuál es la ventaja diferencial de cada uno de las empresas más importantes del sector?

Que cuentan con un staff dedicado a la creatividad de la idea y otras áreas que ya se dedican en la logística, producción, etc.

4. ¿Cuál es la ventaja diferencial que tiene Naranja Producciones S.A.C. con relación a la competencia?

Que somos una empresa joven con buenas ideas; asimismo que contamos con experiencia de primera mano a diferencia de las nuevas empresas.

5. ¿Por qué los clientes deberían escoger Naranja Producciones S.A.C.?

Deberían escogernos porque tenemos la actividad principal para su evento, liquidez para trabajar en el evento y sobre todo experiencia a todo nivel.

6. ¿Cuáles son los servicios sustitutos que tiene el mercado?

Los servicios sustitutos serían vallas publicitarias y redes sociales.

7. ¿Por qué decidió trabajar en Naranja Producciones S.A.C.?

Porque queríamos crear una empresa diferente a las demás y a la vez empezada por nosotros.

8. ¿Usted conoce la visión y misión de empresa?

Si conocemos la visión y misión de nuestra empresa.

9. ¿Cuáles son los valores de la empresa Naranja Producciones S.A.C.?

Los valores que tiene nuestra empresa es el compromiso, creatividad, eficiencia, motivación y respeto entre todos.

10. ¿Usted tiene conocimiento de sus funciones dentro de la empresa?

Si tengo conocimiento de mis funciones.

11. ¿Nos podría explicar cuáles son tus funciones dentro de Naranja Producciones S.A.C.? 
Mis funciones son de revisar contratos, contratar al personal para los eventos, realizar las ediciones de cada evento para la entrega final al cliente y de la decisión de la inversión para cada evento.

12. ¿Usted Considera que las otras personas del equipo lo apoyan en su trabajo? Sí, porque todos nos apoyamos mutuamente al momento de realizar una campaña.

13. ¿Con qué área interactúa más antes de desarrollar un evento? Interactúo más con el área comercial, porque los dos tomamos las decisiones.

14. ¿Qué mejoras crees que se podrían llevar a cabo en tú área? Una mejora es tener un asistente para apoyarme con los clientes y contar con mayor liquidez después de terminar un evento.

15. ¿Nos explicarías como es el proceso desde el inicio del proyecto hasta la culminación del mismo?

El proceso es agendar una reunión con el cliente para conocer el evento que quisieran realizar, después se da varias alternativas con sus respectivas cotizaciones, seguidamente se llega un acuerdo, un pago por adelanto y terminado el evento se entrega el archivo trabajado y el pago faltante es después de 45 días.

16. ¿Qué mejoras propones para el desarrollo de un proyecto integral, incluyendo todas las áreas?

Propongo tener un área creativa para generar nuevas ideas, personal más calificado y tener manuales de funciones para cada persona de su área y a la vez actualizarlo cada 6 meses si es necesario.

17. ¿Qué procesos ha identificado dentro de la empresa que se deberían de mejorar? Debería mejorar el tiempo de coreografías por semana, porque es importante practicar con las bailarinas y otro el tiempo de cobranzas porque a veces no se tiene liquidez para realizar otro evento en la misma semana.

18. ¿Qué mejoras propondrías para los procesos identificados que no están funcionando correctamente?

Contar un coreógrafo por horas que dedique a las bailarinas y sobre las cobranzas podría ser cobrar en tres partes para tener más liquidez.

10. Cuáles son las fortalezas que tiene la empresa Naranja Producciones S.A.C.?

Las fortalezas que puede contar Naranja Producciones S.A.C. es de tener contactos de primera mano, proveedores especializados, trabajadores que tienen experiencia en el rubro y diferenciación en cada uno de sus servicios.

11. ¿Cuáles son las debilidades que tiene la empresa Naranja Producciones S.A.C.? 
Las debilidades que encuentro es la falta de organización entre los miembros, falta de liquidez para eventos más grandes, pérdida de contratos por no contar con personal para eventos de fines de semana, vestimenta antigua por falta de algún cambio tela.

12. ¿Cuáles son las oportunidades que tiene la empresa Naranja Producciones S.A.C.? Las oportunidades que puede tener Naranja Producciones S.A.C. es de crecer en otros partes del Perú, generar nuevos clientes en cada cambio de gobierno y que el BTL es mucho más barato que realizarlo en medios tradicionales.

13. ¿Cuáles son las amenazas que tiene la empresa Naranja Producciones S.A.C.?

Las amenazas que cuenta la empresa es de competir con otras empresas más pequeñas, pues estas dan al cliente cotizaciones mucho más baratas y con poca calidad; mientras que empresas grandes pueden dar la misma cotización que Naranja Producciones S.A.C. pero tienen mejores propuestas creativas para el evento.

14. ¿Cómo ven la empresa dentro de 5 años?

Nos vemos dentro de 5 años como una empresa muy consolidada, con un área creativa netamente en servicios, una oficina mejor implementada y contar con mayor staff de trabajo a tiempo completo.

15. ¿Cómo se ven ustedes en la empresa dentro de 5 años?

Me veo con más tiempo en generar nuevas ideas, tener mi staff de bailarinas con coreografías para cada evento y seguir creciendo como empresaria.

16. ¿Considera que la empresa tiene la posibilidad de crecer?

Si considero que la empresa crezca a un largo plazo, la cuestión es dar mayor seguridad en cada actividad y contar con una buena cartera de clientes.

\section{Gerente Comercial: César Jaén Seminario}

Preguntas para el Focus Group para los miembros de Naranja Producciones S.A.C.

1. ¿Dónde han trabajado anteriormente?

Anteriomente he trabajado como anfitrión y modelo en varias empresas.

2. ¿Qué experiencia tienen trabajando en el rubro?

Mi experiencia es $100 \%$ dedicado a este rubro, ya que al momento de realizar los eventos de anfitrión, las empresas de las marcas reconocidas buscaban nuevas empresas que realicen BTL y puedan confiar sus campañas.

3. Cuáles son las fortalezas que tiene la empresa Naranja Producciones S.A.C.?

Las fortalezas que cuenta Naranja Producciones S.A.C. es de ser una empresa joven, liquidez para eventos, socio estratégico, capacidad de cobertura en varios puntos de Lima y provincias y contar con staff calificado al igual que joven.

4. ¿Cuáles son las debilidades que tiene la empresa Naranja Producciones S.A.C.? 
Las debilidades sería no contar con liquidez para eventos de mayor envergadura, equipos de última tendencia, no tener un área creativa como la competencia y personal con estudios sobre el rubro.

5. ¿Cuáles son las oportunidades que tiene la empresa Naranja Producciones S.A.C.? Las oportunidades que tiene la empresa es que esta solicitada por empresas públicas, tiene una red de contactos para diversos eventos y los gerentes cuentan con la experiencia en el rubro.

6. ¿Cuáles son las amenazas que tiene la empresa Naranja Producciones S.A.C.?

La mayor amenaza es de tener competencia con empresas recientes en el mercado y con cotizaciones muy bajos a una empresa con experiencia.

7. ¿Cómo ven la empresa dentro de 5 años?

Veo a Naranja Producciones S.A.C. como una empresa muy consolidada, con un staff de colaboradores ya consolidados y tener una oficina netamente para Naranja Producciones S.A.C.

8. ¿Cómo se ven ustedes en la empresa dentro de 5 años?

Me veo con mayor tiempo para mi familia, generar nuevas cuentas corporativas, capaz ingresar a otras provincias con staff propio.

9. ¿Considera que la empresa tiene la posibilidad de crecer?

Claro, la empresa esta para crecer mucho más.

\section{Check List:}

1. ¿Usted Considera que el sector de la publicidad (BTL) está creciendo?

$\mathrm{Si}$, antes los clientes realizan unos cuantos eventos para activación, ahora cada mes realizan más eventos para sus trabajadores, clientes potenciales y desean que todos estén contentos para poder consumir o sentirse parte de la empresa.

2. ¿Qué empresas considera que son las más importantes del sector?

Las más importantes están Grey Perú, FCB Mayo y Rocoto Producciones.

3. ¿Cuál es la ventaja diferencial de cada uno de las empresas más importantes del sector?

Que cuentan con renombre a nivel nacional e internacional, tienen personal que han estudiado fuera del país para especializarse y cuentan con área creativa muy potente.

4. ¿Cuál es la ventaja diferencial que tiene Naranja Producciones S.A.C. con relación a la competencia?

Que somos una empresa que tiene experiencia en el mercado nacional, conocemos a nuestros clientes y a las empresas donde laboran; también que contamos con ideas muy ingeniosa para que los clientes estén contentos con el trabajo realizado. 
5. ¿Por qué los clientes deberían escoger Naranja Producciones S.A.C.?

Porque contamos con experiencia en los eventos que soliciten, además podemos realizar los eventos según los requerimientos.

6. ¿Cuáles son los servicios sustitutos que tiene el mercado?

Como servicio sustituto está una empresa Arrow porque interactúan más directo con el público, realizando malabares para llevarlos a un lugar específico, esto lo veo muy novedoso.

7. ¿Por qué decidió trabajar en Naranja Producciones S.A.C.?

Porque quería ser independiente y ya conocía la mayoría de procesos y contactos directos, por eso que me esforcé junto a mi pareja y creamos la empresa.

8. ¿Usted conoce la visión y misión de empresa?

Sí, pero deberíamos mejorarlo para que se proyecte hoy en día. No lo hemos variado desde que iniciamos la empresa.

9. ¿Cuáles son los valores de la empresa Naranja Producciones S.A.C.?

Los valores que tiene Naranja Producciones S.A.C. es creatividad en el servicio, puntualidad de todos para el día pactado y el respeto mutuo para ser un buen equipo entregando un servicio de calidad.

10. ¿Usted tiene conocimiento de sus funciones dentro de la empresa?

$\mathrm{Si}$, aunque al final realizo de todo un poco para avanzar con los eventos; hay momentos que tenemos hasta tres eventos al día en diferentes distritos; pero ahí estamos para cumplir con todos.

11. ¿Nos podría explicar cuáles son tus funciones dentro de Naranja Producciones S.A.C.?

Mis funciones básicamente son reuniones para acuerdos y cierres con clientes corporativos para eventos grandes, visitar la feria de publicidad anual para reuniones o captación de nuevos clientes, actualizar las redes sociales con los últimos eventos, agendar reuniones en base de datos, llevar y recoger a los trabajadores de los eventos y compras junto con gerencia de nuevas vestimentas o equipos.

12. ¿Usted Considera que las otras personas del equipo lo apoyan en su trabajo?

Sí, todos de la empresa nos ayudamos para realizar un excelente evento para el cliente, pero que nos falta más apoyo es indiscutible.

13. ¿Con qué área interactúa más antes de desarrollar un evento?

Interactuamos más con gerencia general por las compras que necesite la empresa y los eventos que son primeros a realizar. También interactúo con el productor general y producción, ya que debe estar a la par por los eventos a realizar. De igual manera, 
con el asistente de marketing, porque me tiene al tanto de los eventos que va a realizar en los fines de semana.

14. ¿Qué mejoras crees que se podrían llevar a cabo en tú área?

Las mejoras deberían ser es tener un manual de funciones urgente porque al final todos hacemos cosas de otros compañeros y a veces nos olvidamos de avanzar nuestros puntos. También, deberíamos realizar un contrato de confidencialidad entre los trabajadores para no tener el inconveniente de robo de información que tanto esfuerzo conseguimos para la empresa, eso nos tiene siempre alerta con nuevos compañeros de trabajo. Otra mejora, es tener una base de datos más organizados en algún sistema porque ahora son un grupo importante de clientes, pero más adelante debemos tener más clientes.

15. ¿Nos explicarías como es el proceso desde el inicio del proyecto hasta la culminación del mismo?

Lo que hacemos en mi caso, es entrevistarme con el cliente y escuchar que necesitan para su evento en la fecha indicada, después se le entrega la propuesta y pactamos que equipos y personas estarían en el evento. A la par, converso con el productor y los asistentes de las funciones que tenemos para el evento y si necesitan nuevas indumentarias o renovar equipos. Ya cuando estamos en el evento, empezamos a trabajar y estar coordinados hasta el final del evento que los llevo hasta sus casas o un punto en común.

16. ¿Qué mejoras propones para el desarrollo de un proyecto integral, incluyendo todas las áreas?

Para un proyecto integral, las mejoras se debe dar desde contar con personal preparado, tener una mejor caja o dinero para proyectos mucho más grande sin recurrir al productor de eventos; otro es contar con contratos con restricciones para no caer en mentiras.

17. ¿Qué procesos ha identificado dentro de la empresa que se deberían de mejorar? Mejorar la comunicación entre los bailarines y el asistente; porque llegado el día del evento no llega o se excusan y es ahí para buscar más personal. Contar con alguien que revise semanalmente el estado de las vestimentas para después no encontrarnos con sorpresas.

18. ¿Qué mejoras propondrías para los procesos identificados que no están funcionando correctamente?

Tener un líder en cada grupo de bailarines para que estén atentos, contratar a una persona que sepa de arreglos en vestimenta y nos dé mención que arreglar o comprar.

10. Cuáles son las fortalezas que tiene la empresa Naranja Producciones S.A.C.? 
Las fortalezas que cuenta Naranja Producciones S.A.C. es de ser una empresa joven, liquidez para eventos, socio estratégico, capacidad de cobertura en varios puntos de Lima y provincias y contar con staff calificado al igual que joven.

11. ¿Cuáles son las debilidades que tiene la empresa Naranja Producciones S.A.C.?

Las debilidades sería no contar con liquidez para eventos de mayor envergadura, equipos de última tendencia, no tener un área creativa como la competencia y personal con estudios sobre el rubro.

12. ¿Cuáles son las oportunidades que tiene la empresa Naranja Producciones S.A.C.? Las oportunidades que tiene la empresa es que esta solicitada por empresas públicas, tiene una red de contactos para diversos eventos y los gerentes cuentan con la experiencia en el rubro.

13. ¿Cuáles son las amenazas que tiene la empresa Naranja Producciones S.A.C.?

La mayor amenaza es de tener competencia con empresas recientes en el mercado y con cotizaciones muy bajos a una empresa con experiencia.

14. ¿Cómo ven la empresa dentro de 5 años?

Veo a Naranja Producciones S.A.C. como una empresa muy consolidada, con un staff de colaboradores ya consolidados y tener una oficina netamente para Naranja Producciones S.A.C.

15. ¿Cómo se ven ustedes en la empresa dentro de 5 años?

Me veo con mayor tiempo para mi familia, generar nuevas cuentas corporativas, capaz ingresar a otras provincias con staff propio.

16. ¿Considera que la empresa tiene la posibilidad de crecer?

Claro, la empresa esta para crecer mucho más.

\section{Productor General de eventos asociado: Leonardo de la Cruz}

Preguntas para el Focus Group para los miembros de Naranja Producciones S.A.C.

1. ¿Dónde han trabajado anteriormente?

Trabaje en el Hotel Radisson en Miraflores, en el área de marketing.

2. ¿Qué experiencia tienen trabajando en el rubro?

Tengo mi empresa de eventos, Mangosta Comunicaciones y hasta ahora tengo seis años de experiencia en el rubro.

3. Cuáles son las fortalezas que tiene la empresa Naranja Producciones S.A.C.?

Las fortalezas que veo en Naranja Producciones S.A.C. es un equipo serio, puntualidad en los eventos y que siempre tienen servicios de primera.

4. ¿Cuáles son las debilidades que tiene la empresa Naranja Producciones S.A.C.? 
La principal debilidad es de no contar con liquidez para realizar sus eventos, entonces o terciarizamos sus servicios o trabajamos por igual entre las dos empresas.

5. ¿Cuáles son las oportunidades que tiene la empresa Naranja Producciones S.A.C.? Las oportunidades que trabaja directo con entidades públicas, tiene el alcance logístico para llevar los eventos, cuenta con shows de acuerdo a la necesidad del mercado.

6. ¿Cuáles son las amenazas que tiene la empresa Naranja Producciones S.A.C.? Como principal amenaza son las nuevas empresas de BTL que dicen entregar buenos servicios cuando la mayoría, no tiene experiencia en el rubro.

7. ¿Cómo ven la empresa dentro de 5 años?

Lo veo como una empresa consolidada, con más equipos audiovisuales e invirtiendo en proyectos muy grandes.

8. ¿Cómo se ven ustedes en la empresa dentro de 5 años?

Me veo apoyando más a mi compañero y entrando a empresas de consumo masivo para realizar eventos de otro nivel.

9. ¿Considera que la empresa tiene la posibilidad de crecer?

Desde que conozco a César, he visto como crece la empresa, además el tiene más clientes y busca trabajar en conjunto conmigo para ser de los eventos de mayor calidad.

\section{Check List:}

1. ¿Usted Considera que el sector de la publicidad (BTL) está creciendo?

Por supuesto, los servicios BTL han crecido rotundamente en todas las empresas, pues buscan que sus clientes internos y externos tengan una integración más directa; para ello ahora invierten más que en publicidad ATL.

2. ¿Qué empresas considera que son las más importantes del sector?

Para mi, Grey Perú y FCB Mayo, puesto que hemos querido trabajar con DirecTV la parte creativa y logística; pero este cliente trabajan con nuestra competencia y nosotros sólo realizamos la logística.

3. ¿Cuál es la ventaja diferencial de cada uno de las empresas más importantes del sector?

Debe ser su área creativa que lo tienen al tope y realizan buenas ideas, porque la parte logística lo terciarizan.

4. ¿Cuál es la ventaja diferencial que tiene Naranja Producciones S.A.C. con relación a la competencia? 
Tiene una logística propia, ya que puede dar el servicio sin problema. Además que si los clientes le pide una idea diferente, ellos lo trabajan y lo proponen sin ningún probema.

5. ¿Por qué los clientes deberían escoger Naranja Producciones S.A.C.?

Porque la empresa de mi compañero César es puntual, serio y tiene mucho profesionalismo en las actividades que realiza.

6. ¿Cuáles son los servicios sustitutos que tiene el mercado?

Observo que son las redes sociales, planfletos y marketing digital.

7. ¿Por qué decidió trabajar en Naranja Producciones S.A.C.?

Porque me asocié con César para llevar a cabo más proyectos juntos e invertir por igual y así captar más clientes.

8. ¿Usted conoce la visión y misión de empresa?

No lo conozco.

9. ¿Cuáles son los valores de la empresa Naranja Producciones S.A.C.?

A mi parecer los valores que tienen la empresa es puntualidad, transparencia, excelente grupo de personas y pasión por el trabajo.

10. ¿Usted tiene conocimiento de sus funciones dentro de la empresa?

Dentro

11. ¿Nos podría explicar cuáles son tus funciones dentro de Naranja Producciones S.A.C.?

Mis funciones como socio exterior, al realizar campaña juntos, es de ser el primer productor y César el segundo productor. Además de trabajar juntos, invertimos por igual para las campañas de mayor envergadura.

12. ¿Usted Considera que las otras personas del equipo lo apoyan en su trabajo?

No, solo César porque trabajo directo con él.

13. ¿Con qué área interactúa más antes de desarrollar un evento?

Con gerencia comercial.

14. ¿Qué mejoras crees que se podrían llevar a cabo en tú área?

Como consultor externo, tener un CMR junto con César para tener una base de datos más rápido.

15. ¿Nos explicarías como es el proceso desde el inicio del proyecto hasta la culminación del mismo?

Inicio contactando un cliente potencial, después de cerrar el trato llamo a César para ver la parte logística y los puntos fuertes a trabajar.

16. ¿Qué mejoras propones para el desarrollo de un proyecto integral, incluyendo todas las áreas? 
En mi caso, mejores proveedores, invertir en los recursos de la empresa e invertir en vestuarios.

17. ¿Qué procesos ha identificado dentro de la empresa que se deberían de mejorar? Debería ser el de mantenimiento de los vestuarios y de los equipos al ser utilizados.

18. ¿Qué mejoras propondrías para los procesos identificados que no están funcionando correctamente?

Para este caso, realizar mantenimiento o cambios cada seis meses para no verse perjudicado.

10. Cuáles son las fortalezas que tiene la empresa Naranja Producciones S.A.C.? Las fortalezas que veo en Naranja Producciones S.A.C. es un equipo serio, puntualidad en los eventos y que siempre tienen servicios de primera.

11. ¿Cuáles son las debilidades que tiene la empresa Naranja Producciones S.A.C.?

La principal debilidad es de no contar con liquidez para realizar sus eventos, entonces o terciarizamos sus servicios o trabajamos por igual entre las dos empresas.

12. ¿Cuáles son las oportunidades que tiene la empresa Naranja Producciones S.A.C.? Las oportunidades que trabaja directo con entidades públicas, tiene el alcance logístico para llevar los eventos, cuenta con shows de acuerdo a la necesidad del mercado.

13. ¿Cuáles son las amenazas que tiene la empresa Naranja Producciones S.A.C.? Como principal amenaza son las nuevas empresas de BTL que dicen entregar buenos servicios cuando la mayoría, no tiene experiencia en el rubro.

14. ¿Cómo ven la empresa dentro de 5 años?

Lo veo como una empresa consolidada, con más equipos audiovisuales e invirtiendo en proyectos muy grandes.

15. ¿Cómo se ven ustedes en la empresa dentro de 5 años?

Me veo apoyando más a mi compañero y entrando a empresas de consumo masivo para realizar eventos de otro nivel.

16. ¿Considera que la empresa tiene la posibilidad de crecer?

Desde que conozco a César, he visto como crece la empresa, además el tiene más clientes y busca trabajar en conjunto conmigo para ser de los eventos de mayor calidad.

\section{Asistente de Marketing: Jorge Seminario Nuñez}

Preguntas para el Focus Group para los miembros de Naranja Producciones S.A.C.

1. ¿Dónde han trabajado anteriormente?

Trabajaba como asistente de marketing en el Sport Boys.

2. ¿Qué experiencia tienen trabajando en el rubro? 
Tengo poca experiencia, más soy la mano derecha de los gerentes para las campañas.

3. Cuáles son las fortalezas que tiene la empresa Naranja Producciones S.A.C.?

Las fortalezas es que tiene gerente que saben mucho del BTL y que trabajan con empresas grandes tanto de municipalidades, ministerios y empresas privadas de todo tipo como DirecTV

4. ¿Cuáles son las debilidades que tiene la empresa Naranja Producciones S.A.C.?

La debilidad que observo que no tiene muchos bailarines para campañas de los fines de semana, cuando estamos en campaña navideña nos falta manos para trabajar con los clientes y nos debemos apoyar entre todos.

5. ¿Cuáles son las oportunidades que tiene la empresa Naranja Producciones S.A.C.? Que puede trabajar junto con su colega de Magosta Producciones y se tiene más eventos.

6. ¿Cuáles son las amenazas que tiene la empresa Naranja Producciones S.A.C.?

Veo que existen pequeñas empresas de BTL que se copian de lo que hacemos o los bailarines se van por eventos de ellos.

7. ¿Cómo ven la empresa dentro de 5 años?

Lo veo que tiene una oficina más grande, con más personal y más equipos grandes.

8. ¿Cómo se ven ustedes en la empresa dentro de 5 años?

Me veo teniendo ya un asistente de marketing y estudiando algo de marketing.

9. ¿Considera que la empresa tiene la posibilidad de crecer?

La empresa más adelante crecerá, mi jefe César trabaja muy bien y tendrá más clientes.

\section{Check List:}

1. ¿Usted Considera que el sector de la publicidad (BTL) está creciendo? Si ha crecido porque existe más empresas de BTL.

2. ¿Qué empresas considera que son las más importantes del sector? He escuchado de Grey Perú porque Mangosta siempre habla de ellos.

3. ¿Cuál es la ventaja diferencial de cada uno de las empresas más importantes del sector?

Que es una empresa más grande que nosotros.

4. ¿Cuál es la ventaja diferencial que tiene Naranja Producciones S.A.C. con relación a la competencia?

Que nosotros realizamos la logística, tenemos shows infantiles que a veces se utiliza en las campañas para los hijos de las empresas.

5. ¿Por qué los clientes deberían escoger Naranja Producciones S.A.C.?

Porque los clientes ya nos conocen y apoyamos en todo lo que piden. 
6. ¿Cuáles son los servicios sustitutos que tiene el mercado?

El marketing digital que hoy se emplea.

7. ¿Por qué decidió trabajar en Naranja Producciones S.A.C.?

Porque tengo experiencia y eso necesitaba César.

8. ¿Usted conoce la visión y misión de empresa?

No.

9. ¿Cuáles son los valores de la empresa Naranja Producciones S.A.C.? No.

10. ¿Usted tiene conocimiento de sus funciones dentro de la empresa? $\mathrm{Si}$

11. ¿Nos podría explicar cuáles son tus funciones dentro de Naranja Producciones S.A.C.?

Yo hago las cotizaciones de los shows infantiles, actualizo las redes sociales con los shows realizados, agendo los eventos pequeños en la base de datos de mi jefe y si no hay personal para el evento, también apoyo.

12. ¿Usted Considera que las otras personas del equipo lo apoyan en su trabajo?

Si veo que me apoyan pero la mayor parte lo realizo.

13. ¿Con qué área interactúa más antes de desarrollar un evento?

Con gerencial comercial y producción.

14. ¿Qué mejoras crees que se podrían llevar a cabo en tú área?

Tengamos más bailarines o separen los bailarines de shows infantiles y otros para los eventos de empresas.

15. ¿Nos explicarías como es el proceso desde el inicio del proyecto hasta la culminación del mismo?

Yo apoyo a mi jefe César con los shows pequeños, realizo desde el contrato hasta el cierre del show; también si no hay gente en los shows, yo debo de apoyar.

16. ¿Qué mejoras propones para el desarrollo de un proyecto integral, incluyendo todas las áreas?

Que la empresa debe ser más organizado.

17. ¿Qué procesos ha identificado dentro de la empresa que se deberían de mejorar?

La logística al realizar los eventos porque a veces estamos contra tiempos.

18. ¿Qué mejoras propondrías para los procesos identificados que no están funcionando correctamente?

Tener un carro más para los equipos.

19. Cuáles son las fortalezas que tiene la empresa Naranja Producciones S.A.C.? 
Las fortalezas es que tiene gerente que saben mucho del BTL y que trabajan con empresas grandes tanto de municipalidades, ministerios y empresas privadas de todo tipo como DirecTV

20. ¿Cuáles son las debilidades que tiene la empresa Naranja Producciones S.A.C.? La debilidad que observo que no tiene muchos bailarines para campañas de los fines de semana, cuando estamos en campaña navideña nos falta manos para trabajar con los clientes y nos debemos apoyar entre todos.

21. ¿Cuáles son las oportunidades que tiene la empresa Naranja Producciones S.A.C.? Que puede trabajar junto con su colega de Magosta Producciones y se tiene mas eventos.

22. ¿Cuáles son las amenazas que tiene la empresa Naranja Producciones S.A.C.?

Veo que existen pequeñas empresas de BTL que se copian de lo que hacemos o los bailarines se van por eventos de ellos.

23. ¿Cómo ven la empresa dentro de 5 años?

Lo veo que tiene una oficina más grande, con más personal y más equipos grandes.

24. ¿Cómo se ven ustedes en la empresa dentro de 5 años?

Me veo teniendo ya un asistente de marketing y estudiando algo de marketing.

25. ¿Considera que la empresa tiene la posibilidad de crecer?

La empresa más adelante crecerá, mi jefe César trabaja muy bien y tendrá más clientes.

\section{Asistente de Producción: José Luis Alvarado}

Preguntas para el Focus Group para los miembros de Naranja Producciones S.A.C.

1. ¿Dónde han trabajado anteriormente?

Es mi primer trabajo, ya que soy estudiante de medicina.

2. ¿Qué experiencia tienen trabajando en el rubro?

Es mi primera experiencia trabajando en BTL.

3. Cuáles son las fortalezas que tiene la empresa Naranja Producciones S.A.C.?

La empresa del señor César conoce mucha gente en el medio y que sus clientes mayormente son del Estado.

4. ¿Cuáles son las debilidades que tiene la empresa Naranja Producciones S.A.C.?

Que la empresa es pequeña a comparación de otras y siempre busca entrar a varias licitaciones.

5. ¿Cuáles son las oportunidades que tiene la empresa Naranja Producciones S.A.C.?

Que hay más shows infantiles y la empresa es conocida por varios clientes.

6. ¿Cuáles son las amenazas que tiene la empresa Naranja Producciones S.A.C.? 
Una amenaza son la competencia.

7. ¿Cómo ven la empresa dentro de 5 años?

Veo que esta mucho mejor y con más clientes.

8. ¿Cómo se ven ustedes en la empresa dentro de 5 años?

Ya trabajando en lo que estudie.

9. ¿Considera que la empresa tiene la posibilidad de crecer?

Si veo la empresa crecer.

\section{Check List:}

1. ¿Usted Considera que el sector de la publicidad (BTL) está creciendo? Si mucho a mi parecer.

2. ¿Qué empresas considera que son las más importantes del sector? Grey Perú.

3. ¿Cuál es la ventaja diferencial de cada uno de las empresas más importantes del sector?

Que tienen área de creatividad, por eso que algunos clientes van con ellos.

4. ¿Cuál es la ventaja diferencial que tiene Naranja Producciones S.A.C. con relación a la competencia?

Que son una empresa nueva y fresca en el mercado.

5. ¿Por qué los clientes deberían escoger Naranja Producciones S.A.C.?

Porque conocemos varios servicios y campañas para apoyar a los clientes.

6. ¿Cuáles son los servicios sustitutos que tiene el mercado?

He visto Facebook e instagram.

7. ¿Por qué decidió trabajar en Naranja Producciones S.A.C.?

Porque fue una opción que no necesitaban experiencia.

8. ¿Usted conoce la visión y misión de empresa? No.

9. ¿Cuáles son los valores de la empresa Naranja Producciones S.A.C.? No lo sé.

10. ¿Usted tiene conocimiento de sus funciones dentro de la empresa? Realizo varías actividades de apoyo.

11. ¿Nos podría explicar cuáles son tus funciones dentro de Naranja Producciones S.A.C.?

Principalmente de utilizar la camioneta para llevar los equipos y el personal.

12. ¿Usted Considera que las otras personas del equipo lo apoyan en su trabajo? No. 
13. ¿Con qué área interactúa más antes de desarrollar un evento?

Con todos.

14. ¿Qué mejoras crees que se podrían llevar a cabo en tú área?

No sé que mejoras se podría realizar con el uso de la camioneta.

15. ¿Nos explicarías como es el proceso desde el inicio del proyecto hasta la culminación del mismo?

Es llevar todas las vestimentas y a las personas a los eventos que tenemos en el día.

16. ¿Qué mejoras propones para el desarrollo de un proyecto integral, incluyendo todas las áreas?

Podría ser de que todos lleguen a tiempo.

17. ¿Qué procesos ha identificado dentro de la empresa que se deberían de mejorar? Que las vestimentas deben estar empaquetadas y no buscarlas a última hora.

18. ¿Qué mejoras propondrías para los procesos identificados que no están funcionando correctamente?

Que guarden las vestimentas a tiempo.

19. Cuáles son las fortalezas que tiene la empresa Naranja Producciones S.A.C.?

La empresa del señor César conoce mucha gente en el medio y que sus clientes mayormente son del Estado.

20. ¿Cuáles son las debilidades que tiene la empresa Naranja Producciones S.A.C.?

La debilidad que observo que no tiene muchos bailarines para campañas de los fines de semana, cuando estamos en campaña navideña nos falta manos para trabajar con los clientes y nos debemos apoyar entre todos.

21. ¿Cuáles son las oportunidades que tiene la empresa Naranja Producciones S.A.C.?

Que puede trabajar junto con su colega de Magosta Producciones y se tiene más eventos.

22. ¿Cuáles son las amenazas que tiene la empresa Naranja Producciones S.A.C.?

Veo que existen pequeñas empresas de BTL que se copian de lo que hacemos o los bailarines se van por eventos de ellos.

23. ¿Cómo ven la empresa dentro de 5 años?

Lo veo que tiene una oficina más grande, con más personal y más equipos grandes.

24. ¿Cómo se ven ustedes en la empresa dentro de 5 años?

Me veo teniendo ya un asistente de marketing y estudiando algo de marketing.

25. ¿Considera que la empresa tiene la posibilidad de crecer?

La empresa más adelante crecerá, mi jefe César trabaja muy bien y tendrá más clientes. 


\section{Contador: Alex Otarola}

Preguntas para el Focus Group para los miembros de Naranja Producciones S.A.C.

1. ¿Dónde han trabajado anteriormente?

Soy contador independiente.

2. ¿Qué experiencia tienen trabajando en el rubro?

Tengo poca experiencia en empresas BTL, más soy contador general.

3. ¿Cuáles son las fortalezas que tiene la empresa Naranja Producciones S.A.C.?

Como soy contador externo, pienso que será que las ventas han incrementado en fechas importante.

4. ¿Cuáles son las debilidades que tiene la empresa Naranja Producciones S.A.C.?

La debilidad primordial es que no tiene dinero para campañas grandes con las entidades públicas.

5. ¿Cuáles son las oportunidades que tiene la empresa Naranja Producciones S.A.C.? Que sabe negociar con los clientes.

6. ¿Cuáles son las amenazas que tiene la empresa Naranja Producciones S.A.C.? No sabría decir que amenazas cuenta la empresa.

7. ¿Cómo ven la empresa dentro de 5 años?

Veo a la empresa que crece en todos los ámbitos y con mayor liquidez.

8. ¿Cómo se ven ustedes en la empresa dentro de 5 años?

Siguiendo ser su contador externo.

9. ¿Considera que la empresa tiene la posibilidad de crecer?

Si veo a la empresa creciendo y generando más dinero.

\section{Check List:}

1. ¿Usted Considera que el sector de la publicidad (BTL) está creciendo? Si porque contablemente, veo varios eventos y que facturan cada vez más.

2. ¿Qué empresas considera que son las más importantes del sector? Desconozco de las empresas.

3. ¿Cuál es la ventaja diferencial de cada uno de las empresas más importantes del sector?

No lo sé.

4. ¿Cuál es la ventaja diferencial que tiene Naranja Producciones S.A.C. con relación a la competencia?

Que tiene activos para sus eventos.

5. ¿Por qué los clientes deberían escoger Naranja Producciones S.A.C.? 
Porque es una empresa que da buen servicio de campañas, además que tiene liquidez para realizar eventos cada semana.

6. ¿Cuáles son los servicios sustitutos que tiene el mercado?

No sabría decir que sustitutos tienen.

7. ¿Por qué decidió trabajar en Naranja Producciones S.A.C.?

Porque soy amigo de César y apoyo en el tema contable.

8. ¿Usted conoce la visión y misión de empresa?

No.

9. ¿Cuáles son los valores de la empresa Naranja Producciones S.A.C.?

Por mi cuenta, serían el respeto y confianza que brindan los gerentes.

10. ¿Usted tiene conocimiento de sus funciones dentro de la empresa?

$\mathrm{Si}$, lo que tengo presente como consultor externo.

11. ¿Nos podría explicar cuáles son tus funciones dentro de Naranja Producciones S.A.C.?

Lo principal que realizo es llevar la contabilidad de la empresa, asesorar en algunos puntos que necesite César y realizar gestiones tributarias ante la SUNAT.

12. ¿Usted Considera que las otras personas del equipo lo apoyan en su trabajo? No porque soy consultor externo.

13. ¿Con qué área interactúa más antes de desarrollar un evento?

Sólo interactúo con los gerentes.

14. ¿Qué mejoras crees que se podrían llevar a cabo en tú área?

Que la empresa debería tener un auxiliar contable para apoyarnos mejor.

15. ¿Nos explicarías como es el proceso desde el inicio del proyecto hasta la culminación del mismo?

César me entrega los documentos para registrarlo en mi sistema, ver cuánto se pagara de tributos y le asesoro en algunos puntos para que se proyecte en los siguientes meses.

16. ¿Qué mejoras propones para el desarrollo de un proyecto integral, incluyendo todas las áreas?

Una mejora es que la empresa debe ser más ordenado con la documentación.

17. ¿Qué procesos ha identificado dentro de la empresa que se deberían de mejorar?

Mejorar más sus inventarios y equipos; porque son sus principales activos para realizar los trabajos.

18. ¿Qué mejoras propondrías para los procesos identificados que no están funcionando correctamente?

Que realicen mejor sus inventarios para no realizar compras innecesarias. 
19. ¿Cuáles son las fortalezas que tiene la empresa Naranja Producciones S.A.C.? La empresa del señor César conoce mucha gente en el medio y que sus clientes mayormente son del Estado.

20. ¿Cuáles son las debilidades que tiene la empresa Naranja Producciones S.A.C.? La debilidad que observo que no tiene muchos bailarines para campañas de los fines de semana, cuando estamos en campaña navideña nos falta manos para trabajar con los clientes y nos debemos apoyar entre todos.

21. ¿Cuáles son las oportunidades que tiene la empresa Naranja Producciones S.A.C.? Que puede trabajar junto con su colega de Magosta Producciones y se tiene mas eventos.

22. ¿Cuáles son las amenazas que tiene la empresa Naranja Producciones S.A.C.? Veo que existen pequeñas empresas de BTL que se copian de lo que hacemos o los bailarines se van por eventos de ellos.

23. ¿Cómo ven la empresa dentro de 5 años?

Lo veo que tiene una oficina más grande, con más personal y más equipos grandes.

24. ¿Cómo se ven ustedes en la empresa dentro de 5 años?

Me veo teniendo ya un asistente de marketing y estudiando algo de marketing.

25. ¿Considera que la empresa tiene la posibilidad de crecer?

La empresa más adelante crecerá, mi jefe César trabaja muy bien y tendrá más clientes. 


\section{ANEXO VIII: TRANSCRIPCIÓN LITERAL: ENTREVISTAS CLIENTES Y NO CLIENTES}

\section{EMPRESA CLIENTE “ESSALUD”}

Contacto el señor Michael Tong- Área de comunicaciones de ESSALUD.

\section{Preguntas:}

1. ¿Por qué buscó servicios de BTL?

El ministerio de salud bajo su Plan Anual de comunicación, busca realizar campañas de prevención de enfermedades. Por tal motivo, el área de comunicación del MINSA, bajo su equipo técnico, lleva a cabo la planificación de varios eventos de comunicación interna y externa como La campaña de prevención de la anemia, del sarampión, por decir algunas.

Ahora, escogimos realizar BTL, porque es la manera más barata de llevar realizar una campaña de comunicación, aquí les decimos campañas socioculturales, porque buscamos que exista una interacción constante entre los usuarios a la red de salud nacional con las personas que realizan la campaña de información.

2. ¿Usted podría mencionarnos cuáles son los criterios de selección para contratar una empresa BTL?

Por lo general yo convoco o sugiero a tres empresas con las cuales ya haya trabajado conmigo. Además, tenemos una base de empresas proveedoras con las cuales trabajamos siempre, pero cuando un proveedor no trabaja bien, lo sacamos de la base. Ahora el que selecciona a las empresas para que estén en la bases son los de logística, debido a que ellos son los que terminan de seleccionar al proveedor, pero siempre tienen en consideración las sugerencias del área de comunicación, pero siempre debe existir confianza y experiencia previa para que nosotros queramos trabajar con algún proveedor. Te podría decir una experiencia, habíamos tenido un muy mal trabajo con un proveedor anterior y cuando el área de logística me dijo que yo trabajaría con él durante mi campaña, le dije a los chicos de logística que no lo haría y documente mi respuesta con el resultado de varias campañas pasadas de otros comunicadores. La confianza es importante, como el éxito de la campaña. El proveedor se quema con todos los comunicadores si hace un mal trabajo.

Los chicos de Naranja Producciones S.A.C.; ya han trabajado desde hace tiempo con el MINSA y estamos contentos de trabajar con ellos, porque nunca nos han fallado y siempre han sido muy colaboradores con nosotros. 
Hay que recordar también que la contratación se puede hacer por dos vías, que son las licitaciones o las contrataciones de menor cuantía. esto sucede cuando las campañas no sobrepasan las 3 UITs que son aproximadamente S/ 11,150.

3. ¿Cuántas empresas considera como máximo para realizar una comparación de servicios para un próximo evento?

Como lo indica antes, evaluamos a 3 empresas. Lo que hace el área de comunicaciones, es enviar el requerimiento o TDR (Términos de Referencias) al área de logística y ellos envían un correo con el TDR a todas las empresas de la base de proveedores y luego que han revisado las cotizaciones enviadas por los proveedores, logística selecciona a 3 empresas para evaluarlas con nosotros, claro está que siempre tenemos a nuestras empresas favoritas, y entre ellas esta Naranja Producciones S.A.C.; por lo general se escoge la cotización de menor precio.

4. ¿Durante el año contrata una sola empresa de BTL para realizar todas sus campañas o contrata a diferentes empresas según el tipo de campaña que va realizar?

Nunca trabajamos con un solo proveedor, sería muy irresponsable. Imagínate si todas mis campañas las hiciera con una sola empresa, el riesgo sería muy alto, si le pasa algo a la empresa como falta de liquidez o si da un pésimo servicio. Siempre trabajamos con varios proveedores para mitigar el riesgo. Por ejemplo, si realizamos un Encuentro de Doctores, tendríamos que contratar los servicios de catering, sonido, luces, toldo, mozos, menaje, etc. Muchas veces, contratamos varias empresas para que nos brinden los diferentes servicios para disminuir el riesgo que alguno de los proveedores nos falle.

5. ¿Cuáles son los medios de comunicación que usted utiliza para comunicarse y enterarse de las empresas BTL?

Mira para trabajar como proveedor del Estado, los proveedores deben contar con RNP (Registro Nacional de Proveedores) vigente y contar con su cuenta de detracciones en el Banco de la Nación. Ahora, como nosotros nos enteramos de ellos, pues en muchos casos, ellos presentan una carta de presentación al MINSA, con sus datos para ser considerados por el área de logística, pero también, nos enteramos de ellos, porque el área de logística empieza a indagar sobre posibles empresas proveedoras y les pide cotizaciones, claro está que al comienzo se les contrata por cosas muy pequeñas, ara ir probándolos.

6. ¿Cuáles son los beneficios que usted espera cuándo realiza una campaña BTL?

Que se cumpla con el TDR (términos de referencias), en el caso de una animación sociocultural, que los actores, vayan debidamente disfrazados y maquillados, que los equipos de audio y sonido estén bien, que sean puntuales, que cumplan en transmitir 
la información brindada por nuestra área, que repartan los folletos y que expliquen adecuadamente su contenido. Que buscamos con todo esto, pues la prevención de las enfermedades, por esos hacemos campañas de comunicación durante todos los meses, para bajar los índices de contagio de las enfermedades.

7. ¿Cómo usted se contactó con Naranja Producciones?

Naranja Producciones S.A.C.; ya había trabajado anteriormente con otros comunicadores y me los recomendaron y así empecé a trabajar con ellos.

8. ¿Por qué escogió Naranja Producciones?

Por la confianza y por la calidad de su servicio.

9. ¿Estuvo satisfecho con el servicio brindado por Naranja Producciones? Hasta ahora no he tenido ningún problema con ellos y el servicio ha sido muy bueno.

10. ¿Usted Logró los beneficios esperados al realizar campañas BTL?

Yo creo que sí, pero hasta el momento no tenemos como cuantificar objetivamente los resultados.

11. ¿Cuál es el presupuesto del año 2014 para las campañas BTL?

La verdad no tengo esa información, pero sé que más de la mitad del presupuesto del área se va a campañas de comunicación tipo BTL.

12. ¿Ud. Considera aumentar el presupuesto asignado a campañas BTL en el próximo año?

Bueno, yo no decido eso, pero depende si el presupuesto del año se llegó a gastar o no, para que al menos el área cuente con el mismo presupuesto.

13. ¿Cuántas veces al año contrata estos servicios y en qué temporadas?

Mínimo yo hago como unas 15 campañas al año de diferente envergadura, pero todas adjudicaciones directas, pero por lo general a mitad del año hacia abajo es la mayor actividad de estas campañas.

14. ¿Qué empresas dedicadas al servicio de BTL conoce actualmente y con cuales ha trabajado en algún momento?

También existen varias empresas en el sector de gran renombre como son: Yellow Btl, Moving Pack Eirl, AKM Warketing, SIVAL y Glenda Yaker Eventos Especiales, pero estas empresas no se presentan para campañas de adjudicación directa, por lo general se lanzan a licitaciones por el monto en efectivo de la campaña.

15. ¿Estuvo satisfecho con el servicio brindado por las empresas BTL que ha contrato hasta el momento?

Hasta ahora si.

16. ¿Qué expectativas futuras usted tiene sobre el BTL en el mercado nacional? Yo creo que sí, porque es la manera más barata y rápida de llegar a los clientes. 
17. ¿Ud. Recomendaría a Naranja Producciones?

$\mathrm{Si}$, porque son confiables y trabajan bien.

\section{EMPRESA CLIENTE "CLUB LA RINCONADA”}

\section{Contacto: El señor Piero Gambini}

\section{Preguntas:}

1. ¿Por qué buscó servicios de BTL?

Porque el BTL tiene mayor contacto con los clientes y es más económico realizar ATL, además por ser un club, nuestro público objetivo por lo general está siempre en las instalaciones y es más fácil la interacción con ellos desde campañas de fidelización hasta eventos por días festivos.

2. ¿Usted podría mencionarnos cuáles son los criterios de selección para contratar una empresa BTL?

Nosotros buscamos siempre que tenga prestigio y tenga una marca consolidada, además buscamos referencias de empresas que ya han trabajado con empresas BTL.

3. ¿Cuántas empresas considera como máximo para realizar una comparación de servicios para un próximo evento?

Si la campaña es pequeña, trabajamos con empresas como Naranja Producciones S.A.C.

Si la campaña es más grande, como fiesta de Fin de Año, buscamos cotizar por lo menos entre 3 a 4 empresas y ver la diferenciación de actividades, diversidad de servicios; porque ahí tienen que trabajar todo el proceso logístico para el gran evento.

4. ¿Durante el año contrata una sola empresa de BTL para realizar todas sus campañas o contrata a diferentes empresas según el tipo de campaña que va realizar?

No, contratamos a varias porque una empresas pequeña, no puede realizar un evento cada dos meses y por ello que buscamos a la segunda y tercera opción para el Club.

5. ¿Cuáles son los medios de comunicación que usted utiliza para comunicarse y enterarse de las empresas BTL?

Bueno, muchas veces utilizamos el internet o pedimos referidos a los socios y en otras ocasiones nos llegan sus cartas de presentación.

6. ¿Cuáles son los beneficios que usted espera cuándo realiza una campaña BTL?

Conseguir que los socios vengan más seguido al Club y tratar de incrementar el número de socios por referidos.

7. ¿Cómo usted se contactó con Naranja Producciones?

Más o menos fue hace un año sino me equivoco, cuando estábamos buscando a un nuevo proveedor de eventos y uno de los socios nos comentó que tenía un amigo que 
hacia eventos en el MINSA y que ya contaba con experiencia, así que le dijimos que nos pasara su número y eso fue todo, así empezamos a trabajar con Naranja Producciones S.A.C.

8. ¿Por qué escogió Naranja Producciones?

Necesitábamos un proveedor para un pequeño catering, así que al ver que Naranja Producciones S.A.C, contaba con experiencia previa para un ministerio, quisimos probarlos. Claro que les dimos un pequeño evento para ver como resultada.

Ya después de ese evento, les empezamos a dar más trabajo, pero de a pocos.

Lo que, si te puedo decir, es que son confiables, pero por el momento solo queremos trabajar con ellos para cosas pequeñas y medianas, por un tema prevención, ya más adelante cuando veamos que están trabajando cosas más grandes, les diremos que nos hagan trabajamos de mayor tamaño.

9. ¿Estuvo satisfecho con el servicio brindado por Naranja Producciones?

Si lo estuvimos, pero también son eventos pequeños y medianos para tener mayor control sobre el proveedor.

10. ¿Usted Logró los beneficios esperados al realizar campañas BTL?

Creemos que sí, porque los eventos salen bien, pero no tenemos forma de medir con números reales los resultados. Hacemos varios esfuerzos para lograr un mayor flujo de socios en el club, pero creemos que al salir los eventos como esperamos, los invitados a el salen satisfechos.

11. ¿Cuál es el presupuesto del año 2014 para las campañas BTL?

No te puedo decir el monto, pero es el $30 \%$ del monto total en publicidad.

12. ¿Ud. Considera aumentar el presupuesto asignado a campañas BTL en el próximo año?

En realidad, sí, pero lo hacemos de a pocos. Este año lo aumentamos en 3\%.

13. ¿Cuántas veces al año contrata estos servicios y en qué temporadas?

Por lo general en fechas festivas como el Día de la madre, del padre, del niño, fiestas patrias, el aniversario del Club, cosas así.

Los eventos se realizan 1 vez cada 2 meses por lo general y en promedio las campañas son de $S / 8,000$ en promedio, porque son pequeñas y medianas.

14. ¿Qué empresas dedicadas al servicio de BTL conoce actualmente y con cuales ha trabajado en algún momento?

Bueno, están las empresas grandes como Rocoto BTL, pero contratamos a empresas como Roho Producciones S.A.C, Naranja Producciones S.A.C, Mangosta Comunicaciones, etc. 
15. ¿Estuvo satisfecho con el servicio brindado por las empresas BTL que ha contrato hasta el momento?

Hasta ahora todo bien, algunos eventos no salieron al $100 \%$, pero en términos generales creemos que todo salió okay.

16. ¿Qué expectativas futuras usted tiene sobre el BTL en el mercado nacional?

Como es más económica que el ATL, creo que va seguir creciendo.

17. ¿Ud. Recomendaría a Naranja Producciones?

Si claro que lo haría.

\section{EMPRESA CLIENTE “ ROHO PRODUCCIONES S.A.C.”}

\section{Contacto: Bertarelli Bustamante Carla Patricia}

\section{Preguntas:}

1. ¿Por qué buscó servicios de BTL?

Es curioso, pero en realidad nosotros nos dedicamos a brindar este servicio a las empresas, pero en muchas ocasiones, subcontratamos algunos procesos de los servicios, porque ya no nos damos abasto.

Hacemos campañas medianas y grandes, tenemos clientes como Cencosud y Backus por citar algunos ejemplos.

2. ¿Usted podría mencionarnos cuáles son los criterios de selección para contratar una empresa BTL?

Para subcontratar a una empresa de BTL, vemos que cuente con algunos años 5 años en el mercado como mínimo, que tengan una cartera de clientes interesante, que cuenten con equipos como audio y sonido propios, etc.

3. ¿Cuántas empresas considera como máximo para realizar una comparación de servicios para un próximo evento?

Por ejemplo, citamos a 3 empresas para escoger a una de ellas, pero todas las empresas ya han trabajado con nosotros en el pasado.

4. ¿Durante el año contrata una sola empresa de BTL para realizar todas sus campañas o contrata a diferentes empresas según el tipo de campaña que va realizar?

Sería imposible solamente contratar a una empresa, porque hacemos campañas realmente grandes para clientes importantes, así que subcontratamos a varias, claro está que nuestro cliente cree que nosotros brindamos todos los servicios de la campaña. 
5. ¿Cuáles son los medios de comunicación que usted utiliza para comunicarse y enterarse de las empresas BTL?

Mira, en nuestro caso es por un tema de relaciones públicas por decirlo de una manera. César Jaén es el amigo de la universidad de uno de los socios de la empresa y por eso empezamos a trabajar con ellos.

Pero si queremos trabajar con otra empresa de campañas BTL, pues googlemos.

6. ¿Cuáles son los beneficios que usted espera cuándo realiza una campaña BTL? Que nuestros clientes nos vuelvan a llamar.

7. ¿Cómo usted se contactó con Naranja Producciones?

Como te dije anteriormente, César es amigo de uno de los socios. Ambos estudiaron en la Universidad Agraria, sino me equivoco.

8. ¿Por qué escogió Naranja Producciones?

Los chicos de Naranja Producciones son geniales, porque tiene capacidad de acción y saben responder rápido a los problemas. Además, cuentan con equipos, atuendos, disfraces y suficiente personal.

9. ¿Estuvo satisfecho con el servicio brindado por Naranja Producciones?

$\mathrm{Si}$, aunque a veces son algo impuntuales, pero en general todo esta regio.

10. ¿Usted Logró los beneficios esperados al realizar campañas BTL?

Conseguimos que nuestros clientes nos vuelvan a contratar.

11. ¿Cuál es el presupuesto del año 2014 para las campañas BTL?

Como explicarlo, nuestra mejor carta de presentación son las campañas realizadas a nuestros clientes, o sea, si realizamos un evento que sale al $100 \%$ las demás empresas nos van a querer contratar, además lo difundimos por redes sociales.

Al ser nuestro público objetivo empresas que contratan a empresas de BTL, nosotros como organización buscamos hacernos conocidos por redes sociales y por nuestro trabajo como ya indiqué. En realidad, es un tema de relaciones públicas.

Pero si se que nuestros clientes por lo general destinan entre un 20 a un $30 \%$ de su presupuesto en BTL.

12. ¿Ud. Considera aumentar el presupuesto asignado a campañas BTL en el próximo año?

Esperamos que nuestros clientes contraten más empresas BTL, yo creo que sí. Estoy convencida que si van a destinar más dinero en BTL el próximo año.

13. ¿Cuántas veces al año contrata estos servicios y en qué temporadas?

A ver ah, siempre nos contratan durante todo el año, pero durante el verano hay bastantes campañas en las playas del Sur Chico y en Asia. 
14. ¿Qué empresas dedicadas al servicio de BTL conoce actualmente y con cuales ha trabajado en algún momento?

A parte de nosotros, esta Mangosta Comunicaciones, Rocoto BTL, Yellow Btl, Circus, Glenda Yaker Eventos Especiales, Mayo, en realidad hay bastantes empresas en el sector, grandes y pequeñitas.

15. ¿Estuvo satisfecho con el servicio brindado por las empresas BTL que ha contrato hasta el momento?

Hay empresas que nos ha fachado en más de una ocasión y ya no trabajamos con ellas, pero yo creo que si hemos tenido suerte con varias empresas de BTL.

16. ¿Qué expectativas futuras usted tiene sobre el BTL en el mercado nacional?

Querida, que va seguir creciendo cada año y eso le conviene a nuestra empresa.

17. ¿Ud. Recomendaría a Naranja Producciones?

Si lo haría.

\section{EMPRESA CLIENTE "Mangosta Comunicaciones S.A.C."}

\section{Contacto: Leonardo de La Cruz.}

1. ¿Por qué buscó servicios de BTL?

Tío, nosotros hacemos campaña BTL, nuestro primer cliente fue Directv, porque yo hace años trabajaba para el Hotel Radisson de Miraflores y ahí Directv hacia varios eventos. Empece alquilándole luces y ahora les hago todas o casi todas sus campañas, pero solo la parte logística, ya que ellos contratan a otra empresa en hacer la idea creativa.

Porque subcontrato a veces, es porque hay campañas que son muy pero muy grandes y no nos alcanza nuestra capacidad logística y ahí entra Naranja Producciones S.A.C., pero también a veces trabajamos con ellos como socios, por falta de capital.

2. ¿Usted podría mencionarnos cuáles son los criterios de selección para contratar una empresa BTL?

Que cuente con suficiente liquidez para poder asociarnos con ella para realizar campañas de gran tamaño. También que cuente con su propia logística y base de proveedores, además, de contar con experiencia y con su propia cartera de clientes.

3. ¿Cuántas empresas considera como máximo para realizar una comparación de servicios para un próximo evento?

Creo que 3 a lo mucho, pero entre ellas siempre esta Naranja Producciones S.A.C.; debido a que a César lo conozco desde hace muchísimos años. 
4. ¿Durante el año contrata una sola empresa de BTL para realizar todas sus campañas o contrata a diferentes empresas según el tipo de campaña que va realizar? Hemos contratado a varias, pero por lo general a la empresa de César.

5. ¿Cuáles son los medios de comunicación que usted utiliza para comunicarse y enterarse de las empresas BTL?

Siempre utilizo redes sociales e internet en general, pero con los años que tengo en el sector, me conozco a varios dueños de empresas de BTL.

6. ¿Cuáles son los beneficios que usted espera cuándo realiza una campaña BTL? Yo soy muy exigente y nunca dejo que nada se escape. Me gusta la excelencia, la puntualidad, el orden y un trabajo bien hecho. Nunca te dirán que Mangosta Comunicaciones haya presentado un mal trabajo, así que siempre busco como beneficio el éxito de la campaña de BTL.

7. ¿Cómo usted se contactó con Naranja Producciones?

En realidad, de casualidad, porque en un evento conocí a César y luego nos hicimos amigo y después me enteré que él también tenía una empresa de BTL pero más pequeña y así empezamos a trabajar juntos.

8. ¿Por qué escogió Naranja Producciones?

Por la puntualidad y profesionalismo de Cesar y Shery. Nunca me han fallado y eso es para mí muy importante, la confianza que se genera a la hora de trabajar.

9. ¿Estuvo satisfecho con el servicio brindado por Naranja Producciones? Siempre lo he estado.

10. ¿Usted Logró los beneficios esperados al realizar campañas BTL?

Claro que sí, nunca hemos perdido a un cliente por realizar una mala campaña de BTL.

11. ¿Cuál es el presupuesto del año 2014 para las campañas BTL?

Yo sé que en el sector por lo general destinan más o menos un $25 \%$. Por ejemplo, Directv destina ese porcentaje más o menos y trabaja con tres proveedores de BTL, entre ellos estamos nosotros.

Naranja ha trabajado con Directv pero bajo el nombre de Mangosta Comunicaciones.

12. ¿Ud. Considera aumentar el presupuesto asignado a campañas BTL en el próximo año?

Nosotros trabajamos por un tema de relaciones públicas, pero si sé que nuestros clientes si van a aumentar su presupuesto, en cuanto no lo sé.

13. ¿Cuántas veces al año contrata estos servicios y en qué temporadas?

Tenemos mucho trabajo desde mitad de año hasta cavando el verano, luego baja un poco. 
14. ¿Qué empresas dedicadas al servicio de BTL conoce actualmente y con cuales ha trabajado en algún momento?

Hay varias, más de 20, pero Mayo, Grey son las más grandes, pero por lo general empresas como Directv las contratan a ellas para realizar la idea creativa y a nosotros nos contratan para la producción de esa idea.

Hemos trabajado con las más grandes y con naranja Producciones S.A.C..

15. ¿Estuvo satisfecho con el servicio brindado por las empresas BTL que ha contrato hasta el momento?

Algunas si me han fallado y nunca más las hemos contratado.

Hay muchas empresas que ya no existen, debido a que el sector es muy competitivo e informal.

16. ¿Qué expectativas futuras usted tiene sobre el BTL en el mercado nacional?

Que va seguir creciendo. El mercado aún no se ha desarrollado en su plenitud, solo hay que ver a nuestros vecinos como Brasil y Argentina, en donde el BTL está muy desarrollado.

17. ¿Ud. Recomendaría a Naranja Producciones?

Of course. César es mi amigo y un gran socio.

\section{EMPRESA CLIENTE "Campos Abogados e Infraestructura" \\ Contacto: Renzo Seminario Cordova.}

1. ¿Por qué buscó servicios de BTL?

Porque necesitábamos realizar eventos corporativos, contratar anfitrionas, equipos de sonido y audio, coffee break, merchandising, estructuras metálicas relacionados a temas inmobiliarios.

2. ¿Usted podría mencionarnos cuáles son los criterios de selección para contratar una empresa BTL?

Que ya hayan trabajado con empresas de mediano tamaño como minimo, que cuenten con 5 años de experiencia previa, que tengan documentada su facturación con montos de campañas y eventos no menores a 50 soles, por decir algunas.

3. ¿Cuántas empresas considera como máximo para realizar una comparación de servicios para un próximo evento?

Por lo general 5 empresas.

4. ¿Durante el año contrata una sola empresa de BTL para realizar todas sus campañas o contrata a diferentes empresas según el tipo de campaña que va realizar? 
Contratamos a varias, pero no pasan de 4 al año,

5. ¿Cuáles son los medios de comunicación que usted utiliza para comunicarse y enterarse de las empresas BTL?

Las empresas envían cartas de presentación al Estudio de Abogados y buscamos empresas referidas.

Ahora, cuando tenemos algún requerimiento mandamos correos a los proveedores de servicios y revisamos sus propuestas.

6. ¿Cuáles son los beneficios que usted espera cuándo realiza una campaña BTL?

Que nuestros clientes salgan totalmente satisfechos de nuestras conferencias y eventos.

7. ¿Cómo usted se contactó con Naranja Producciones?

La verdad, es que César es mi primo hermano y por eso lo contrate.

8. ¿Por qué escogió Naranja Producciones?

Porque ya sabía que habían trabajado anteriormente con varias instituciones públicas y privadas como la constructora Urbana.

9. ¿Estuvo satisfecho con el servicio brindado por Naranja Producciones?

Si lo estuve y lo sigo estando.

10. ¿Usted Logró los beneficios esperados al realizar campañas BTL?

Sí, pero por lo general lo que nosotros hacemos son conferencias, así que mientras esta salga bien, nuestro objetivo está cumplido.

11. ¿Cuál es el presupuesto del año 2014 para las campañas BTL?

Más o menos un $23 \%$, se trabaja mucho el tema de relaciones públicas.

12. ¿Ud. Considera aumentar el presupuesto asignado a campañas BTL en el próximo año?

Creo que sí, pero tampoco sería mucho, más o menos un $4 \%$.

13. ¿Cuántas veces al año contrata estos servicios y en qué temporadas?

Serán como 8 veces al año, pero con indistintas empresas y en temporadas indefinidas en realidad.

14. ¿Qué empresas dedicadas al servicio de BTL conoce actualmente y con cuales ha trabajado en algún momento?

La verdad, no muchas, porque no trabajamos con empresas grandes, porque más que todo hacemos eventos.

Hemos trabajado con Roho, Mangosta y Naranja, pero no me acuerdo las demás.

15. ¿Estuvo satisfecho con el servicio brindado por las empresas BTL que ha contrato hasta el momento? 
Si, la verdad que sí. No tuvimos ningún problema, además, ponemos penalidad del $10 \%$ por falta al contrato.

16. ¿Qué expectativas futuras usted tiene sobre el BTL en el mercado nacional?

Es probable que siga creciendo.

17. ¿Ud. Recomendaría a Naranja Producciones?

Lo haría.

\section{NO CLIENTE EMPRESA “EVERANDES S.A.C."}

\section{Contacto Yessica Delgado, Jefa de Gestión de Talentos}

\section{Preguntas:}

1. ¿Por qué buscó servicios de BTL?

Buscamos servicios de BTL, para tener un estilo diferente en cada actividad junto con nuestros colegas; de esa manera vemos si esa empresa llena nuestras expectativas ó en un próximo evento llamamos a nuestra segunda opción.

2. ¿Qué opinión tiene sobre las campañas BTL?

Mi opinión que tengo sobre las diversas campañas, que es un gran apoyo para el área; ya que nosotros buscamos 3 meses antes referencias sobre empresas de BTL que ya realizaron una campaña / evento similar al que necesitamos emprender. Por ejemplo, Aniversario de Evergreen pero al estilo Hollywood.

3. ¿Usted podría mencionarnos cuáles son los criterios de selección para contratar una empresa BTL?

Los criterios que buscamos son: optimizar tiempos, ubicar en un primer plano sin distractores y respetar siempre el presupuesto; esos serían los puntos principales que vemos. De igual manera, que sus servicios sean variados dando nuevas ideas y a la vez que tenga prestigio entre sus clientes.

4. ¿Cuáles son los criterios para invitar a una empresa de BTL a un proceso de selección?

Lo principal que pedimos referencias entre nuestros conocidos de los gerentes, colegas; sino buscamos por web que empresas de BTL. Apartir de ello, los criterios son: Presencia en el mercado, diversidad de servicios, cartera de clientes, inversión a gran escala para los eventos, contar con proveedores de gran magnitud.

5. ¿Cuántas empresas considera como máximo para realizar una comparación de servicios para un próximo evento?

Al menos debemos contar con 5 empresas. 
6. ¿Durante el año contrata una sola empresa de BTL para realizar todas sus campañas o contrata a diferentes empresas según el tipo de campaña que va realizar?

Durante el año, tenemos tres eventos principales (setiembre, diciembre y cierre del año), aquí tenemos 2 empresas principales. Para otros eventos (por ejemplo, día de la madre, día del niño, etc.) ya buscamos a una empresa que pueda proyectar todos estos pequeños eventos y sí responde con nuestras perspectivas, podemos darle una campaña mucho más grande.

7. ¿Cada vez que realizan una convocatoria de selección de algún proveedor para realizar una campaña de BTL, se promueve la rotación de estos proveedores, para que exista una mayor oferta o siempre se realizar la convocatoria a los mismos proveedores cada vez que se realiza una campaña?

En estos últimos 3 años, convocamos a las mismas tres empresas para que nos realicen los presupuestos y ver con quien quedarnos.

8. ¿Cuáles son los medios de comunicación que usted utiliza para comunicarse y enterarse de las empresas BTL?

Mayormente, el medio de comunicación es las redes sociales y páginas web. Si veo un spot publicitario y me impacta, puede ser que llame para tener mayores referencias.

9. ¿Cuáles son los beneficios que usted espera cuándo realiza una campaña BTL?

Como ya comenté anteriormente son: optimizar tiempo, eliminar distractores y siempre respetar los presupuestos, porque después no queremos pagar adicionales sin tener un porqué cuando ya se cerró el contrato.

10. ¿Qué empresas conoces para el servicio de campaña de BTL?

Las empresas que conozco es Draming Up y Mediaticae Innova; siempres trabajamos con ellos.

11. ¿Qué empresas ha utilizado para dichos servicios?

Las que mencioné: Draming Up y Mediaticae Innova.

12. ¿Cómo se llama la última empresa que contrato para realizar campañas BTL?

Limaq, para un día de integración en Fiestas Patrias.

13. ¿Qué opinión a favor y contra tiene usted sobre la última empresa que contrató?

Bien, para ser un nueva empresa que trabaja con nosotros. Pero le faltaba darnos un feedback o que improvisto se pudo observar para tenerlo encuenta.

14. ¿Cuantas veces al año usted rota de proveedor de servicios de BTL?

No mucho rotamos, cada año buscamos a nuevas empresas para ver que servicios ofrecen y sus cotizaciones, porque tenemos un tope de inversión.

15. ¿Cuántas veces al año usted contrata este servicio? 
3 eventos que son las principales; de ahí depende de Gerencia si desean realizar integraciones.

16. ¿Cuáles son los meses de mayor demanda del servicio de BTL?

Como mencioné, los meses de setiembre y diciembre.

17. ¿En qué medios usted se enteró de las empresas de BTL?

Para estas últimas que mencioné, por web los pude encontrar.

18. ¿usted recomendaría a la última empresa de BTL que contrató?

Claro, si lo recomendaría a mis colegas.

19. ¿Cuál es el presupuesto del año 2014 para las campañas BTL?

Nuestra gerencia nos indica para pequeñas campañas hasta 5000 soles; ya para grandes como cierre de año puede ser 12000 soles aproximadamente.

20. ¿Ud. Considera aumentar el presupuesto asignado a campañas BTL en el próximo año?

Por supuesto, debería aumentarse porque uno nuevo año, son nuevos proyectos para nuestros colaboradores.

\section{EMPRESA NO CLIENTE “AGROIMEX TRADING”:}

\section{Contacto Suley Lincham, Asistente de Gerencia General}

\section{Preguntas:}

1. ¿Por qué buscó servicios de BTL?

Buscamos servicios de BTL porque nos ayudan aumentar la confianza con nuestros clientes potenciales y a la vez damos el BTL no apoya creativamente en varios proyectos.

2. ¿Qué opinión tiene sobre las campañas BTL?

Que son buenas para nuestro sector agrario, ya que al entregar información a nuestros clientes, lo realizan de manera didáctica y de fácil uso. Asimismo, las campañas BTL son para nosotros mucho más productivo que entregar tarjetas; pues se realizan eventos corporativos tanto en Lima como en provincia.

3. ¿Usted podría mencionarnos cuáles son los criterios de selección para contratar una empresa BTL? 
El criterio que tenemos es la creatividad, pues buscamos ser didácticos en cada campaña, también que sus proveedores estén en varios puntos del país y así sea fácil la movilización de los materiales.

4. ¿Cuáles son los criterios para invitar a una empresa de BTL a un proceso de selección?

Primero que buscamos 3 meses antes varios proveedores y a partir de ello buscamos la cotización, nivel de inversión, tiempo de espera, diversidad de servicios que brindan y a la vez si otras empresas del medio han trabajado con el futuro proveedor.

5. ¿Cuántas empresas considera como máximo para realizar una comparación de servicios para un próximo evento?

Consideramos 3 empresas para empezar el proyecto.

6. ¿Durante el año contrata una sola empresa de BTL para realizar todas sus campañas o contrata a diferentes empresas según el tipo de campaña que va realizar?

Durante el año, contratamos a varias; porque nuestras campañas se encuentran en Lima y Provincias (Ica, Arequipa, Trujillo).

7. ¿Cada vez que realizan una convocatoria de selección de algún proveedor para realizar una campaña de BTL, se promueve la rotación de estos proveedores, para que exista una mayor oferta o siempre se realizar la convocatoria a los mismos proveedores cada vez que se realiza una campaña?

Tratamos de no rotar mucho a los proveedores, ya que tenemos confianza en su trabajo. Pero si en un momento, nos falla en un evento / feria, dejamos de trabajar con ellos y vemos nuestra segunda mejor opción.

8. ¿Cuáles son los medios de comunicación que usted utiliza para comunicarse y enterarse de las empresas BTL?

Mayormente es por la web, medios audiovisuales o en lo común, por referencial de compañeros.

9. ¿Cuáles son los beneficios que usted espera cuándo realiza una campaña BTL?

Los beneficios que esperamos es integridad, confianza con el cliente y conocer nuestros servicios pre y post trabajo.

10. ¿Qué empresas conoces para el servicio de campaña de BTL?

Conocemos dos: Studio Manda y Soluciones S.A.C..

11. ¿Qué empresas ha utilizado para dichos servicios?

Hemos utilizado a las dos empresas mencionadas.

12. ¿Cómo se llama la última empresa que contrato para realizar campañas BTL?

Studio Manda para una feria ADEX.

13. ¿Qué opinión a favor y contra tiene usted sobre la última empresa que contrató? 
Sobre la empresa, estamos muy contentos en trabajar con ellos, porque nos da ideas creativas, brochure muy didácticos y están a tiempo con la formación del stand. En contra, podría mencionar que se pasan un $20 \%$ del presupuesto justo antes de empezar la feria; pero se puede arreglar en ese momento o disminuir algunas cosas.

14. ¿Cuantas veces al año usted rota de proveedor de servicios de BTL?

Dos veces como máximo.

15. ¿Cuántas veces al año usted contrata este servicio?

Contratamos servicios para eventos como Ferias ADEX, Expoalimentaria y Siuva(Ica).

16. ¿Cuáles son los meses de mayor demanda del servicio de BTL?

Como estamos en el medio agrícola, los meses serian de Julio, Setiembre y Octubre.

17. ¿En qué medios usted se enteró de las empresas de BTL?

Por web, correos corporativos o por compañeros.

18. ¿Usted recomendaría a la última empresa de BTL que contrató?

Si claro, es una buena empresa que nos apoya hace varios años.

19. ¿Cuál es el presupuesto del año 2014 para las campañas BTL?

El presupuesto varia, en una Siuva de tres días (ICA) es 3000 soles aproximadamente y ya una feria Expoalimentaria de 3 días es 7500 soles aproximadamente.

20. ¿Ud. Considera aumentar el presupuesto asignado a campañas BTL en el próximo año?

No, el próximo año estamos viendo que eventos si ir y el otro ser solo visitantes; de esa manera bajamos los costos.

\section{EMPRESA NO CLIENTE “UNIVERSIDAD PERUANA DE CIENCIAS APLICADAS -} UPC"

Contacto Pamela Sanchez, asistente de Marketing.

Preguntas:

1. ¿Por qué buscó servicios de BTL?

Buscamos servicios de BTL, porque nos ayuda a interactuar más cerca con nuestros clientes, asimismo el servicio debe ser $360^{\circ}$ para que puedan trabajar con nosotros.

2. ¿Qué opinión tiene sobre las campañas BTL?

Mi opinión sobre las campañas, es que son muy fundamentales para lograr mayor la captación de los clientes. En nuestro caso, es en cada distrito que estará un campus de la UPC, cada colegio que quiera integrarse con nosotros; y para ello, necesitamos tener a la mano un servicio de BTL excepcional. 
3. ¿Usted podría mencionarnos cuáles son los criterios de selección para contratar una empresa BTL?

Los criterios que consideramos es su cartera de clientes, nivel de inversión para proyectos grandes, diferenciación de servicios en Lima y si tuvieran en provincias y capital humano que trabajan en la empresa.

4. ¿Cuáles son los criterios para invitar a una empresa de BTL a un proceso de selección?

Los criterios para invitar sería su nivel de puntualidad, clientes que tuvieron para realizar las preguntas pertinentes, compromiso y creatividad en cada trabajo.

5. ¿Cuántas empresas considera como máximo para realizar una comparación de servicios para un próximo evento?

Consideramos 3 empresas.

6. ¿Durante el año contrata una sola empresa de BTL para realizar todas sus campañas o contrata a diferentes empresas según el tipo de campaña que va realizar?

No, siempre contratamos a dos empresas; ya si una de ellas no puede tener a cargo un evento, vamos por nuestra tercera opción más acertada.

7. ¿Cada vez que realizan una convocatoria de selección de algún proveedor para realizar una campaña de BTL, se promueve la rotación de estos proveedores, para que exista una mayor oferta o siempre se realizar la convocatoria a los mismos proveedores cada vez que se realiza una campaña?

No, ya tenemos nuestros proveedores en base de datos.

8. ¿Cuáles son los medios de comunicación que usted utiliza para comunicarse y enterarse de las empresas BTL?

Por referencia y red social.

9. ¿Cuáles son los beneficios que usted espera cuándo realiza una campaña BTL?

Los beneficios que esperamos es la mejor comunicación con nuestros alumnos y futuros alumnos; ya que de esta manera la UPC sería su primera opción para postular.

10. ¿Qué empresas conoces para el servicio de campaña de BTL?

Conozco a Grey Perú, GyC Media y Creart, Marketing Visual 360.

11. ¿Qué empresas ha utilizado para dichos servicios?

Hemos trabajado con GyC Media y Marketing Visual 360.

12. ¿Cómo se llama la última empresa que contrato para realizar campañas BTL?

La última empresa GyC Media.

13. ¿Qué opinión a favor y contra tiene usted sobre la última empresa que contrató?

Es una empresa buena, cuenta con buenos estándares de servicios y además que nosotros planteamos la idea y ellos crean todo. 
14. ¿Cuantas veces al año usted rota de proveedor de servicios de BTL?

No rotamos mucho, puede ser una vez al año.

15. ¿Cuántas veces al año usted contrata este servicio?

Contratamos el servicio cada inicio de nuevos ciclos y fin de año.

16. ¿Cuáles son los meses de mayor demanda del servicio de BTL?

Febrero, Marzo y Noviembre.

17. ¿En qué medios usted se enteró de las empresas de BTL?

Por la web nos enteramos y publicidad.

18. ¿usted recomendaría a la última empresa de BTL que contrató?

Si claro, recomendaría a mis colegas.

19. ¿Cuál es el presupuesto del año 2014 para las campañas BTL?

El presupuesto es de 5000 soles por campaña.

20. ¿Ud. Considera aumentar el presupuesto asignado a campañas BTL en el próximo año?

Esperemos que el próximo año se pueda aumentar, ya que tendremos más sucursales de la universidad.

\section{EMPRESA NO CLIENTE "Laberinto BTL"}

\section{Contacto Jimmy Jaén Seminario, Gerente General}

Preguntas:

1. ¿Por qué buscó servicios de BTL?

Nosotros damos servicio BTL, pero también buscamos a empresas que realizan para trabajar a la par.

2. ¿Qué opinión tiene sobre las campañas BTL?

Las campañas BTL están creciendo a gran escala, ya que no todo es publicitado por televisión o radio; sino por redes sociales y cara en cara. Con ello, es importante estar en contacto con nuestros clientes directo de UBER, los conductores y no directos, los pasajeros de UBER.

3. ¿Usted podría mencionarnos cuáles son los criterios de selección para contratar una empresa BTL?

Los criterios que se debería tener es nivel de inversión, diversidad de proveedores y personal creativa para el trabajo.

4. ¿Cuáles son los criterios para invitar a una empresa de BTL a un proceso de selección? 
Debería ser la cartera de clientes que cuentan y el poder adquisitivo para un buen proyecto.

5. ¿Cuántas empresas considera como máximo para realizar una comparación de servicios para un próximo evento?

Mínimo tres empresas para contar con varias propuestas.

6. ¿Durante el año contrata una sola empresa de BTL para realizar todas sus campañas o contrata a diferentes empresas según el tipo de campaña que va realizar?

Para este caso, contratamos o trabajamos a la mano con dos empresas.

7. ¿Cada vez que realizan una convocatoria de selección de algún proveedor para realizar una campaña de BTL, se promueve la rotación de estos proveedores, para que exista una mayor oferta o siempre se realizar la convocatoria a los mismos proveedores cada vez que se realiza una campaña?

No variamos de proveedores porque ya tenemos identificados los eventos a trabajar y ellos ya cuenta con todas las herramientas.

8. ¿Cuáles son los medios de comunicación que usted utiliza para comunicarse y enterarse de las empresas BTL?

En nuestro caso con UBER, es por redes sociales que es la última tendencia.

9. ¿Cuáles son los beneficios que usted espera cuándo realiza una campaña BTL?

Los beneficios que buscamos, es llegar a captar más clientes, entiendan el propósito de la campaña y lograr fidelidad con la campaña.

10. ¿Qué empresas conoces para el servicio de campaña de BTL?

Conozco a Manya, Marketing Visual 360 y Enfokarte.

11. ¿Qué empresas ha utilizado para dichos servicios?

Hemos trabajado a la mano con Creart.

12. ¿Cómo se llama la última empresa que contrato para realizar campañas BTL? Una campaña de integración con Creart.

13. ¿Qué opinión a favor y contra tiene usted sobre la última empresa que contrató?

Podría ser que falta financiamiento para lograr trabaja por igual.

14. ¿Cuantas veces al año usted rota de proveedor de servicios de BTL?

Sería una vez cada seis meses, para ir viendo como están en sus eventos y clientes.

15. ¿Cuántas veces al año usted contrata este servicio?

Dos veces al año.

16. ¿Cuáles son los meses de mayor demanda del servicio de BTL?

Con mi cliente potencial, UBER, tenemos todos los meses campañas, pero podría activar con mayor influencia los meses de Julio y Diciembre.

17. ¿En qué medios usted se enteró de las empresas de BTL? 
Por la web y comentarios de compañeros.

18. ¿usted recomendaría a la última empresa de BTL que contrató?

Si recomendaría a la empresa.

19. ¿Cuál es el presupuesto del año 2014 para las campañas BTL?

Para UBER, el presupuesto es de 2000 soles por mes.

20. ¿Ud. Considera aumentar el presupuesto asignado a campañas BTL en el próximo año?

Esperemos para el próximo año aumentar el presupuesto.

\section{EMPRESA NO CLIENTE "Sinapsis Productores S.A.C"}

\section{Contacto Renato Sarmiento, Productor}

\section{Preguntas:}

1. ¿Por qué buscó servicios de BTL?

Buscamos servicios BTL para nuestros clientes, para lograr mayor fidelización con sus clientes.

2. ¿Qué opinión tiene sobre las campañas BTL?

Que son excelentes cuando están en buenas manos e idealizando todo el trabajo para ponerlo en marcha.

3. ¿Usted podría mencionarnos cuáles son los criterios de selección para contratar una empresa BTL?

Los criterios que debería tenerse siempre es la liquidez para un evento, diversidad de servicios, proveedores $\mathrm{A} 1 \mathrm{y}$ tener prestigio en cada evento que realizan.

4. ¿Cuáles son los criterios para invitar a una empresa de BTL a un proceso de selección?

Deberían ser todos los mencionados hace un momento.

5. ¿Cuántas empresas considera como máximo para realizar una comparación de servicios para un próximo evento?

Debería ser por lo menos tres empresas.

6. ¿Durante el año contrata una sola empresa de BTL para realizar todas sus campañas o contrata a diferentes empresas según el tipo de campaña que va realizar?

Contratamos a un par por los eventos que realizamos.

7. ¿Cada vez que realizan una convocatoria de selección de algún proveedor para realizar una campaña de BTL, se promueve la rotación de estos proveedores, para 
que exista una mayor oferta o siempre se realizar la convocatoria a los mismos proveedores cada vez que se realiza una campaña?

Son los mismos, no buscamos rotar a muchos.

8. ¿Cuáles son los medios de comunicación que usted utiliza para comunicarse y enterarse de las empresas BTL?

Por medio de contactos y web.

9. ¿Cuáles son los beneficios que usted espera cuándo realiza una campaña BTL?

Los beneficios que buscamos es captación de clientes y fidelización.

10. ¿Qué empresas conoces para el servicio de campaña de BTL?

Comunica Ideas y otras más pequeñas.

11. ¿Qué empresas ha utilizado para dichos servicios?

Hemos trabajado con Comunica Ideas.

12. ¿Cómo se llama la última empresa que contrato para realizar campañas BTL?

Último fue Elama Eventos en una activación.

13. ¿Qué opinión a favor y contra tiene usted sobre la última empresa que contrató?

Para trabajar por primera vez, muy buen servicio y equipos en buen estado.

14. ¿Cuantas veces al año usted rota de proveedor de servicios de BTL? Muy poco rotamos, son casos excepcionales.

15. ¿Cuántas veces al año usted contrata este servicio?

Dos veces por año.

16. ¿Cuáles son los meses de mayor demanda del servicio de BTL?

Dependiendo de los clientes, pero tenemos mayor demanda en Julio y Diciembre.

17. ¿En qué medios usted se enteró de las empresas de BTL?

Mayormente nos enteramos por web, ferias y publicidad por Linkedin.

18. ¿usted recomendaría a la última empresa de BTL que contrató?

$\mathrm{Si}$, es una buena empresa que está empezando; pero como se ve hoy en día cada vez existen más empresas informales y que no tienen mucha experiencia o terciarizan sus servicios.

19. ¿Cuál es el presupuesto del año 2014 para las campañas BTL?

Tenemos desde 2000 soles a más, ya es dependiendo del cliente.

20. ¿Ud. Considera aumentar el presupuesto asignado a campañas BTL en el próximo año?

Buscamos que cada año, aumenten el presupuesto para lograr mayores logros en cada empresa. 


\section{ANEXO IX: TRANSCRIPCIÓN LITERAL: Opiniones de Expertos en el Sector}

\section{Empresa: Tresenraya BTL}

\section{Contacto: Sergio Montes - Asistente Producción}

\section{Preguntas:}

1. ¿Por qué buscó servicios de BTL?

Para terciarizar algunos de los trabajos de nuestros clientes debido a que nuestra empresa se encarga básicamente de la parte creativa.

2. ¿Qué opinión tiene sobre las campañas BTL?

Ayudan a promocionar los productos o servicios de las empresas y las campañas se realizan orientadas a un segmento .

3. ¿Usted podría mencionarnos cuáles son los criterios de selección para contratar una empresa BTL?

Experiencia, Precio y cartera de clientes.

4. ¿Cuáles son los criterios para invitar a una empresa de BTL a un proceso de selección?

Que tengan experiencia en el segmento de clientes a donde estamos dirigidos como el sector de farmacias, snacks e inmobiliario.

5. ¿Cuántas empresas considera como máximo para realizar una comparación de servicios para un próximo evento?

Como máximo necesitamos 4 comparaciones de precio.

6. ¿Durante el año contrata una sola empresa de BTL para realizar todas sus campañas o contrata a diferentes empresas según el tipo de campaña que va realizar?

Contratamos a varias empresas.

7. ¿Cada vez que realizan una convocatoria de selección de algún proveedor para realizar una campaña de BTL, se promueve la rotación de estos proveedores, para que exista una mayor oferta o siempre se realizar la convocatoria a los mismos proveedores cada vez que se realiza una campaña?

De las invitaciones que enviamos siempre tratamos de incorporar por lo menos una empresa nueva.

8. ¿Cuáles son los medios de comunicación que usted utiliza para comunicarse y enterarse de las empresas BTL?

Básicamente las redes sociales y el contacto directo con los proveedores.

9. ¿Cuáles son los beneficios que usted espera cuándo realiza una campaña BTL? 
Rentabilidad, ampliar cartera de clientes y una buena imagen de la empresa.

10. ¿Qué empresas conoces para el servicio de campaña de BTL?

Naranja Producciones, Rocoto Producciones, Chrimoya Producciones, Marketing Alterno y 360 BTL.

11. ¿Qué empresas ha utilizado para dichos servicios?

Hemos trabajado con Naranja Producciones, Chirimoya Producciones y 360 BTL.

12. ¿Cómo se llama la última empresa que contrato para realizar campañas BTL?

La última fue Chirimoya Producciones.

13. ¿Qué opinión a favor y contra tiene usted sobre la última empresa que contrató?

Tienen buen servicio pero la cobertura sólo es en Lima.

14. ¿Cuantas veces al año usted rota de proveedor de servicios de BTL?

Por lo menos rotamos 1 veces al año.

15. ¿Cuántas veces al año usted contrata este servicio?

Por lo menos contratamos el servicio 3 veces al año.

16. ¿Cuáles son los meses de mayor demanda del servicio de BTL?

Los meses de diciembre a mayo.

17. ¿En qué medios usted se enteró de las empresas de BTL?

A través de las redes sociales.

18. ¿usted recomendaría a la última empresa de BTL que contrató?

Si la campaña es en Lima, si la recomendaría.

19. ¿Cuál es el presupuesto del año 2015 para las campañas BTL?

Es cerca de S/ 200,000.

20. ¿Ud. Considera aumentar el presupuesto asignado a campañas BTL en el próximo año?

Se tiene planificado un incremento entre un $20 \%$ a $40 \%$ para el próximo año.

\section{Empresa: Energigas}

\section{Contacto: Sandra Milla Sandonas - Analista de Bienestar}

\section{Preguntas:}

1. ¿Por qué buscó servicios de BTL?

Bueno, utilizamos este tipo de servicio para nuestros eventos, talleres de comunicación interna, eventos y día de integración de la empresa (full days).

2. ¿Qué opinión tiene sobre las campañas BTL?

Mi opinión como Analista de Bienestar Social veo que se nota un cambio positivo en nuestros colaboradores luego de los talleres y full days que realizamos. 
3. ¿Usted podría mencionarnos cuáles son los criterios de selección para contratar una empresa BTL?

Bueno, básicamente buscamos experiencia en talleres, campañas de activación y actividades novedosas que se puedan realizar en los full days.

4. ¿Cuáles son los criterios para invitar a una empresa de BTL a un proceso de selección?

Básicamente buscamos experiencia, referencias y cartera de clientes.

5. ¿Cuántas empresas considera como máximo para realizar una comparación de servicios para un próximo evento?

Sólo buscamos 3 cotizaciones.

6. ¿Durante el año contrata una sola empresa de BTL para realizar todas sus campañas o contrata a diferentes empresas según el tipo de campaña que va realizar?

No, generalmente usamos 2 empresas de BTL al año.

7. ¿Cada vez que realizan una convocatoria de selección de algún proveedor para realizar una campaña de BTL, se promueve la rotación de estos proveedores, para que exista una mayor oferta o siempre se realizar la convocatoria a los mismos proveedores cada vez que se realiza una campaña?

Sí, siempre tratamos de rotar a los proveedores en campañas.

8. ¿Cuáles son los medios de comunicación que usted utiliza para comunicarse y enterarse de las empresas BTL?

Bueno, utilizamos mucho las redes sociales y experiencia de otras empresas.

9. ¿Cuáles son los beneficios que usted espera cuándo realiza una campaña BTL?

La efectividad y calidad del servicio.

10. ¿Qué empresas conoces para el servicio de campaña de BTL?

Yellow BTL, Naranja Producciones, AKM Warketing y OB 460.

11. ¿Qué empresas ha utilizado para dichos servicios?

Hemos utilizado a Yellow BTL y Naranja producciones el último año.

12. ¿Cómo se llama la última empresa que contrato para realizar campañas BTL? Yellow BTL.

13. ¿Qué opinión a favor y contra tiene usted sobre la última empresa que contrató?

Cumple con nuestras expectativas, pero los costos son un poco más elevados que el de otros proveedores, los cuales tenemos que asumir si estamos con el tiempo en contra.

14. ¿Cuantas veces al año usted rota de proveedor de servicios de BTL?

Bueno, siempre tratamos de que la rotación por lo menos sea una vez al año.

15. ¿Cuántas veces al año usted contrata este servicio? 
Contratamos el servicio por lo menos 4 veces al año los servicios de empresas BTL tanto para campañas como para eventos internos.

16. ¿Cuáles son los meses de mayor demanda del servicio de BTL?

Comenzamos nuestras campañas por el servicio que brindamos desde Noviembre para el aumento de consumo de gasolina en verano hasta mayo.

17. ¿En qué medios usted se enteró de las empresas de BTL?

Bueno, actualmente tengo trabajando en la empresa desde hace 2 años y desde que entré a trabajar ya se venía utilizando los servicios de empresas de BTL.

18. ¿usted recomendaría a la última empresa de BTL que contrató?

$\mathrm{Si}$, de todas maneras, sobre todo si estás con los tiempos bastante ajustados.

19. ¿Cuál es el presupuesto del año 2014 para las campañas BTL?

Bueno, por temas de confidencialidad de información no podemos indicar el importe que tenemos asignado, pero este año hemos tenido asignado un presupuesto de $15 \%$ del presupuesto de Recursos Humanos.

20. ¿Ud. Considera aumentar el presupuesto asignado a campañas BTL en el próximo año?

$\mathrm{Si}$, se tiene planificado la solicitar un aumento del $20 \%$ en el presupuesto del próximo año.

\section{Empresa: CreativoEPM}

\section{Contacto: Segio Perez Reyez - Asistente Producción}

\section{Preguntas:}

1. ¿Por qué buscó servicios de BTL?

En CreativoEPM buscamos servicios BTL para integrarlo en nuestra cadena de servicios o tercerizar los servicios solicitados por algunos de nuestros clientes ya que nosotros brindamos mayormente productos de merchandising y mobiliarios haciendo que se diferencia la imagen de una empresa.

2. ¿Qué opinión tiene sobre las campañas BTL?

Son bastante aceptadas por el público en general y está creciendo su demanda.

3. ¿Usted podría mencionarnos cuáles son los criterios de selección para contratar una empresa BTL?

Básicamente lo que busca es que tenga buenos precios y calidad de servicio.

4. ¿Cuáles son los criterios para invitar a una empresa de BTL a un proceso de selección?

Buscamos que brinden servicios afines a la necesidad de nuestros clientes. 
5. ¿Cuántas empresas considera como máximo para realizar una comparación de servicios para un próximo evento?

Ya tenemos una lista de empresas con las cuales trabajamos y generalmente nos basta con un par de opciones.

6. ¿Durante el año contrata una sola empresa de BTL para realizar todas sus campañas o contrata a diferentes empresas según el tipo de campaña que va realizar?

No, nada que ver, tenemos que tener muy en cuenta el tipo de cliente que tenemos para buscar la empresa de BTL a la que elegiremos.

7. ¿Cada vez que realizan una convocatoria de selección de algún proveedor para realizar una campaña de BTL, se promueve la rotación de estos proveedores, para que exista una mayor oferta o siempre se realizar la convocatoria a los mismos proveedores cada vez que se realiza una campaña?

No rotamos muchos a los proveedores, tenemos generalmente proveedores por tipo de especialidad de servicio, creativos o los que ejecutan la campaña.

8. ¿Cuáles son los medios de comunicación que usted utiliza para comunicarse y enterarse de las empresas BTL?

Básicamente utilizamos los contactos que tenemos con nuestros proveedores debido a que es un círculo bastante pequeño.

9. ¿Cuáles son los beneficios que usted espera cuándo realiza una campaña BTL? Buscamos básicamente calidad de servicio y precio.

10. ¿Qué empresas conoces para el servicio de campaña de BTL?

FCB MAYO Perú, Yellow BTL, Chirimoya BTL, Moving Pack, AKM Warketing.

11. ¿Qué empresas ha utilizado para dichos servicios?

Hemos trabajado con FCB Mayo y Yellow BTL.

12. ¿Cómo se llama la última empresa que contrato para realizar campañas BTL? Hemos trabajo con Yellow BTL.

13. ¿Qué opinión a favor y contra tiene usted sobre la última empresa que contrató?

El desempeño del servicio fue bueno, y cumplió las expectativas que se tenía del servicio.

14. ¿Cuantas veces al año usted rota de proveedor de servicios de BTL?

Rotamos varias veces, mucho depende del tipo de servicio que necesitamos brindar.

15. ¿Cuántas veces al año usted contrata este servicio?

Generalmente nos integramos de acuerdo a la necesidad del cliente y sub contratamos los servicios o entramos a trabajar en sociedad de acuerdo a la magnitud del requerimiento.

16. ¿Cuáles son los meses de mayor demanda del servicio de BTL? 
Realmente es todo el año pero tenemos lo más fuerte es en diciembre.

17. ¿En qué medios usted se enteró de las empresas de BTL?

En la empresa ya se venía trabajando desde hace varios años a raíz de la tercerización de una parte de los servicios que teníamos que brindar a un cliente y tuvimos que buscar y coordinar con algunos proveedores, y luego hemos ampliado la red de contactos a través de las redes sociales.

18. ¿usted recomendaría a la última empresa de BTL que contrató?

$\mathrm{Si}$, de todas maneras.

19. ¿Cuál es el presupuesto del año 2014 para las campañas BTL?

Mucho depende de que es lo que se necesite, por ejemplo este año a julio vamos ejecutando casi el $70 \%$ del presupuesto, lo cual representa cerca del $15 \%$ de nuestra rentabilidad.

20. ¿Ud. Considera aumentar el presupuesto asignado a campañas BTL en el próximo año?

$\mathrm{Si}$, se tiene considerado aumentar un 5\% para el próximo año.

\section{Empresa: Financiera Confianza}

\section{Contacto: Giovana Lozada - Gerenta de Marketing.}

\section{Preguntas:}

1. ¿Por qué buscó servicios de BTL?

Hacemos pocas campañas a nuestros clientes pero buscamos mejorar mejorar el ambiente de trabajo en nuestras oficinas.

2. ¿Qué opinión tiene sobre las campañas BTL?

Desde la experiencia que tengo en el sector, vemos que son bien recibidas.

3. ¿Usted podría mencionarnos cuáles son los criterios de selección para contratar una empresa BTL?

Buscamos mucho la reducción de costos pero sin afectar la calidad de servicio.

4. ¿Cuáles son los criterios para invitar a una empresa de BTL a un proceso de selección?

Costos y calidad.

5. ¿Cuántas empresas considera como máximo para realizar una comparación de servicios para un próximo evento?

Por temas normativos y procedimientos internos necesitamos que existan por lo menos 3 propuestas. 
6. ¿Durante el año contrata una sola empresa de BTL para realizar todas sus campañas o contrata a diferentes empresas según el tipo de campaña que va realizar?

No, siempre buscamos incorporar nuevos proveedores y escuchar las propuestas que tienen.

7. ¿Cada vez que realizan una convocatoria de selección de algún proveedor para realizar una campaña de BTL, se promueve la rotación de estos proveedores, para que exista una mayor oferta o siempre se realizar la convocatoria a los mismos proveedores cada vez que se realiza una campaña?

Definitivamente, siempre buscamos incorporar nuevos proveedores.

8. ¿Cuáles son los medios de comunicación que usted utiliza para comunicarse y enterarse de las empresas BTL?

A través de las campañas que se ven en medio, la búsqueda de nuevos proveedores por parte de nuestra área de Administración y por redes sociales.

9. ¿Cuáles son los beneficios que usted espera cuándo realiza una campaña BTL?

Buscamos llegar a nuestros clientes externos e internos.

10. ¿Qué empresas conoces para el servicio de campaña de BTL?

Con las últimas que hemos trabajado ha sido con Naranja Producciones, BTL 360 y Mangosta producciones.

11. ¿Qué empresas ha utilizado para dichos servicios?

Hemos utilizado a Naranja Producciones.

12. ¿Cómo se llama la última empresa que contrato para realizar campañas BTL? Hemos utilizado a Naranja Producciones.

13. ¿Qué opinión a favor y contra tiene usted sobre la última empresa que contrató?

Brindan un buen servicio y tienen precios bastante asequibles.

14. ¿Cuantas veces al año usted rota de proveedor de servicios de BTL?

Por lo menos una vez al año.

15. ¿Cuántas veces al año usted contrata este servicio?

Contratamos un promedio de 3 a 4 veces al año.

16. ¿Cuáles son los meses de mayor demanda del servicio de BTL?

Utilizamos más este servicio para realizar el full day de la empresa (mayo). Luego por Fiestas Patrias y por Navidad.

17. ¿En qué medios usted se enteró de las empresas de BTL?

A través de contactos al interno de la empresa (área de Administración).

18. ¿usted recomendaría a la última empresa de BTL que contrató?

Sin dudarlo, obtuvimos una buena campaña al interior del país para promocionar nuestros servicios. 
19. ¿Cuál es el presupuesto del año 2014 para las campañas BTL?

Vamos utilizando el 35\% del presupuesto asignado a nuestra área para el rubro de imagen y marketing.

20. ¿Ud. Considera aumentar el presupuesto asignado a campañas BTL en el próximo año?

Se está considerando solicitar un aumento en el presupuesto del próximo año (10\%) en donde utilizaremos también medios de radio y periódicos local. 


\section{BIBLIOGRAFÍA}

ARELLANO, Rolando. (2010) Marketing, Enfoque para América Latina. 1er ed. México: Pearson autorización de México.

BREALEY, Richard A.; MYERS, Stewart C. (1993) Principios de Finanzas Corporativas. $4^{\circ}$ ed. España: McGraw-Hill.

CHAN KIM, W y MAUBORGNE, Renée. (2005) La Estrategia del Océano Azul. 19 ed. Bogotá: Norma.

DAVID; Fres R. (2013) Conceptos de administración estratégica. $14^{\circ}$ ed. México D.F.: Pearson Educación.

EIGLIER, Pierre. LANGEARD, Eric. Servucción. MCGRAW HILL GITMAN, Lawrence J. ZUTTER, Chad J. ( 2012) Principios de Administración Financiera. 12da ed. Naucalpan de Juárez: Perason Educación.

KOTLER, Philip; ARMSTRONG, Gary.(2008) Fundamentos de marketing. $8^{\circ}$ ed. México D.F.: Pearson Educación.

KOTLER, Philip. LANE KELLER, Kevin. (2006) Dirección de Marketing. 12ma ed. México DF.: Pearson Educación de México.

PORTER, Michael. (1997) Estrategia Competitiva, Técnicas para el análisis de los sectores industriales y de la competencia. México D.F.: Continental. ROBBINS, Steph en P. \& COULTER, Mary, Administración, Pearson, 10ed/2010.

THOMPSON, Peteraf y GAMBLE, Stricklan. (2012) Administración Estratégica. 18va ed. México DF.: McGraw-Hill/Interamericana Editores. 


\section{REFERENCIAS ELECTRÓNICAS}

MD Group, articulo en Diario Gestión. (en línea), Jueves, 29 de mayo del 2014. Disponible: http://gestion.pe/empresas/empresas-peruanas-destinan-s-45000-promedio-campanas$\underline{\text { btl-2098810 }}$

MD Group. "Empresas peruanas destinan S/ 45,000 en promedio a campañas BTL". En: Diario Gestión. [en línea], PE, mayo, 2014. [citado 22 septiembre 2014]. Disponible: http://gestion.pe/empresas/empresas-peruanas-destinan-s-45000-promedio-campanasbtl-2098810

MD Group. "Empresas peruanas destinan S/ 45,000 en promedio a campañas BTL". En: Diario Gestión. [en línea], PE, mayo, 2014. [citado 22 septiembre 2014]. Disponible: http://gestion.pe/empresas/empresas-peruanas-destinan-s-45000-promedio-campanasbtl-2098810

MD Group. "Empresas peruanas destinan S/ 45,000 en promedio a campañas BTL". En: Diario Gestión. [en línea], PE, mayo, 2014. [citado 28 septiembre 2014]. Disponible: http://gestion.pe/empresas/empresas-peruanas-destinan-s-45000-promedio-campanasbtl-2098810

“EI BTL en Perú es un adolescente por S.A.C.ar su DNI". En: InfoMarketing. [en línea], PE, noviembre, 2014. [citado 10 noviembre 2014]. Disponible: http://www.infomarketing.pe/btlint.php?id=4

“Especial BTL: Haciendo Camino al andar”. En: InfoMarketing. [en línea], PE, noviembre 2014. [citado 15 noviembre] Disponible: http://www.infomarketing.pe/btl-int.php?id=8 “Especial BTL: Haciendo Camino al andar". En: InfoMarketing. [en línea], PE, noviembre 2014. [citado 15 noviembre] Disponible: http://www.infomarketing.pe/btl-int.php?id=8

"Especial BTL: Haciendo Camino al andar". En: InfoMarketing. [en línea], PE, noviembre 2014. [citado 15 noviembre] Disponible: http://www.infomarketing.pe/btl-int.php?id=8

"Especial BTL: Haciendo Camino al andar". En: InfoMarketing. [en línea], PE, noviembre 2014. [citado 15 noviembre] Disponible: http://www.infomarketing.pe/btl-int.php?id=8 
Boletín mensual Marketreport. [en línea]. Lima: Compañía Peruana de Estudios de Mercado y Opinión Pública (CPI). Enero 2014. [citado 12 octubre 2014]. Adobe Acrobat. Disponible en: http://www.cpi.pe/images/upload/paginaweb/archivo/26/MR 201401 01.pdf

Boletín mensual Marketreport. [en línea]. Lima: Compañía Peruana de Estudios de Mercado y Opinión Pública (CPI). Enero 2015. [citado 27 junio 2016]. Adobe Acrobat. Disponible en: cpi.pe/banco/market-report.html

Boletín mensual Marketreport. [en línea]. Lima: Compañía Peruana de Estudios de Mercado y Opinión Pública (CPI). Enero 2016. [citado 23 junio 2016]. Adobe Acrobat. Disponible en: cpi.pe/banco/market-report.html

Boletín mensual Marketreport. [en línea]. Lima: Compañía Peruana de Estudios de Mercado y Opinión Pública (CPI). Enero 2016. [citado 23 junio 2016]. Adobe Acrobat. Disponible en: cpi.pe/banco/market-report.html

Inversión publicitaria en el Perú cayó en un 8\%. [en línea]. Lima: Mercado Negro. Julio 2015. [citado 27 junio 2016]. Disponible en: cpi.pe/banco/market-report.html http://www.mercadonegro.pe/noticia/5638/inversin-publicitaria-en-el-per-cay-en-un-8

ASENCIOS, Maritza. “Jorge Jara, gerente general de Periscopio: "Internet no es un medio alternativo, es el medio"'. En: Serperuano. [en línea] PE, noviembre 2014. [citado 05 diciembre 2014]. Disponible: http://www.serperuano.com/2013/06/empresas-peruanasinvertiran-mas-de-us-900-millones-en-servicios-de-marketing-y-publicidad-durante-2013/

KAITEN, Juan Carlos. Importancia de la Visión y Misión dentro de las organizaciones. En: revista mensual de Contaduría Pública, Instituto Mexicano de Contadores Públicos. [en línea]. México D.F.: abr., 2007. [citado 12 octubre 2014]. p.20. Adobe Acorbat. Disponible en: http://spip.imcp.org.mx/spip.php?article1587

Radio Nacional, artículo en línea, jueves 28 de julio 2016 - 15:27 horas. Disponible en: http://www.radionacional.com.pe/informa/politica/lee-el-mensaje-completo-del-presidentepedro-pablo-kuczynski

Presidencia del Consejo de Ministros (PCM), artículo de la Sala de Prensa e Imagen Institucional de la PCM [en línea], 28 de noviembre de 2016. Disponible: 
http://www.pcm.gob.pe/2016/11/jefe-del-gabinete-anuncia-medidas-para-la-reactivaciony-generacion-de-empleo-y-oportunidades-en-todas-las-regiones-del-pais/

Presidencia del Consejo de Ministros (PCM), artículo de la Sala de Prensa e Imagen Institucional de la PCM [en línea], 28 de noviembre de 2016. Disponible: http://www.pcm.gob.pe/2016/11/jefe-del-gabinete-anuncia-medidas-para-la-reactivaciony-generacion-de-empleo-y-oportunidades-en-todas-las-regiones-del-pais/

Presidencia del Consejo de Ministros (PCM), artículo de la Sala de Prensa e Imagen Institucional de la PCM [en línea], 28 de noviembre de 2016. Disponible: http://www.pcm.gob.pe/2016/11/jefe-del-gabinete-anuncia-medidas-para-la-reactivaciony-generacion-de-empleo-y-oportunidades-en-todas-las-regiones-del-pais/

Presidencia del Consejo de Ministros (PCM), artículo de la Sala de Prensa e Imagen Institucional de la PCM [en línea], 28 de noviembre de 2016. Disponible: http://www.pcm.gob.pe/2016/11/jefe-del-gabinete-anuncia-medidas-para-la-reactivaciony-generacion-de-empleo-y-oportunidades-en-todas-las-regiones-del-pais/

Presidencia del Consejo de Ministros (PCM), artículo de la Sala de Prensa e Imagen Institucional de la PCM [en línea], 28 de noviembre de 2016. Disponible: http://www.pcm.gob.pe/2016/11/jefe-del-gabinete-anuncia-medidas-para-la-reactivaciony-generacion-de-empleo-y-oportunidades-en-todas-las-regiones-del-pais/

Presidencia del Consejo de Ministros (PCM), artículo de la Sala de Prensa e Imagen Institucional de la PCM [en línea], 22 de diciembre de 2016. Disponible: http://www.pcm.gob.pe/2016/12/fernando-zavala-el-2017-sera-un-ano-de-crecimiento-dela-economia-y-de-generacion-de-empleo/

Presidencia del Consejo de Ministros (PCM), artículo de la Sala de Prensa e Imagen Institucional de la PCM [en línea], 22 de diciembre de 2016. Disponible: http://www.pcm.gob.pe/2016/12/fernando-zavala-el-2017-sera-un-ano-de-crecimiento-dela-economia-y-de-generacion-de-empleo/ 
Presidencia del Consejo de Ministros (PCM), artículo de la Sala de Prensa e Imagen Institucional de la PCM [en línea], 27 de diciembre de 2016. Disponible http://www.pcm.gob.pe/2016/12/fernando-zavala-gobierno-tiene-metas-concretas-a-dosanos-en-materia-de-seguridad-ciudadana/

Presidencia del Consejo de Ministros (PCM), artículo de la Sala de Prensa e Imagen Institucional de la PCM [en línea], 27 de diciembre de 2016. Disponible http://www.pcm.gob.pe/2016/12/fernando-zavala-gobierno-tiene-metas-concretas-a-dosanos-en-materia-de-seguridad-ciudadana/

Presidencia del Consejo de Ministros (PCM), artículo de la Sala de Prensa e Imagen Institucional de la PCM [en línea], 27 de diciembre de 2016. Disponible http://www.pcm.gob.pe/2016/12/fernando-zavala-gobierno-tiene-metas-concretas-a-dosanos-en-materia-de-seguridad-ciudadana/

Presidencia del Consejo de Ministros (PCM), artículo de la Sala de Prensa e Imagen Institucional de la PCM [en línea], 21 de diciembre de 2016. Disponible: http://www.pcm.gob.pe/2016/12/gobierno-aprueba-14-decretos-legislativos-en-materiade-agua-saneamiento-seguridad-ciudadana-reactivacion-economica-y-formalizacion/

Banco Central de Reserva del Perú, articulo en Semana Económica. (en línea), 18 de marzo de 2016.2 Disponible: http://semanaeconomica.com/article/economia/macroeconomia/183372-bcr-mantuvoproyeccion-de-crecimiento-de-la-economia-peruana-del-2016-pero-redujo-la-del-2017/

INEI, artículo en el Diario El Comercio. (en línea), lunes 15 de febrero 2016. Disponible: http://elcomercio.pe/economia/peru/increible-diciembre-hace-crecer-pbi-326-2015-noticia1879017

INEI, artículo en el Diario El Comercio. (en línea), lunes 15 de febrero 2016. Disponible: http://elcomercio.pe/economia/peru/increible-diciembre-hace-crecer-pbi-326-2015-noticia$\underline{1879017}$

Pulso Perú, artículo en el Diario Gestión. (en línea), lunes 15 de febrero 2016. Disponible: http://gestion.pe/economia/pulso-peru-siete-cada-diez-peruanos-sostienen-que-estangastando-mas-este-ano-que-2015-2154553 
Apoyo Consultoría, articulo en Diario Gestión (en línea), jueves, 27 de octubre del 2016. Disponible: $\quad$ http://gestion.pe/economia/cae-confianza-familias-limenas-octubre-tercer$\underline{\text { mes-consecutivo-2173327 }}$

YPO Global Pulse, articulo en Diario Perú 21 (en línea), miércoles, 08 de febrero de 2017. Disponible: http://peru21.pe/economia/peru-encabeza-ranking-confianza-region-2270179

ACCP, articulo en Diario El Comercio (en línea), jueves, 18 de septiembre del 2014. Disponible: http://elcomercio.pe/economia/peru/ventas-centros-comerciales-alcanzaranus7000-mlls-2014-noticia-1757814

Cámara de comercio de Lima, (en línea), 10 de octubre 2016. Disponible: http://www.camaralima.org.pe/principal/noticias/noticia/ventas-del-sector-retail-crecerian12-en-el-2016-y-14-en-el-2017/622

Reuters. Artículo en Diario Gestión. (en línea), miércoles 08 de febrero de 2017. Disponible: http://gestion.pe/mercados/tipo-cambio-cierra-baja-ante-retroceso-global-dolar-2181677

Reuters. Artículo en Diario Gestión. (en línea), miércoles 08 de febrero de 2017. Disponible: http://gestion.pe/mercados/tipo-cambio-cierra-baja-ante-retroceso-global-dolar-2181677 "EI BTL en Perú es un adolescente por S.A.C.ar su DNI". En: InfoMarketing. (en línea) PE, domingo, 09 de noviembre del 2014. Disponible: http://www.infomarketing.pe/btlint.php?id=4

"Desafíos del BTL: Made in Perú". En: AndaPerú. (en línea) PE, domingo, 08 de marzo del 2015. Disponible: http://www.andaperu.pe/desafios-del-btl-made-in-peru/

"Desafíos del BTL: Made in Perú". En: AndaPerú. (en línea) PE, domingo, 08 de marzo del 2015. Disponible: http://www.andaperu.pe/desafios-del-btl-made-in-peru/

“¿Cómo ha evolucionado el BTL?”. En: Infomarketing. (en línea) PE, domingo, 04 de marzo del 2016. Disponible: http://www.informabtl.com/como-ha-evolucionado-el-btl/ 
SOMOSEMPRESA, "Aprovecha las técnicas que te ofrece el BTL para tu promoción". (en línea) PE. Citado el 15 de noviembre del 2014. Disponible en: http://somosempresa.pe/soy-empresario/marketing-y-ventas/aprovecha-las-tecnicas-quete-ofrece-el-btl-para-tu-promocion

HERNÁNDEZ, ROGER. “¿Por qué no despegan las compras por Internet en el Perú?”. En: EI Diario El Comercio. (en línea) PE, Jueves, 29 de mayo del 2014. (citado 18 octubre 2014) Disponible: http://elcomercio.pe/economia/negocios/que-no-despegan-comprasinternet-peru-noticia-1707759

HERNÁNDEZ, ROGER. “¿Por qué no despegan las compras por Internet en el Perú?”. En: EI Diario El Comercio. (en línea) PE, Jueves, 29 de mayo del 2014. (citado 18 octubre 2014) Disponible: http://elcomercio.pe/economia/negocios/que-no-despegan-comprasinternet-peru-noticia-1707759

ARELLANO, RONALD. “¿Peruanos visitan redes sociales entre 6 y 7 veces por semana?”. En: RPP Noticias. (en línea) PE, Jueves, 03 de julio del 2014. (citado 18 octubre 2014) Disponible: http://www.rpp.com.pe/2014-07-03-arellano-peruanos-visitan-redes-socialesentre-6-y-7-veces-por-semana-noticia 705033.html

ARELLANO, RONALD. “¿Peruanos visitan redes sociales entre 6 y 7 veces por semana?”. En: RPP Noticias. (en línea) PE, Jueves, 03 de julio del 2014. (citado 18 octubre 2014) Disponible: http://www.rpp.com.pe/2014-07-03-arellano-peruanos-visitan-redes-socialesentre-6-y-7-veces-por-semana-noticia 705033.html

ARELLANO, RONALD. “¿Peruanos visitan redes sociales entre 6 y 7 veces por semana?”. En: RPP Noticias. (en línea) PE, Jueves, 03 de julio del 2014. (citado 18 octubre 2014) Disponible: http://www.rpp.com.pe/2014-07-03-arellano-peruanos-visitan-redes-socialesentre-6-y-7-veces-por-semana-noticia 705033.html

Boletín Tiempo de Opinión. [en línea]. Lima. ESAN, 2013, (citado 21 octubre 2014). Adobe Acrobat. Disponible en: http://www.esan.edu.pe/publicaciones/2013/06/11/tiempo de opinion antonieta hamann. pdf 
VISUAL TRADE." El futuro (hoy) del sector". En: La Guía del Marketing 2014. (en línea).PE, 232, (citado 20 octubre 2014). Disponible en: http://www.mdgroup.com.pe/guia marketing.html

MD Group, articulo en Diario Gestión. (en línea), Jueves, 29 de mayo del 2014. Disponible: http://gestion.pe/empresas/empresas-peruanas-destinan-s-45000-promedio-campanasbtl-2098810

MD Group, articulo en Diario Gestión. (en línea), Jueves, 29 de mayo del 2014. Disponible: http://gestion.pe/empresas/empresas-peruanas-destinan-s-45000-promedio-campanas$\underline{\text { btl-2098810 }}$

MD Group, articulo en Diario Gestión. (en línea), Jueves, 29 de mayo del 2014. Disponible: http://gestion.pe/empresas/empresas-peruanas-destinan-s-45000-promedio-campanasbtl-2098810

"EI BTL en Perú es un adolescente por S.A.C.ar su DNI". En: InfoMarketing. (en línea) PE, domingo, 09 de noviembre del 2014. Disponible: http://www.infomarketing.pe/btlint.php?id=4

“Especial BTL: Haciendo Camino al andar”. En: InfoMarketing. (en línea) PE, domingo, 09 de noviembre del 2014. Disponible: http://www.infomarketing.pe/btl-int.php?id=8

"Empresas peruanas invertirán más de US\$900 millones en servicios de Marketing y Publicidad durante 2013". En: BizNews. (en línea) PE, domingo, 09 de noviembre del 2014. Disponible: http://biznews.pe/entrevistas/jorge-jara-gerente-general-periscopio-internetno-es-medio-alternativo-es-medio

“El Ranking de las Mejores Agencias de El Ojo 2014”. En: El Ojo de Iberoamérica. (en línea), 2014. Disponible: http://www.elojodeiberoamerica.com/el-ranking-de-las-mejoresagencias-de-el-ojo-2014/

ROSADO, Roberto. “¿En qué se basa el BCR para prever que el PBI crecerá 4,8\%?”. En: Diario El Comercio. [en línea]. PE. 2015. [citado 28 enero 2015]. Disponible en: http://elcomercio.pe/economia/peru/que-se-basa-bcr-prever-que-pbi-crecera-48-noticia$\underline{1786731 ? \mathrm{flsm}=1}$ 
“FMI recorta su estimación y prevé que Perú crecerá 4\% en 2015”. En: Diario El Comercio.

[en línea]. PE. 2015. [citado 28 enero 2015]. Disponible en:

http://elcomercio.pe/economia/peru/fmi-recorta-su-estimacion-y-preve-que-economia-

peruana-crecera-4-2015-noticia-1786193 